\title{
Workflows and software for the design of integrated lighting solutions
}

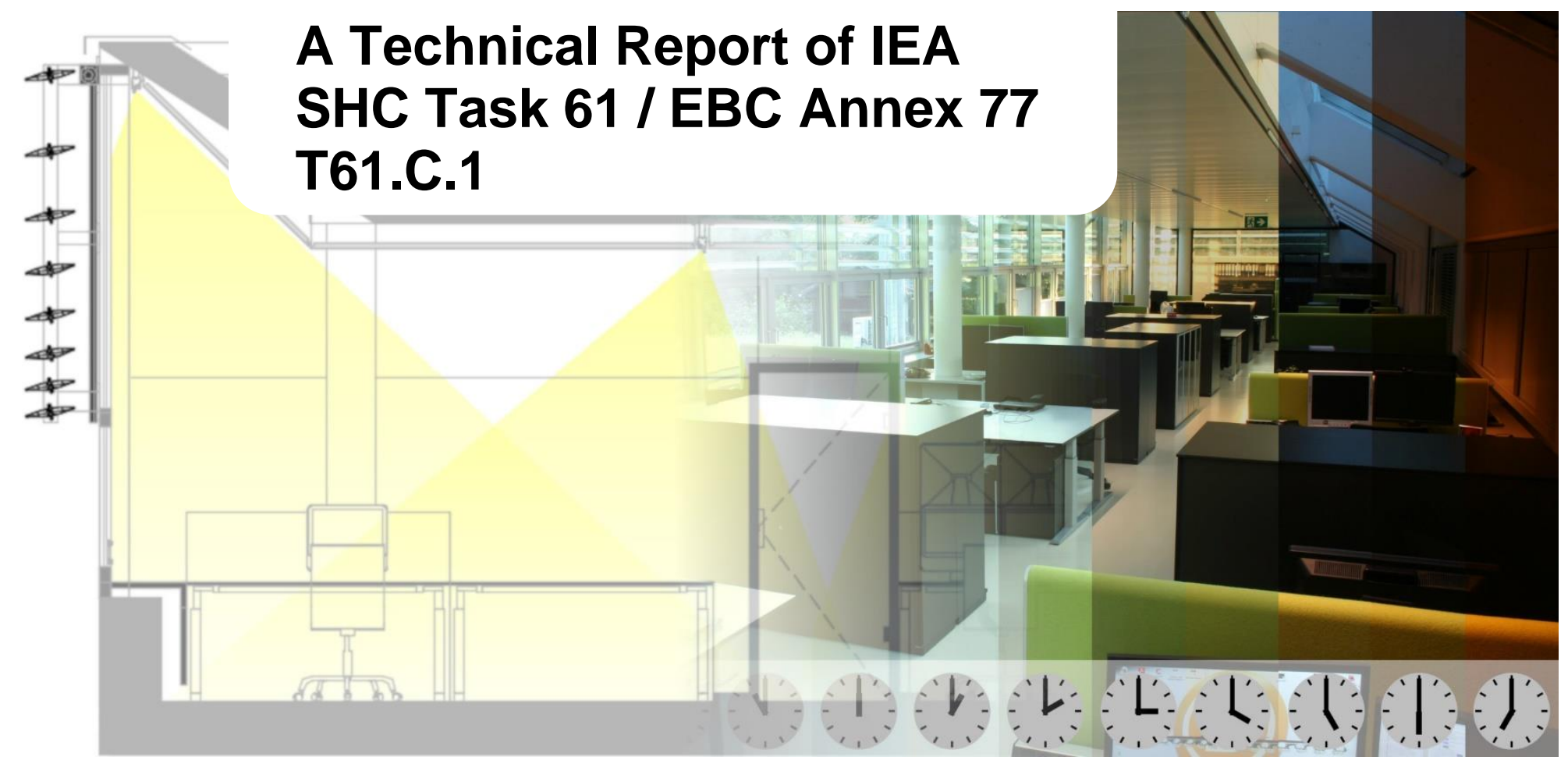




\section{IEA Solar Heating and Cooling Technology Collaboration Programme (IEA SHC)}

The Solar Heating and Cooling Technology Collaboration Programme was founded in 1977 as one of the first multilateral technology initiatives ("Implementing Agreements") of the International Energy Agency. Its mission is "To enhance collective knowledge and application of solar heating and cooling through international collaboration to reach the goal set in the vision of solar thermal energy meeting $50 \%$ of low temperature heating and cooling demand by 2050."

The members of the IEA SHC collaborate on projects (referred to as Tasks) in the field of research, development, demonstration (RD\&D), and test methods for solar thermal energy and solar buildings.

Research topics and the associated Tasks in parenthesis include:

- Solar Space Heating and Water Heating (Tasks 14, 19, 26, 44, 54)

- Solar Cooling (Tasks 25, 38, 48, 53)

- Solar Heat for Industrial or Agricultural Processes (Tasks 29, 33, 49, 62, 64)

- Solar District Heating (Tasks 7, 45, 55)

- Solar Buildings/Architecture/Urban Planning

(Tasks 8, 11, 12, 13, 20, 22, 23, 28, 37, 40, 41, 47, 51, 52, 56, 59, 63)

- Solar Thermal \& PV (Tasks 16, 35, 60)

- Daylighting/Lighting (Tasks 21, 31, 50, 61)

- Materials/Components for Solar Heating and Cooling (Tasks 2, 3, 6, 10, 18, 27, 39)

- Standards, Certification, and Test Methods (Tasks 14, 24, 34, 43, 57)

- Resource Assessment (Tasks 1, 4, 5, 9, 17, 36, 46)

- Storage of Solar Heat (Tasks 7, 32, 42, 58)

In addition to our Task work, other activities of the IEA SHC include our:

$>$ International Conference on Solar Heating and Cooling for Buildings and Industry

$>$ SHC Solar Academy

$>$ Solar Heat Worldwide annual statics report

$>$ Collaboration with solar thermal trade associations

\section{Country Members}

$\begin{array}{lll}\text { Australia } & \text { France } & \text { South Africa } \\ \text { Austria } & \text { Germany } & \text { Spain } \\ \text { Belgium } & \text { Italy } & \text { Sweden } \\ \text { Canada } & \text { Netherlands } & \text { Switzerland } \\ \text { China } & \text { Norway } & \text { Turkey } \\ \text { Denmark } & \text { Portugal } & \text { United Kingdom } \\ \text { European Commission } & \text { Slovakia } & \end{array}$

\section{Sponsor Members}

European Copper Institute

ECREEE

International Solar Energy Society

CCREEE

PCREEE

EACREEE

RCREEE

SACREEE

For more information on the IEA SHC work, including many free publications, please visit www.iea-shc.org. 


\title{
Workflows and software for the design of integrated lighting solutions
}

\author{
T61.C.1 - A Technical Report of Subtask C \\ IEA SHC Task 61 / EBC Annex 77 \\ Integrated Solutions for Daylighting and Electric Lighting \\ From component to user centered system efficiency
}

2019-11-05

Editor: David Geisler-Moroder

Authors (in alphabetical order):

Bruno Bueno, Fraunhofer ISE, Germany

David Geisler-Moroder, Bartenbach, Austria

Ulf Greiner Mai, Member of the Management Board of the LiTG, Germany

Markus Hegi, Relux Informatik AG, Switzerland

Chris Jackson, Lighting Analysts Ltd, UK

J. Alstan Jakubiec, University of Toronto, Canada and Solemma, LLC, USA

Fabian Jarrin, Kyushu University, Japan

Jérôme Kämpf, Idiap Research Institute and kaemco, Switzerland

Yasuko Koga, Kyushu University, Japan

Marios Liaros, Inform Design, Sweden

Tao Luo, CABR, China

Biljana Obradovic, Norconsult, Norway

Bernard Paule, Estia SA, Switzerland,

Harris Poirazis, Inform Design, Sweden

Dave Speer, Lighting Analysts Inc, USA

Zhen Tian, School of Architecture, Soochow University, Suzhou, China

Taoning Wang, Lawrence Berkeley National Laboratory, California, USA

Daniel Witzel, DIAL, Germany

The contents of this report do not necessarily reflect the viewpoints or policies of the International Energy Agency (IEA) or its member countries, the IEA Solar Heating and Cooling Technology Collaboration Programme (SHC TCP) members or the participating researchers. 


\section{Contents}

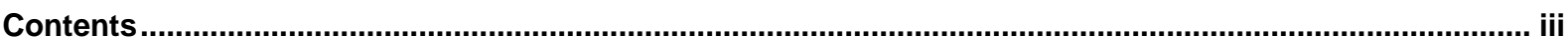

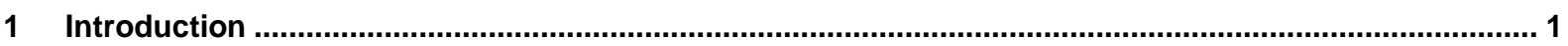

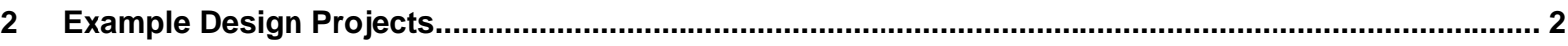

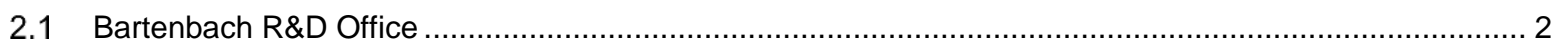

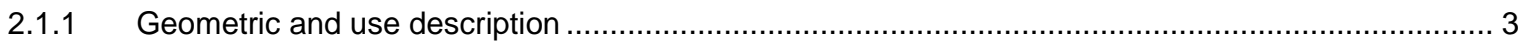

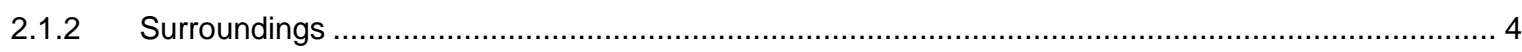

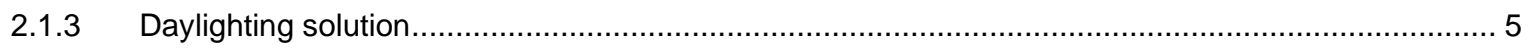

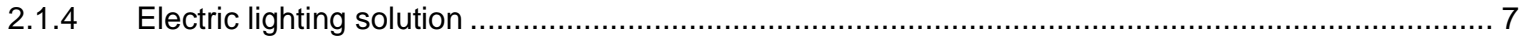

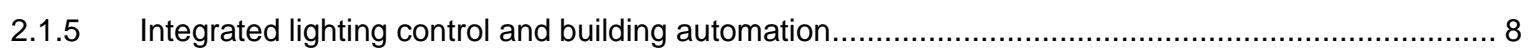

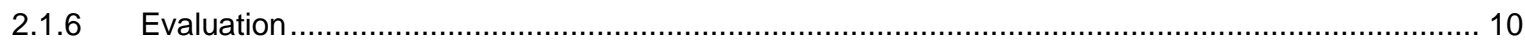

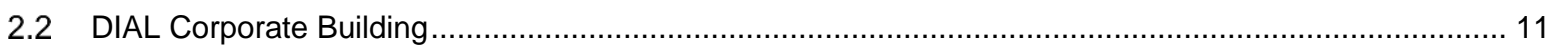

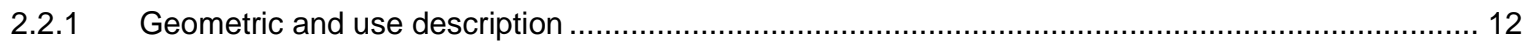

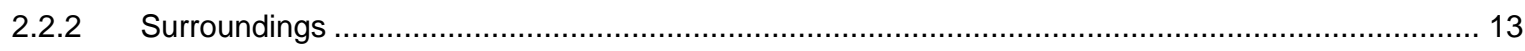

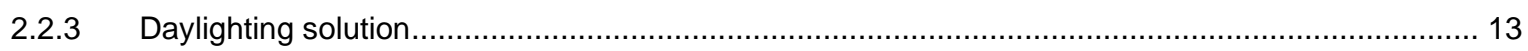

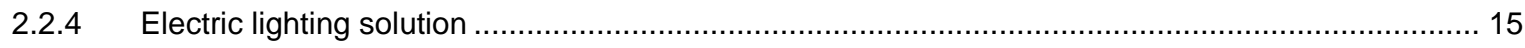

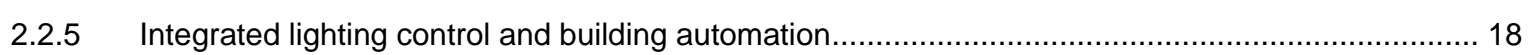

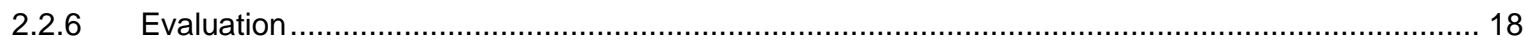

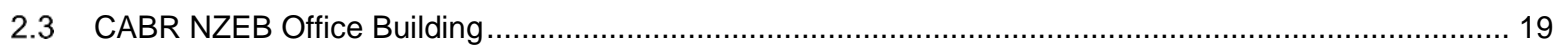

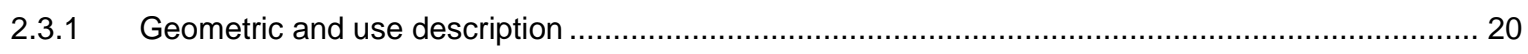

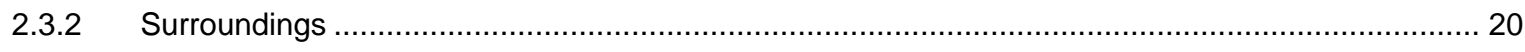

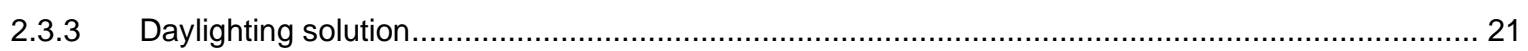

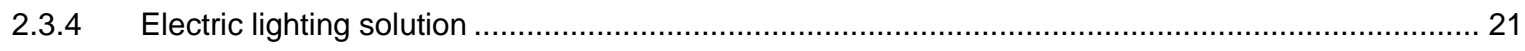

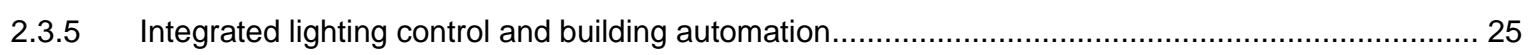

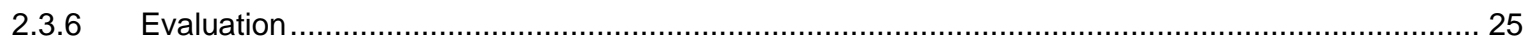

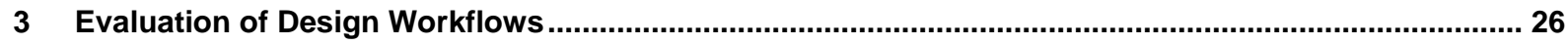

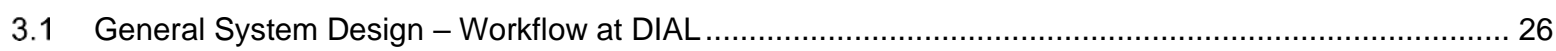

3.2 Design in day-by-day work - the DIAL Heavy User........................................................... 28

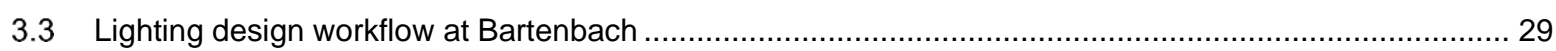

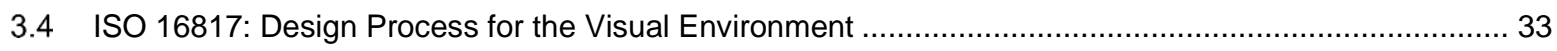

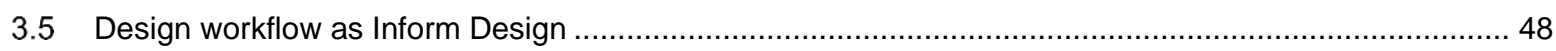

3.6 The role of the simulation engine Fener in the design workflow of façade systems .............................50

3.7 Workflow for lighting design projects in Norconsult and Norway ............................................... 53

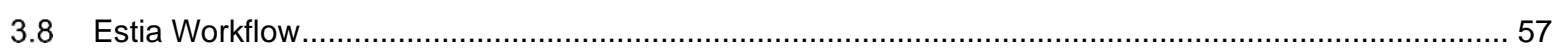

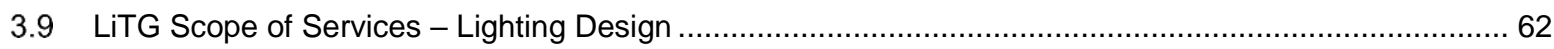

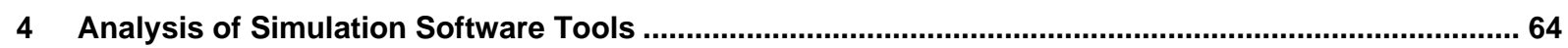

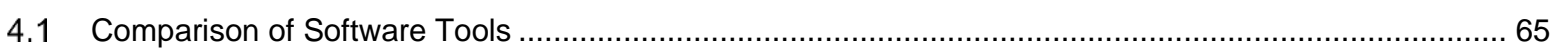

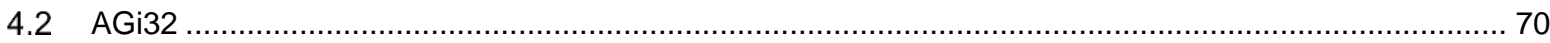

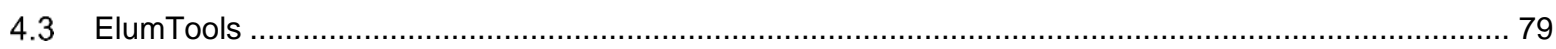

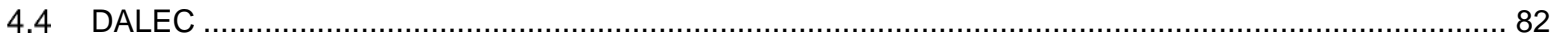




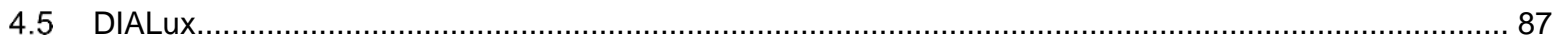

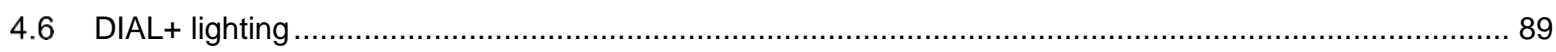

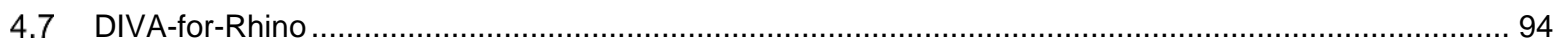

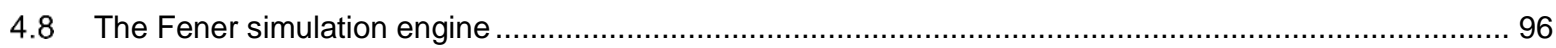

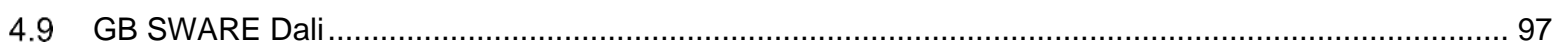

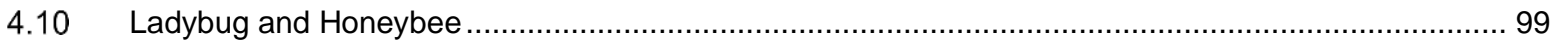

4.11 PKPM-Daylight - Daylight Simulation and Analysis Software for Green Building .......................... 102

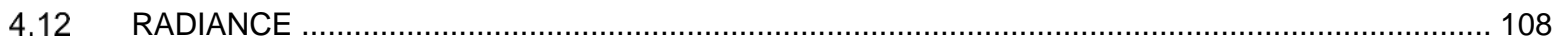

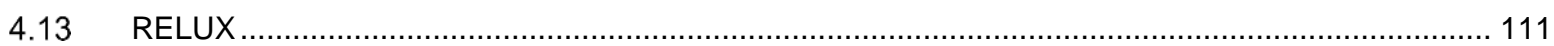

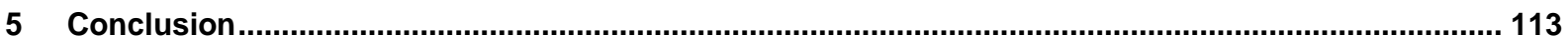


Practitioners are using a wide variety of different workflows, methods and tools in the planning of integrated solutions for daylighting, electric lighting and lighting controls. Lighting design projects cover a huge variety of applications with different requirements as well as project types and sizes. Within the Subtask C "Design Support for Practitioners - Tools, Standards, Guidelines" of the IEA SHC Task 61 / EBC Annex 77 "Integrated Solutions for Daylighting and Electric Lighting: From Component to User Centered System Efficiency" currently applied workflows in practical applications have been reviewed.

In a first step three different projects with integrated daylighting and electric lighting solutions have been selected. These example design projects are described in detail to give an idea how possible design projects with integrated lighting solutions look like and where the described workflows and tools might be applied. The three buildings are located in Austria, Germany and China, respectively, and represent modern office spaces which were recently built or renovated. Thus, the installed lighting solutions give a good feeling for the state-of-theart technology.

With these example design projects in mind, typical workflows for the planning process of integrated lighting solutions have been collected and documented. They cover examples of workflows that are currently applied by practitioners as well as information about design workflows as they are proposed in standards or guidelines. The workflow evaluation documents project phases and their associated design depths as well as main problems and open issues. This allows to assess the applicability of the single workflows to specific design tasks.

All described workflows utilize software tools to a greater or lesser extent to support the planning process or to evaluate design options. To provide an overview of the possibilities, strengths, weaknesses and barriers of the state-of-the-art in lighting simulation, relevant and widely used software tools have been analyzed and documented. A tabulated comparison of the features of the single tools gives a good indication which tools are suitable for which user group, design phase and application. 


\section{Example Design Projects}

\subsection{Bartenbach R\&D Office}

by David Geisler-Moroder, Bartenbach, Austria

The Bartenbach R\&D office is a single-story building located in the countryside close to Innsbruck, Austria. The building has a south oriented, glazed facade and skylights on the north side. The office was used as a testbed for various artificial lighting systems and daylighting systems over the last 15 years. In 2015 the building was refurbished to provide a cutting-edge office space with an integrated day- and artificial lighting control, dynamic and biological active electric lighting, and an innovative daylight solution.

This newly refurbished space provides a good example to analyze the current state of the art workflows in integrated lighting design as well as the potential of different simulation tools.

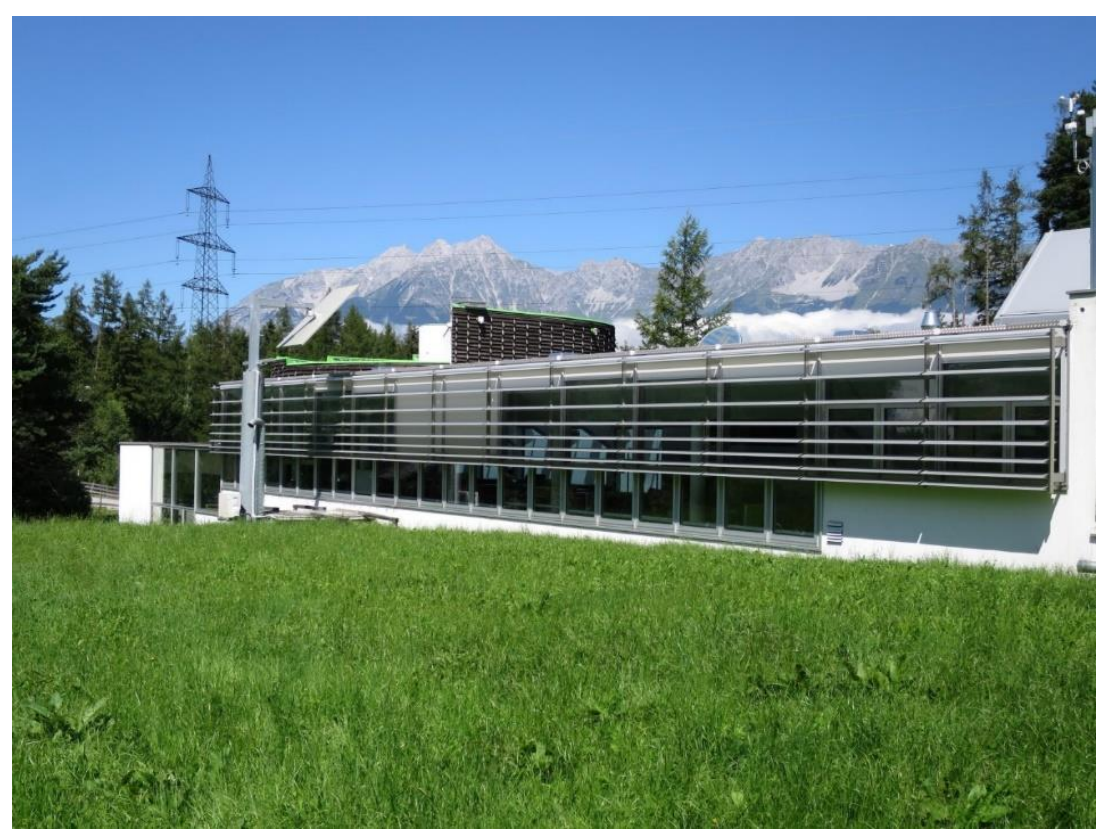

Figure 1: Bartenbach R\&D office in Aldrans, Austria.

The building is located at $47.245^{\circ} \mathrm{N}$ and $11.458^{\circ} \mathrm{E}$ and an altitude of $880 \mathrm{~m}$ in the village of Aldrans in the western part of Austria, close to the city of Innsbruck. The closest weather data station with data available on https://energyplus.net/weather is at Innsbruck airport about $8 \mathrm{~km}$ away at an altitude of $590 \mathrm{~m}$. (There is another IWEC2 weather data set from the station at the summit of "Patscherkofel" at $2246 \mathrm{~m}$, which is however not an adequate data set for evaluations in the valley.) 


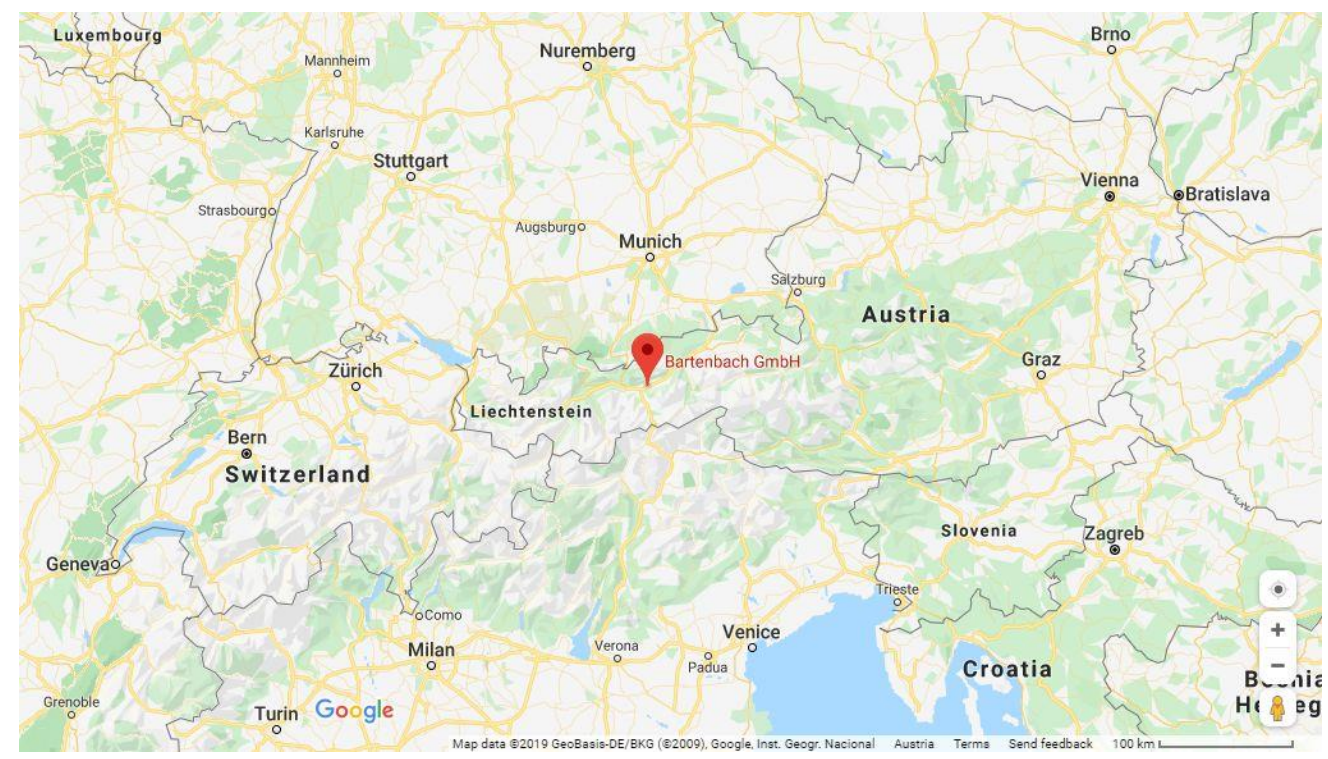

Figure 2: Location of Bartenbach R\&D office in the western part of Austria. Map data (2019 Google, GeoBasis-DE/BKG (@2009), Inst. Geogr. Nacional

\subsubsection{Geometric and use description}

The example office is an open-plan office with $169 \mathrm{~m}^{2}(26,20 \mathrm{~m} \times 6,45 \mathrm{~m})$, room height $2,75 \mathrm{~m}$, and an adjacent double office and a meeting area with overall additional $29 \mathrm{~m}^{2}(4,50 \mathrm{~m} \times 6,45 \mathrm{~m})$. The open-plan office is designed to host 10 persons along the nearly south-oriented façade and 9 along the north side under the pitch roof, respectively. Additional workplaces in the middle line are used for interns or as additional workspace.

The intended usage is office work, thus the appropriate regulations and standards (especially EN12464 for lighting) must be met.

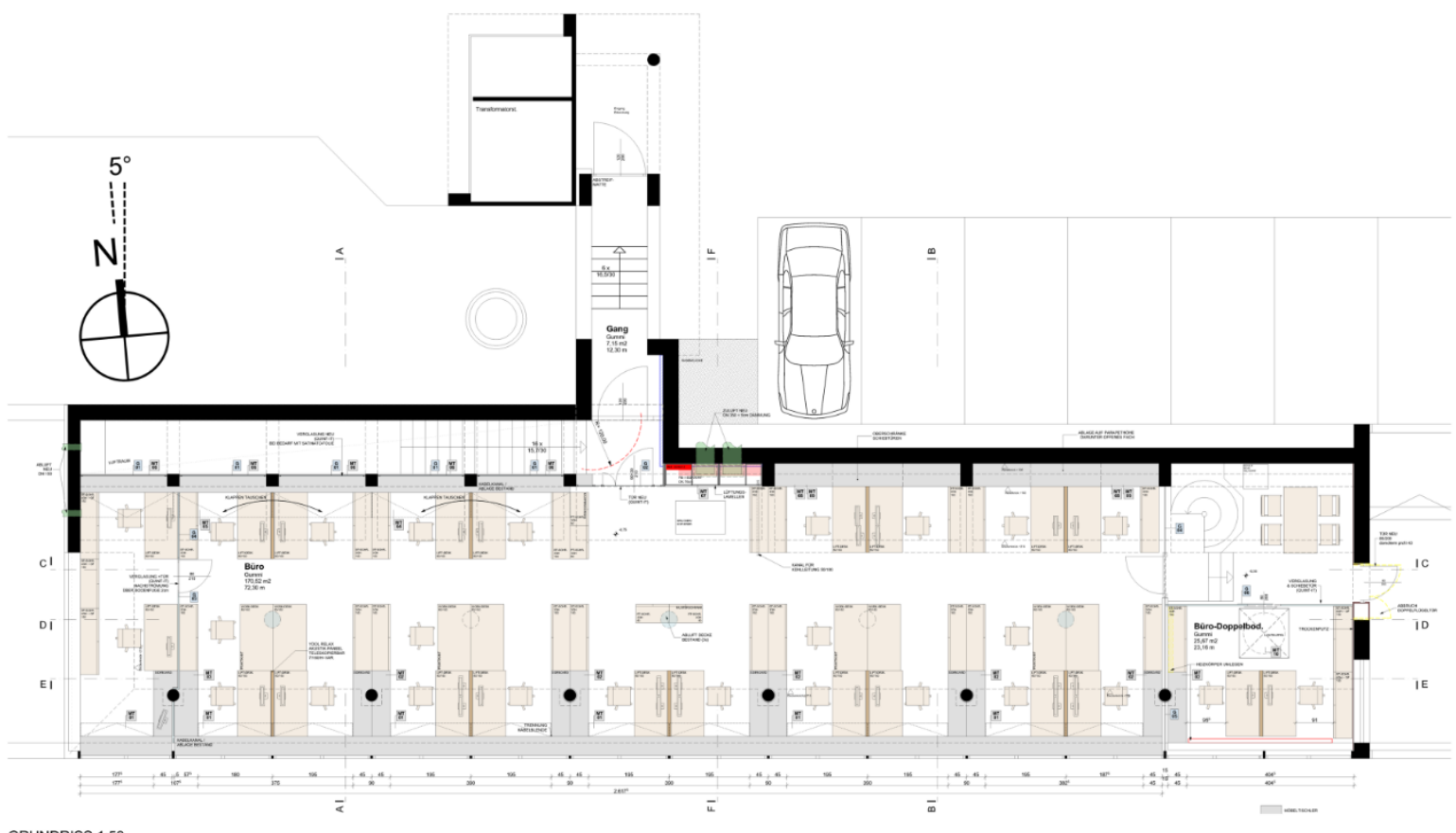

Figure 3: Floor plan of the example office space. 


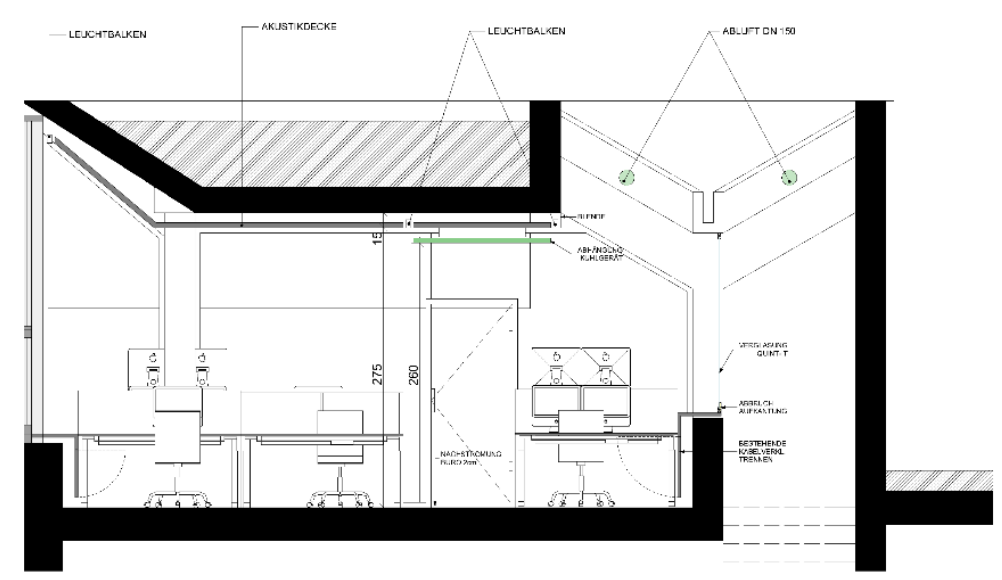

Figure 4: Section of the example office space.

\subsubsection{Surroundings}

The R\&D office is located in the countryside close to Innsbruck, Austria. The building was constructed in 1997 as annex to the existing office building. The building has a large south oriented facade, a smaller facade to the west and skylights in the northern pitch roof area.

The nearby crest from Patscherkofel to Glungezer causes natural shading, especially in the mornings of the months around winter solstice. There are no obstructions from close buildings. Figure 5 shows the surroundings in front of the south façade.

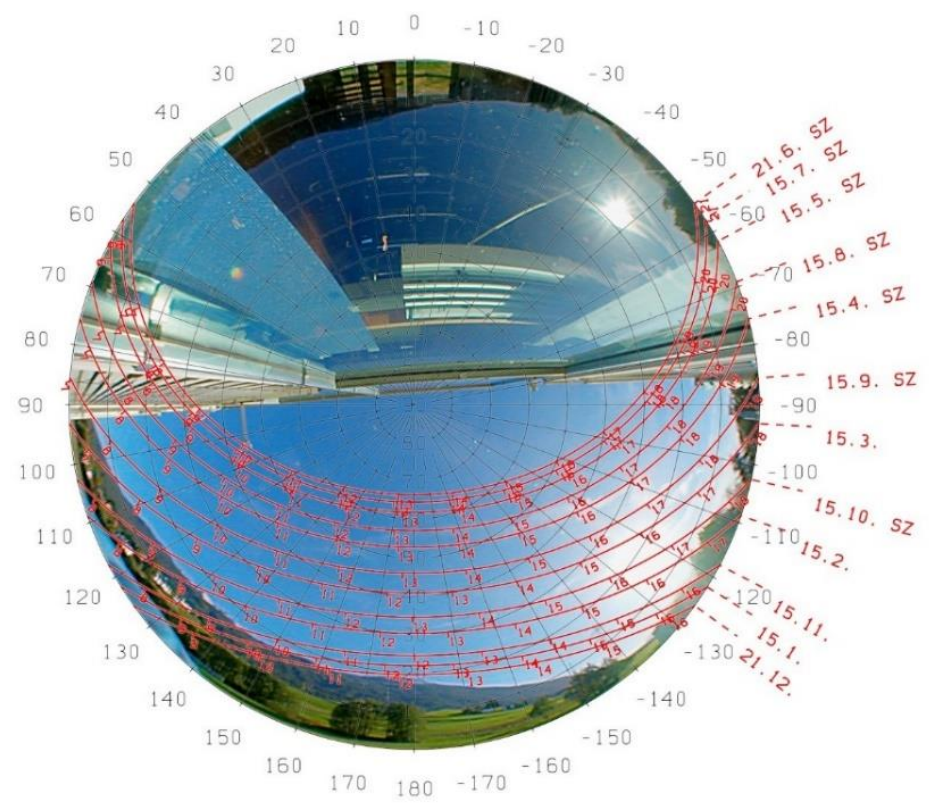

Figure 5: Fisheye photograph showing obstruction through mountains overlaid with sun path diagram. 


\subsubsection{Daylighting solution}

Different daylighting solutions were installed at the southern façade and at the northern pitch roof. In each case a static system is combined with moveable systems to provide sun and glare protection as well as high daylight provision.

\section{Southern façade solution, upper part}

- Exterior fixed large louvers for sun protection (A)

- Varying distances between blades at the façade optimized for sun paths at specific location

- Last blade functions as awning for the lower part

- Additional automated exterior diffusing screen between glazing and louvers for luminance control and glare protection, motorized (B)

\section{Southern façade solution, lower part}

- Interior top-down/bottom-up diffusing screen behind glazing for luminance control and glare protection by user, manual (C)

\section{Northern pitch roof solution}

- Exterior fixed shading for roof pitch with geometry and tilt angle designed for sun paths at specific location (D)

- Additional automated interior diffusing screen for luminance control and glare protection. Motorized (E)

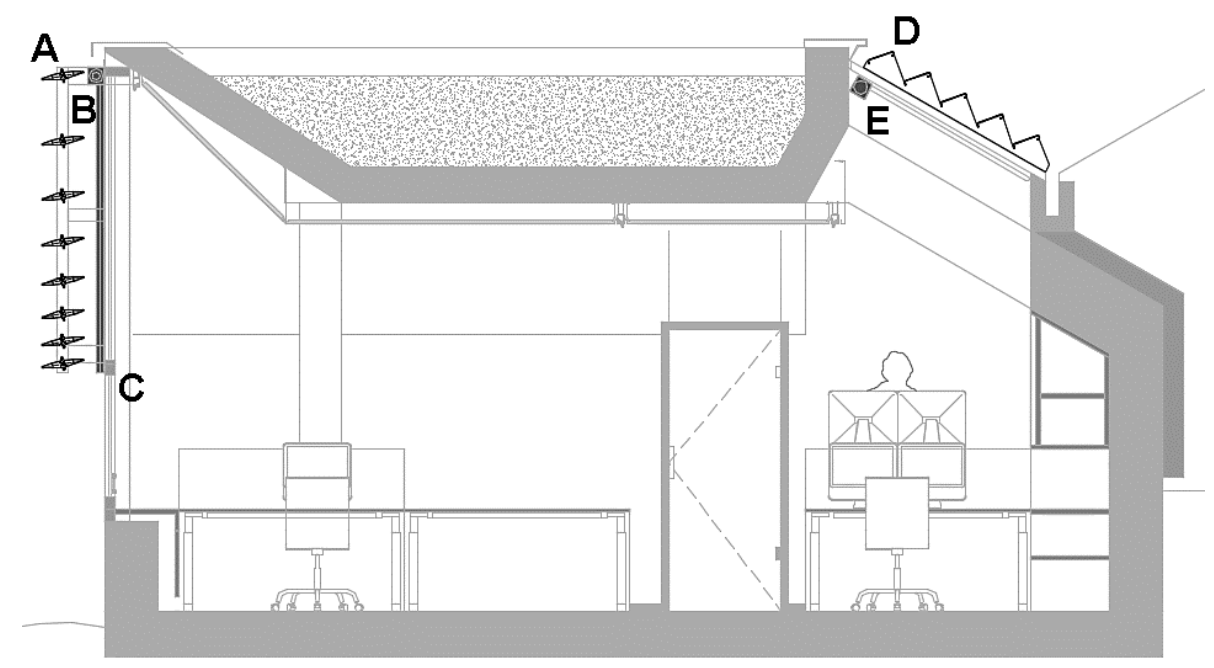

Figure 6: Daylighting solutions in example office space: (A) exterior louvers, (B) exterior diffusing screen, (C) interior diffusing screen, (D) exterior fixed structure, (E) interior diffusing screen. 

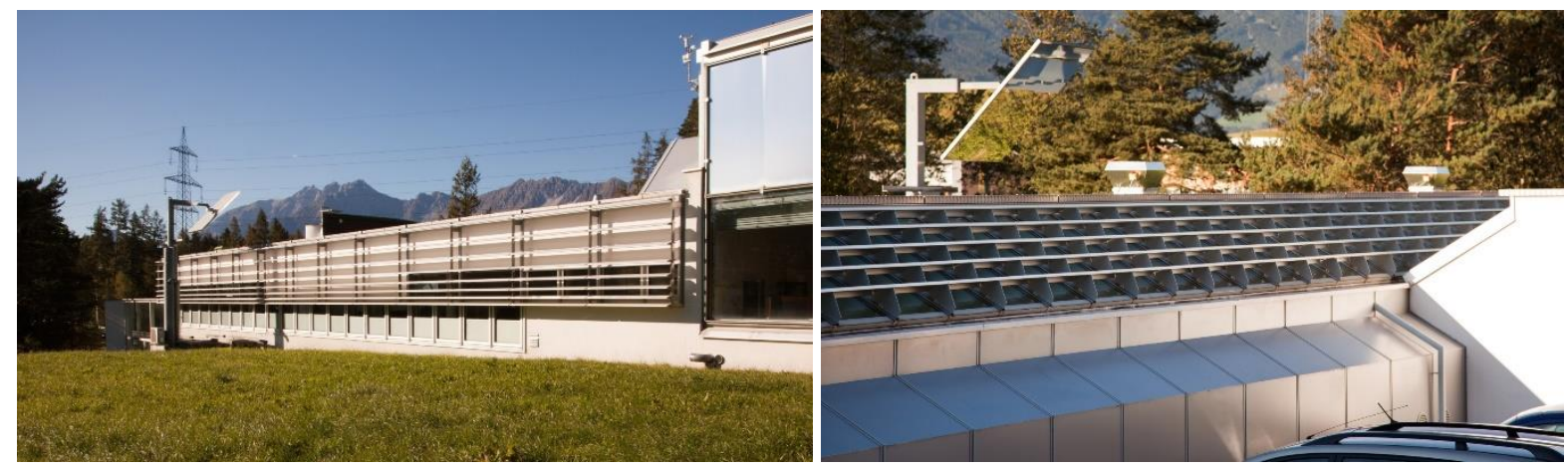

Figure 7: Exterior view of example office with exterior louvers and screen at south façade (left) and sun shading structure at northern pitch roof (right). The heliostat in the right image is used to bring daylight to the basement.
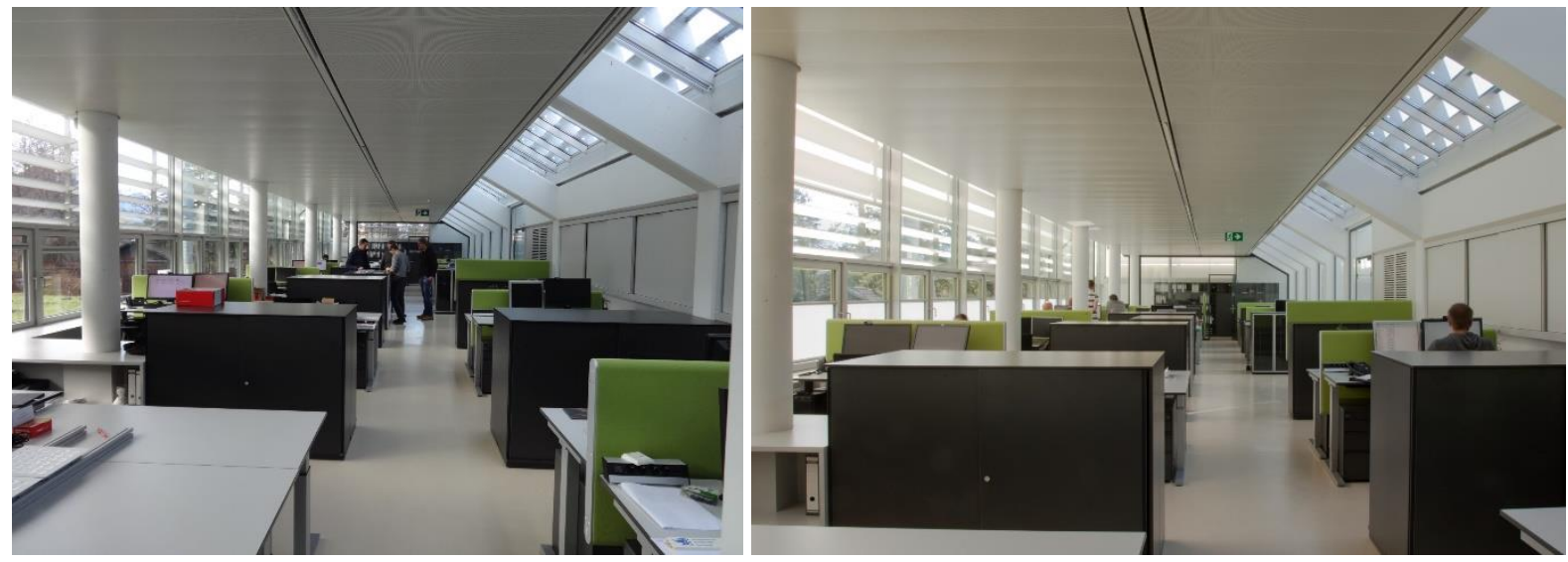

Figure 8: Interior view of example office at overcast conditions with movable systems retracted (left) and at sunny conditions with movable systems in positions to avoid direct sun penetration (right).

The installed daylighting solution provides high daylight availability and uniformity for both overcast and sunny sky conditions. With up to $2500 \mathrm{~lx}$ horizontal and $1200 \mathrm{~lx}$ vertical illuminance at the workplaces it really enables biologically active lighting through intelligent use of daylight. The sun and glare protection systems ensure a pleasing and glare free visual environment.

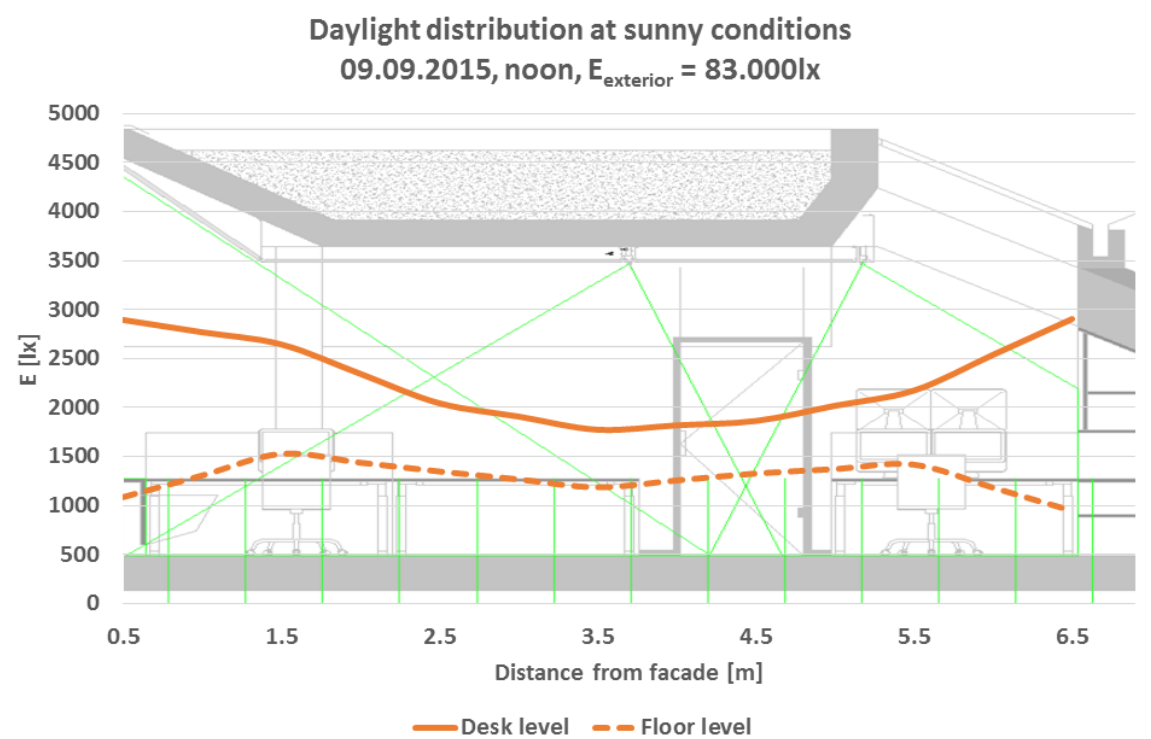

Figure 9: Measured daylight distribution at sunny conditions. 


\subsubsection{Electric lighting solution}

The installed electric lighting system with freeform-surface reflectors was developed by Bartenbach. The ceiling integrated LED luminaires contain two light colors (warm-white at $2200 \mathrm{~K}$ and cool-white at $5000 \mathrm{~K}$ ) in every single reflector and thus allow a highly homogeneous light mixture out of the luminaire.

At highest current feed of $7.1 \mathrm{~W} / \mathrm{m}^{2}, 1200 \mathrm{x}$ horizontal illuminance on the workplaces can be provided in every light color between $2200 \mathrm{~K}$ and $5000 \mathrm{~K}$ to enable a highly dynamic and biologically active lighting.

Key facts of the electric lighting system are:

- Architecture integrated LED luminaires

- Installed lighting power density of $7.1 \mathrm{~W} / \mathrm{m}^{2}$

- Overall annual electricity consumption for electric lighting only $5.1 \mathrm{kWh} / \mathrm{m}^{2} \mathrm{a}$

- Variable color temperature between $2200 \mathrm{~K}$ and $5000 \mathrm{~K}$ for biologically active lighting

- Up to 1200 lx horizontal illuminance possible in every color temperature

- Daylight and occupancy responsive control

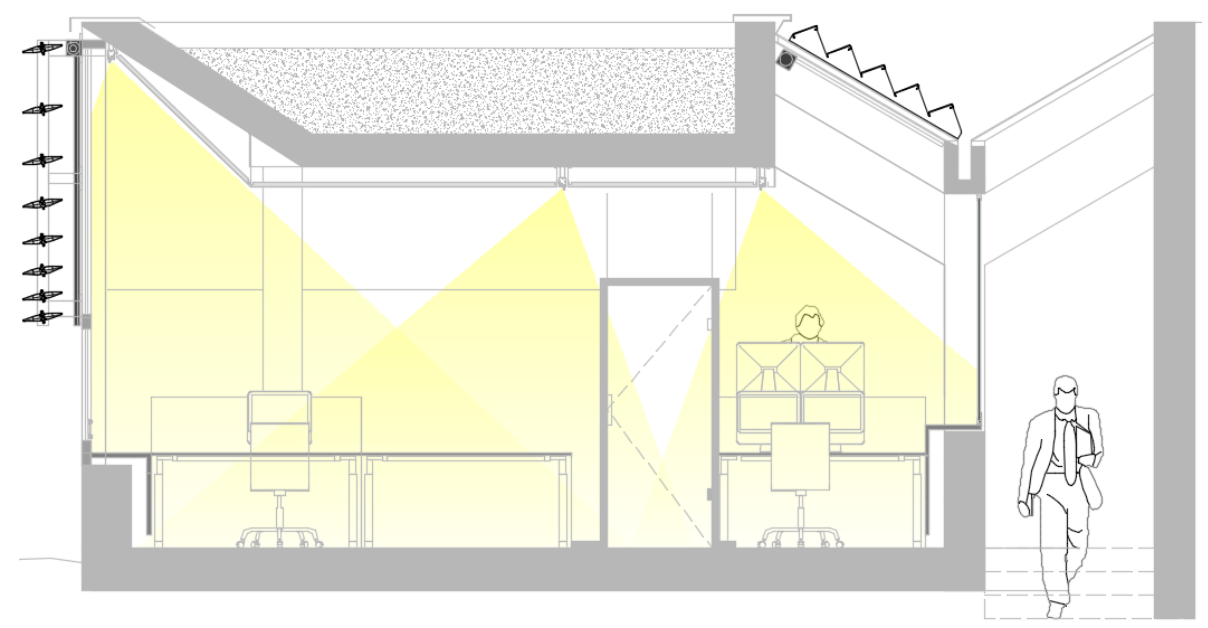

Figure 10: Design concept for electric lighting solution.

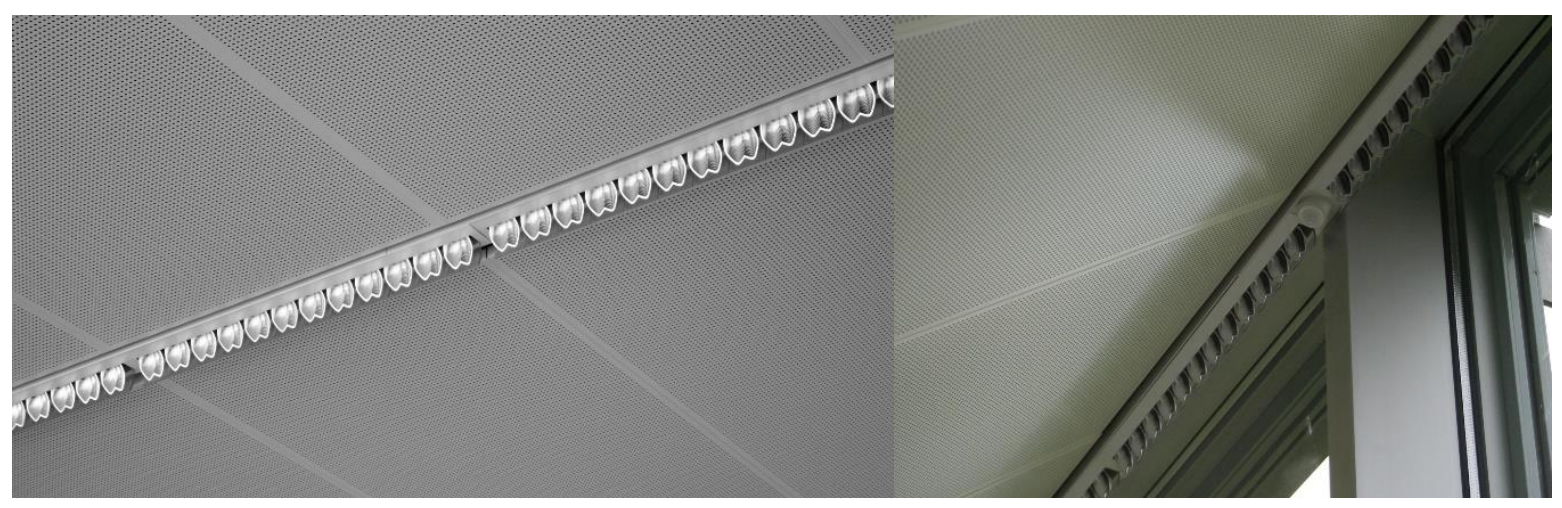

Figure 11: Architecture-integrated electric lighting system installed in example office space. 

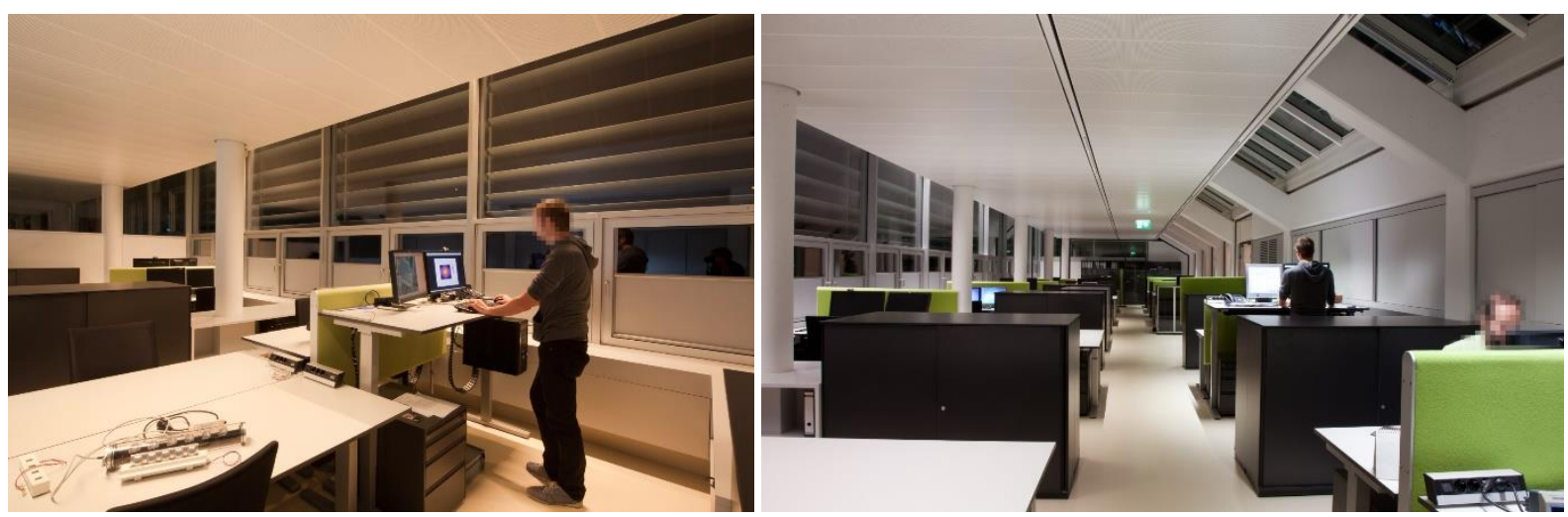

Figure 12: The tunable white electric lighting system provides color temperatures from $2200 \mathrm{~K}$ to $5000 \mathrm{~K}$.

\subsubsection{Integrated lighting control and building automation}

The control for the electric and daylight systems as well as for heating and ventilation is integrated in a holistic Beckhoff control system. A total of 48 sensors for occupancy, workplane illuminance, exterior illuminance, wind speed and temperature provide input for the integrated control of the daylight and the electric lighting systems. The color temperature of the electric lighting is dependent on the time of the day and the exterior daylight situation, the workplane illuminance is set to the target illuminance via a closed-loop control. The automated shading systems at the south façade and at the north pitch roof are closed to provide sun and glare protection with sun position dependent settings to avoid direct sun penetration.

Additionally, every user has the possibility to override the illuminance settings for the electrical lighting and the movable daylighting systems for his/her own area. The top-down/bottom-up glare protection screens in the lower part of the southern façade are controlled by the users manually.

Summarized, the bullet points of the integrated lighting control system are:

- Daylight responsive electric lighting control

- Control of color temperature dependent on time and daylight conditions

- Automated sun and glare protection system control according to exterior conditions

- Indoors sensors for workplane illuminance, occupancy and temperature as well as outdoor sensors for exterior illuminance, wind speed and temperature

- Integrated closed-loop control for daylight, electric light, heating and ventilation 


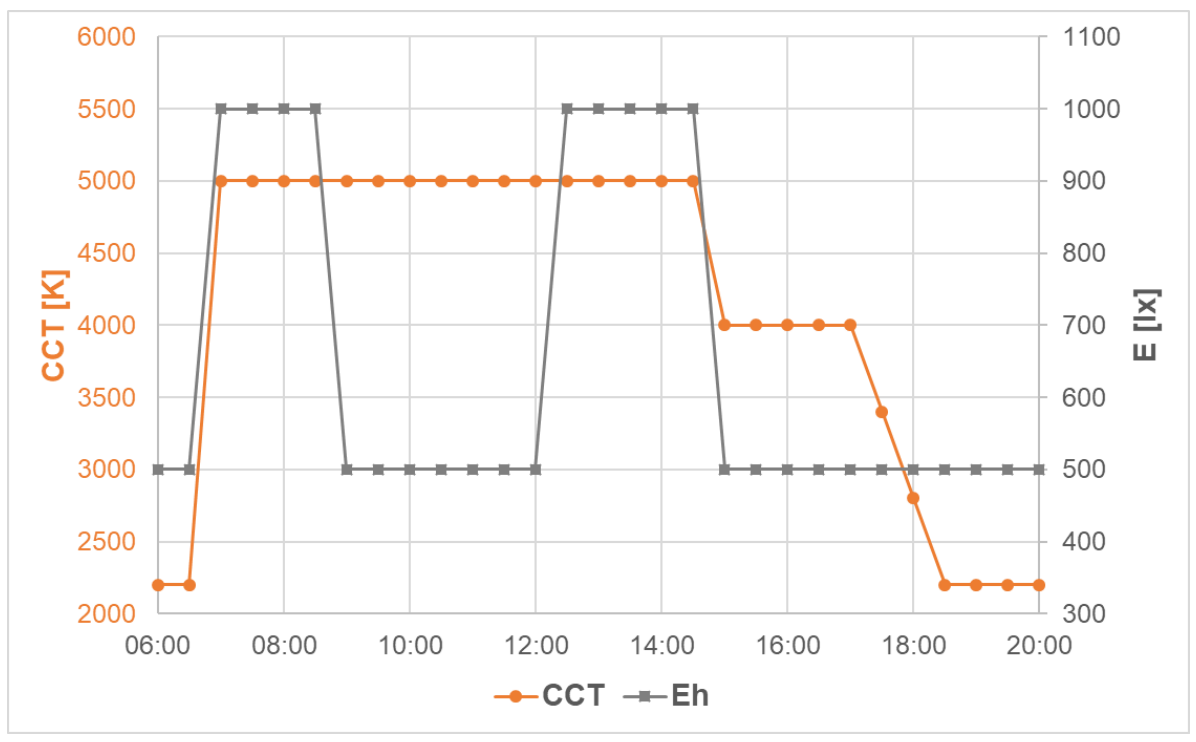

Figure 13: Control specification for dynamic interior lighting.

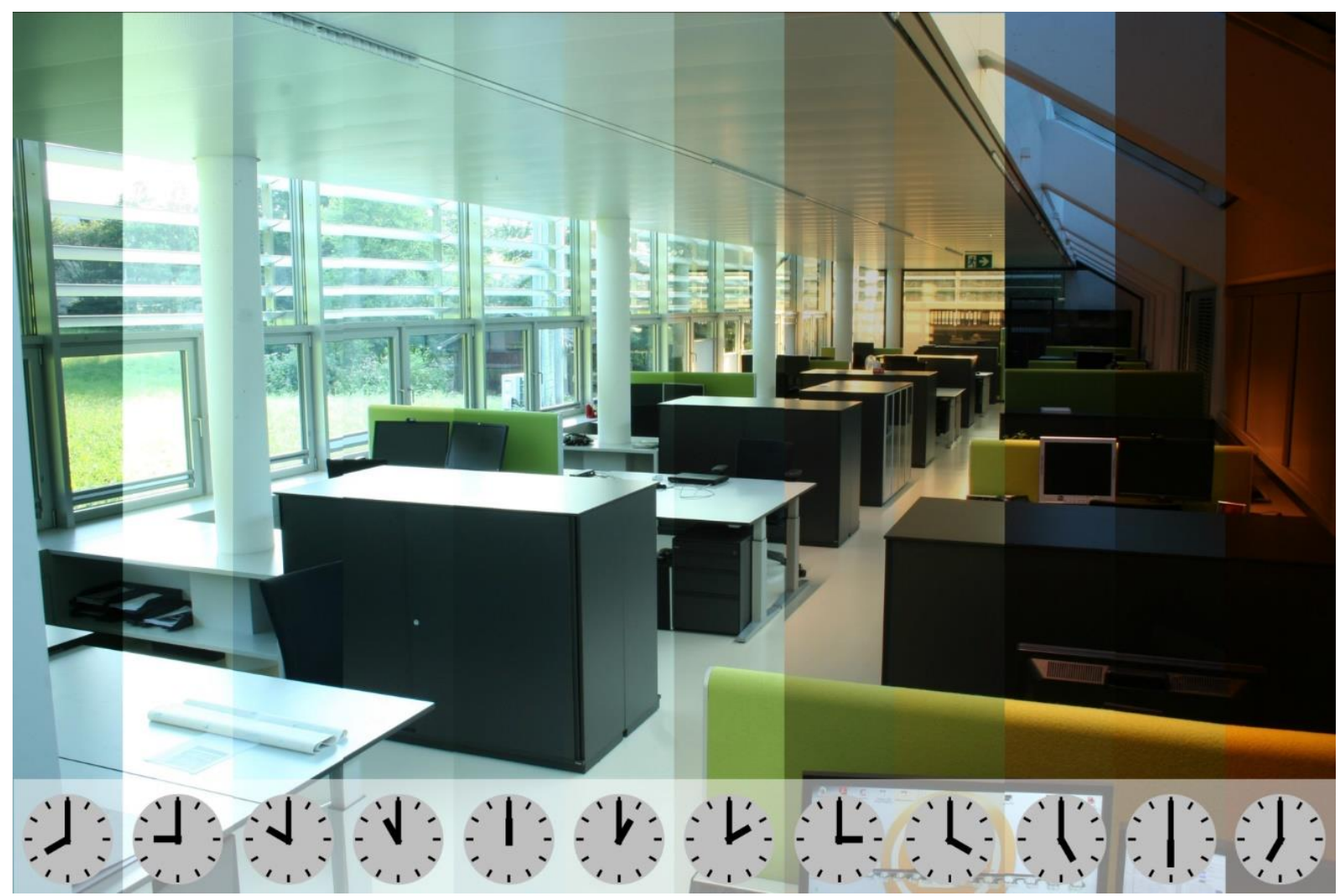

Figure 14: Example sequence of interior lighting conditions in the office space. 


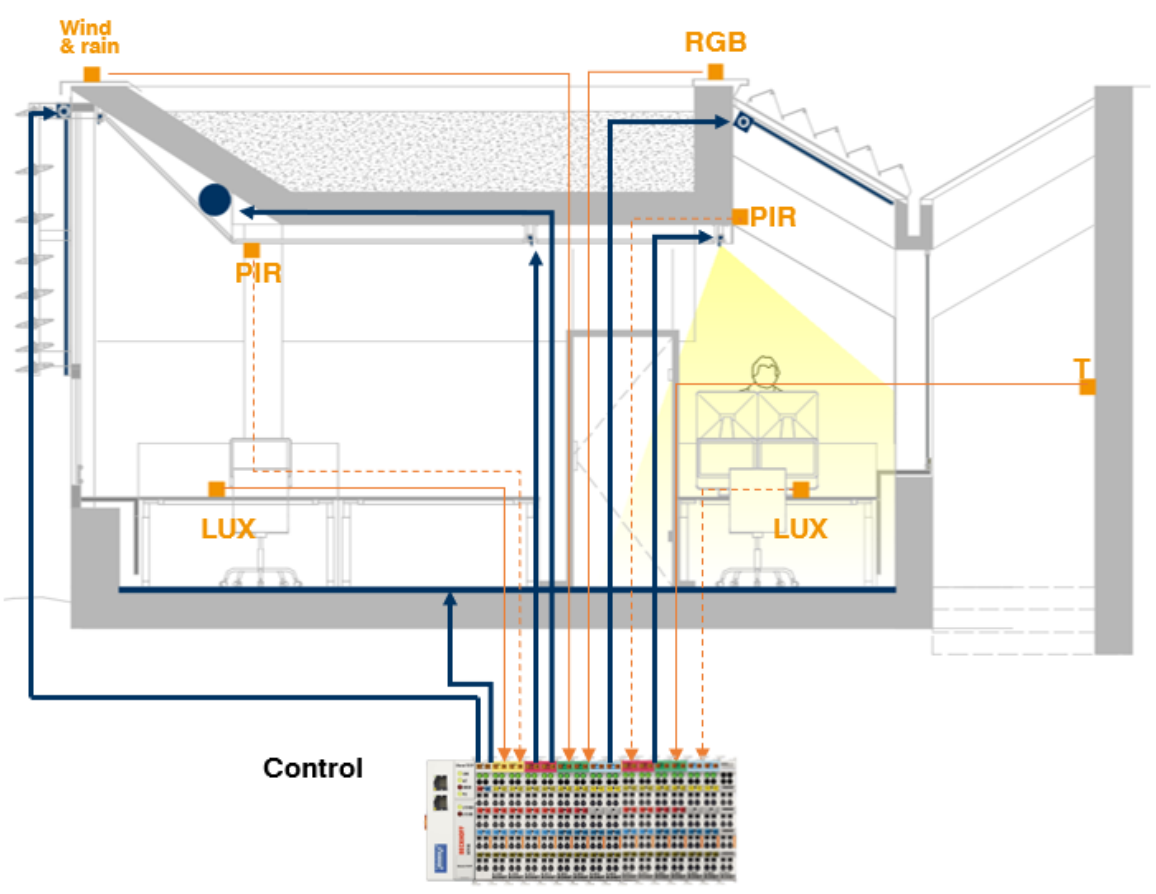

Figure 15: Control setup.
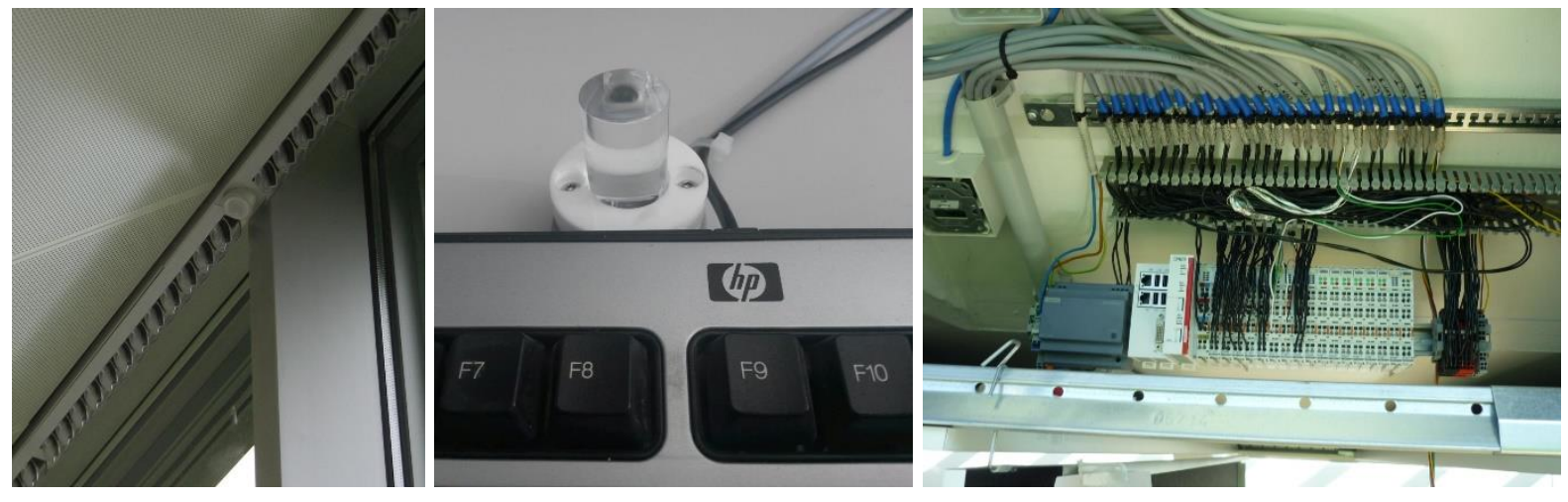

Figure 16: Occupancy sensors between luminaires (left), workplane illuminance sensors (center), and embedded PC in the control cabinet (right).

\subsubsection{Evaluation}

A comprehensive monitoring and evaluation of the Bartenbach R\&D office is done within Subtask D "Lab and field study performance tracking" of this IEA SHC Task 61 / EBC Annex 77 "Integrated solutions for daylight and electric lighting". The results will be published in the report of this Subtask and will be available on http://task61.iea-shc.org/. 


\subsection{DIAL Corporate Building}

\section{by Daniel Witzel, DIAL, Germany}

The DIAL Company building is a three-story office, administration and training building in Lüdenscheid, North Rhine Westphalia, Germany. The architecture and overall technical concepts were designed in-house and managed by DIAL in a lead capacity through to occupation of the building in 2013. Since then, the software-controlled building has been continuously developed and improved. From the very beginning, the focus of the design was on people, their needs and comfort in the building, in accordance with the philosophy, that the user does not have to operate anything, the intelligent building serves the user.

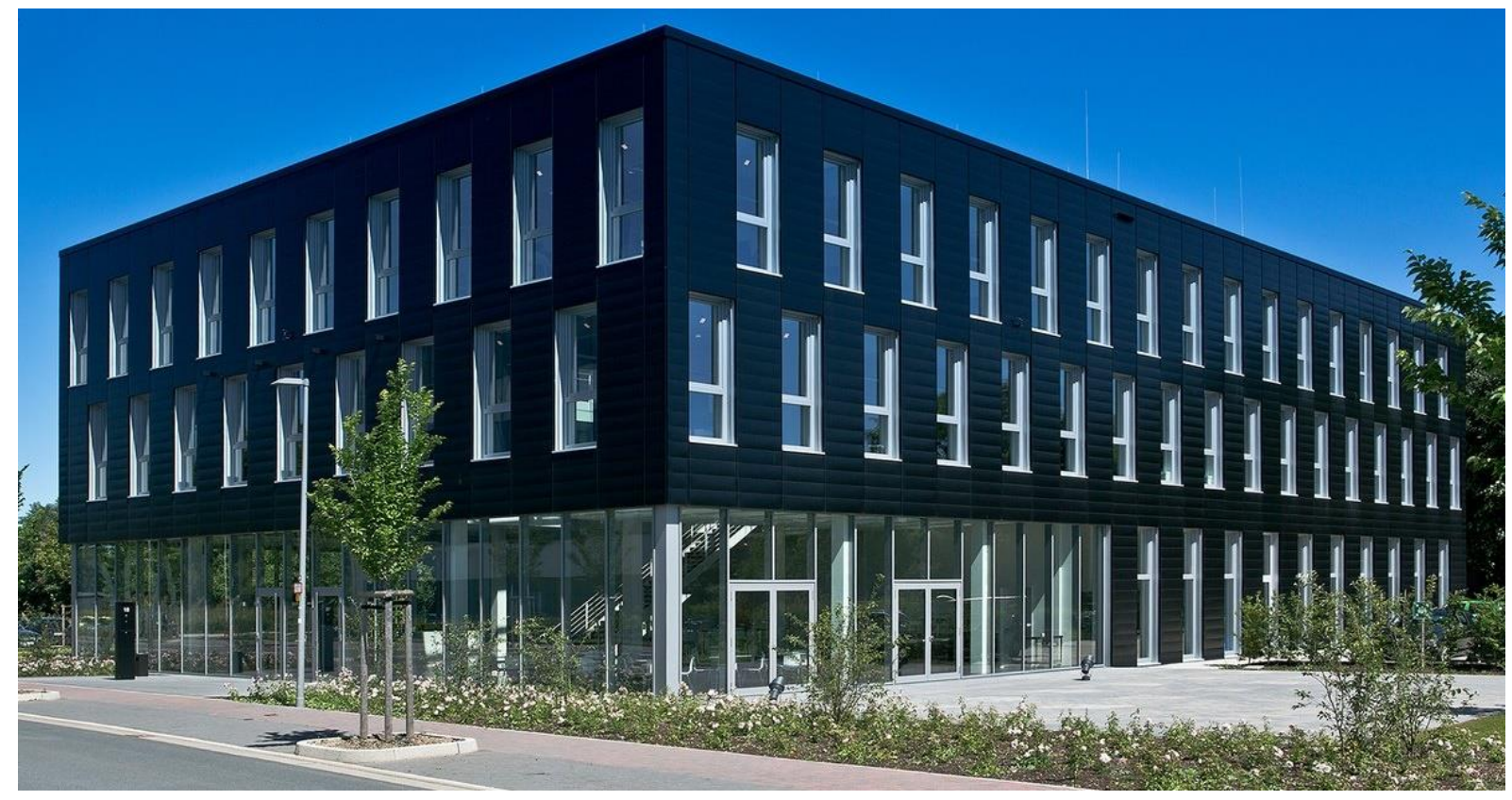

Figure 17: DIAL Corporation Building Lüdenscheid.

The integrated design of architecture and technology follows a holistic concept. All technical component groups are networked with each other, no system functions autonomously.

The DIAL building is located at $51.219^{\circ} \mathrm{N} 7.63^{\circ} \mathrm{E}$ at an altitude of $415 \mathrm{~m}$ above sea level in the region of South Westphalia, near the Ruhr area. 


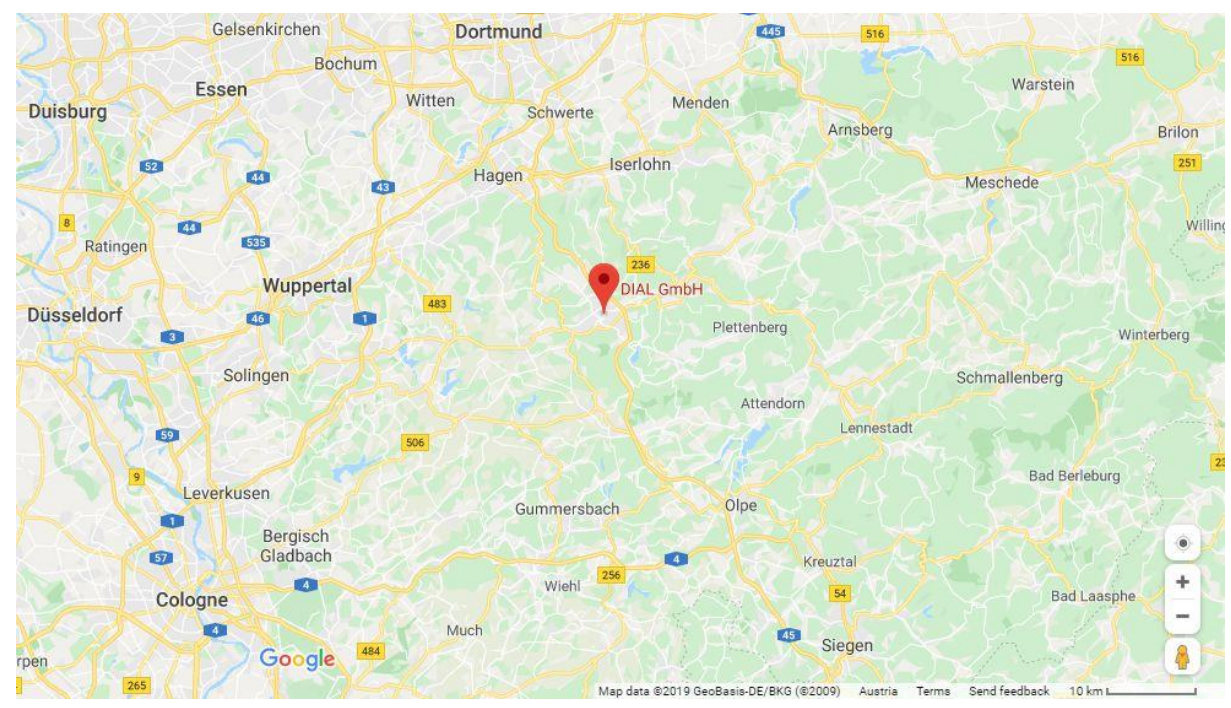

Figure 18: Location of DIAL Corporation Building, NRW Germany. Map data $\odot 2019$ GeoBasis-DE/BKG (@2009), Google

\subsubsection{Geometric and use description}

On three floors about 2,900 $\mathrm{m}^{2}$ of space for 100 employees are available. The complex space program includes among others:

- a central foyer with catering area (atrium)

- office and conference rooms

- an experiment laboratory for lighting (white lab)

- a photometric laboratory (black lab)

- an automation laboratory

- further seminar and experimental rooms

The building is a cuboid with rectangular ground plan. It is oriented with its long side parallel to the building of the adjacent tax office. The external dimensions of the building are $25.85 \mathrm{~m}$ wide and $44.05 \mathrm{~m}$ long. The normal floor height is in the first and second floor at $3.60 \mathrm{~m}$, on the ground floor at $5.15 \mathrm{~m}$. The clear height is in the first and second floor at $2.95 \mathrm{~m}$, on the ground floor at $4.50 \mathrm{~m}$. The main entrance is at the street side of Bahnhofsallee. Further access is via the necessary stairwells, on the north and south side, as well as via the bistro area and the delivery entrance on the east side. The stairwells on the north and south side also forms the first escape route of the building.
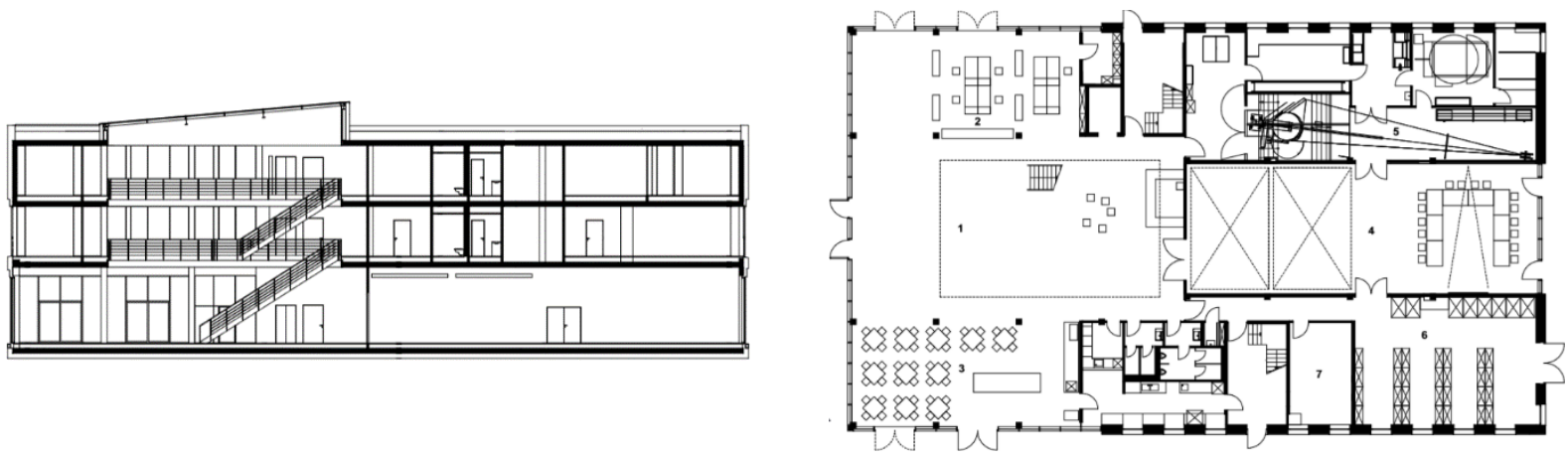

Figure 19: Section and ground floor of DIAL Corporation building. 

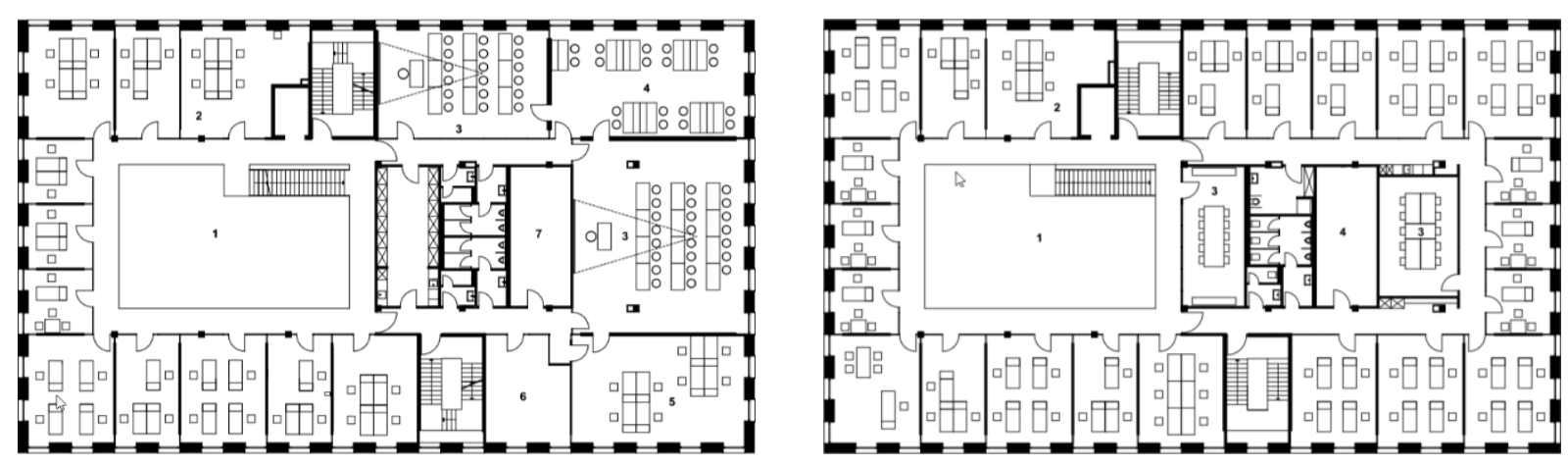

Figure 20: First and second floor of the DIAL building.

\subsubsection{Surroundings}

The plot for the DIAL Corporate building is located north of the tax office at the Bahnhofsallee opposite the University of Applied Sciences South-Westphalia. It is divided into two parcels of different sizes, which can be built by DIAL in two construction phases as an option. The plot area for the first construction phase is $5,266 \mathrm{~m}^{2}$, the covered building area is approximately $1,000 \mathrm{~m}^{2}$. There is room for a possible extension to the north with additional $3,000 \mathrm{~m}^{2}$.

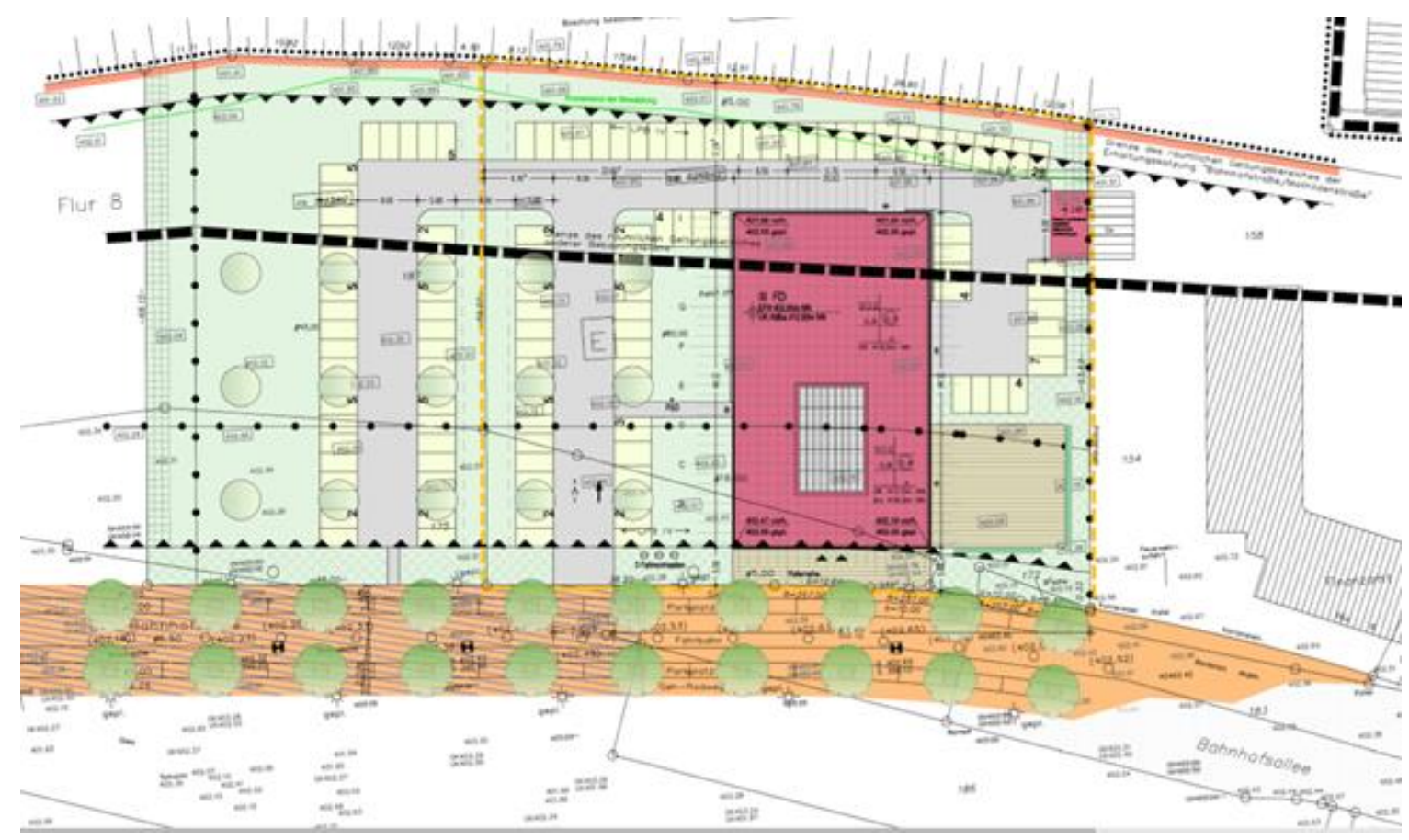

Figure 21: Surroundings of the DIAL building.

Lüdenscheid has several weather stations. Current weather data are available via the German weather service from the station 3098 at $51.25^{\circ} \mathrm{N} 7.64^{\circ} \mathrm{E}$ in $386 \mathrm{~m}$ above sea level in about $3 \mathrm{~km}$ distance.

\subsubsection{Daylighting solution}

The building is equipped with external blinds that are controlled by a central weather station of the building automation system depending on the position of the sun. Since no sunshine is to be expected on the north side, no blinds were planned on this façade side. The central atrium 
is supplied with daylight via a $124 \mathrm{~m}^{2}$ skylight, which has no sun protection so far. At the ground floor only the storage room, the technical central, the white laboratory and the south stairwell have sun blinds.

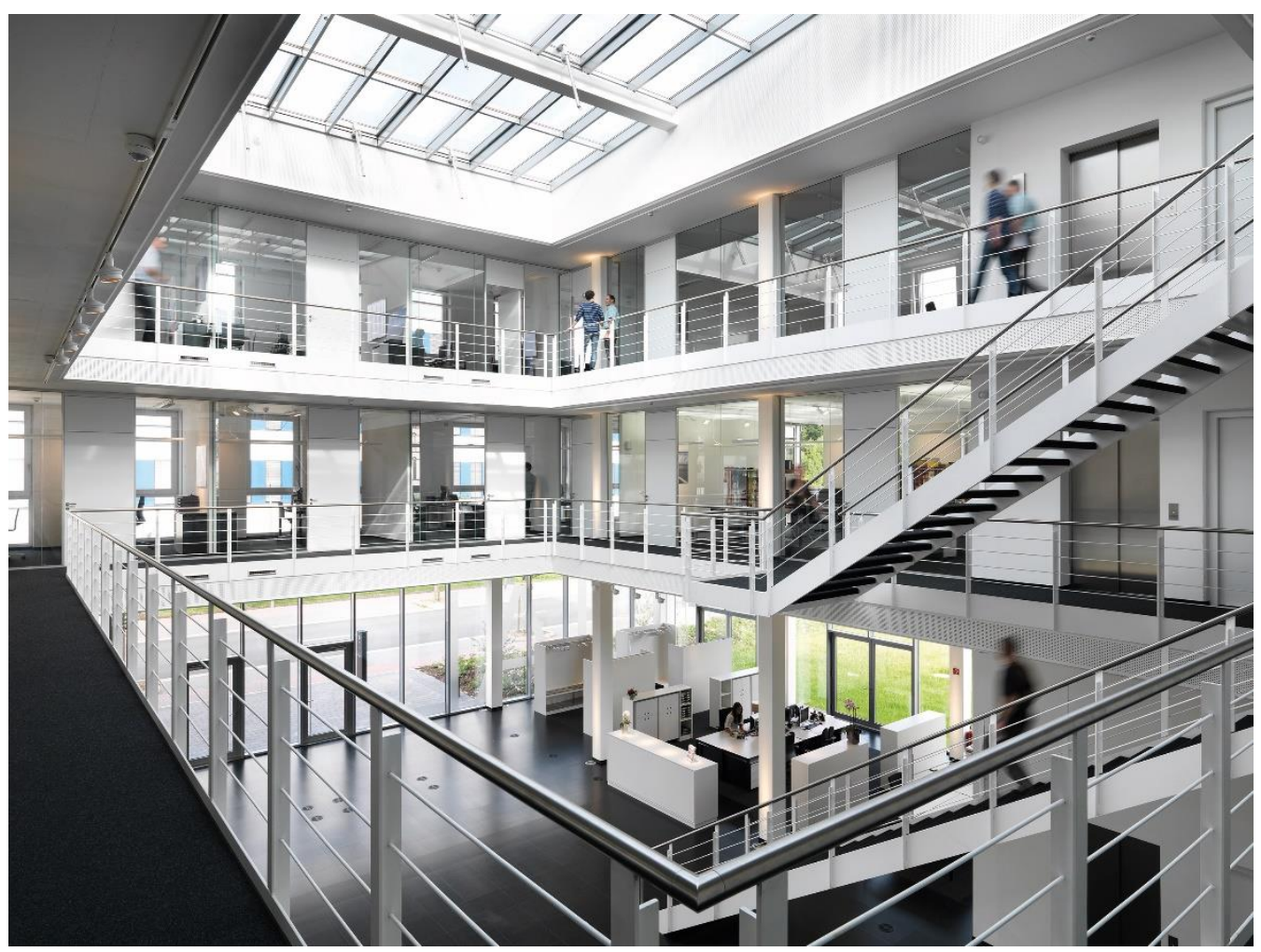

Figure 22: DIAL building atrium.

The individual rooms and offices are, with a few exceptions, visually connected to the corridors and the atrium with glass partitions to cope with the supply of daylight and the planned requirement for transparency. The floor-to-ceiling windows without lintels together with the bright material on the surface of the soffits ensure maximum daylight entry.

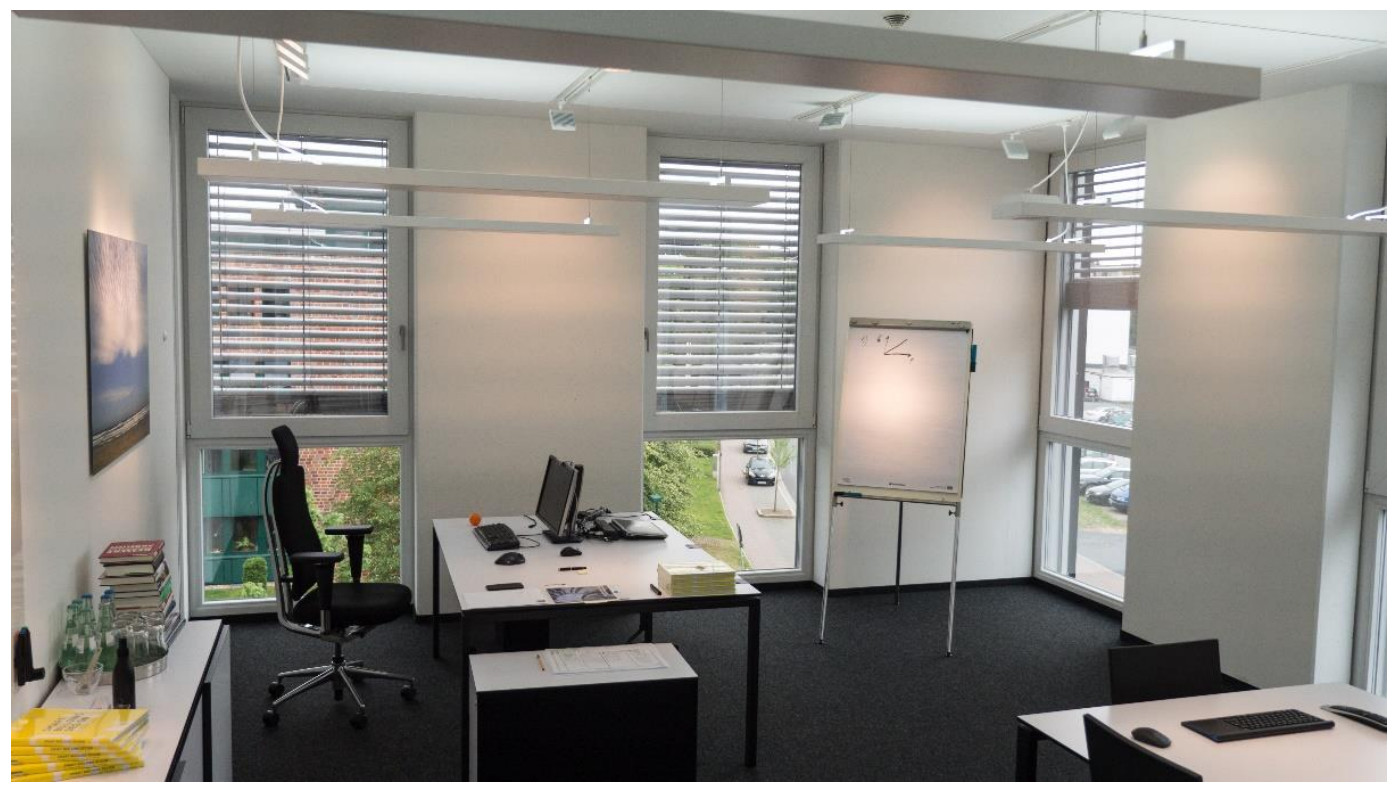

Figure 23: Office room in the DIAL building. 


\subsubsection{Electric lighting solution}

The office lighting consists of indirect ceiling lighting as well as additional spots that set accents of light at certain points.
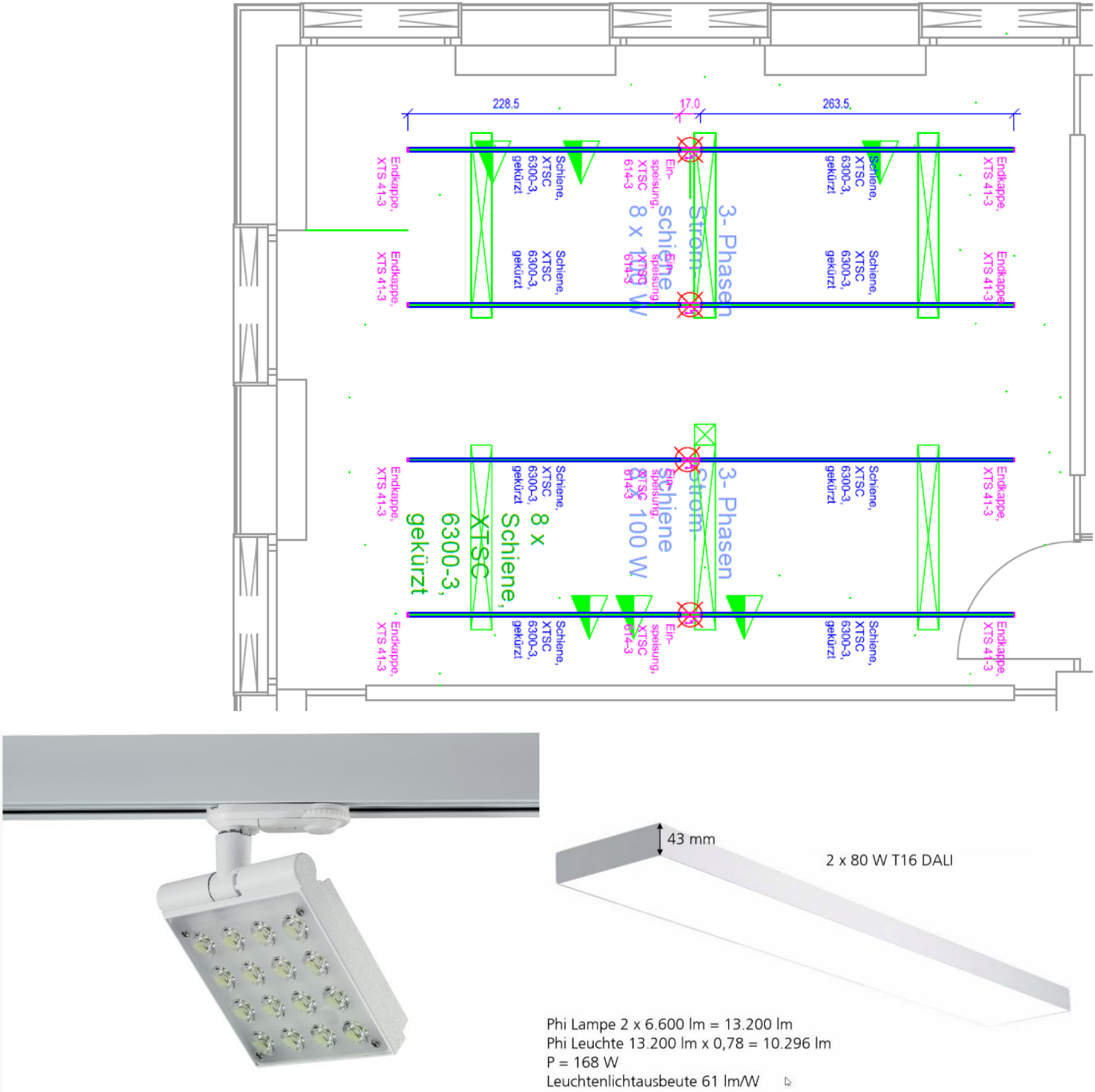

$2 \times 80$ W T16 DALI

Figure 24: LED Spot 20W, Indirect Illumination 2x 80W.

The office lighting is based on the concept of Human Centric Lighting. The light adapts to the biological rhythm of the day, but can be adapted at any time to the requirements of the user through an app. 


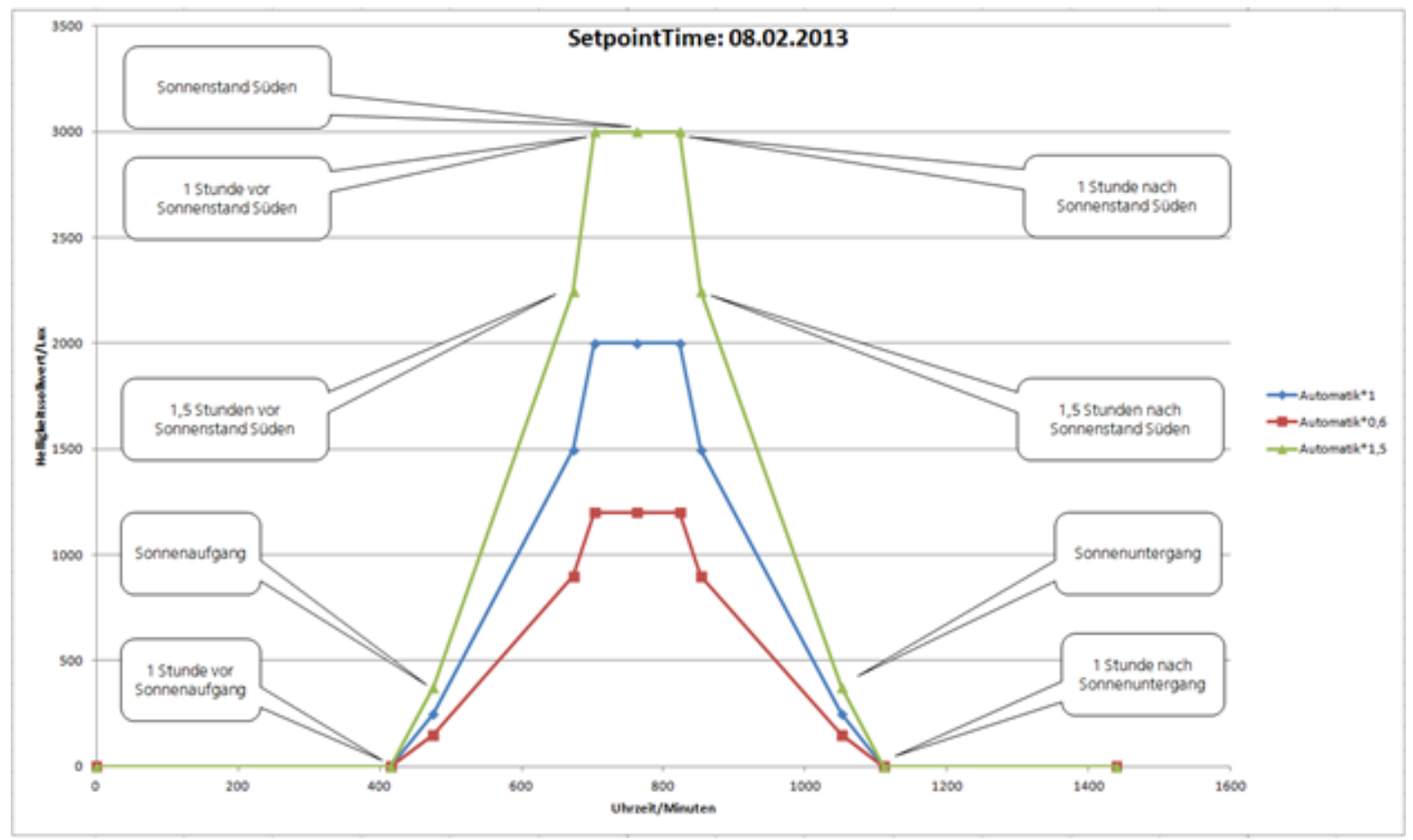

Figure 25: Individual settings for HCL.

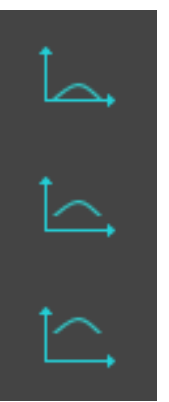

Setpoint shift by -500 lux from the calculated daily setpoint.

Standard daily course setpoint.

Setpoint shift by -500 lux from the calculated daily setpoint.

The sun protection was planned with blinds with adjustable slats, so that even with lowered blinds daylight is part of the illumination. The shading is automatically controlled by sensors on the outer wall, but can also be controlled by the user individually via the app.

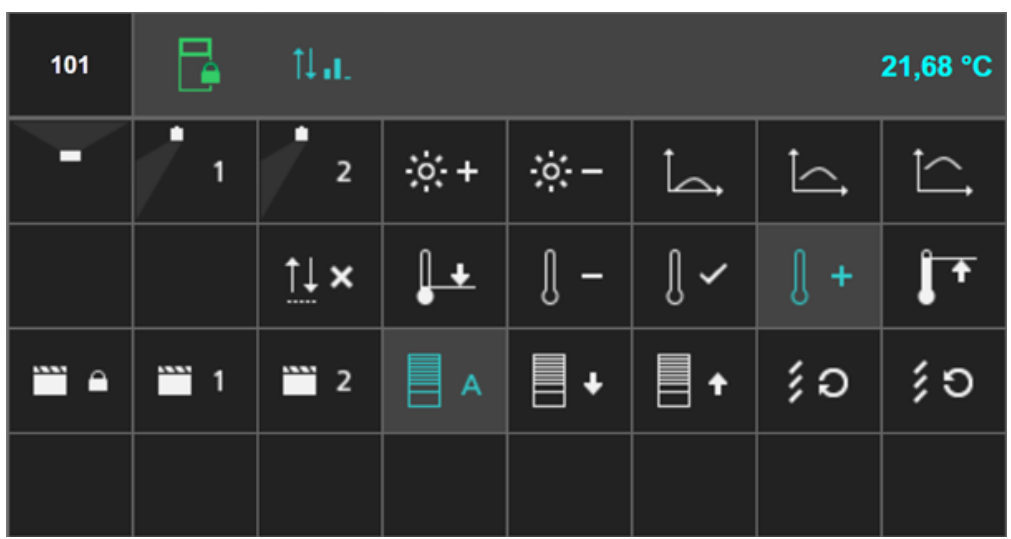

Figure 26: User app. 


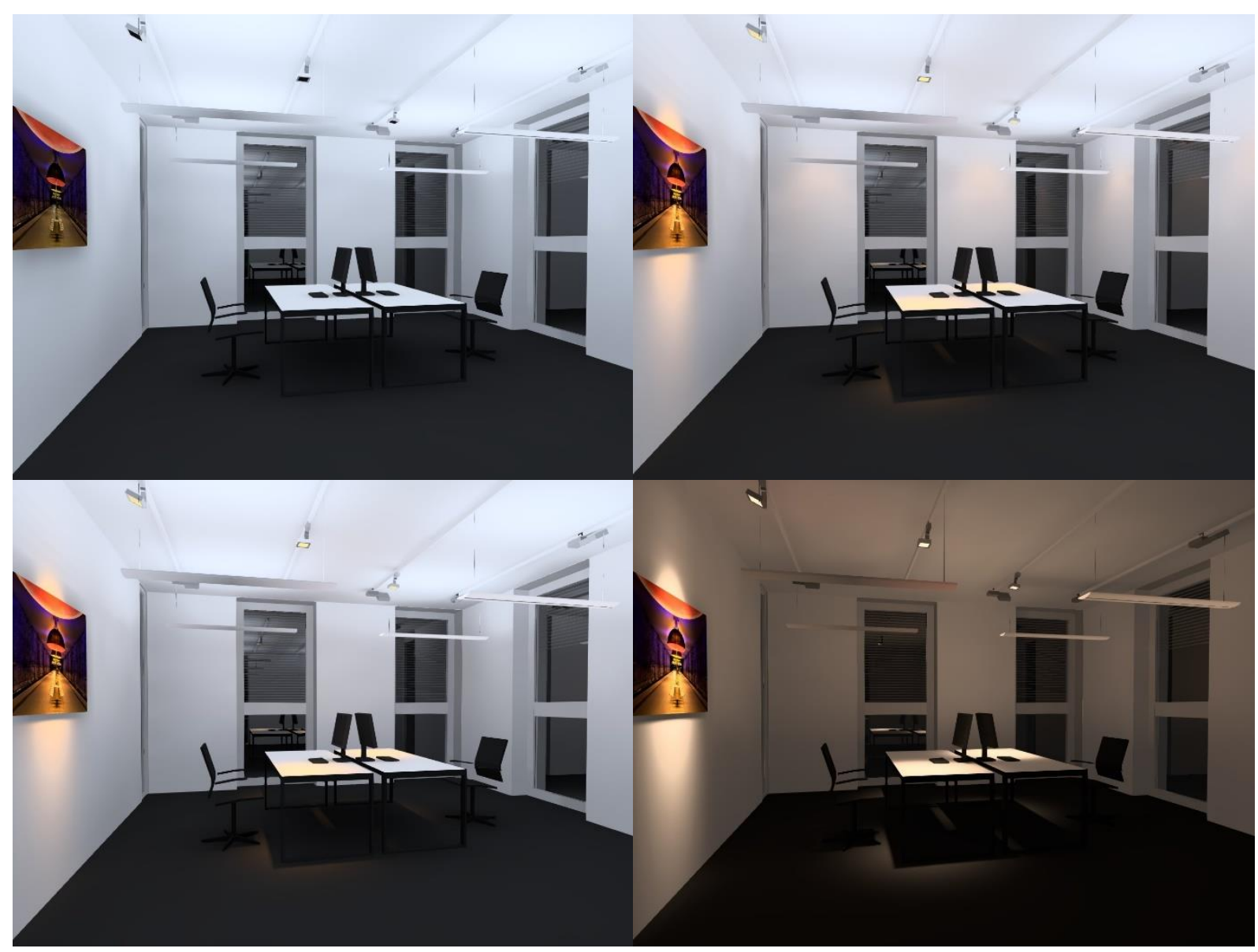

Figure 27: Concepts for individual light scenes.

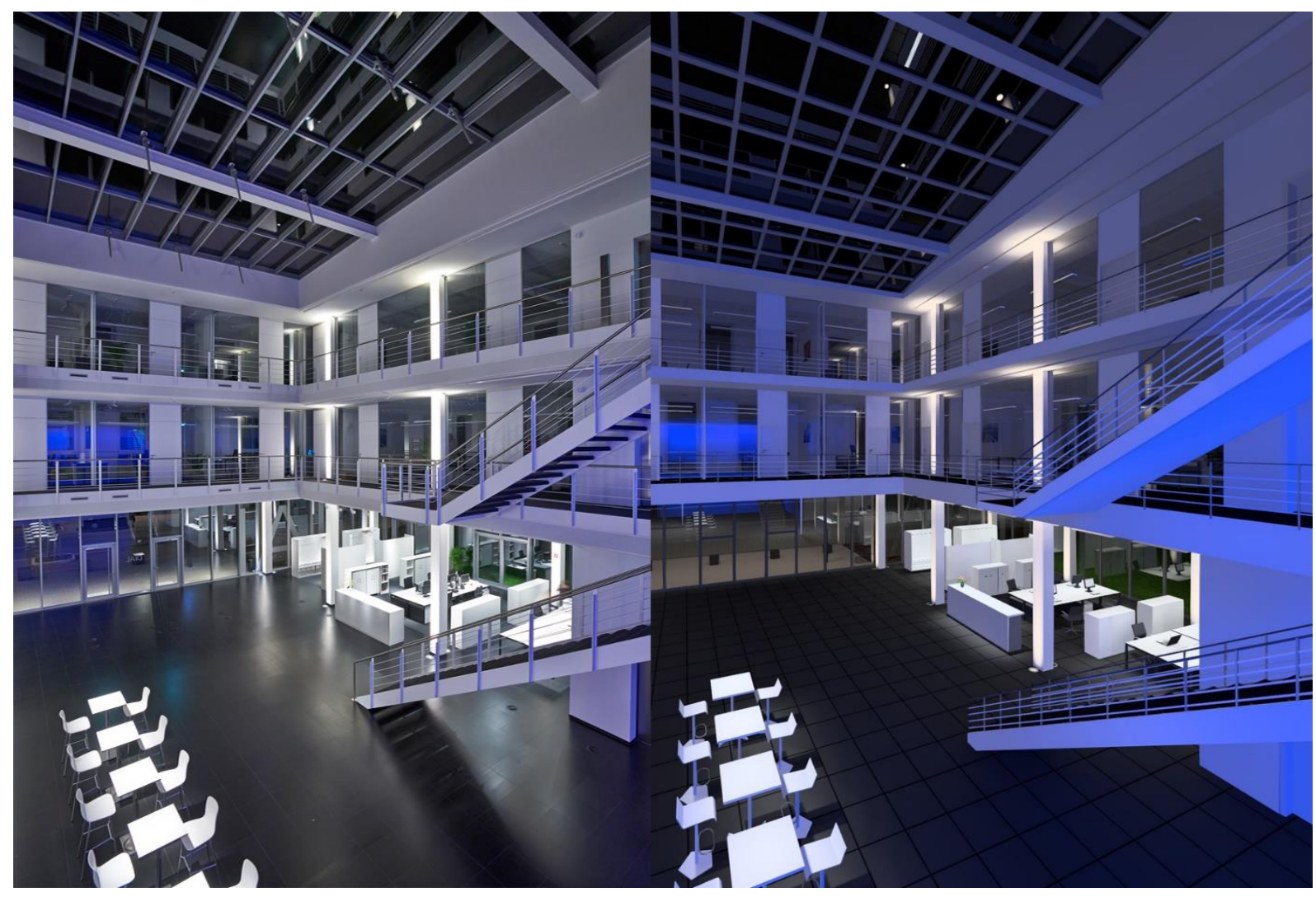

Figure 28: Light scenes Atrium: plan and implementation. 


\subsubsection{Integrated lighting control and building automation}

The comprehensive technical systems were planned in dependence on each other. All component groups are networked with each other. An operating system controls and regulates the functions of the building based on the available information. In order to operate the building energy-efficiently and at the same time comfortably at all times, it is necessary to implement dynamic operating strategies with the help of building automation.

The installation of the technical equipment is mostly done in a raised floor. From here, the introduction of the supply air into the room and removal of the exhaust air from the room takes place. This arrangement is unlike to schoolbook knowledge and was therefore simulated first by a heating, ventilation and air conditioning supplier.

Decisive for the successful operation of the intelligent building is certainly the use of a softwarebased technical building management. In order to balance the daylight and artificial light as efficiently and ergonomically as possible, a dynamic light management of sun protection and lighting is required. Basically, all application functions are automated as required. Most rooms do not feature conventional switches. Nevertheless, high value was set on providing the user with individual influence options.

The operation of the building is mainly via the PC or cell-phone app, with which employees can influence the air, temperature and light quality. With just a few clicks, you can customize your workplace to suit your needs. On the one hand, this involves the central display of the operating states and operation of the building's technical systems, and on the other hand the recording and continuous evaluation of the operating data in order to maintain and optimize the building performance.

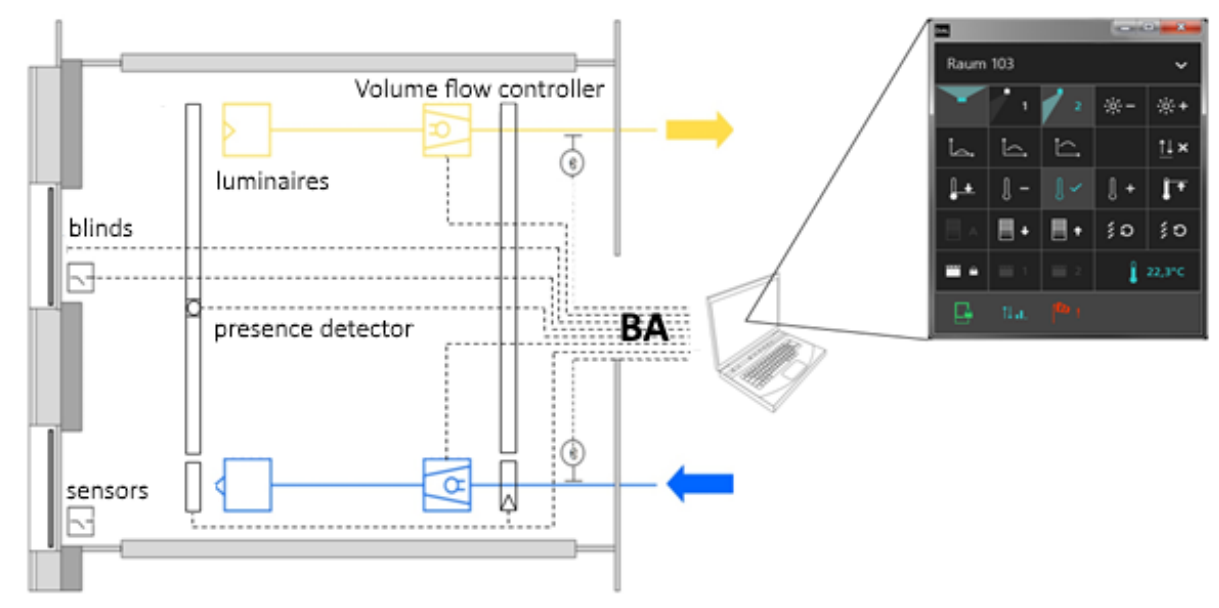

Figure 29: Building automation and user interface.

\subsubsection{Evaluation}

A comprehensive monitoring and evaluation of the DIAL building is done within Subtask D "Lab and field study performance tracking" of this IEA SHC Task 61 / EBC Annex 77 "Integrated solutions for daylight and electric lighting". The results will be published in the report of this Subtask and will be available on http://task61.iea-shc.org/. 


\subsection{CABR NZEB Office Building}

\section{by Luo Tao, CABR, China}

The China Academy of Building Research Near Zero Energy Office Building is located in No.30, BeiSanHuanDong Road, Chaoyang district of Beijing. The building was officially put into use in 2014, and the certification target is 3-star level green building and LEED-NC platinum.

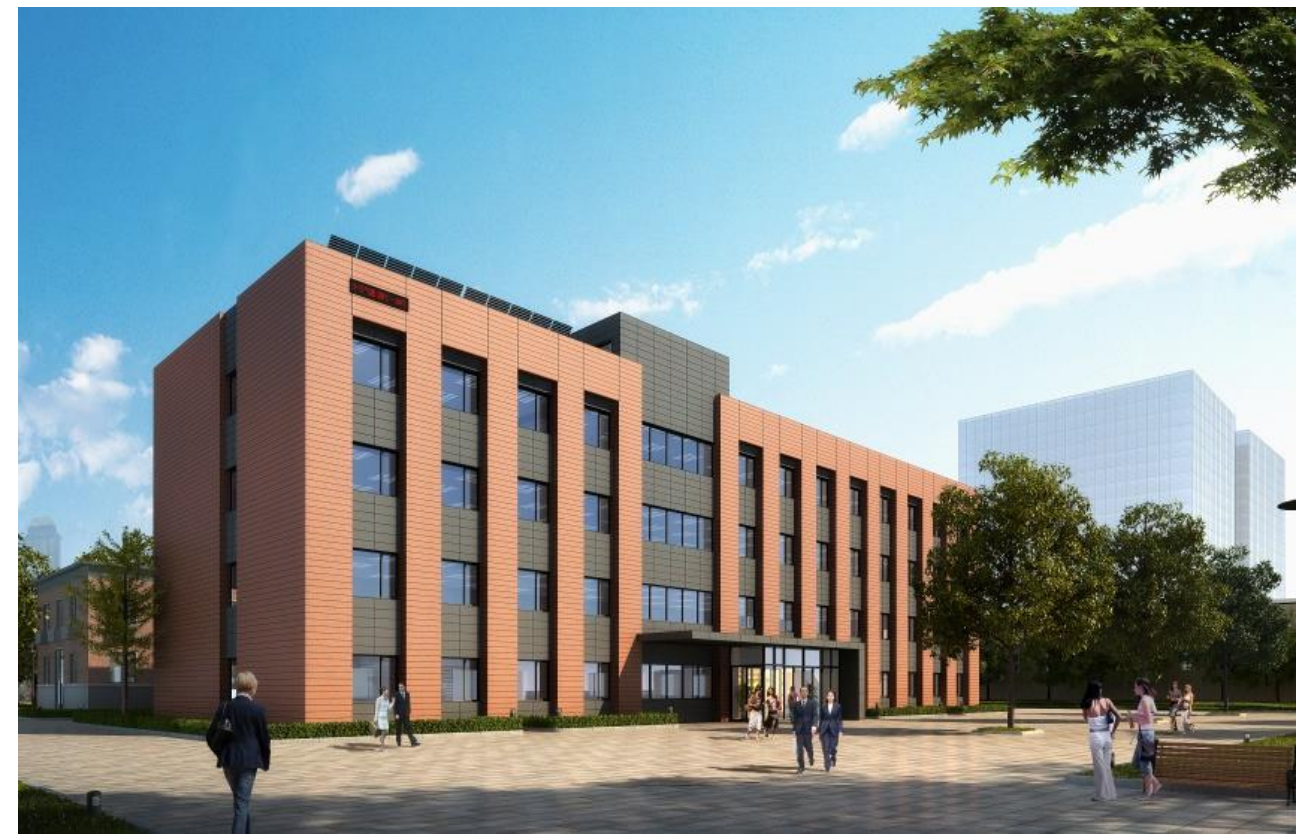

Figure 30: CABR NZEB in Beijing, China.

According to the principles "passive priority, active optimization, economical and practical", this office building integrates advanced building technology, evaluating with actual data, as a demonstration for the development of ultra-low-energy buildings in China. This project is located at east longitude $116^{\circ} 20^{\prime}$, north latitude $39^{\circ} 56^{\prime}$, in Beijing.

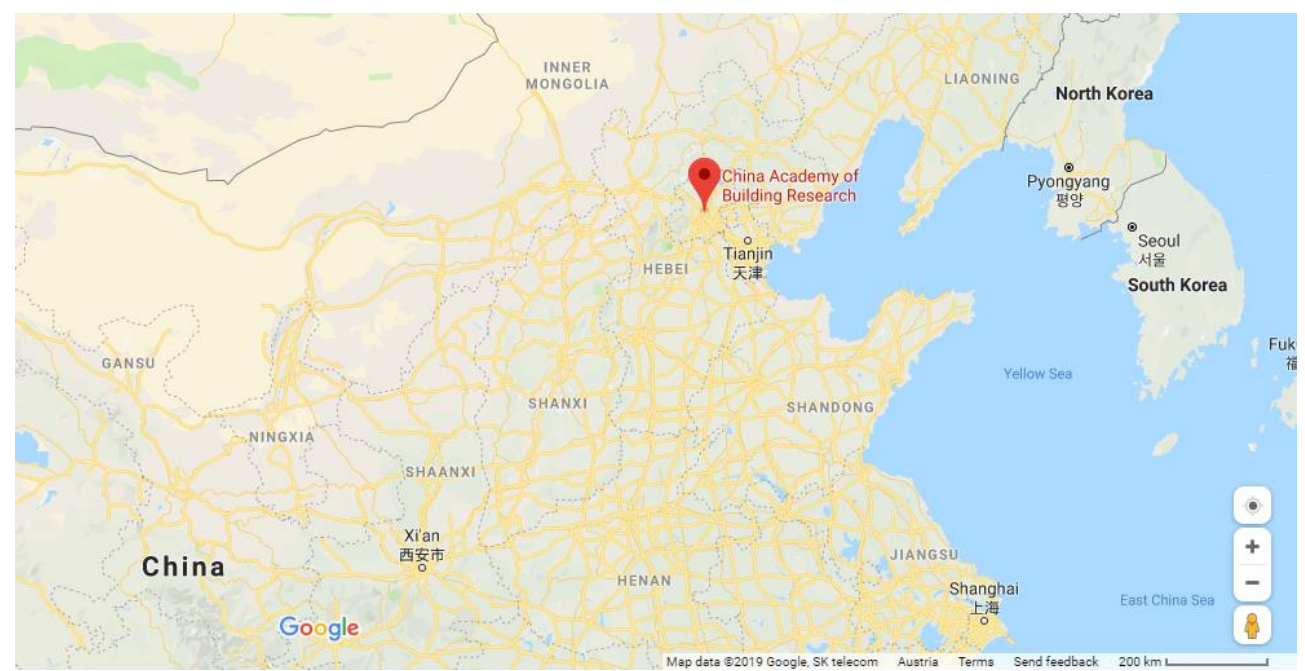

Figure 31: Location of CABR NZEB in the eastern part of China. Map data @2019 Google, SK telecom 


\subsubsection{Geometric and use description}

This 4-storey office building, with a total area of 3,692 square meters, is mainly used for office and conference occupation, and hosts about 160 staff.

The plans of each floor are shown as below:

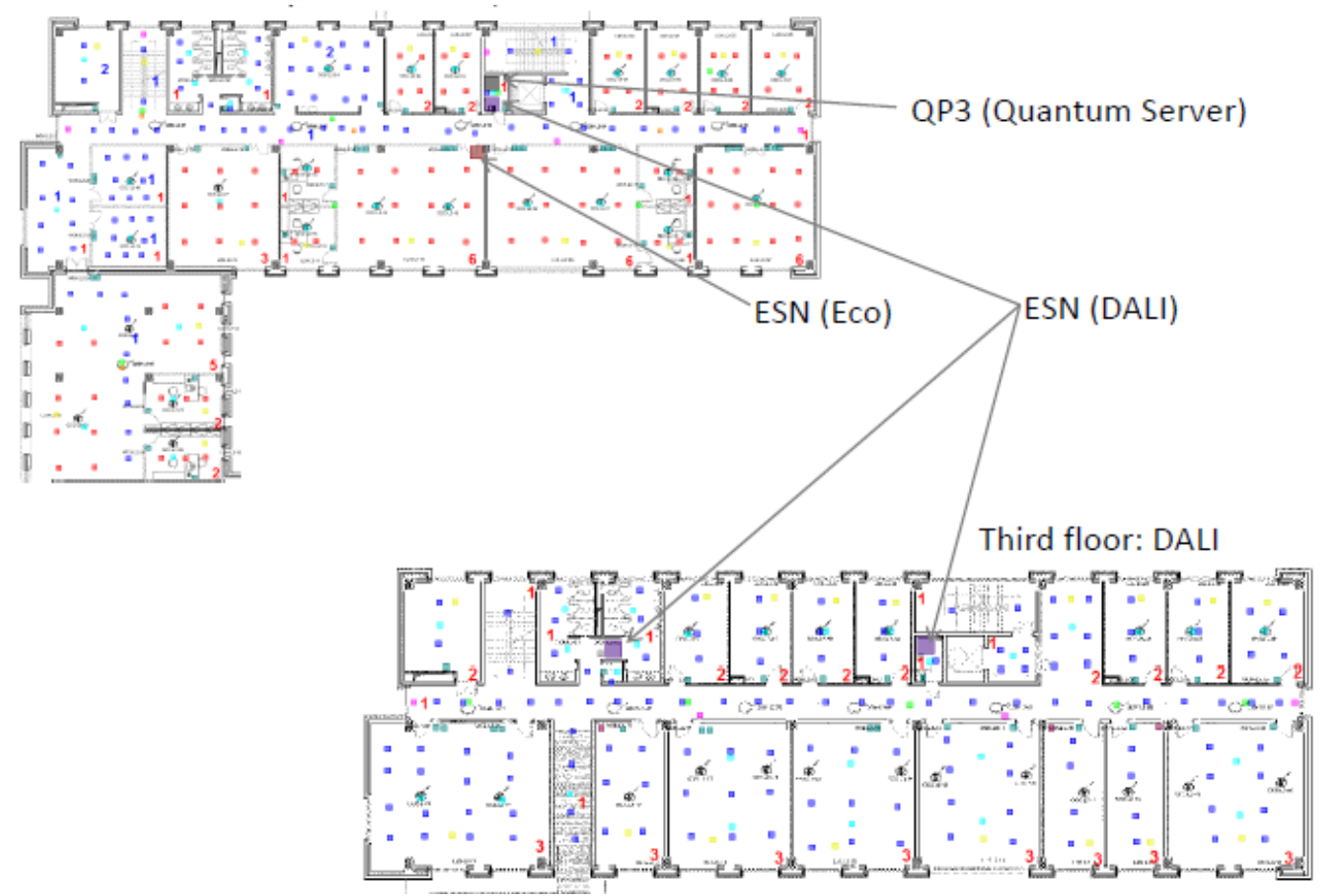

Figure 32: Floor plan of the building.

\subsubsection{Surroundings}

The north and northeast side of the office building is the high-rise office building of CABR, and the south side is the office building of institute of building fire research.

The first and second floors of the office building are significantly sheltered, and the third and fourth floors have good views and daylighting.

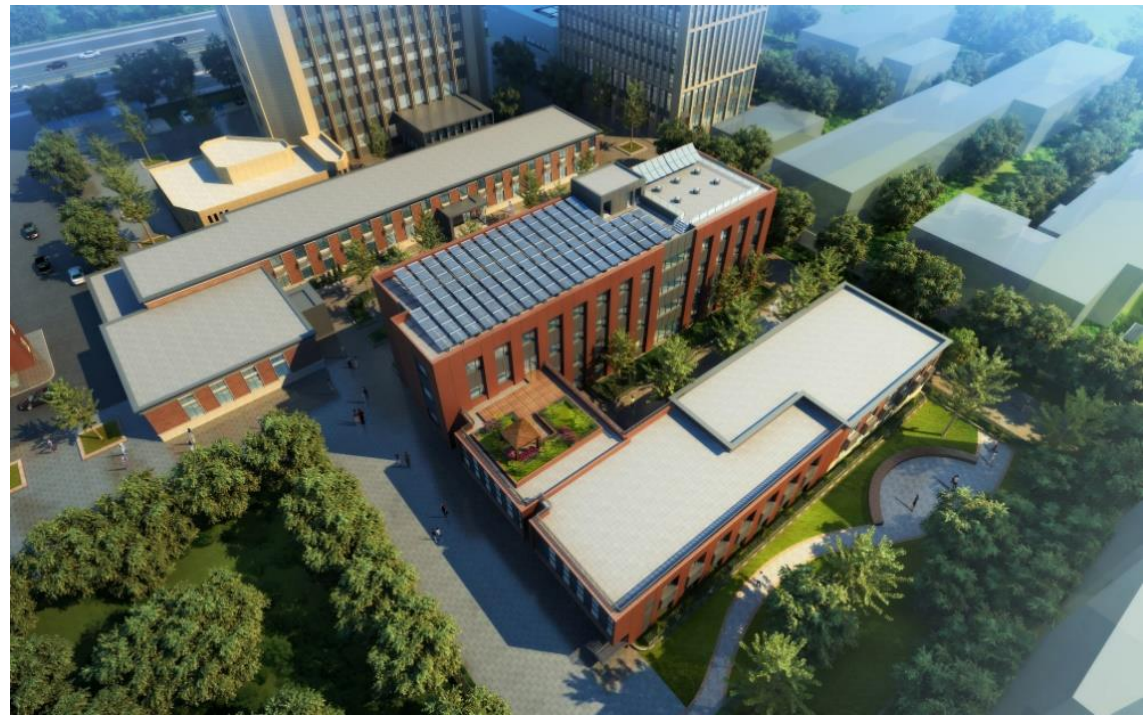

Figure 33: Surroundings of the CABR building. 


\subsubsection{Daylighting solution}

Compared to traditional roller shades, the embedded horizontal blinds have a better adjustment performance, which can make indoor illuminance more uniform and make full use of daylight while avoiding glare, as shown in the following figure:

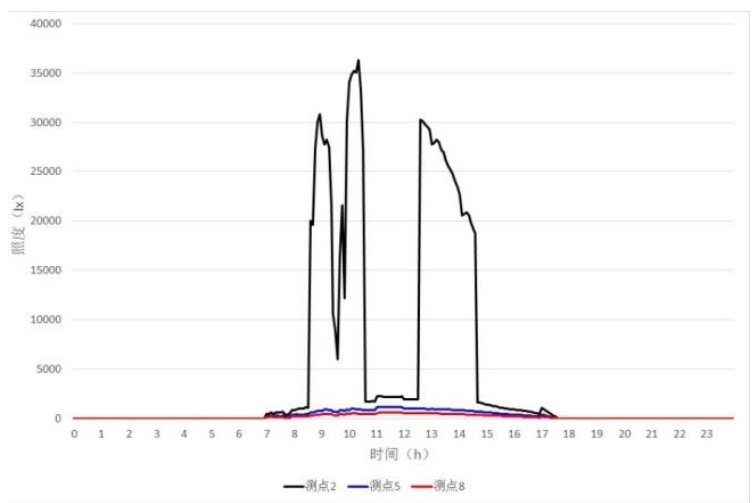

Indoor illuminance distribution without blinds

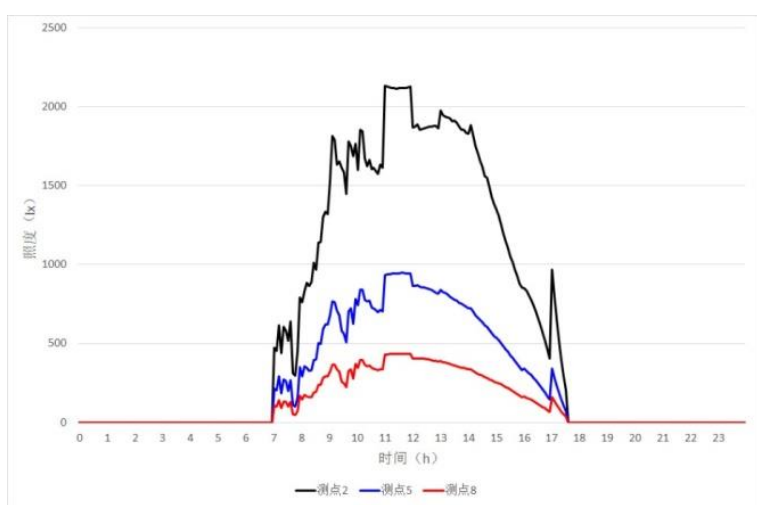

Indoor illuminance distribution with embedded blinds

Figure 34: Fenestration optimization

The conference room on the fourth floor of CABR demonstration building adopts an adjustable light pipe lighting system to ensure light and avoid excessive heat entering the room.

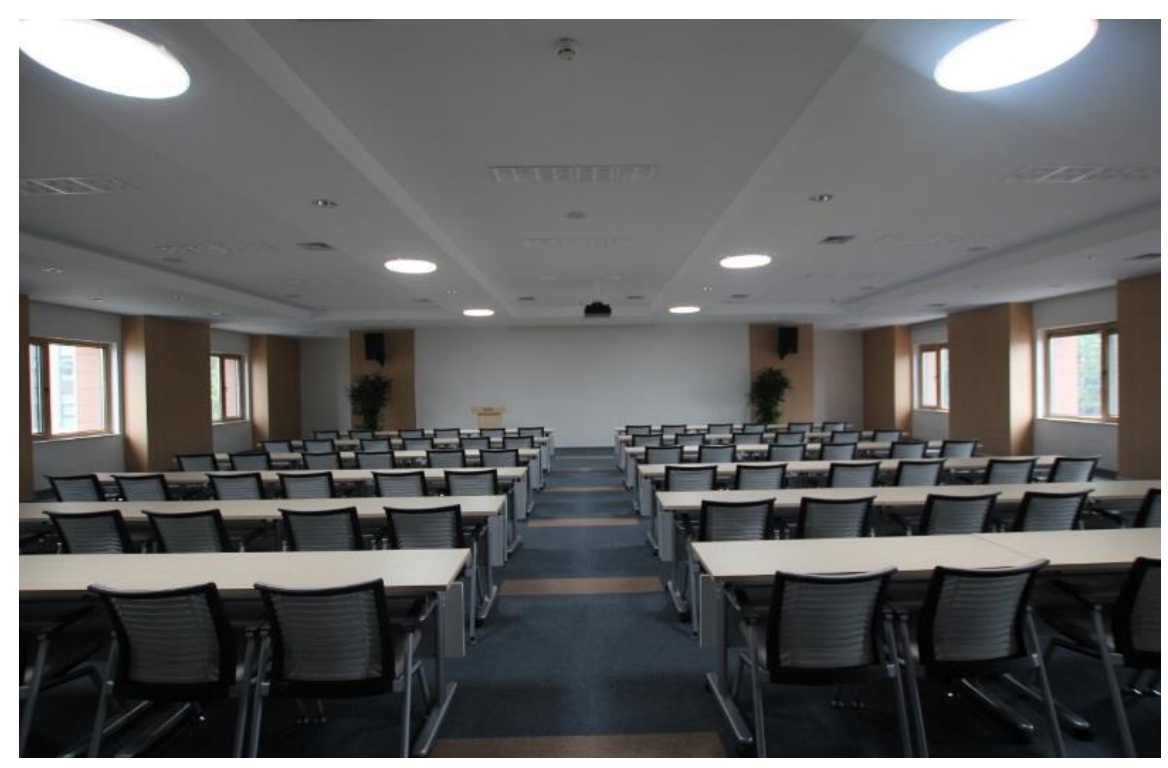

Figure 35: Tubular daylighting system

\subsubsection{Electric lighting solution}

A total of 655 sets of high-efficiency energy-saving luminaires and 167 sensors of illuminance, infrared, mobile and so on are used in this project. The luminaires used in this demonstration building are all from Philips. Office general lighting adopts fluorescent grille with T5 fluorescent lamps and LEDs (for comparative analysis), in addition, corridors and public spaces adopt LED downlights. Detailed information is shown in Table 1.

Room 407 on the fourth floor adopts POE power supply technology with 8 sets of luminaires, which can realize centralized control and single luminaire control mode with a mobile phone app. 
We carried out the optimization of the lighting design on the basis of choosing high-efficient luminaires, and under the premise of meeting the lighting requirements, the lighting installation power is reduced to achieve lighting energy saving. Below is the illuminance distribution of typical rooms.

Table 1: List of the luminaires

\begin{tabular}{|c|c|c|c|c|}
\hline No. & luminaire type & luminaire specification & installation & application area \\
\hline 1 & $\begin{array}{l}\text { Embedded fluorescent } \\
\text { grating lamp }\end{array}$ & TBS737 2XEco TL5-25W HFE ETO & Embedded & Office \\
\hline 2 & $\begin{array}{l}\text { Embedded fluorescent } \\
\text { grating lamp (light } \\
\text { sensor) }\end{array}$ & $\begin{array}{l}\text { TBS737 2XEco TL5-25W HFR 1- } \\
\text { 10V ETO }\end{array}$ & Embedded & Office by the window \\
\hline 3 & $\begin{array}{l}\text { Embedded LED } \\
\text { luminaire }\end{array}$ & $\begin{array}{l}\text { PowerBalance RC600B } \\
\text { LED41S/840 W30L120 PSD }\end{array}$ & Embedded & Office, conference \\
\hline 4 & $\begin{array}{l}\text { Embedded LED } \\
\text { luminaire (light sensor) }\end{array}$ & $\begin{array}{l}\text { PowerBalance RC600B } \\
\text { LED41S/840 W30L120 PSD + ACL }\end{array}$ & Embedded & Office by the window \\
\hline 5 & $\begin{array}{l}\text { Embedded LED } \\
\text { luminaire }\end{array}$ & $\begin{array}{l}\text { SmartPanel RC160V LED34S/ } 840 \\
\text { PSD W30L120 }\end{array}$ & Embedded & Reception room \\
\hline 6 & $\begin{array}{l}\text { Embedded LED } \\
\text { luminaire }\end{array}$ & $\begin{array}{l}\text { GreenPerform Troffer RC100C } \\
\text { LED35S/840 PSD W30L120 }\end{array}$ & Embedded & monitor room \\
\hline 7 & $\begin{array}{l}\text { Embedded LED } \\
\text { downlight }\end{array}$ & $\begin{array}{l}\text { LuxSpace BBS489 1000Im 4000K } \\
\text { PSD-DALI }\end{array}$ & Embedded & conference \\
\hline 8 & $\begin{array}{l}\text { Embedded LED } \\
\text { downlight }\end{array}$ & $\begin{array}{l}\text { GreenSpace DN181B 1000Im } \\
4000 \mathrm{~K}\end{array}$ & Embedded & Corridor, toilet \\
\hline 9 & $\begin{array}{l}\text { Embedded LED } \\
\text { downlight }\end{array}$ & $\begin{array}{l}\text { GreenSpace DN182B 1500Im } \\
4000 \mathrm{~K}\end{array}$ & Embedded & Main entrance hall \\
\hline 10 & LED ceiling light & Hengjie LED ceiling lamp & $\begin{array}{l}\text { Surface } \\
\text { mounted }\end{array}$ & staircase \\
\hline 11 & LED batten luminaire & $\begin{array}{l}\text { GreenPerform Batten BN208C } \\
\text { LED40/NW L1200 FR }\end{array}$ & $\begin{array}{l}\text { Surface } \\
\text { mounted }\end{array}$ & $\begin{array}{l}\text { air-conditioning control } \\
\text { room, storeroom }\end{array}$ \\
\hline
\end{tabular}




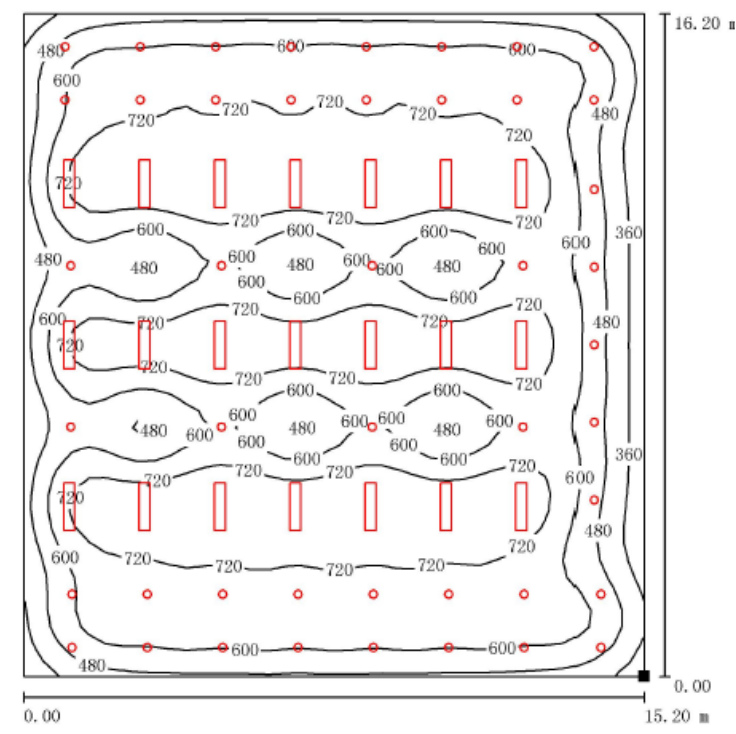

Conference room on the fourth floor

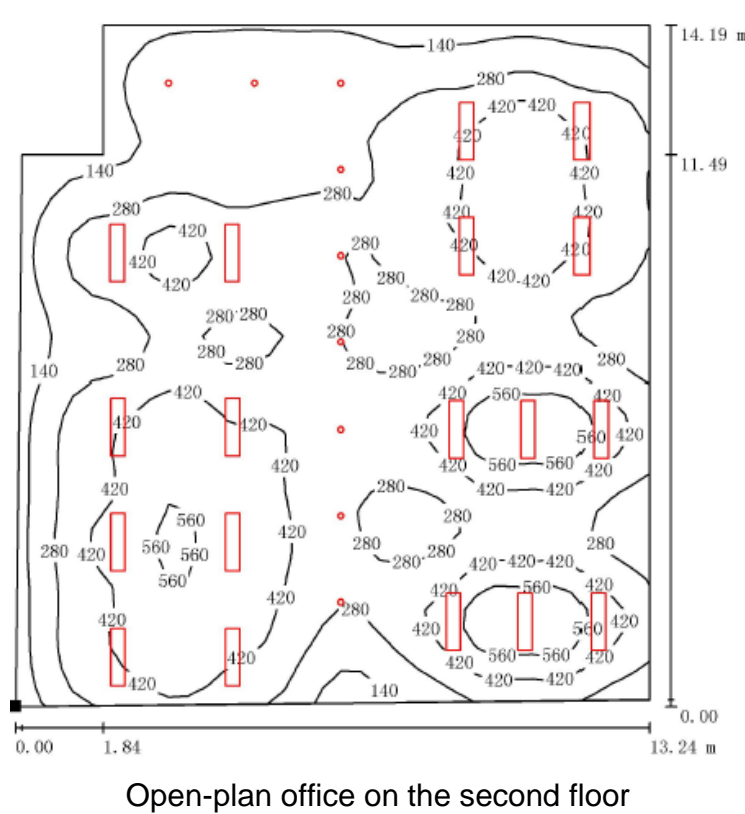

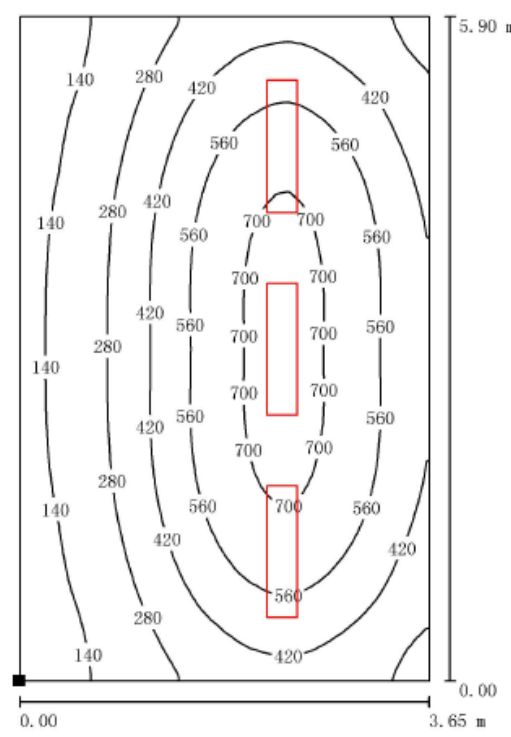

Reception room on the second floor

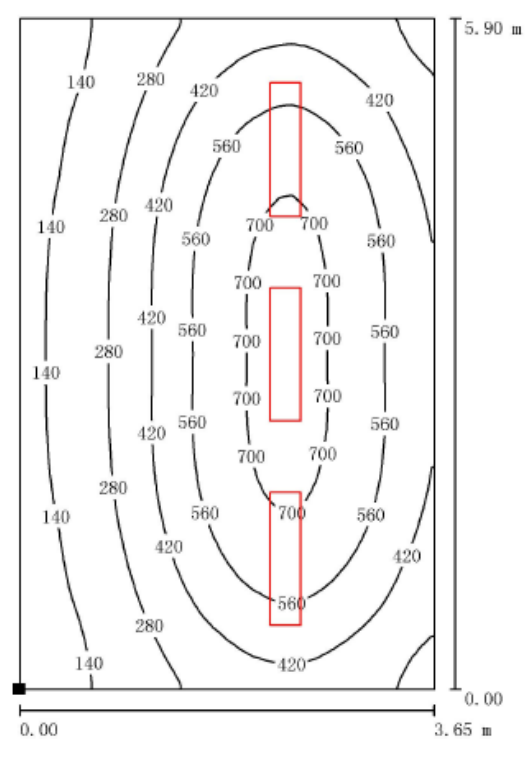

Private office

Figure 36: Calculation results for artificial lighting.

The lighting effect is shown in following figures:

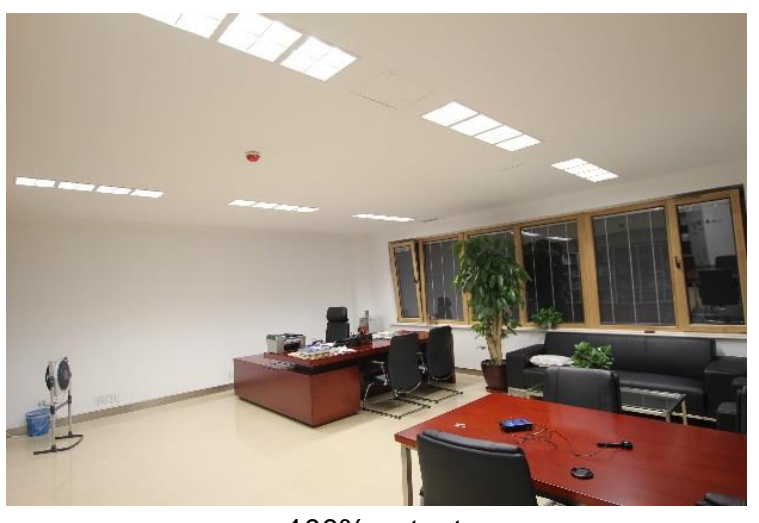

$100 \%$ output

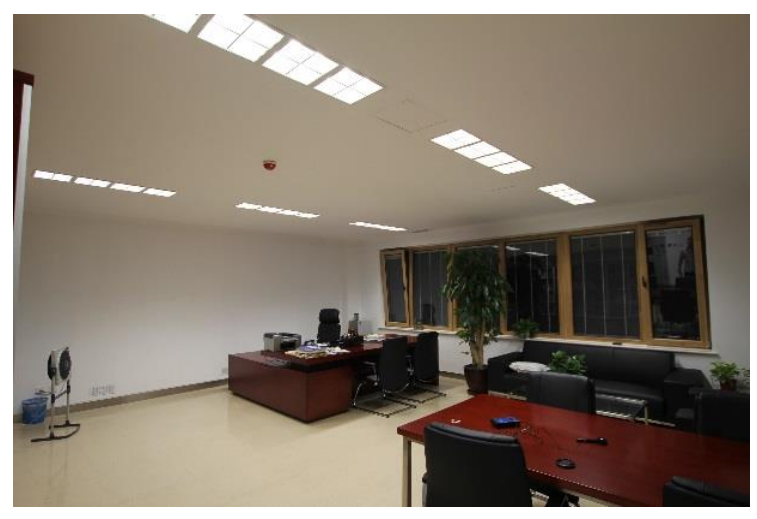

$50 \%$ dimming

Figure 37: Lighting environment of the private office (LED. 


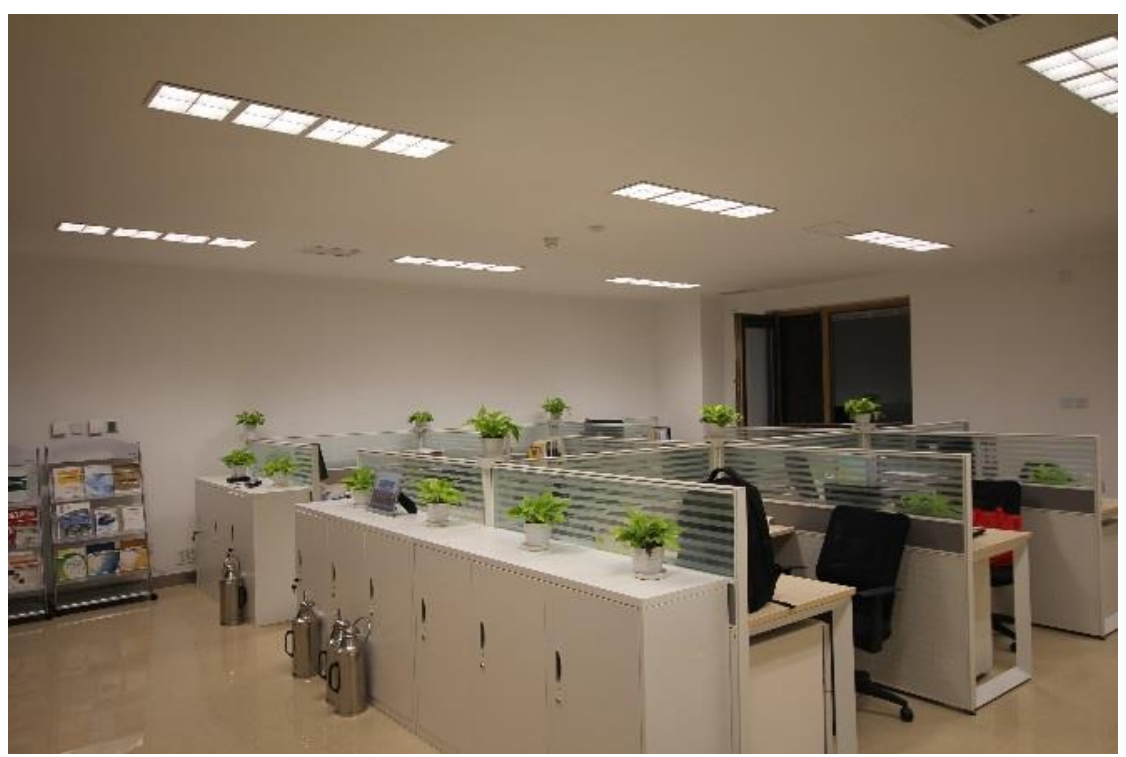

Figure 38: Lighting environment of the open-plan office (LED).
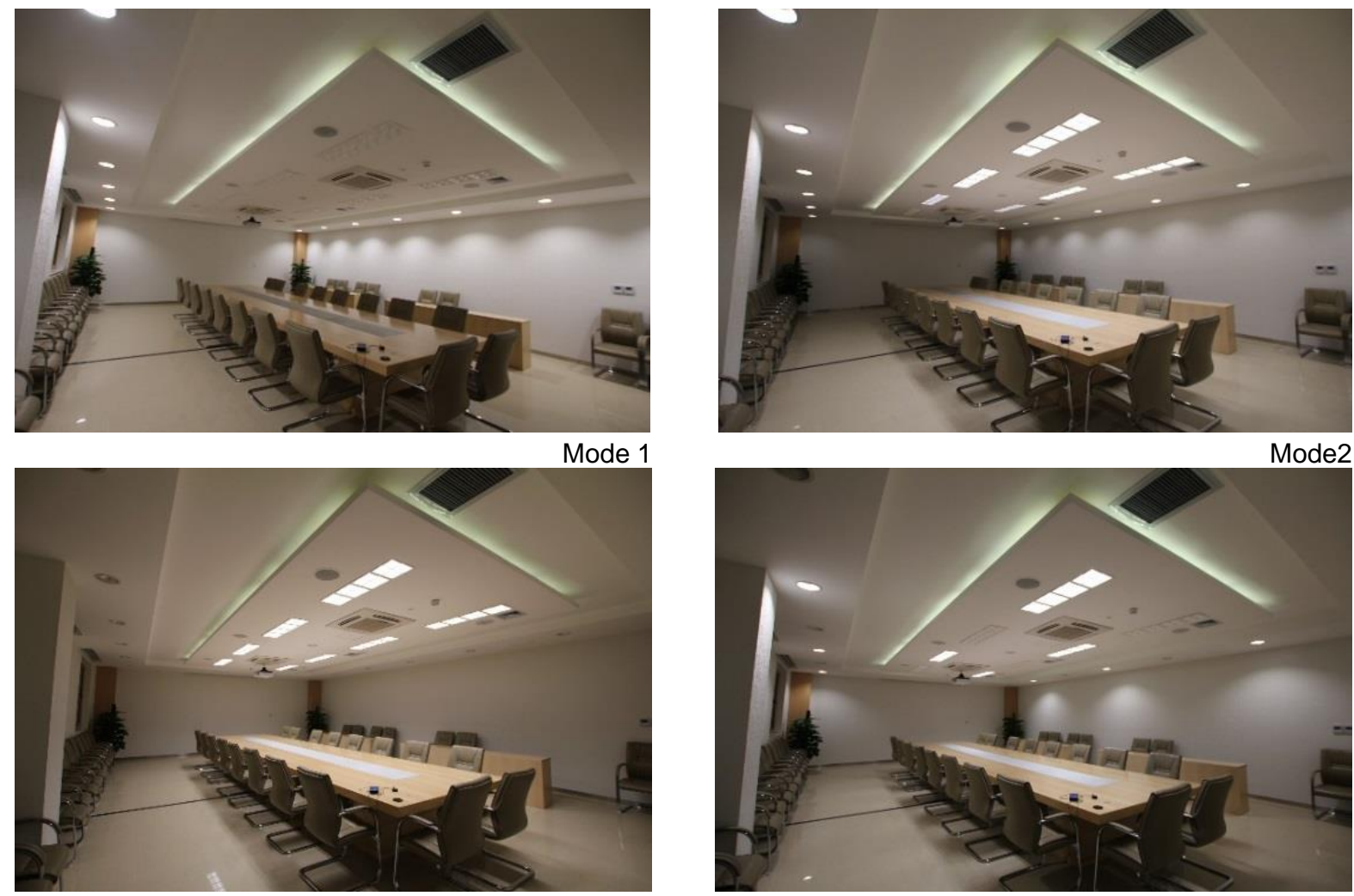

Mode 3

Mode 4

Figure 39: Lighting environment of the video conference room (LED). 


\subsubsection{Integrated lighting control and building automation}

The lighting control system adopts the intelligent lighting control system provided by Philips and Lutron, human body induction, dimming and other control methods. Luminaires near windows can adjust the light output according to the daylight and areas such as conference room, office and corridor are equipped with human body induction probes so as to automatically turn off lights when people are absent. A variety of lighting modes are set up in the conference room to reduce lighting energy consumption.

\subsubsection{Evaluation}

A comprehensive monitoring and evaluation of the CABR building is done within Subtask $D$ "Lab and field study performance tracking" of this IEA SHC Task 61 / EBC Annex 77 "Integrated solutions for daylight and electric lighting". The results will be published in the report of this Subtask and will be available on http://task61.iea-shc.org/. 


\section{Evaluation of Design Workflows}

The example design projects in chapter 2 are used as basis for the qualitative description of different approaches for design workflows in the planning of an integrated electric lighting and daylighting solution. This analysis should sharpen the understanding of the single steps in the design process, present the utilized tools, and highlight the areas where software still provides unsatisfactory support.

\subsection{General System Design - Workflow at DIAL}

by Daniel Witzel, DIAL, Germany

All building functions (user interface / automatisms) of the software-controlled, intelligent building were first determined on the basis of a structured demand and project analysis and embedded in an overall technical concept as General System Design.

This defines the basics of the whole planning, from which planning objectives for the object planning and all required specialist planning including simulations were derived and realized as part of an integral planning process. What is meant by specialist planning in building construction can be read very well from the fee structure for architects and engineers (HOAI).

In addition to the object planning by the architect (HOAI 3-1), the actual technical planning is divided into structural design (HOAl 4-1) and technical planning of technical equipment (HOAI 4-2). This is divided into the specialist planning of eight relevant facility groups:

1. sewage, water and gas facility

2. heating systems

3. air conditioning systems

4. power installations and lighting

5. telecommunication and information technology systems

6. transportation

7. use-specific equipment

8. building automation

The technical planning of the partial air conditioning via the ventilation system in the context of point 2 and 3 was evaluated by means of thermal simulations and flow simulations. In addition to the electrical planning in the context of point 4 and 5 the lighting design and planning of the building automation (BA) were carried out in-house. In order to ensure the meaningful interlocking of the component groups in the planning the technical planning building automation had a priority role. 


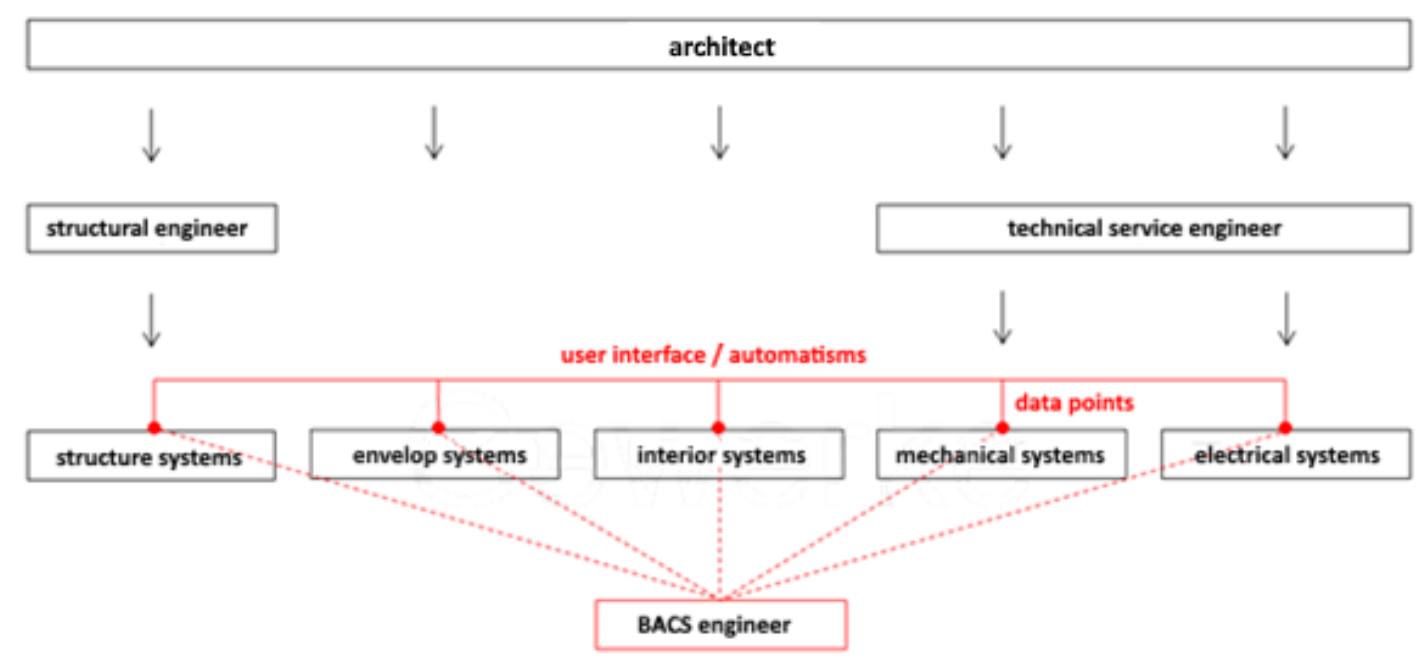

Figure 40: component planning of the building automation

A planning of intelligent functions or automatic processes in the context of building automation involves several storylines, which have been successively concretized and updated. On top to conventional installation plans this included a specification sheet in which all central requirements for building automation were described.

By means of suitable automation schemes, all technical systems were allocated to the data points necessary for the automation. Based on this automation schemas building automation function lists were created. They describe the required functions of the data points according to the specification sheet. Normally the technical systems go through typical sequences of states that have been described via program flow diagrams.

\section{Problems and Challenges in the Planning Process at DIAL GmbH Building Lüdenscheid}

Even today, it is not common practice for all those involved in the project to carry out simulations at a very early stage. In individual cases, the specialist planners must be persuaded that a simulation does not automatically lead to higher overhead and that planning errors found early reduce follow-up costs.

As with many planning processes, problems in planning and execution, even in the holistic planning approach, are due to missing or poor communication. Lack of collusion or missing hints lead to wrong assumptions and thus to wrong specifications for the simulations, which should be avoided. As with conventional planning approaches, where the design specifications do not conform to the rules of engineering, the same problems occur in the early simulation. In fact, the early simulations lead to an apparent planning certainty, which is no longer questioned in individual cases.

Modern Building Automation and Control Systems (BACS) offer the possibility to adjust the control and control algorithms afterwards.

Building automation allows and requires updates adapted to the real world, as we already know from software products for decades. However, they are no excuse for avoidable planning errors and in turn cause time and expense. 


\subsection{Design in day-by-day work - the DIAL Heavy User}

by Daniel Witzel, DIAL, Germany

The planning of holistic building concepts is unfortunately not common in everyday planning. In many cases the planner has only a few hours or less to record the requirements, to do the exemplary planning, and create the presentation in quotation form. The reason for this is a lack of specialist knowledge, lack of understanding about integrated system solutions or simply cost pressure.

In many cases offices, warehouses, but also shops are planned according to normative minimum specifications.

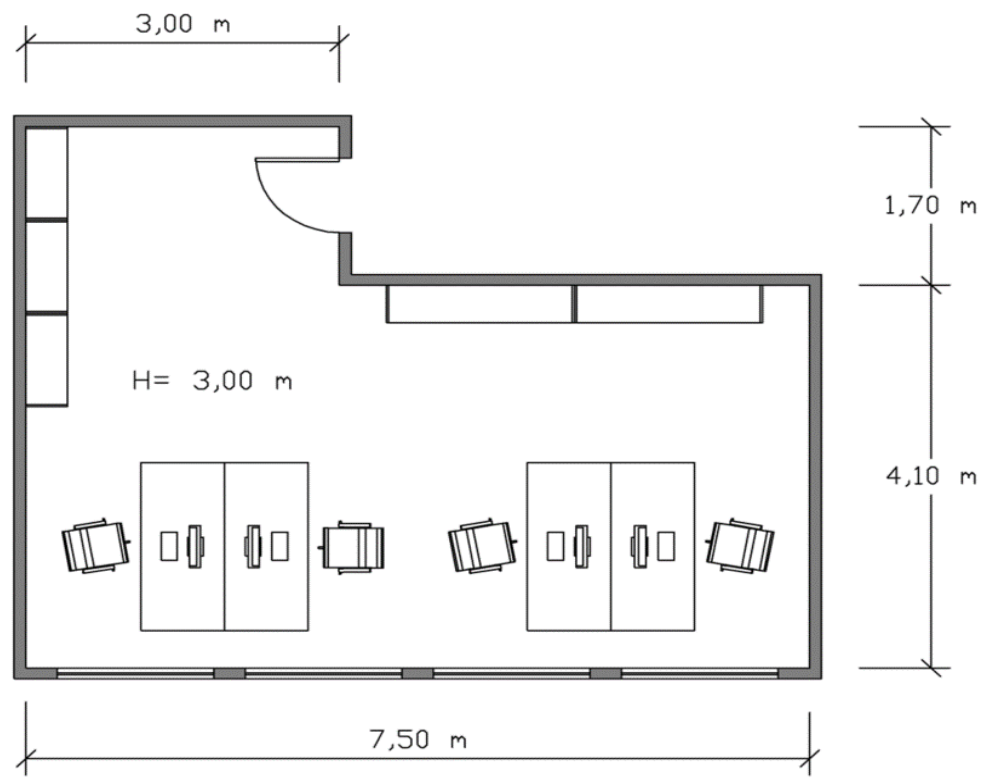

Figure 41: The "Heavy User" selects one or a few typical spaces for design.

A typical use case for this type of planning is a sales representative talking to a potential customer. The geometry of one or of a few exemplary spaces is roughly captured and e.g. passed by telephone to a lighting designer.

The task of the lighting designer is to find and place suitable luminaires to fulfil normative requirements for illuminance and uniformity in the given areas. Alternatively, the sales employee himself may be the lighting designer and uses his notes for a lighting design.

The customer of the lighting designer usually wants to know how many luminaires have to be used and what the expected investment and operating costs are. Very often different lighting variants are calculated, compared and presented to the customer for selection.

\section{Main issues / open questions}

This type of planning is usually not charged separately and is a free service. Unfortunately, energy saving potentials through effective control systems and holistic consideration remain unused, although they play an important role in the estimation of operating costs.

Since most of the currently planned projects are created under these conditions, these planners were named "heavy user" by DIAL. New design processes, standardization and tools must meet this requirement in the future. 


\subsection{Lighting design workflow at Bartenbach}

\section{by David Geisler-Moroder, Bartenbach, Austria}

Bartenbach has more than 90 employees in the divisions lighting design, lighting solutions, research and development, and lighting academy. We serve our clients in the fields of

- daylighting design,

- artificial lighting design,

- research and development,

- model construction and visualization,

- material consultation, and

- full service - lighting solutions.

This broad structure and the knowledge of the dedicated experts allows us to select a "highperformance team" based on every single project's needs. The following figure shows an exemplary selection of projects and the respective required competences.

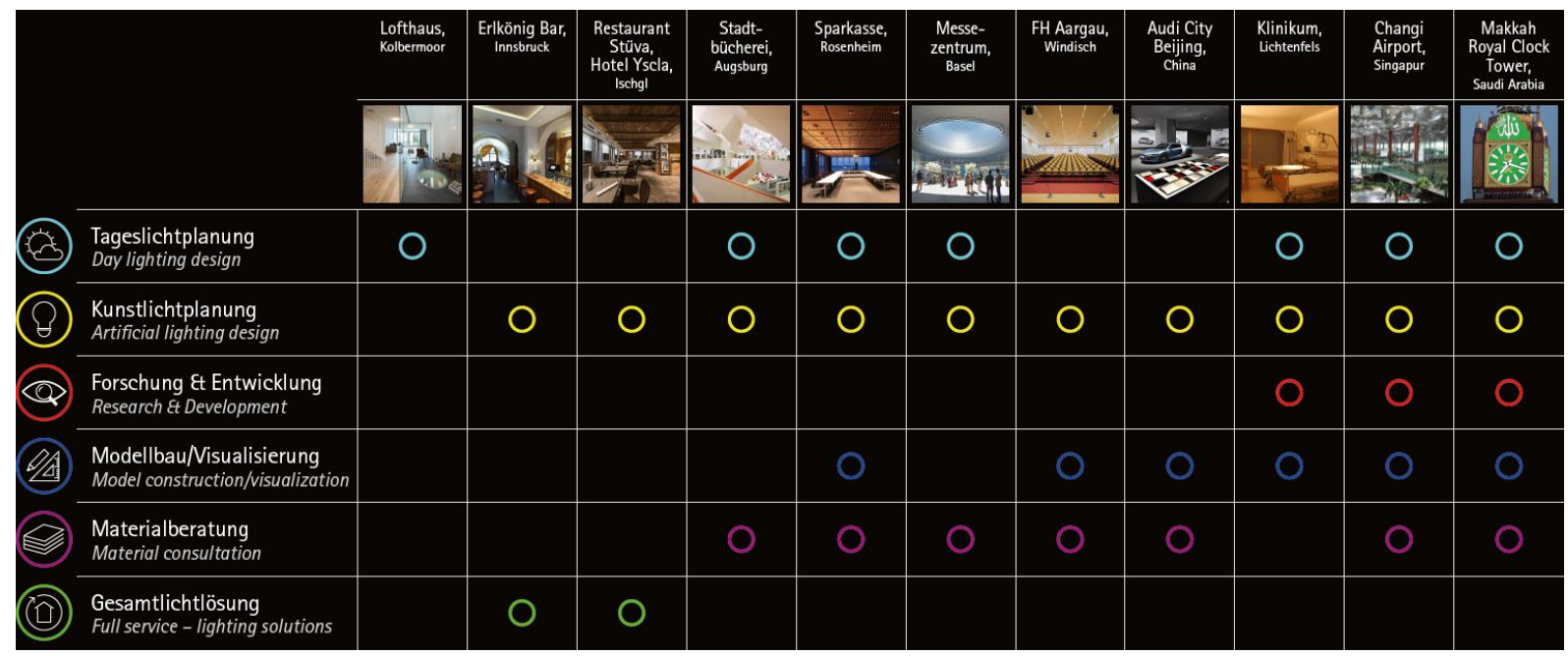

Figure 42: Bartenbach competences are selected specifically for every project.

The general lighting design workflow structure at Bartenbach is closely connected to the established work phases defined in the HOAI - Fee Structure for Architects and Engineers ${ }^{1}$ :

- Basic evaluation

- Schematic design

- Preliminary design

- Approval planning

- Detailed design

- Preparation of contracting

- Assistance in contracting

- Site supervision and documentation

- Project support

\footnotetext{
${ }^{1}$ Honorarordnung für Architekten und Ingenieure, https://www.hoai.de/
} 


\section{Basic evaluation}

In a first step the project requirements are prepared and analyzed. This contains an inspection of the existing plans, the intended use of the spaces, the standards and regulations to be applied and the overall building and surroundings context. Beyond that, in the Bartenbach design work the perception psychology component is considered from the very beginning to satisfy the users' visual and non-visual lighting demands. For a first daylighting impression, a shading and climate analysis is also performed in this phase. Additionally, wishes by the architects or building owners are collected.

In this phase CAD software is used for checking the available plans to receive an impression of the project. A shading analysis to evaluate the basic needs for sun shading systems and a perception-based analysis according to our model of stable perception are done with in-house Bartenbach tools.

\section{Schematic design}

First specifications for the integrated daylight and electric lighting solution are defined. Starting from the room layout, different lighting concepts are evaluated and compared. The Bartenbach idea is to work backwards from the desired room appearance towards the technical solutions that provide the favored effects. From that, possible luminaire positionings are checked according to distribution characteristics, glare risk, shadowing, etc., and photometrical requirements are assessed. A dimensioning (target area, electric light characteristics, flux and number of luminaires, positioning, average transmission and general functionality of daylight systems) is performed. First control concepts including temporal and intensity patterns for integrated artificial lighting and daylight are elaborated. Finally, the different investigated concepts are then presented to the architect or building owner for a decision.

The evaluation of the technical concepts and dimensioning as well as perception psychology assessments are done with simplified in-house Bartenbach tools in Excel and the resulting concepts are presented with graphics tools (see image below for the example design space).

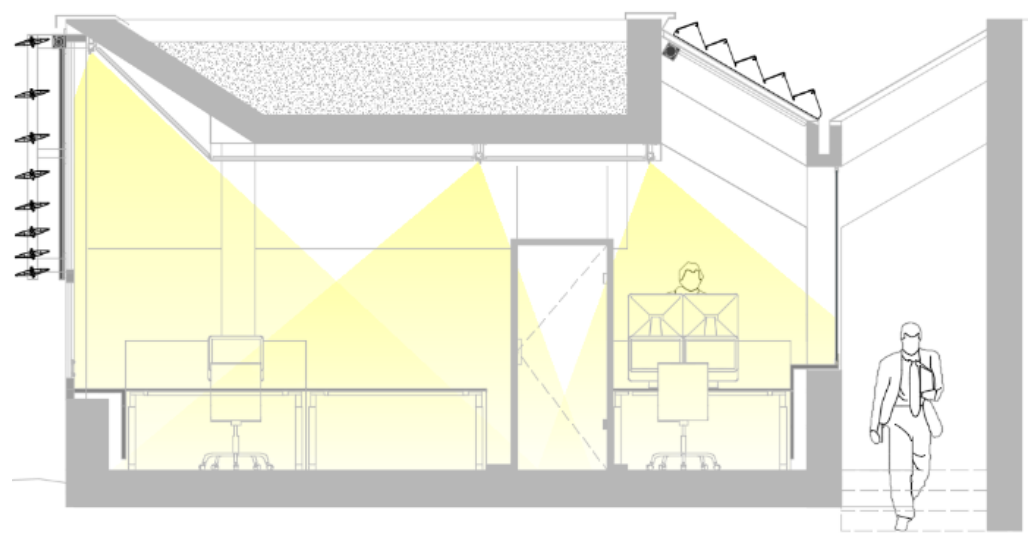

Figure 43: Schematic design of light distributions in conceptual planning.

\section{Preliminary design}

During the preliminary design, the chosen concept from the previous phase is further refined and continued into a functional planning. The requirements defined by standards and by the lighting designer together with the building owner and occupants are analyzed and further elaborated (e.g. illuminance levels, glare ratings, uniformities, human centric lighting and nonvisual lighting effects, etc.). The positions of the luminaires are defined and the 3D geometry of the space - usually provided by the architects, otherwise modeled in CAD software - is used 
for first lighting simulations. Therefore, the required luminous intensity distributions (LIDs) for the luminaire positions are calculated. Possible luminaires and optics that provide the needed LIDs are selected or - if not available on the market - are specifically developed by the Bartenbach R\&D team. In this phase also the integrated electric lighting and daylighting control is elaborated.

CAD software is used for modeling or adapting the space for lighting simulations and these are performed with standard lighting design software DIALux or Relux and Radiance or Radiance-based tools (DIVA for Rhino, Honeybee). For special analysis (e.g. conservation, non-visual effects, ...) own in-house Bartenbach tools are used.

\section{Approval planning and detailed design}

In this phase the systems are finally defined, and detailed specifications are elaborated. This contains the definition of luminous fluxes, color temperatures and color rendering classes of electric lighting systems, direct and diffuse transmission as well as redirection properties of daylighting systems and constructive details, mounting, and protection classes. This is still in tight collaboration with Bartenbach's perception psychologists to guarantee the fulfillment of the occupants' visual and non-visual lighting needs.

The final concept is evaluated with standard lighting design tools such as DIALux or Relux, and daylighting simulations are done with Radiance or Radiance-based tools such as DIVA for Rhino or Honeybee. For special analysis (e.g. conservation, non-visual effects of lighting, ...) again Bartenbach in-house software tools are used. These tools are developed in the own Bartenbach Research \& Development department.

\section{Preparation and assistance for contracting}

During these phases the lighting designers are only accompanying the process. Specifications from the detailed design phase are provided as input and the relevant parts in tenders are checked and approved.

No lighting simulation software tools are used in these steps.

Table 2: Software tools used in workflow phases

\begin{tabular}{l|l} 
WORKFLOW PHASE & USED SOFTWARE TOOLS \\
\hline Basic evaluation & $\begin{array}{l}\text { CAD software (AutoCAD, Rhino, Revit, ...), } \\
\text { own Bartenbach tools e.g. for shading } \\
\text { analysis and perception (Bartenbach model } \\
\text { of stable perception) }\end{array}$ \\
\hline Conceptual Planning & $\begin{array}{l}\text { Excel calculations, graphics tools (e.g. } \\
\text { Photoshop), PowerPoint }\end{array}$ \\
\hline preliminary design & $\begin{array}{l}\text { CAD software (AutoCAD, Rhino, Revit, ...), } \\
\text { DIALux, Relux, Radiance, DIVA4Rhino, } \\
\text { Ladybug\&Honeybee, DALEC, own } \\
\text { Bartenbach tools }\end{array}$ \\
\hline $\begin{array}{l}\text { Approval planning and } \\
\text { Detailed design }\end{array}$ & $\begin{array}{l}\text { DIALux, Relux, Radiance, DIVA4Rhino, } \\
\text { Ladybug\&Honeybee, DALEC, own } \\
\text { Bartenbach tools }\end{array}$ \\
\hline $\begin{array}{l}\text { Preparation and } \\
\text { Assistance for Contracting }\end{array}$ & Word, Dynamics NAV \\
\hline
\end{tabular}




\section{Main issues / open questions}

A main challenge for the lighting design workflow is the vast variety of different project and application types Bartenbach is facing in its daily design business. As an example, working on a hotel lobby or bar lighting project requires substantially different approaches than designing a lighting solution for an overall airport. This is also reflected in the selection of appropriate simulation tools for the single project's requirements. Starting from a $2 \mathrm{D}$ plan in a small renovation project or from a comprehensive BIM model for a new skyscraper calls for different lighting simulation tools to evaluate the designed lighting solution. This is also the reason why Bartenbach has always been developing its own specialized tools for various lighting simulation and evaluation tasks. The gap of available software tools to cover all needs for the simulation of integrated daylighting, electric lighting and lighting control systems is even more prevalent.

A second issue especially for the integration of daylight and electric lighting is tightly linked to the general breakup of the planning process between the different trades involved in the design. The daylight design is closely connected to the façade and thus the structural engineering, while the electric lighting design is linked to the electrical planning and interior design. As these trades are mainly acting at different phases of the planning process, it remains a challenge to be involved with the integrated lighting design at the right time. In the integrated design of daylight and electric lighting, Bartenbach always considers also the link to building physics. Both, electric lighting, but even more the daylighting design significantly influences the energy performance of the building. 


\title{
3.4 ISO 16817: Design Process for the Visual Environment
}

\author{
by Fabian Jarrin and Yasuko Koga, Kyushu University, Japan
}

ISO 16817:2017 "Building environment design - Indoor environment - Design process for the visual environment" provides an integrated design process for achieving a high-quality indoor visual environment in the design process for buildings, under the umbrella of ISO 16813:2006 "Building environment design - Indoor environment - General principles". ISO 16813:2006 provides general principles of building environment design and a standard flow of the design process. Both standards are applicable to building environment design for new buildings and the retrofit of existing buildings. ISO 16817:2017 focuses on guiding the design team towards achieving a high-quality visual environment and implementing nine general principles of sustainability (NGPS) in buildings, as described in ISO 15392:2008 "Sustainability in building construction - General principles". The NGPS are as follows:

- continual improvement;

- equity;

- global thinking;

- holistic approach;

- involvement of interested parties;

- long-term consideration;

- precaution and risk;

- responsibility;

- transparency.

It is important to understand that the visual environment is an element of the building environment. The good environment in buildings is achieved by a holistic design approach covering different environmental elements such as heat, light and sound, environmental systems such as cooling, heating and lighting, environmental control systems, and the energy efficiency, in a manner integrated with building design. ISO/TC205 "Building Environment Design", an ISO technical committee, has been developing standards for acceptable indoor environment and practicable energy conservation and efficiency. Building environment design involves not only architectural building design for achieving the required environmental quality but also environmental system design associated with effective controls. ISO/TC205 covers building environment design addressing building systems such as building automation and control systems, related architectural aspects, design processes and methods, design outcomes, and design-phase building commissioning. The indoor environment includes air quality and moisture, and thermal, visual and acoustic factors.

ISO 16813:2006 defines the design process as "course of actions performed to produce a set of design drawings and specifications describing the functions for which a building has the potential to provide". During the course, iterations of decisions and evaluations of the design outcomes happen. Any changes in the building environment design are required to be analyzed until the final design stage is accomplished. The design process for the visual environment follows it. Designing the indoor visual environment has architectural and engineering aspects of daylighting and electric lighting. The goal is to obtain user satisfaction, health, well-being and productivity as well as the energy performance and sustainability of buildings.

\section{Design team defined by ISO 16817:2017}

On multiple occasions, ISO 16817:2017 mentions the idea of developing the visual environment following an integrated architectural approach, i.e. it should address the critical interactions among the building envelope (which transfers heat, light, sound and so on), the 
building interior and all light sources such as daylight and electric light. In the integrated multidisciplinary approach to building environment design, each member of the design team is required to facilitate sharing of information and integrated working.

The structure of the design team depends on the scale and complexity of the project. Larger projects tend to require larger design teams. However, it should typically consist of an architect surrounded by a team with abilities in electrical engineering, illuminating engineering, HVAC systems, landscape design, structural engineering and construction management.

\section{Implementation of an iterative design process}

One of the first and more important contributions of this design process is the introduction of the concept of an "iterative design process" which was hinted in the introductory statement while describing this workflow as a systemic, iterative and progressive approach. The iterative process can be defined as a "process for calculating a desired result by means of a repeated cycle of operations [...] it should come closer to the desired result as the number of iterations increases"

It is important to highlight this point because implementing programming terms has implications for subsequent development of tasks listed in this design process (ISO 16817:2017). Terms such as information, results and evaluation are replaced by its "programming" counterparts INPUT, OUTPUT and ITERATION, chosen to reflect the advancement on each stage of this design process.

It could be questioned that the contribution brought by the concept of the iterative design process is nonexistent and nothing but a change of words to conform to the CAD (computeraided design) trend, because the development of a project is always an exercise of going back and forward in the design process until achieving the desired result. While this may seem the case, advantages of the iterative design process are seen on how to structure the cycle of iterations (evaluations) so that they can be positioned on strategic points that will serve as thresholds to prevent the design team from having to revert to an early stage of the project because of forgotten INPUT (information).

This doesn't mean that all errors are eliminated, as there is no foolproof method, but following the workflow provided by ISO 16817:2017 will definitely help the practitioner to reduce the chances of facing a critical error that could have been prevented at early stages. To further illustrate this concept, the following image is an example of how this iteration or cycle of operations occurs (Figure 44).

2 ITERATIVE PROCESS. Available at: http://pespmc1.vul.ac.be/ASC/ITERAT PROCE.html. (Accessed: 9th October 2018) 


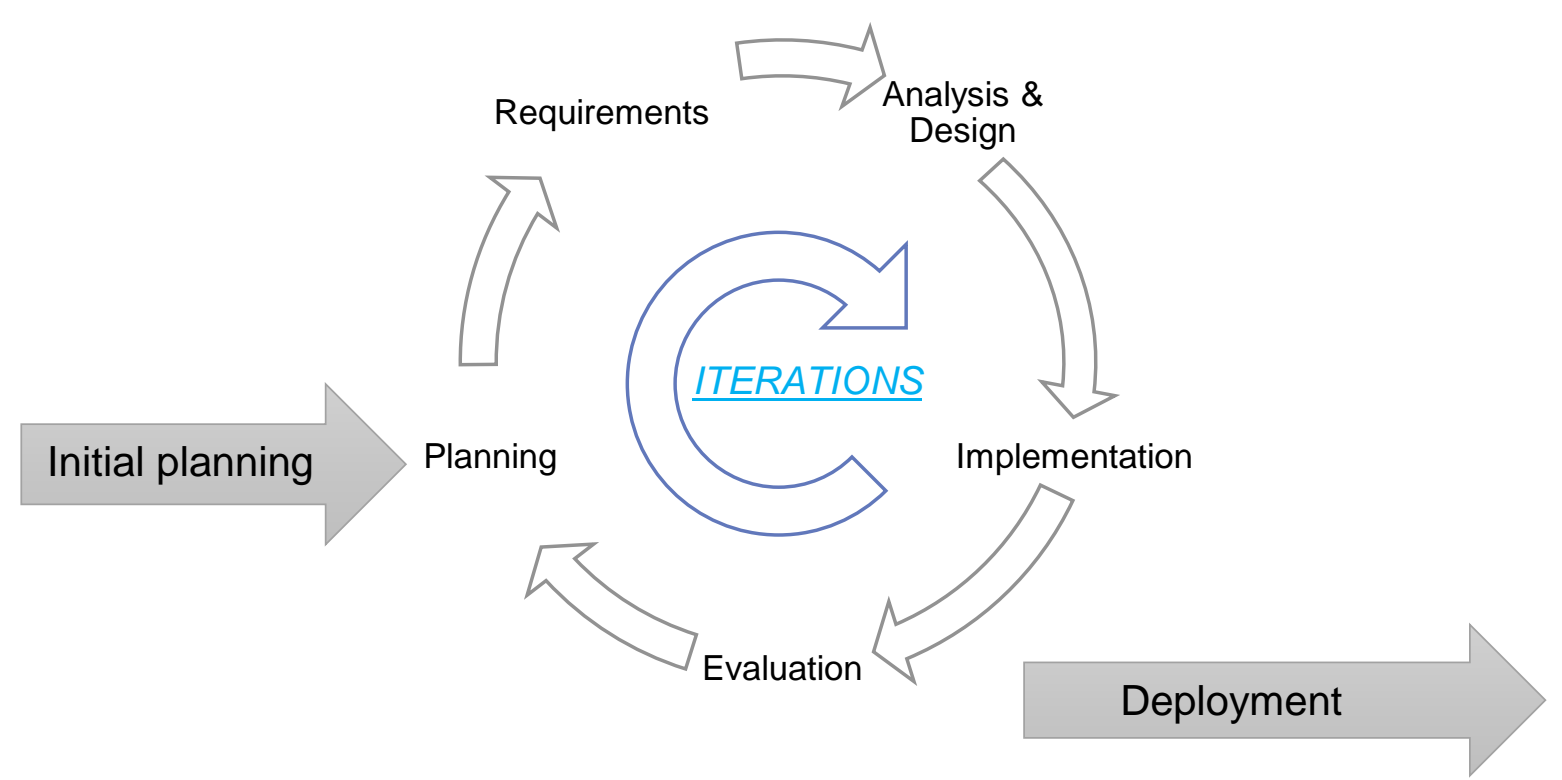

Figure 44. An example of the iterative design process.

\section{Four stages of the design process}

Building design is carried out in a stepwise manner. In general, the design process is roughly divided into four stages. ISO 16813:2006 defines the stages of the process for designing the building environment accordingly. Therefore, by following it, ISO 16817:2017 provides what the design team should consider and implement at each stage for achieving the required visual environment and ensuring that the output of one stage serves as the input of the next. The four stages of the design process are as follows:

\begin{tabular}{|c|l|}
\hline Stage I & Formulation of project definition (Programming phase) \\
\hline \hline Stage II & Schematic design \\
\hline \hline Stage III & Detail design \\
\hline \hline Stage IV & Final design \\
\hline \hline End of Design & Construction assessment \\
\hline
\end{tabular}

Figure 45. Four stages of the design process for the visual environment, according to the ISO 16817:2017.

Implementation of the design process and its four stages as well as the placement of where each iteration (evaluation) should occur are illustrated by means of an "iteration flowchart" in ISO 16813:2006 and can be found in ISO 16817:2017 as an annex. Fragments of this flowchart, representing each of the four stages, will be used to complement the description of each stage, none the less, up next you can see a complete version of the flowchart. It can be used as a reference to contextualize each of the following sections. This flowchart plays a key role in helping to familiarize the design team with tasks provided in the standard. 


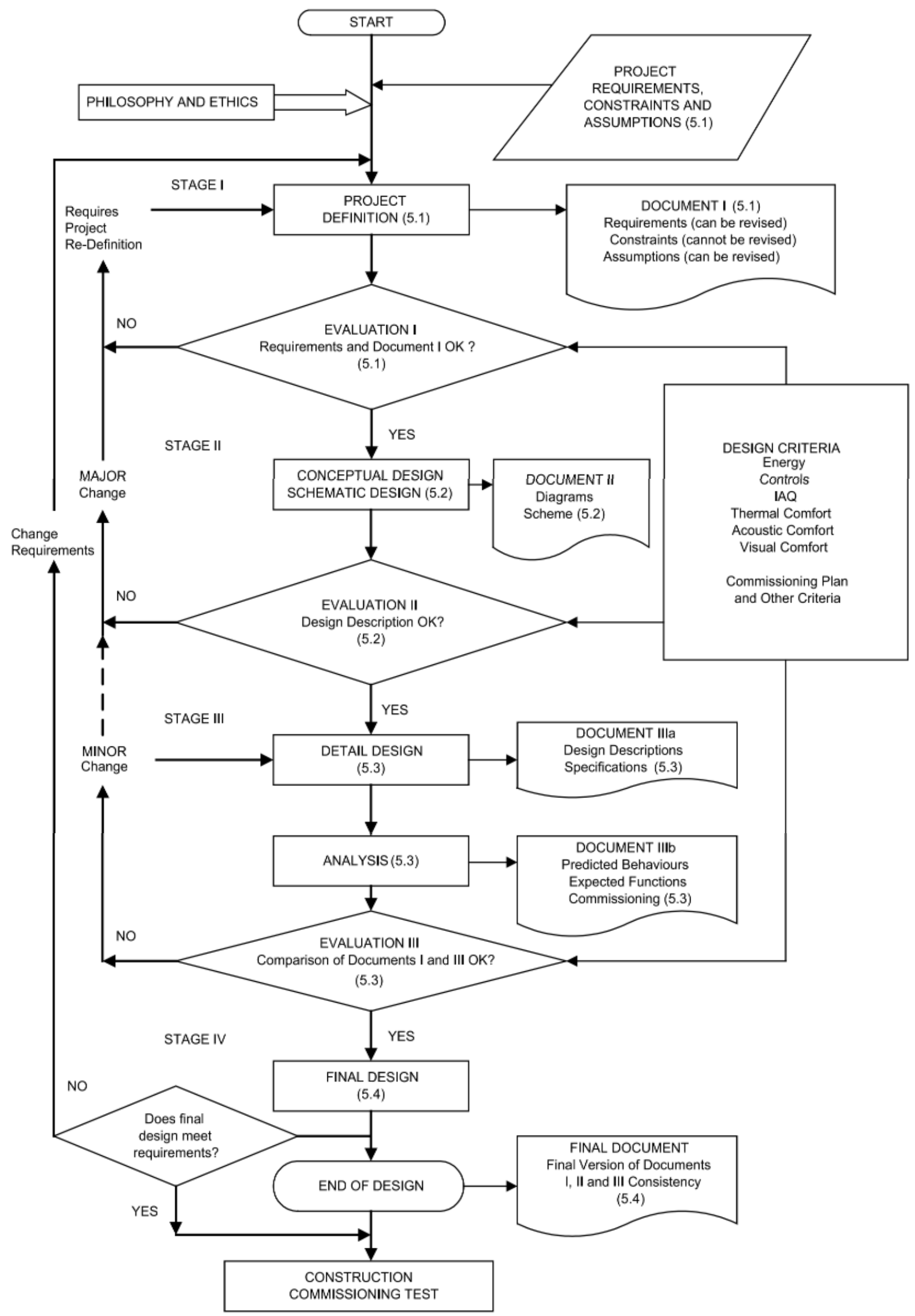

Figure 46. Iteration flowchart summarizing the design process for the building environment including the visual environment.

(ISO 16813:2006 Building environment design - Indoor environment - General principles) 


\section{Stage I. Formulation of project definition or programming phase}

As in every other design workflow, the first phase of this design process is directed towards collecting all the relevant data or information that will assist in designing a high performance and high-quality visual environment. Such a visual environment complies with sustainability policies, ensures the safety of users and is structured under the constrains of the law.

This stage is divided in the following sections:

- Project Definition (Requirements)

- Existing Conditions

- Requirements

- Assumptions

- Philosophy, ethics and theories

- Output - Document I

- Evaluation I

- Output - Approval of document I

- Iteration

These components can be visualized in the following diagram, a fragment showing stage I, extracted from the iterative flowchart (Figure 46).

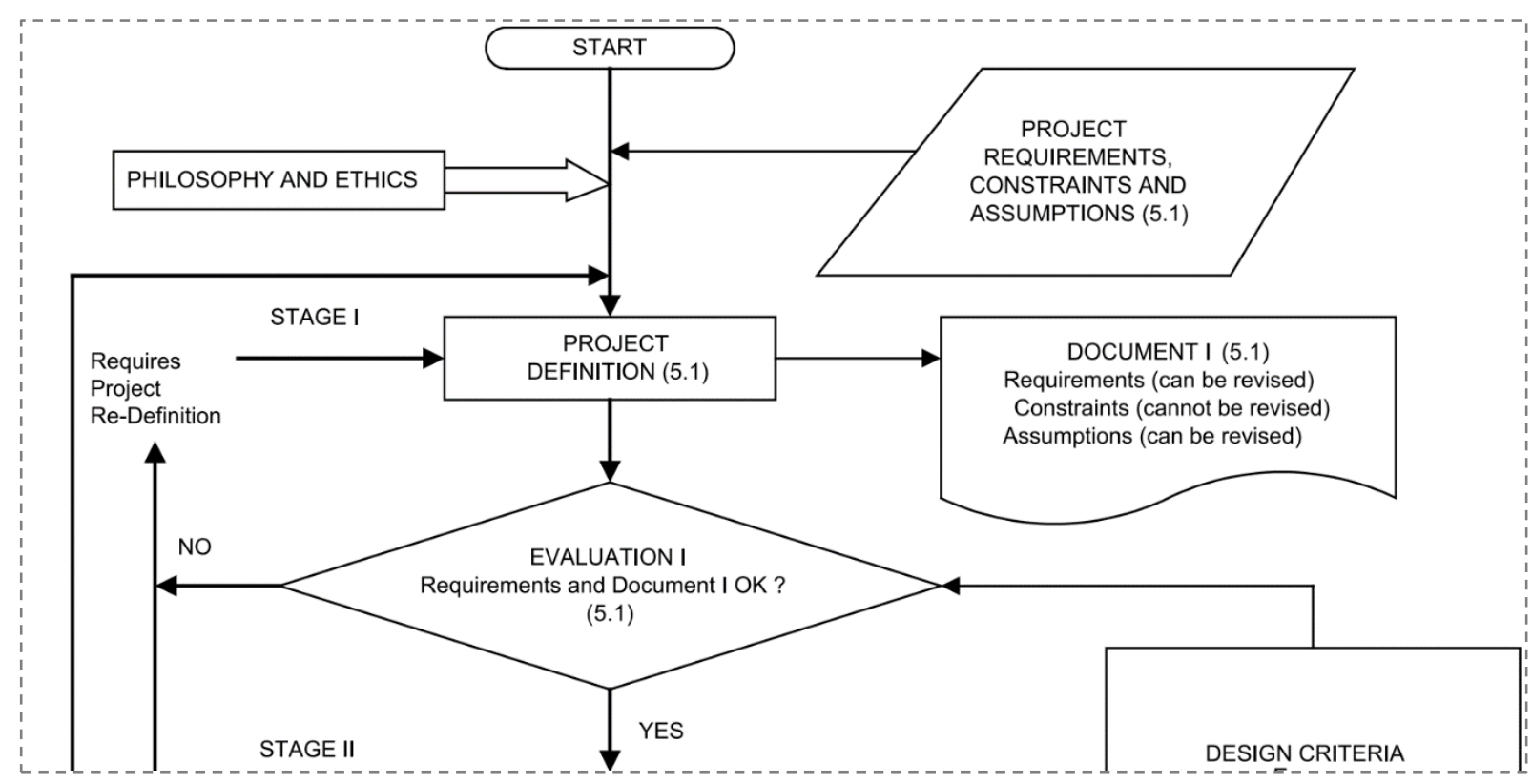

Figure 47. Fragment of the flowchart representing "Stage I" of the design process for the visual environment.

ISO 16817:2017 recommends an integrated architectural approach when designing the visual environment. The integrated approach addresses critical interactions among the building envelope (which transfers heat, light, sound and so on), the building interior and all light sources such as daylight and electric light.

The input for this phase is carefully detailed and divided into existing conditions, constraints, requirements, assumptions, philosophy, ethics and theories. To aid us in establishing a project definition, this standard provides a set of tables, checklist and even surveys to ensure that all relevant information is carefully reviewed. 
The output from this first iteration of the design process is referred to as "Document I", and contains the explicit description of the project definition, i.e. requirements, assumptions and constraints. It can be an oral presentation of the facts defined by the design team or a brief report including programmatic and very preliminary criteria statements. It is then evaluated to receive feedback from the design team in order to assess interactions between the responses to the constraints and the requirements of all aspects of the design. After this set of evaluations, the document will be approved, and we can progress to the next phase of the design process.

\section{Stage II. Schematic design}

Upon the completion of the programming phase (Stage I), the design team is prepared to undertake schematic design: developing preliminary ideas or schemes for the visual environment of the project. The input for this stage is the information redacted from document I, i.e. the output of the programming phase.

This stage is divided in the following sections:

- Input

- Output - Document II

- Evaluation II

- Output - Approval of document II

- Iteration from conceptual design and schematic design

- Iteration from project definition

These components can be visualized in the following diagram, a fragment showing stage II, extracted from the iterative flowchart (Figure 46).

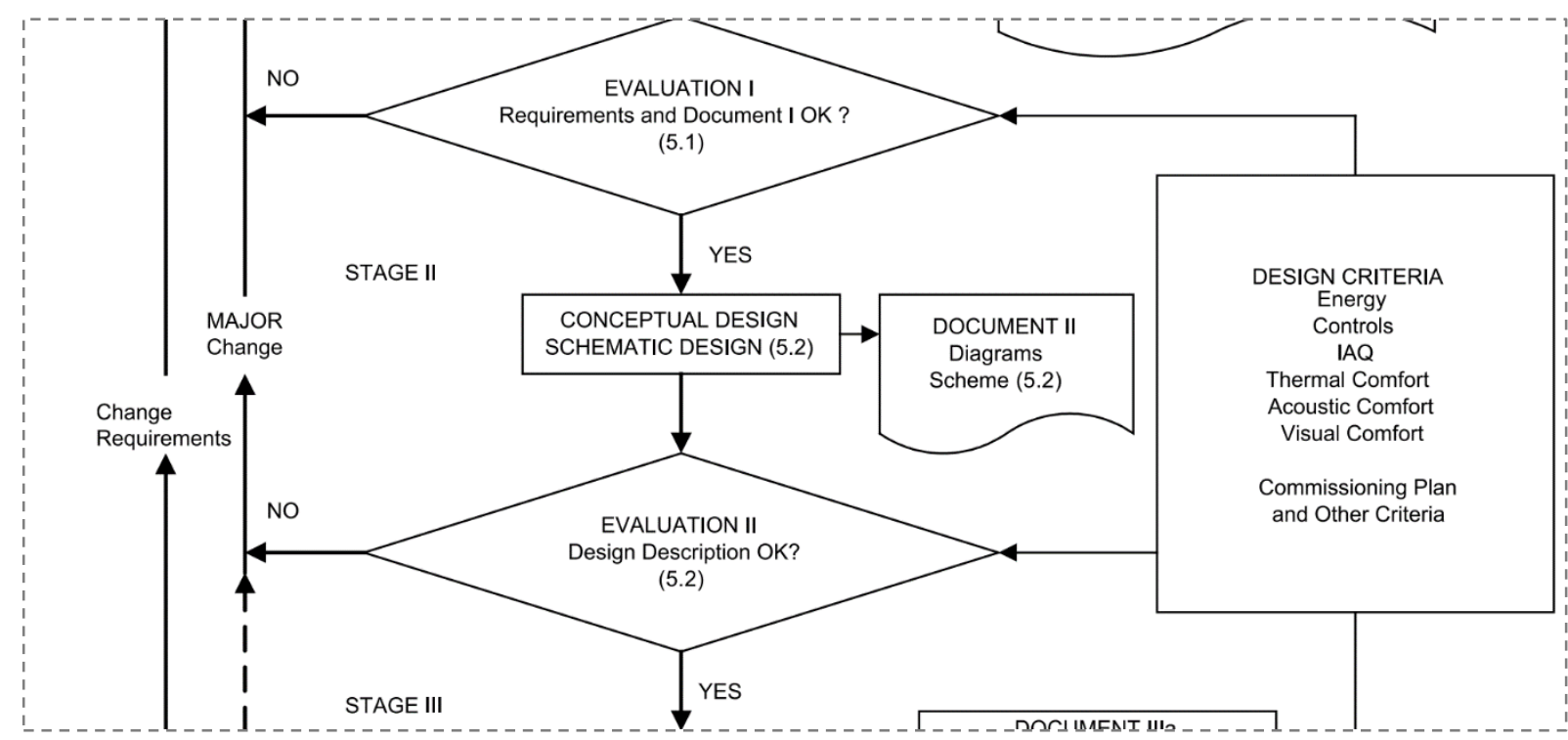

Figure 48. Fragment of the flowchart representing "Stage II" of the design process for the visual environment.

At the schematic design stage, the design concept and scheme are created and proposed for the project. Schematic design of the visual environment typically results in an understanding and agreement among the team members about visual environment criteria, penetration of daylight, general lighting approaches, styling of luminaries and the visual relationship between 
the inside and the outside. ISO 16817:2017 puts emphasis on the iterative process of designing the visual environment as well as the building at this stage.

The output of this iteration is referred to as "Document II" and contains the preliminary architectural and lighting plans that illustrate the scope and strategies to create a comfortable and energy-efficient visual environment.

This stage is not tasked with specifics as its schemes will still have to be submitted for client review. Once approved by both the client and the design team, the project can advance to the detailed design stage.

\section{Stage III. Detailed design}

Stage III is the main phase of the visual environment design process and is where a detailed design is performed. According to ISO 16817:2017, the detailed design should be expressed without priority design elements of the visual environment such as colors and reflectance of interior surfaces, types of light source and luminaire, geometric and photometric characteristics of daylight openings, sunlight control schemes, light reflecting and transmitting devices and types of control to reduce electric lighting energy.

This stage is divided in the following sections:

- Input - Background

- Output - Document IIIa

- Analysis

- Output - Document IIIb

- Evaluation III

- $\quad$ Output - Approval of documents IIla and IIIb

- Iteration into detail design

These components can be visualized in the following diagram, a fragment showing stage III, extracted from the iterative flowchart (Figure 46).

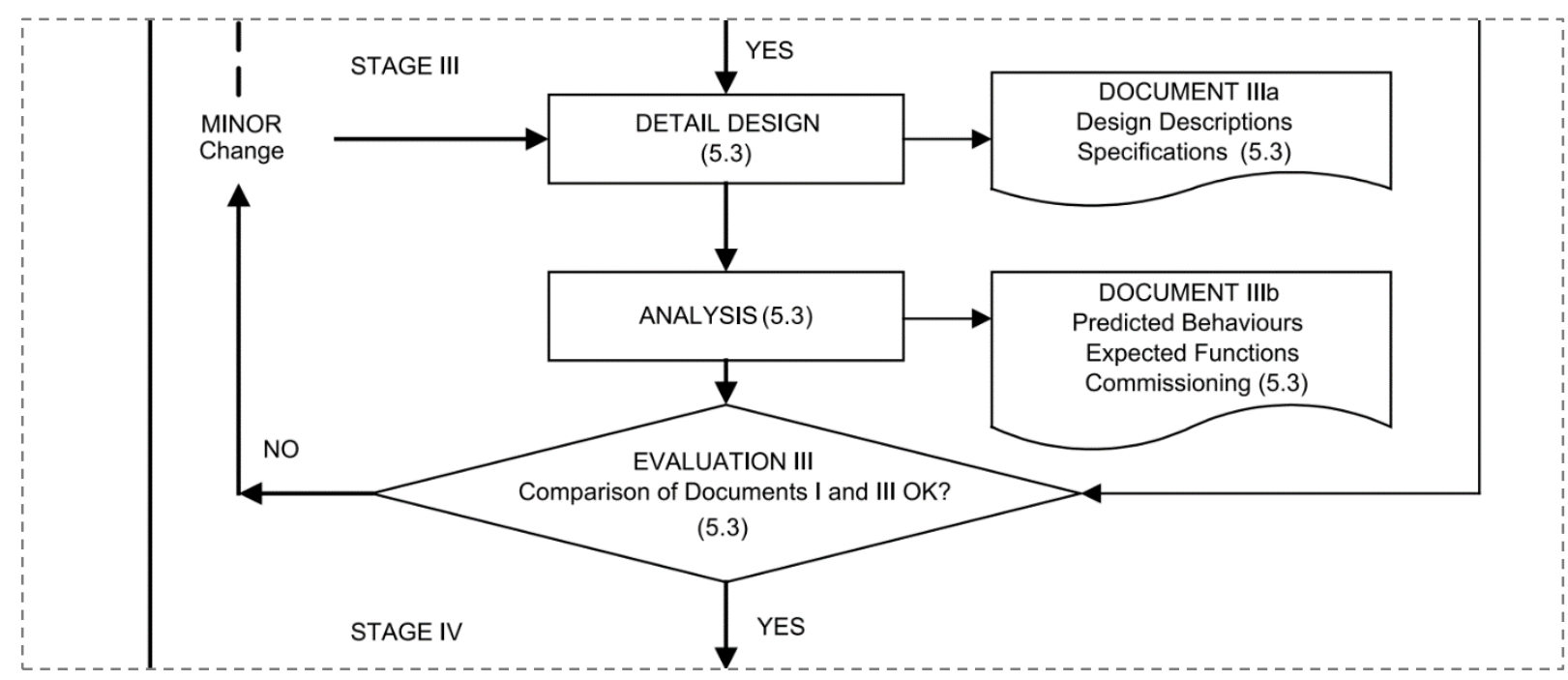

Figure 49. Fragment of the flowchart representing "Stage III" of the design process for the visual environment. 
Detailed predictions and analyses through computer simulations and/or measurements with physical models should be performed during this stage. ISO 16817:2017 does not recommend nor mention specific software to be used because technology tends to quickly change, and new products would supersede existing ones accordingly. However, the standard lists considerations to cover both quantitative and qualitative aspects in evaluating the quality of the visual environment. Computer simulation programs should be capable of conducting such analyses. Here are some of the aspects to be analyzed:

- illuminance levels on work plans, glare potential based on the luminance distributions, color rendering, directionality of light;

- on daylighting solutions, solar shading and daylight performance;

- on electric lighting, design based on control scenarios.

A more detailed description on these analyses can be found in the ISO 16817:2017. All system designs shall be included in stage III. The output of this stage is divided into two documents referred to as "Document IIIa" and "Document IIIb".

Document Illa contains the explicit description of the electric lighting and daylighting systems. It consists of the drawing and lighting specifications, including the relationship with the building design. It also includes the architectural design, daylight design, selection of light sources, luminaires design/selection and lighting control design.

On the other hand, document IIlb contains drawings and is the explicit complementary description of the electric lighting and daylighting systems. The drawings include plans such as the electric lighting plan indicating the locations and luminaire types with details regarding mounting specifications and custom arrangements in the form of sections and elevations. Document IIlb also includes luminaire attributes and catalogue numbers with specifications to outline general requirements.

Because stage III is considered the most important phase in the whole design process, another evaluation is necessary, that is, one that includes feedback from the entire team. The detail designs are evaluated form the specific user positions and viewpoints to minimize uncomfortable outcomes such as glare. In addition, energy efficiency shall not be relinquished and is once again analyzed. Rendered images are also a tool recommended to gain an understanding of the resultant visual environment and useful to gain the approval of the client and users.

\section{Stage IV. Final design}

It is at this stage that construction documents are generated. The final design phase is divided in the following sections:

- Commissioning documents

$\circ$ Design drawings

- Specifications

- Commissioning plan

- Cost estimation

- Output - Final document

These components can be visualized in the following diagram, a fragment showing stage IV, extracted from the iterative flowchart (Figure 46). 


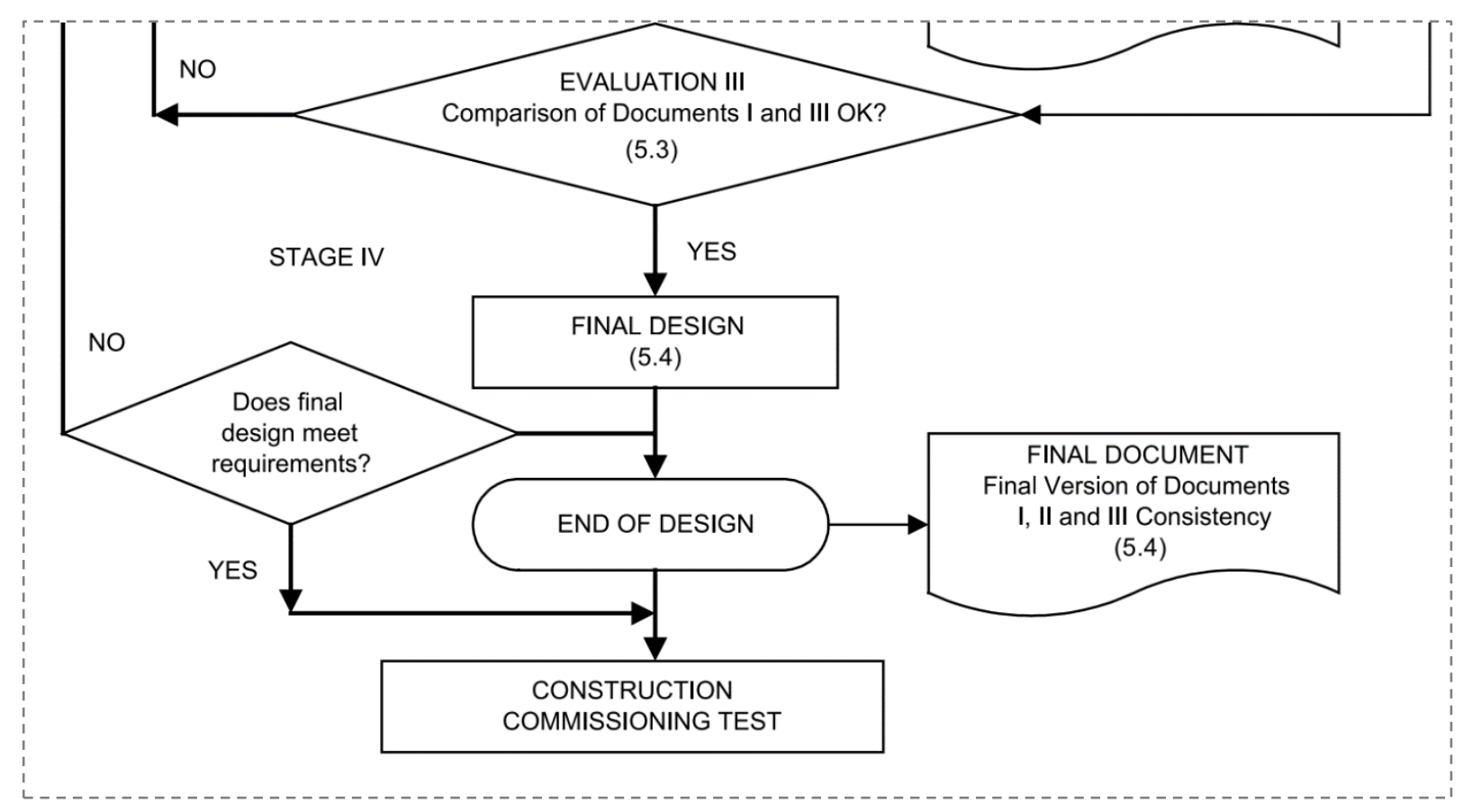

Figure 50. Fragment of the flowchart representing "Stage IV" of the design process for the visual environment.

The commissioning documents shall include the location and dimensions of daylight openings, the level of illuminance provided by windows and other types of daylight opening on the façade or roof, characteristics of glazing, the color of the surfaces, lighting design drawings containing lighting systems graphically expressed as architectural reflected ceiling plans, elevations, and sections with accurate dimensions.

The commissioning plan is a detailed description of systemic steps to be taken to test that every system is working normally and to be conducted after construction but before occupancy to ensure quality control.

The output from this stage is named "Final Document" and brings together design drawings, lighting specifications, operating manuals, commissioning and maintenance documents as well as an estimated cost for installation and maintenance. It is then validated by the client and finally issued to contractors for pricing and/or bidding.

\section{End of design}

The design process for the visual environment is concluded once the four stages are covered and the final documents are generated. Nevertheless, one last iteration is run based on the four following questions:

- Is the stated definition adequate and feasible?

- Is the environmental design for quality visual environment feasible?

- Is the specified structure expected to satisfy the environmental, economic and social constraints and requirements?

- Is the building capable of providing the quality visual environment and performance required? 
If answered positively to all of them then the project can continue towards the bidding and construction administration phases, where ISO 16817:2017 identifies the next steps such as:

- bid assistance;

- review and approval of shop drawings;

- construction assistance and assessment of installation progress;

- commissioning of the installed lighting systems;

- learning from experience: capitalization;

- user feedback and lessons from experience:

- user behavior.

The outcome of the whole design process is also illustrated in the iteration flowchart (Figure 46) and can be referenced on the following image, extracted from it.

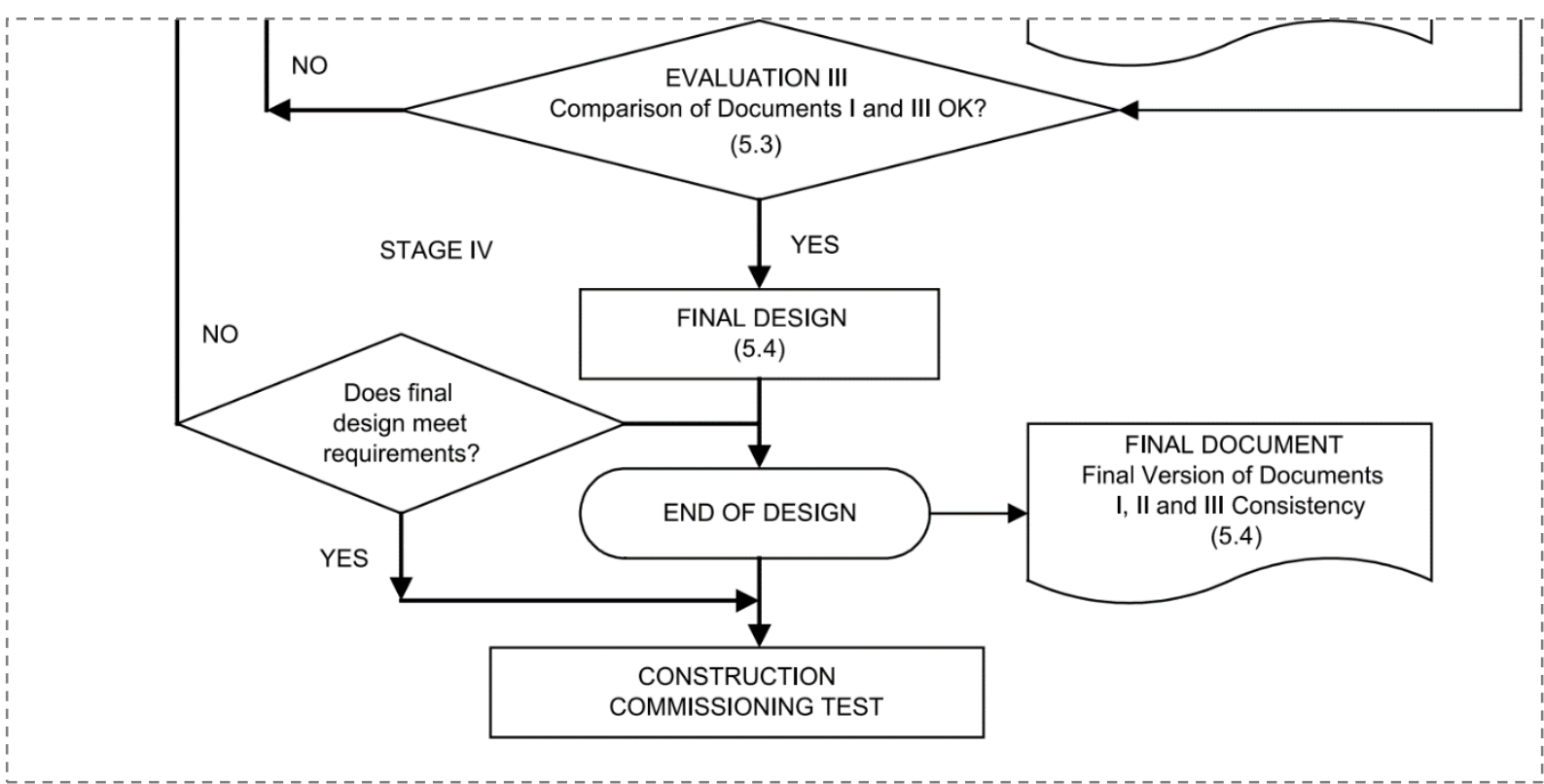

Figure 51. Fragment of the flowchart representing "End of design" phase. The outcome of the design process for the visual environment.

\section{Conclusion}

The design process for the indoor visual environment according to the ISO 16817:2017 is a systematic approach that uses the concept and structure of an "iterative design process" to conceive a workflow toward the development of a high-quality indoor visual environment including architectural and engineering aspects of daylighting and other lighting systems. The process is divided into four stages that serve as safeguards against major changes through the enforcement of evaluations after each output in the form of iterations to be repeated until achieving the desired result which will in turn be used as input for the next stage. 


\begin{tabular}{|c|l|}
\hline Stage I & $\begin{array}{l}\text { Formulation of project } \\
\text { definition }\end{array}$ \\
\hline \hline Stage II & Schematic design \\
\hline \hline Stage III & Detail design \\
\hline \hline Stage IV & Final design \\
\hline \hline $\begin{array}{c}\text { End of } \\
\text { Design }\end{array}$ & Construction assessment \\
\hline
\end{tabular}

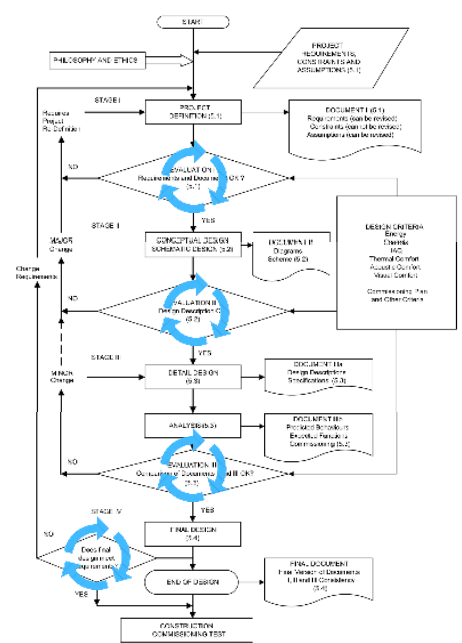

Figure 52. Four stages of the design process and the flowchart.

There are several advantages in following this workflow but, for the most part, it is up to the ability of the design team to grasp the information on the early stages of the project and use this refining process, represented in every iteration, that will generate the best results and guide to a better understanding of the project. Finally, it is its broad approach combined with a detailed schematic structure, in a holistic manner, that makes it possible to use this design workflow, for the visual environment, to solve several degrees of complexity. It would be a great tool for both new professionals, looking for a guide to start their practice, and experienced practitioners who want to improve their methods and want to compare their practices to a standardized model.

\section{Main issues / open questions}

The integrated approach to designing the building environment enables multidisciplinary consideration and the resultant solutions for high-performance and energy-efficient buildings. It is especially effective in designing zero-energy buildings (ZEBs). The definition of ZEB is not yet agreed internationally, but it is defined, in Japan, as a building that achieves substantial energy efficiency by reducing loads, utilizing natural energy and improving energy-efficiency of the technical building systems without deteriorating the quality of indoor and outdoor environments, introduces on-site renewable energy, and consequently makes the balance of annual energy demand and supply nearly zero or makes the annual energy supply greater than the annual energy demand during operation of the building ${ }^{3}$. The success in realizing ZEBs is entirely dependent on controls of the building and the indoor environment as well as the design and construction.

There are some good examples of ZEBs in Japan4. Here, we show the Taisei's urban ZEB project for their ZEB Demonstration Building. It illustrates the holistic and integrated approach to designing the high-performance and energy-efficient building. It has been built in the Taisei Technology Center in Yokohama City. A design team of architects, engineers in structural design and technical building systems design including lighting, HVAC systems, system controls and sanitation, and the technical development personnel cooperated and tackled the project from a very early stage of the design process. Targets in design were installing highefficient building equipment and achieving comfortable and attractive workplaces having the

\footnotetext{
${ }^{3}$ Recommendation by the Society of Heatng, Air-Conditioning and Sanitary Engineers of Japan, 2017.

${ }^{4}$ ZEB in Japan - Net Zero Energy Building Advanced Case Collection, Society of Heatng, Air-Conditioning and Sanitary Engineers of Japan (SHASE) $100^{\text {th }}$ Anniversary, 2017.
} 
high energy performance. They have introduced a façade design that optimally utilizes natural energy through photovoltaic walls, a daylighting system with a specially-designed light guide, and a radiant air-conditioning system combined with a reverse-beam structure and a flat concrete slab (Figure 53 to Figure 55). Post occupancy evaluations for consecutive three years proved that the annual energy balance is zero.

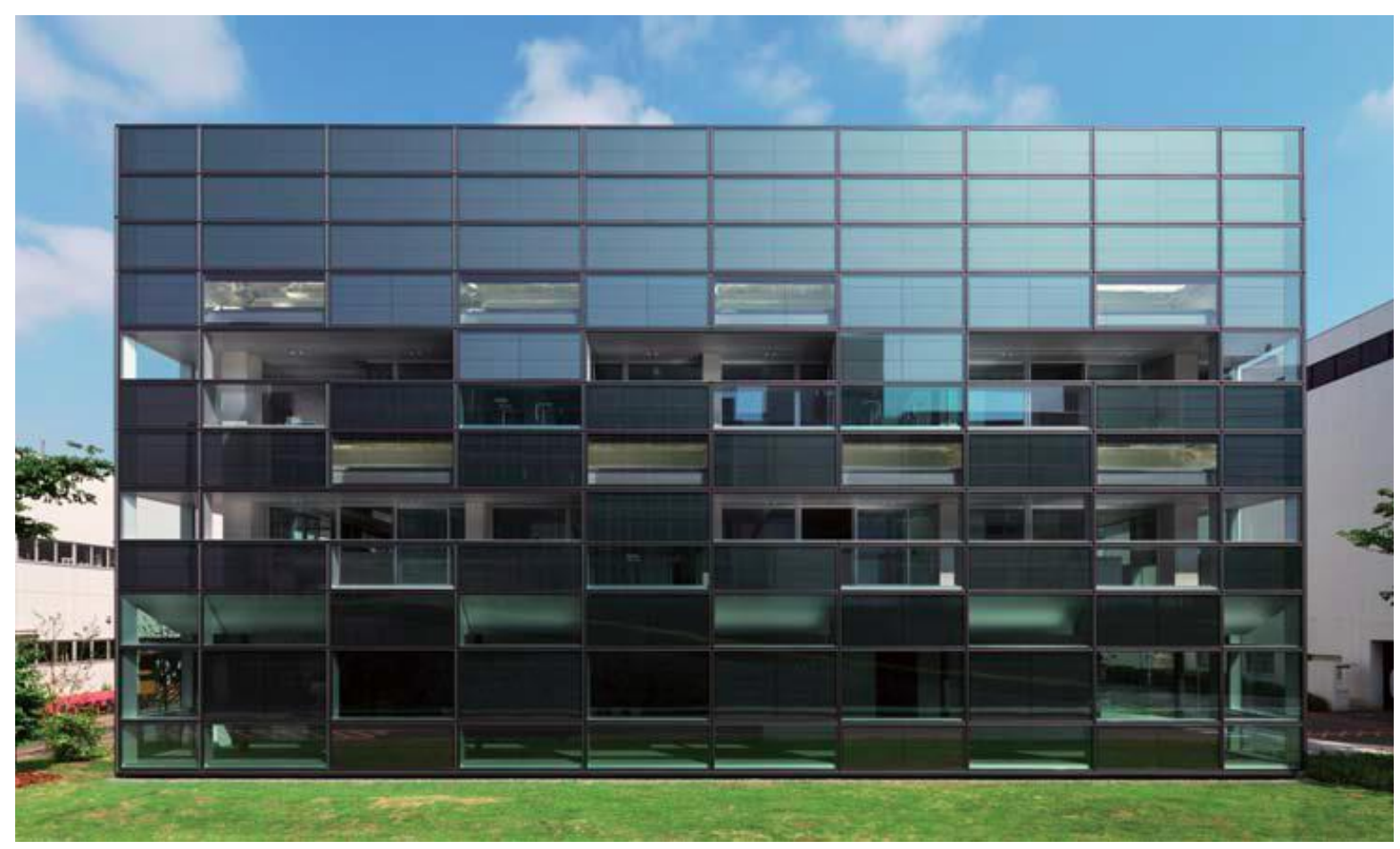

Figure 53: Photovoltaic façade system of Taisei ZEB Demonstration Building. 


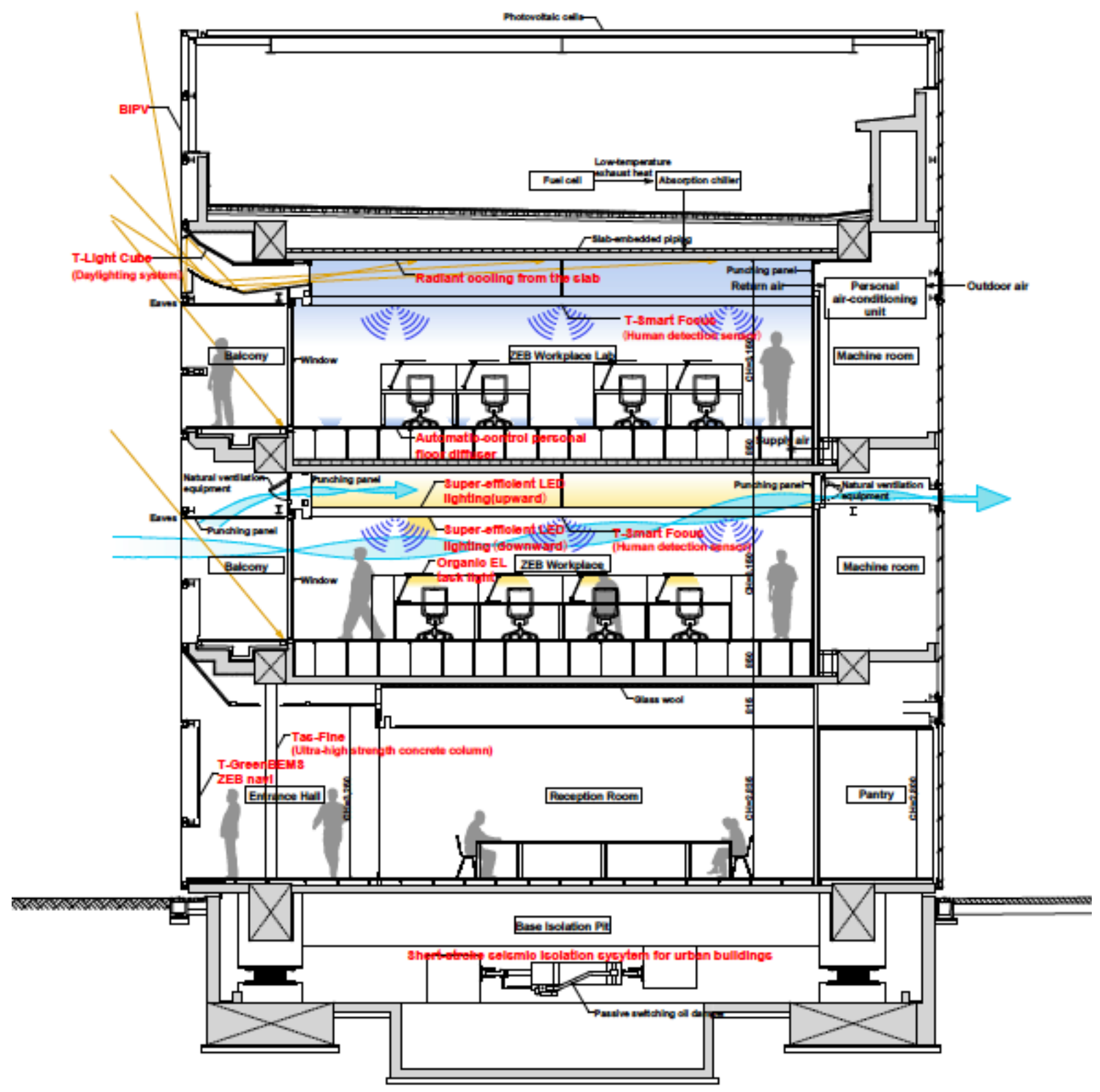

Figure 54: Integration of architectural, structural and environmental design with building system design.
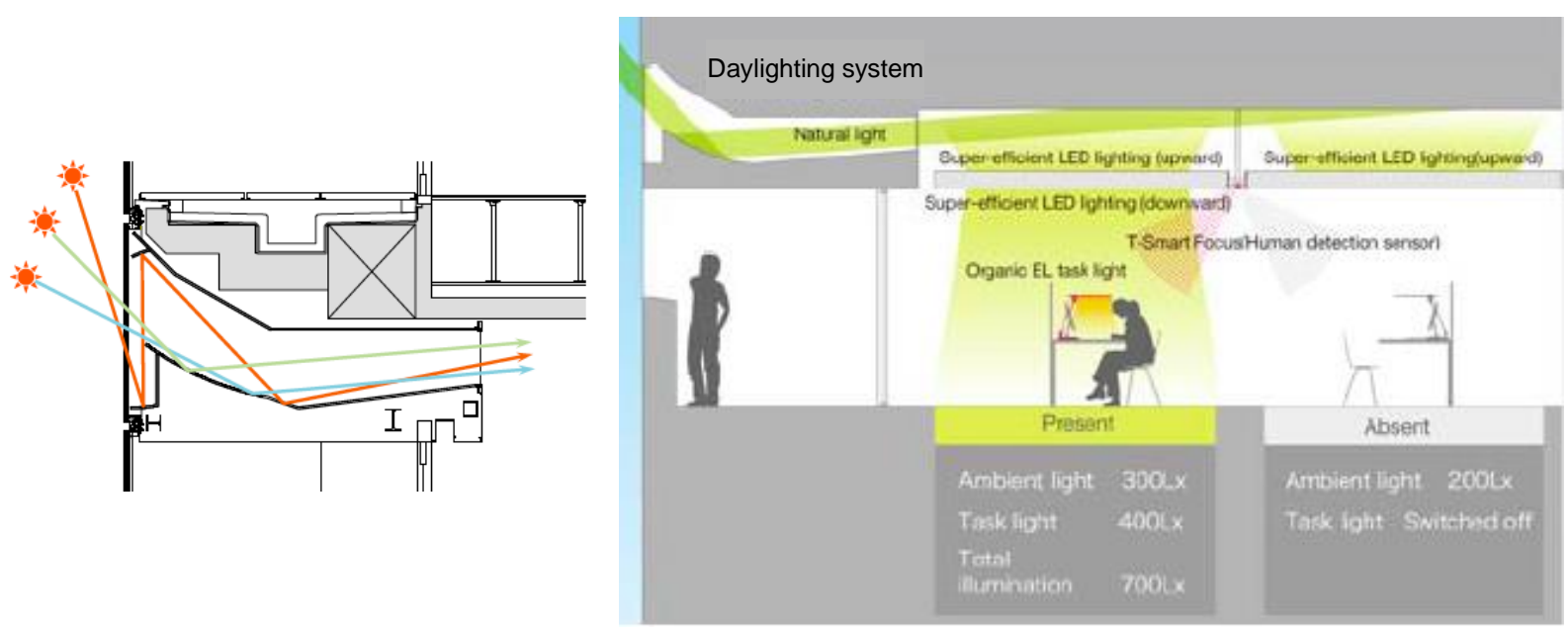

Figure 55: Integrated lighting system of Taisei ZEB Demonstration Building. 
The ISO $16817: 2017$ is a standard on a framework of the integrated design process and provides considerations for the indoor visual environment at each stage of the design process. It does not provide design parameters nor criteria to realize the general principles of sustainability in buildings. Iterative design repeats concurrent planning, developing, testing, and evaluating activities. It is crucial to consider all possible options, but reworking and the iteration cycles should be as little as possible in practice due to time and cost constraints. In order to facilitate iterative design, it is important to establish an appropriate evaluation system including evaluation indices and the target values at each design stage.

Computational simulations are indispensable to analyze the visual environment. The ISO 16817:2017, in the subclause about the detail design process, emphasizes the importance of qualitative and quantitative analysis to validate the decisions of the design team. The vast majority of these analyses are performed through computational simulations. However, the ISO 16817:2017 does not recommend any specific software. It is understandable considering the nature of any international standard regarding commercial software, but a lack of information might confuse a design team trying to cope with analyses mentioned in the standard such as luminance distributions, daylight performances and glare evaluations, and they might end up discouraging from in-depth analyses. With that in mind, the software DIALux and Radiance can be recommended not only because of their potential to generate most, if not all, of the simulations required, but also because of their easy accessibility and convenience.

Since the ISO 16817:2017 is intended only for designing the indoor visual environment, it has inevitably its limitations in terms of a holistic approach to energy-efficient building design. The holistic approach implies that all types of building-related energy use (heating, cooling, lighting, air conditioning, ventilation and hot water) as well as indoor climate requirements should be considered altogether ${ }^{5}$. This is a relevant issue not only because of our responsibility to ensure a more responsible and sustainable future but also because of existing legislation such as the "Energy Performance of Building Directive" (EPBD) launched in 2010 for the European Union that mandates that "member states shall ensure that new buildings occupied and owned by public authorities are NZEBs after December 31, 2018 and that all new buildings are NZEBs by December 31, 2020"6, which clearly shows a trend that should be encouraged.

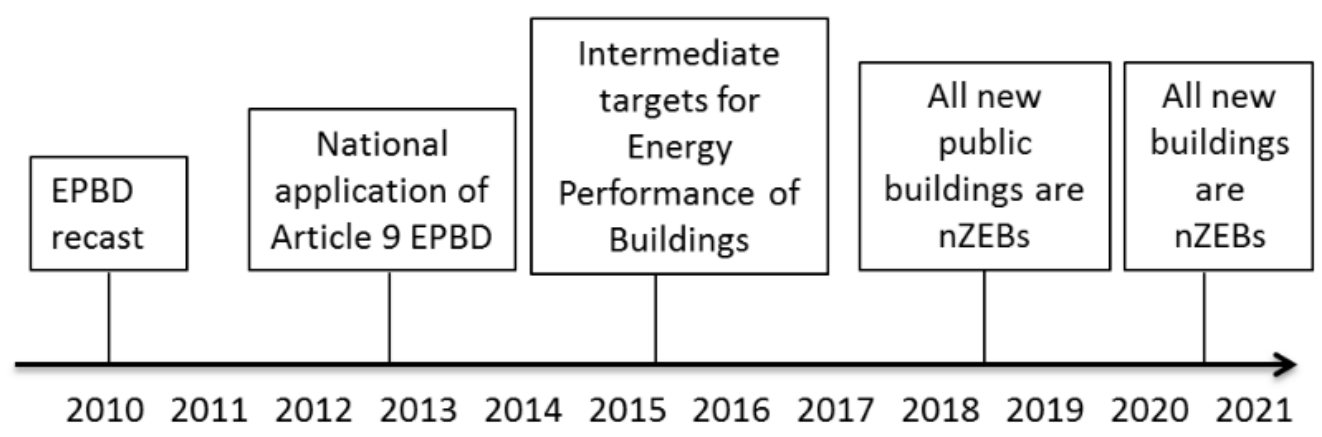

Figure 56: Timeline for NZEBs implementation according to the EPBD recast. Obtained from the Synthesis Report on the National Plans for Nearly Zero Energy Buildings (NZEBs) Progress of Member States towards NZEBs (2016).

The Government of Japan has also set goals in the $5^{\text {th }}$ Strategic Energy Plan that newly constructed public buildings are ZEBs by 2020 and that newly constructed public and private

\footnotetext{
${ }^{5}$ Available at: https://epb.center/epb/holistic-approach (Accessed: 10 March 2019).

${ }^{6}$ Agostino, D. D. Synthesis Report on the National Plans for Nearly Zero Energy Buildings (NZEBs ) Progress of Member States towards NZEBs (2016). doi:10.2790/659611
} 
buildings are ZEBs on average by $2030^{7}$. However, the know-how to realize ZEBs prevails insufficiently yet. Therefore, ZEB design guidelines and spreadsheet programs for energy calculation are released for practitioners, and booklets to promote ZEBs are published for building owners ${ }^{8}$. The ZEB design guidelines and spreadsheet programs are prepared individually for small- and middle-scale offices, nursery and welfare homes, supermarkets and DIY stores, and hospitals.

There is still room for further revision in the ISO 16817:2017. Commissioning is an issue. Building commissioning is a series of activities that ensure the building and the technical building systems are functioning in accordance with the design requirements and parameters throughout the building lifetime. It starts with identifying owners project requirements at the pre-design stage and includes post occupancy evaluations. Even if the design is optimal, the actual environmental performance is dependent on construction. It is indisputable that longterm consideration is essential in building design and that the actual energy performance of a building depends on a manner of operating and managing the building.

\footnotetext{
7 METI, The $5^{\text {th }}$ Strategic Energy Plan, July 2018, Available at: http://www.meti.go.jp/english/press/2018/0703_002.html (Accessed: 10 March 2019).

${ }^{8}$ Sustainable Open Innovation Initiative, Japanese documents only, Available at:

https://sii.or.jp/zeb/guideline/comment/verify_complete/FA2NMWku7e (Accessed: 10 March 2019).
} 


\title{
3.5 Design workflow as Inform Design
}

\author{
by Marios Liaros and Harris Poirazis, Inform Design, Sweden
}

Inform Design is working with daylight issues from conceptual to more detailed stages. As the company plays a clearly supporting role to architectural practices, providing the necessary engineering background to inform their design is essential. The projects may vary significantly but a basic axis between building physics, indoor climate and daylight benefits is often used to improve the building quality. Therefore, in our methods dynamic thermal modelling and daylight assessments are closely linked.

\section{Inform Design project role}

As our support to the clients is rather broad, our involvement often starts from early design stages. Therefore, it is within our scope to drive design solutions rather than to assess the performance of given facades in order to improve the daylight quality and availability in real life practice. The consistency in our methods from conceptual to detailed design is essential to ensure the accuracy of our results. In most cases a fee can be set from an early phase that allows us to often work with rather sophisticated tools (at least more sophisticated than what is currently used as common practice in Sweden). One more parameter that differentiates Inform Design from other practices in Sweden is the freedom to suggest ideas that alter the design concept (up to a certain degree). This leads us to a more design-related rather than performance-assessment role.

\section{Common practice in Sweden}

Commonly the daylight consultant practices in Sweden work with building certifications and assessing the building's daylight performance. The building certification program most often used in Sweden is called Miljöbyggnad, developed by the Swedish Green Building Council. Regarding daylight it only monitors the Daylight Factor in one point in each occupied space. The approach is rather simplified and cannot always give a comprehensive assessment of the daylight conditions in the examined spaces. Nevertheless, because of its simplicity the outcome is broader and more practices, less specialized in daylight, can carry out the necessary assessment.

\section{Basic evaluation}

The first discussion with the client is usually done over the vision that they have for their building using draft plans and hand-drawn sketches. The main scope at this stage is to understand the needs and provide them with a technical background in which they can qualify and quantify the performance of the discussed design ideas. Brainstorming on possible solutions and different alternatives is communicated together with schematic diagrams of the actions needed to be taken. At this stage, basic information is mainly used (location of the project and surroundings). Clarifying the set performance requirements at this early stage is essential for a successful communication to meet the agreed upon targets; this has a great impact of the methods to be selected and used.

\section{Conceptual planning}

After these early discussions, we break down and rebuild the concept with the architect and define and structure the methodology according to the particular needs of each project/case. Detailed examination of the material provided by the design team (plans, information on the materials, use of spaces and limitations) along with further examination of necessary information (weather files, applicable standards and regulations) are carried out to set the framework of our work (potentials and limitations). For the reason previously mentioned, Rhino and Grasshopper are used to a great extend together with Excel at this early stage. 
Ladybug/Honeybee are also utilized for the preliminary analysis mainly focused on the impact of the weather.

It is essential that at this early stage we establish a solid link between our dynamic thermal modelling and daylight methods to ensure that all the requested input for the daylight analysis can be outputted.

\section{Preliminary design/analysis}

We analyze the base-case scenario using the indices we previously selected. Through a parametric study, we assess the potential for improvement of different design alternatives. The workflow usually includes adjustments to the working models using the same tools as in the previous stage (Rhino and Grasshopper). The daylight analysis is mostly carried out using Ladybug/Honeybee and to a lesser extend natively in Radiance. In this stage, we refine the parameters of the analysis to a point that will reflect the sensibility of the improvement potentials and properly inform the design (drive the design towards the right direction).

This part of the process is critical to our added project value and absolutely necessary. It is very often that this process feeds us with a large amount of data that we need to filter or post process before deriving clear conclusions. The most common scenario involves processing in Excel or specialized software tools (based on each case) - in order to extract the required information tailored each time to the specific needs of the project.

\section{Final design}

After communication with the client (most often architects), decisions are taken, including any possible changes or updates. The design is adjusted accordingly, and the final analysis is carried out to quantify the benefit of the final option - same process as before with more elaborate and focused output.

\section{Main issues / open questions}

The main issues concerning our workflows in Ladybug/Honeybee relate to:

1. The flexibility in changing the different geometrical states of the shading devices for both setting the scenarios to be simulated and analyzing the results (e.g. adjusting slat angles for venetian blinds).

2. The accuracy of calculations regarding the impact of (advanced) glazing and shading façade elements (e.g. screens with different openness factors and selective glazing) to indoor daylight and solar performance. 


\title{
3.6 The role of the simulation engine Fener in the design workflow of façade systems
}

\author{
by Bruno Bueno, Fraunhofer ISE, Germany
}

The Fener tool can be used in the conceptual planning of façade systems. It is especially useful to compare the performance of alternative façade systems and to design a control strategy for them. In the following sections, the steps required to select a fenestration system and a control strategy with the assistance of the Fener tool are described.

\section{a) Selection of representative rooms in the building}

The façade system responds to the specific use, dimensions, orientation and location of a room. Therefore, the design of a façade system must be carried out first at room level. Once the façade solutions for the individual rooms are analyzed, a harmonized solution at building level can be determined, which must then be re-tested at room level.

\section{b) Analysis of each room from the point of view of façade functions}

The building facade provides the aesthetic signature of a building, but it also provides important functions, such as visual contact with the outside, daylight provision, glare protection and solar gain management, which make the building usable and energy efficient. These functions often oppose each other, so the selection and design of facade systems and their control for a certain building application should depend on those functions that the designer wants to promote to the detriment of the other functions.

\section{c) Selection of design alternatives for the fenestration system}

Weighting the different façade functions for each studied room is followed by a preselection of suitable façade systems. Considerations such as exterior, in-between glazing or interior, fixed or retractable shading devices, and the type of shading device (e.g. roller shutters, roller blinds or venetian blinds) must be taken at this stage.

d) Selection of evaluation criteria

In order to compare design alternatives, the different façade functions must be quantified with metrics. Metrics can refer to component features, such as the normal-normal transmittance, normal-hemispherical transmittance, U-value and g-value, or to the dynamic performance of the fenestration system for a given building application. Table 3 summarizes the set of metrics supported by the Fener tool.

\section{e) Characterization of fenestration systems}

The calculation of some of the metrics reported in the previous section requires information about the optical and thermal properties of fenestration systems. In the case of Fener, the U-value, BSDF and DSHGC of the whole façade system (glazing unit combined with shading device) are required as input parameters. These parameters can be directly measured with a solar calorimeter [1] and with a photogoniometer equipped with suitable detectors [2], combined or not with ray-tracing techniques.

\section{f) Definition of control strategies}

Movable shading devices or switchable elements are necessary in order to dynamically balance the different façade functions, which are of varying relevance, depending on the time of the day and season. This implies the consideration of a control strategy. Innovative control strategies may depend on thermal and daylighting variables. These can be measured by a set of sensors in the room or dynamically calculated by simulations [3]. The controlling variables and their priority must be chosen depending on the façade functions 
to be promoted. Examples of controlling variables that can be defined in the Fener tool are time of the day, day of the year, indoor and outdoor air temperature, exterior solar irradiance on the roof/at the façade, horizontal and vertical illuminance and computed comfort metrics such as PMV and DGP.

g) Running dynamic simulations for different design alternatives

The different design alternatives are compared in terms of the metrics calculated by the Fener tool. Boundary conditions for the simulations must be specified from the information available at the conceptual planning phase.

h) Selection of the fenestration system and control strategy

The results of the simulation-based comparison among design alternatives can be used as a basis for selecting the fenestration system and control strategy. The aim here is not to replace expert design decisions by simulation results, but to use simulation tools to assist in the design process from the beginning.

Table 3: Metrics supported by the Fener tool for different façade functions.

\begin{tabular}{|l|l|}
\hline Function & Metrics supported by Fener \\
\hline Visual contact with the outside & Direct-direct visual transmittance from BSDF \\
\hline Glare protection & $\begin{array}{l}\text { Direct-direct visual transmittance from BSDF } \\
\text { Enhanced Simplified DGP [4] } \\
\text { Maximum vertical illuminance or simplified DGP }\end{array}$ \\
\hline Daylight provision & $\begin{array}{l}\text { Diffuse-diffuse visual transmittance from BSDF } \\
\text { Average workplane illuminance } \\
\text { Daylight Autonomy } \\
\text { Daylight Factor } \\
\text { Lighting energy demand }\end{array}$ \\
\hline Thermal comfort & $\begin{array}{l}\text { U-value } \\
\text { Effective g-value } \\
\text { Predicted Mean Vote (PMV) } \\
\text { Predicted Percentage Dissatisfied (PPD) }\end{array}$ \\
\hline Solar heat gain management & $\begin{array}{l}\text { Effective g-value } \\
\text { Heating and cooling energy demand }\end{array}$ \\
\hline Privacy & Direct-direct visual transmittance from BSDF \\
\hline
\end{tabular}

\section{Main issues / open questions}

A number of issues must be taken into account by the designer when applying this workflow.

\section{a) Conflict of interests}

The selection and prioritization of façade functions can pose a conflict of interest among the different actors of a building. The users of a building are usually concerned about visual and thermal comfort, while the owner of the building might be interested in prioritizing energy efficiency. In the case of renovation projects, interventions to the exterior façade often require the approval of the architect. The architect might be interested in conserving the original façade for aesthetics reasons compromising the ability of the retrofit solution to improve comfort conditions in the building. The designer must collect and understand the criteria of the different interest groups prior design.

\section{b) Additional design criteria}

The selection of a fenestration system and control strategy is, in most cases, not as flexible as the designer may want. In some cases, the designer is constrained to a certain provider, 
which limits the choice of systems that can be selected. Additional criteria apart from those related with the functions of the façade have to be considered, for example:

- cost of equipment and cost of installation,

- quality and life duration of the equipment,

- resilience to adverse weather conditions (e.g. wind), burglary, etc.,

- need of maintenance and post-installation services offered by the provider.

\section{c) Input data and computational resources}

The selection of evaluation criteria poses a specific problem, because some façade functions are easier to quantify than others. The choice of the evaluation criteria must be adjusted to the type of fenestration systems considered, and the characterization data and computational resources that are available. Sometimes, criteria at component level (e.g. normal-normal, normal-hemispherical transmittance) are more reliable than computationally complex dynamic calculations if the input information is limited and the numerical models inadequate.

\section{d) Characterization of fenestration systems}

The optical and thermal characterization of fenestration system is expensive and often unaffordable by a planning team. Therefore, design decisions have to rely on the technical data provided by manufacturers, which might be incomplete and/or inaccurate. A number of tools and models are, however, available to test and eventually expand the amount of characterization data provided by the manufacturer. Example of such tools are the LBNL's suit of tools (Window, Optics, Therm). The Fener tool offers pre-processing routines to calculate the BSDF and DSHGC for fenestration systems composed of a glazing unit and an internal or external shading device [5].

\section{References}

[1] T. E. Kuhn, Calorimetric determination of the solar heat gain coefficient $g$ with steadystate laboratory measurements, Energy and Buildings 84 (0) (2014) 388 - 402.

[2] P. Apian-Bennewitz. New scanning gonio-photometer for extended BRTF measurements. In Proc. SPIE 7792, Reflection, Scattering, and Diffraction from Surfaces II, September 2010.

[3] A. Katsifaraki, B. Bueno, T. E. Kuhn, A daylight optimized simulation-based shading controller for venetian blinds, Building and Environment 126 (Supplement C) (2017) 207 220.

[4] J. Wienold, J. Christoffersen. Evaluation methods and development of a new glare prediction model for daylight environments with the use of CCD cameras, Energy and Buildings 38(7) (2006) 743-757.

[5] B. Bueno, J.-M. Cejudo-Lopez, T. E. Kuhn, A general method for the evaluation of the thermal impact of complex fenestration systems in building zones, Energy and Buildings 155 (2017) 43-53. 


\title{
3.7 Workflow for lighting design projects in Norconsult and Norway
}

\author{
by Biljana Obradovic, Norconsult, Norway
}

Norconsult is one of the largest interdisciplinary advisors in Norway, in the field of social planning and engineering. Through long experience they have established a solid foundation as a leading player both nationally and internationally. Norconsult is covered by an interdisciplinary team based on both technical and aesthetic subjects within lighting. With experience and expertise from all phases of a project, lighting designers in Norconsult can solve a wide range of tasks related to the field. In Norconsult, there are lighting designers and lighting planners with education in light design, electrical engineering, energy and environment, architecture and energy efficiency.

In Norconsult, the lighting design is a process where the esthetical, functional, technical, conceptual, environmental economical demands and expectations are taken in consideration for the final result. The lighting design takes care of health, technical and aesthetical demands and therefore has measurable and non-measurable (but descriptive) qualities.

Norconsult is offering design services for all or just some of the steps in the lighting design process, such as:

- location, historical, place and buildings analysis,

- conditional analysis,

- design concepts and functional description,

- master lighting plan,

- lighting calculation,

- (electrical design),

- 3D visualization,

- cost estimation,

- calculation of annual operational cost and life cycle costs,

- $\quad$ specification and tender documents.

Those steps present also the design flow for an entire project. Lighting designers in Norconsult are dealing with many market areas as: housing, hotels, shopping centers, office buildings, cultural centers, hospitals and institutional buildings, educational buildings, industry (also offshore), sports facilities, parking places, road and streets, tunnels, bridges, stations, building façades and town plans.

Lighting designers in cooperation with the architect and other relevant subjects in the project prepare an overall lighting concept. The most usual demand for the lighting solution is flexibility, which forces lighting design to stick to the plainest uniform layout. Lighting designers strive to overgo this demand by designing lighting in layers. Variations in the light environment and light effects help to create different identities. Light design and light effects give time dimension to an architectural space or place. Therefore, guidelines for light control are established already in the concept phase. The lighting concept is described with text and illustrations and are forming basis for the lighting plan. A design proposal is prepared for the lighting, in which factors such as investment cost, energy consumption and operating costs, maintenance, aesthetics and experience are weighted. Luminaires and equipment are selected based on the task the light has to solve. The lighting designer works closely with the electric adviser to ensure the installation and operating quality of the solutions. The design process provides innovative lighting solutions that achieve the perfect balance between function and aesthetics. 
The design of artificial functional lighting for offices is done after the guidance from the "Lyskultur publications", which is Norway's leading competence network within light and lighting. This association was founded in 1936 and is nationwide with regional departments and committees, and is an accredited member of the CIE. It gathers leading players in the lighting industry, from lighting designers and consulting engineers, manufacturers, installers, importers and the sales leaders in lighting. Members of the Lyskultur (Lighting Culture) are active contributors in the development of national and international standards, reports and guidelines. Lyskultur has among many other publications prepared and published, the "Office lighting publication" 10 which is a direct guideline for lighting designers dealing with the office lighting. This publication is prepared according to the current Norwegian laws and regulations for the design of office spaces and installations. The law hierarchy in Norway that lighting designers need to consider looks like this:

- $\quad$ Laws, such as the Working Environment Act ${ }^{11}$;

- followed by Regulations, for example Building Technical Regulations (TEK) ${ }^{12}$;

- guidelines and interpretations prepared in the public administration, for example, guidance to technical regulations (VTEK) 13 ;

- Current Norwegian Standards (NS) and Lux-tables (Lyskultur's publication 1B ${ }^{14}$ and $\left.1 \mathrm{C}^{15}\right)$ as guides to the standards NS-EN 12464-116 and NS-EN 12464-217.

The guidance for office lighting focuses on some design acts which are not so much acclaimed in the European standards for lighting, as:

- importance of vertical and cylindrical lighting for good modeling in different settings;

- or analysis for special needs for increased or reduced level of recommended lighting, according to the Norwegian standards for "design for everyone" (NS 11001-118, NS $11001-2^{19}$ and NS 11001-5).

The publication is also giving advices about the lighting design treatment for the working area, as desk and environment. Workplace lighting should be built up in layers according to needs. This will create a differentiated lighting that describes the room's features more clearly than a steady light. Separate treatment of the lighting of the workplace, environment and background (vertical surfaces) results in a visual hierarchy that allows us to read and understand space in a better way. Recommended lighting principle is, that focus-working field, environments and backgrounds should be treated separately, but at the same time balanced to form a good entirety. A combination of local workplace lighting, direct spotlighting for background contrasts and a moderate ambient light provides an optimized lighting environment for comfort and wellbeing.

The design of artificial indoor lighting should always be done considering the daylight features at the project locations. Based on Norway's geographical location far north, especially the northernmost land areas, the presence of daylight might represent a slightly more particular role in people's life than at other places on earth. The sun height is very low for many hours, especially in the winter, but also during spring and autumn. Daylight on a low sky passes

\footnotetext{
9 https://www.lyskultur.no/

10 https://www.lyskultur.no/12-kontorbelysning.5996519-342096.html

$11 \mathrm{https}: / /$ lovdata.no/dokument/NLE/lov/2005-06-17-62

12 https://dibk.no/byggereglene/byggteknisk-forskrift-tek17/

13 http://radem.no/dok/dibk/VTEK.pdf

14 https://www.lyskultur.no/1b-luxtabell-og-planleggingskriterier-for-innendoersbelysningsanlegg.5765498-342096.html

15 https://www.lyskultur.no/1c-luxtabell-og-planleggingskriterier-for-belysning-av-utendoersarbeidsplasser.5768459-342096.html

16 https://www.standard.no/no/Nettbutikk/produktkatalogen/Produktpresentasjon/?ProductID=507703

17 https://www.standard.no/nettbutikk/produktkatalogen/produktpresentasjon/?ProductlD=687229

18 http://www.standard.no/nettbutikk/sokeresultater/?search=NS+11001-1

19 http://www.standard.no/nettbutikk/sokeresultater/?search=NS+11001-2
} 
through several atmospheric layers, which refract the light, causing sky and clouds to be lit by a colored light. A colored sky is a visual presentation that people associate with the presence of daylight. Figure 57 shows the thoughts. Spring evenings are often enhanced by a warm sky. During the summer, entire landscape is usually green, and this color associates the presence of daylight. During the winter, snow covers many parts of the land, causing daylight, even during the very short daytime, to be reflected and caught on the clouds as a blue light. This is a phenomenon called "the blue hour" and it happens mostly during the twilight.
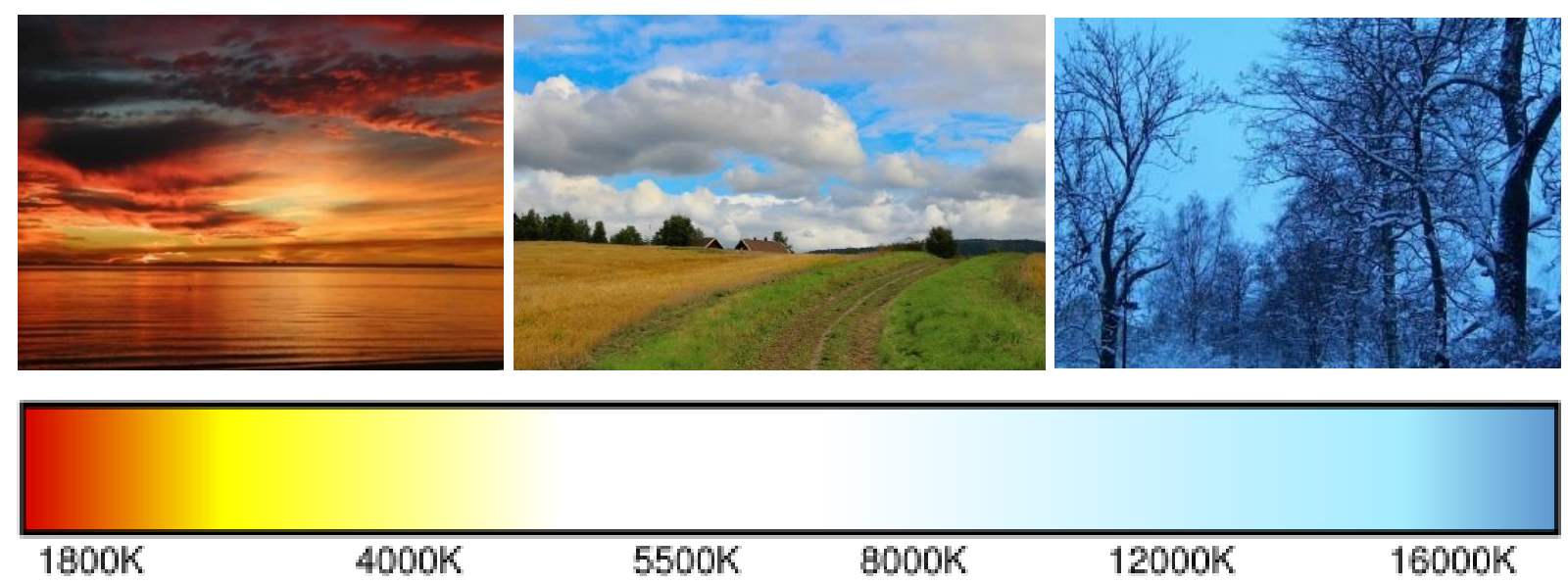

Figure 57: 1. The sky in spring, 2. The sky in the summer, 3. The sky in the winter. Source Norconsult

The lighting designers in Norconsult are trying to design artificial lighting in accordance to the daylighting variability. Depending on a building function, room type, site position (sun availability during the summer and winter can be quite different on the different sides of the object) the electric functional light can be designed to tune the color and light intention, to adopt to the Human Centric Lighting concept. Additionally, the electrical effect lighting can be designed to adopt the variations of the daylight color outside, at the particular moment during the day.

The design of the artificial light according to the available daylight flux is done adjusting the daylight controlling systems input levels and positioning the sensors on the right places. There is a practice of dividing the rows of the luminaires in the lighting system to be incrementally dimmed. However, there is a very little common thinking about the altitude of the sun and the different angles it will have during the day and the year. Our experience in Norconsult is that there is very little cooperation between architects and lighting designers for the sunscreen's solution. It often happens that architects do not specify details on this, just describe market available equipment, without consulting lighting designers at all. Sometimes the information about the sunscreen's solution is not available to lighting designers until the final phase of the project. The design of the daylighting controls for the artificial lighting often goes uncoordinated with the design of the sunscreens. The designers in Norconsult are trying to enhance the importance of this issue, but we see that the problem lies very much in the disciplinary integrity, in not totally developed collaboration practice and culture in a national level.

Design software that lighting designers use in Norconsult are mostly DIALux and DIALux EVO. For professional sports lighting, street- and tunnel lighting RELUX software is more in use. In the last 5 years, there have been a huge increasement of REVIT use for multidisciplinary projects in Norconsult, and Norway in general. The use of AutoCAD and ArchiCAD are still more connected to the small architectural projects. 


\section{Main issues / open questions}

It is important that lighting design software is compatible with the architectural or engineering software that are in common use, so that results can be quickly imported and exported, in order to be checked against collisions of all technical equipment. This is somehow not the case, at least not yet. It is necessary to get standardizations of files extensions that all projects actors use. There are many software solutions available on the market, many of them are expensive for small companies, so they often choose those that are available to use. There are permanently emerging many small software and applications, and designers are delighted to try to use them, but the models that should be exported from them are usually not compatible with the standardized software as DIALux or Revit. There are also a limited import and export options in DIALux too. The lighting designers' job can be complicated because no digital underlay for their work exists. Without proper models, the design cannot be done in the best manner and according to the best practice. 


\subsection{Estia Workflow}

by Bernard Paule, Estia SA, Switzerland

\section{Introduction}

Estia is a spin-off company of the Solar Energy and Building Physics Laboratory (LESO-PB / EPFL), installed since 1998 on the EPFL campus in Lausanne (EPFL Innovation Park). The team consists of highly qualified engineers and architects, boasting a wide experience.

Our mission is to promote innovation and, particularly, the implementation of principles of sustainable development in the built environment. Estia provides consulting services independently, favoring a global approach of the building physics.

Our view to daylighting is part of this perspective. It is therefore original in that, for almost all projects, we build our response taking into account the other issues related to the performance of the building envelope, such as summer comfort, thermal loads and natural ventilation strategies. In concrete terms, our workflow is organized as follows.

\section{Quantitative Aspects}

After having familiarized ourselves with a new project, its environment and the different building function, we select some representative rooms that will serve as a basis for reflection.

At this phase, we also interview the designer to find out how much flexibility he has in relation to his initial intentions.

As a general rule, we use DIAL+ software to analyze the first sketches proposed by the architect. Since DIAL+ allows us to conduct detailed analysis very quickly, we can be involved in the very early stages of the design process, even in the architectural competition phase.

a) Preliminary studies

As a first approach, we rely on Daylight Factor and Diffuse-Daylight Autonomy (DDA) values to assess the daylighting performance. The limited computing time requested to run these simulations allows us to study different variants in order to consider the potential optimization tracks. The idea is to present a comparison of the results of the initial design with those obtained with different possible alternatives.
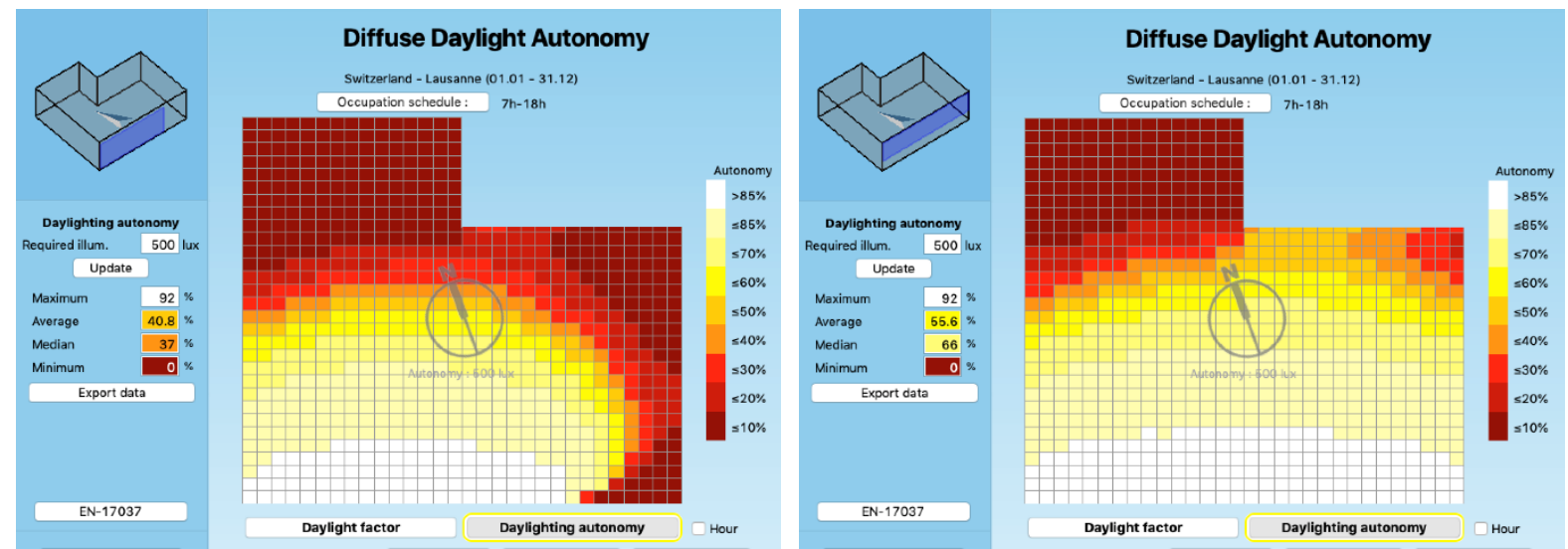

Figure 58: Medical office in Lausanne: Comparison of two variants of a given room with the same window to floor ratio (WFR $=23 \%$ ) but a different window shape (Simulation: DIAL+). 


\section{b) Detailed studies}

When necessary, we also carry out dynamic simulations in order to know the behavior of the room according to the different periods of the year and, in particular, to take into account the influence of solar penetrations. During these simulations, the effects of solar protections (including control system) are taken into account. The results are usually presented using the Spatial Daylight Autonomy (sDA).

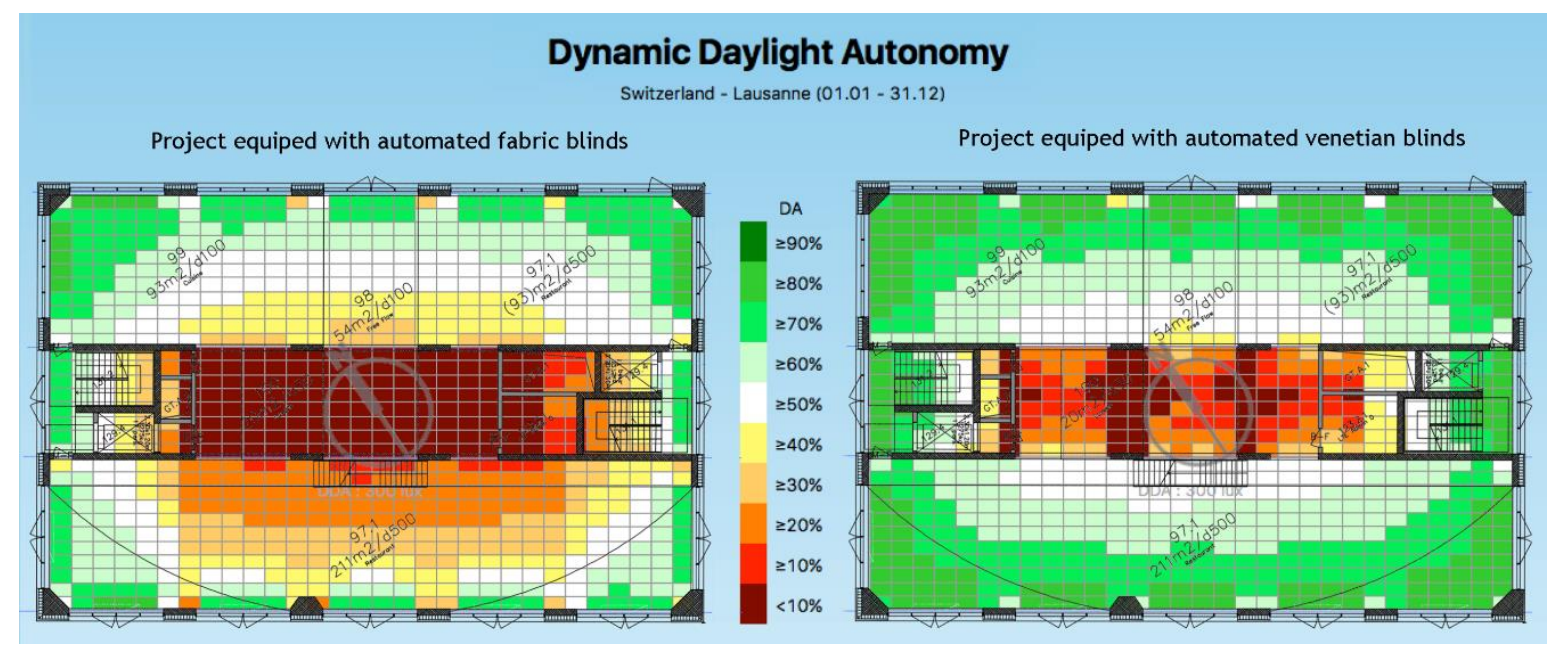

Figure 59: Office building in Lausanne: Comparison of the Daylight Autonomy with the openings equipped with fabric blinds (left) or venetian blinds (right). Simulation: DIAL+.

In this regard, we often use temporal maps to understand how the daylighting system actually works along the different seasons (position of the sun protections, average illuminance, etc.).

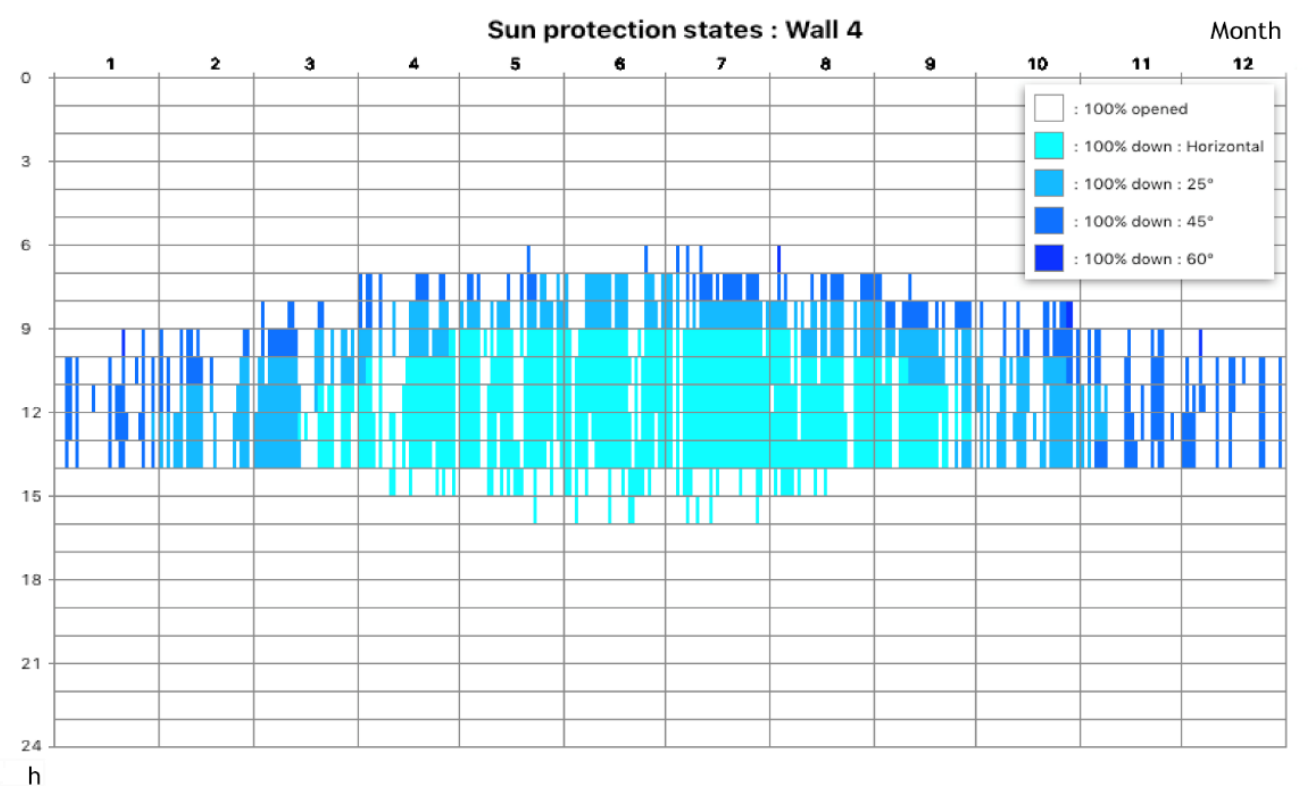

Figure 60: Office building in Geneva: Temporal map of the shading device position (Automated venetian blinds: East oriented façade). Simulation: DIAL+.

\section{Qualitative aspects}

In addition to the analyses performed with the DIAL+ software, we often use 3D software such as Velux Daylight Visualizer. This allows us to produce realistic computer-generated images, 
which is particularly useful if the geometry of the project is complex or if the problems to be solved are more oriented towards qualitative aspects. In this case, we use either the 3D files provided by the architects or the files that we build ourselves to describe the volumes to study. The main results exploited with that kind of software concern the luminance fields. This approach is useful to help designers better understand how daylight is distributed in the space. It also facilitates the communication of results to the building owner.
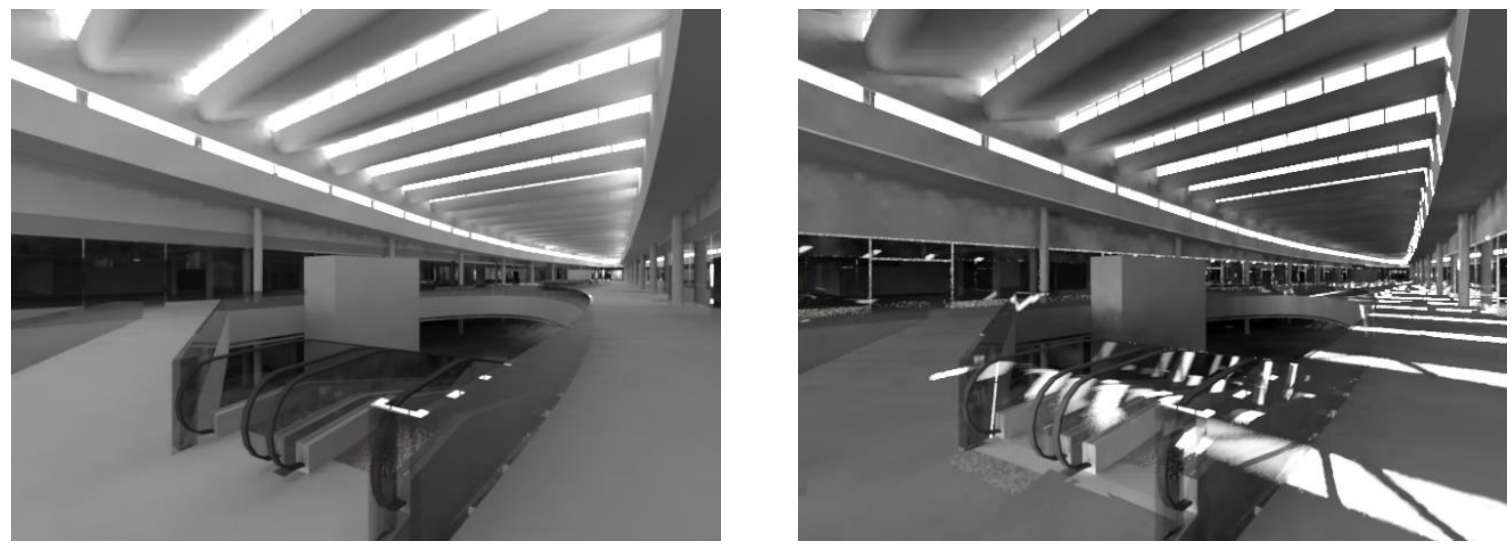

Figure 61: Shopping center: Study of zenithal openings. Left: overcast sky conditions. Right: Sunny conditions. Simulation: Daylight Visualizer.

We also exploit the results provided in terms of illuminance and daylight factor to estimate the annual coverage of lighting requirements. To this end, we use the indicative values given by the European standard 17037 to extrapolate the autonomy values from the DF values (see next figure).

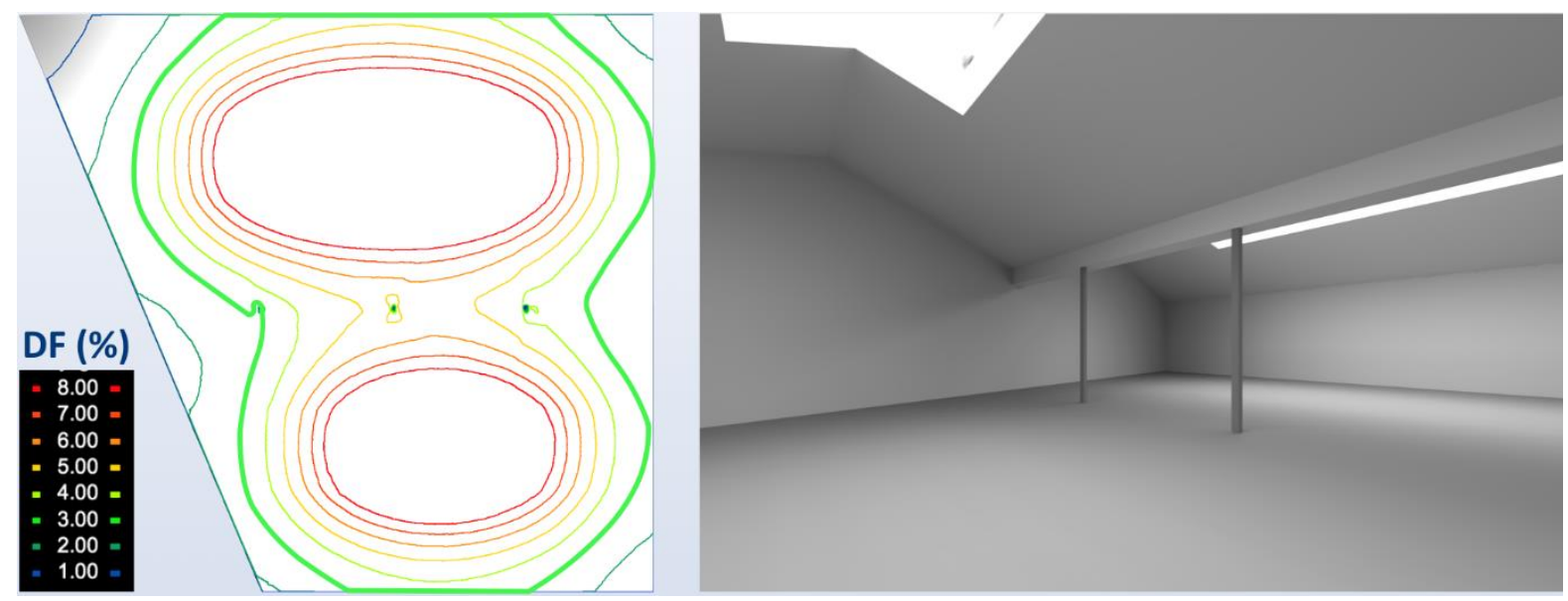

Figure 62: Exhibition hall: According to EN 17037, the area delimited by the green curve (DF > $3 \%$ ) will benefit from 500 lux during more than $50 \%$ of the daylight hours (Simulation: Daylight Visualizer).

\section{Mock-ups}

Architects sometimes build models that can be excellent tools for daylighting analysis. We then use the LESO-PB artificial sky and heliodon to take measurements (DF) and thus integrate these models into the decision process. 

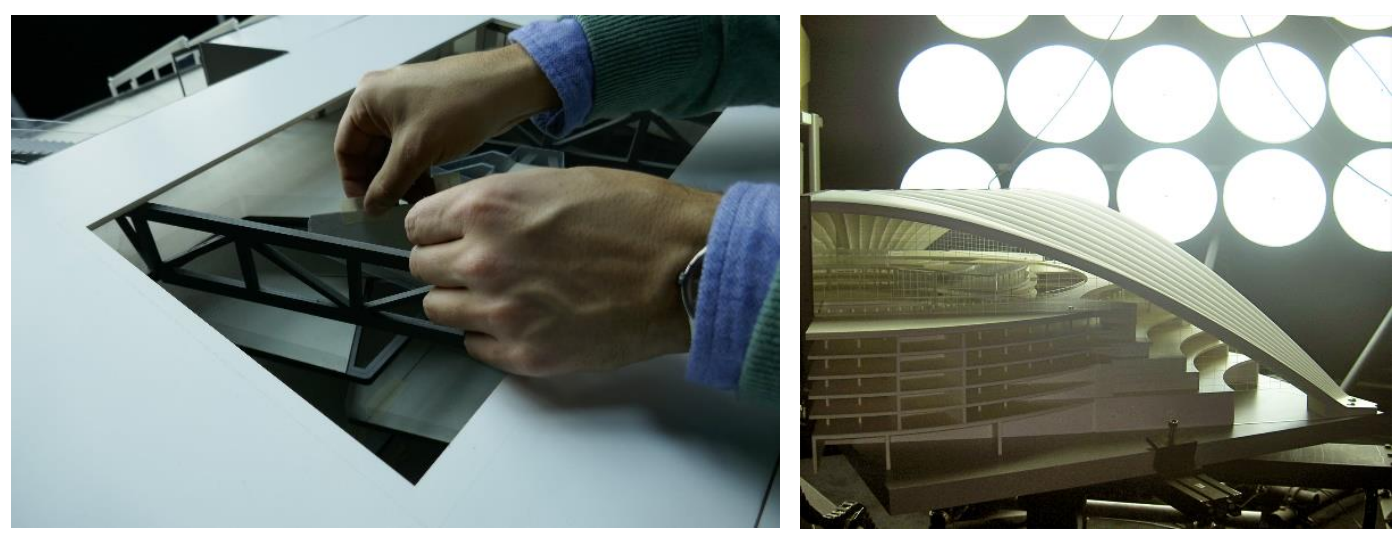

Figure 63: Office buildings in Paris: mock-ups test under the LESO-PB/EPFL artificial sky.

If necessary, we also perform video animations showing the effect of solar penetration, either on typical days or throughout the year. This is very useful for illustrating the variety of daylight effects.

\section{Thermal aspects}

As mentioned above, the proposed variants are also systematically evaluated from a thermal point of view. For this purpose, we use the thermal module of DIAL+.

The results obtained from the dynamic simulations include temperature profiles, solar gains, number of overheating hours, heating and cooling needs, etc. The analysis of these results allows us to verify that the variant we are going to recommend do indeed present an interesting "overall performance".

The figure below shows, for a given room, the influence of the type of shading device and ventilation strategy. This example points out that the design of daylighting systems must be coupled with an analysis of the other themes of building physics to be able to propose, in a given context, the most suitable solution.

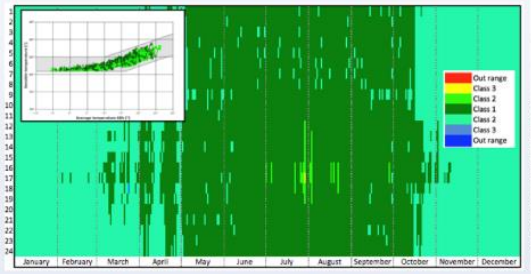

Automated venetian blinds + Night ventilation :

0 overheating hours

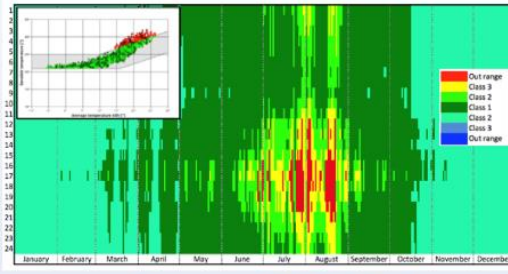

Automated Fabric blinds + Night ventilation : 252 overheating hours

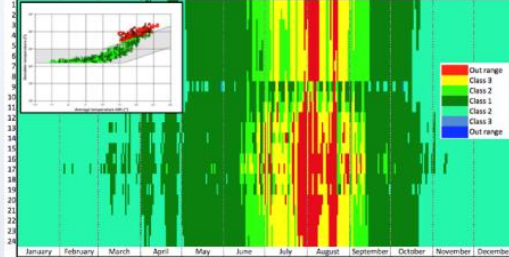

Automated venetian blinds + Daytime ventilation only : 449 overheating hours

Figure 64: Office building: analysis of the comfort zone according to EN 15251 (thermal analysis / DIAL+ simulation).

\section{Deliverables}

Given the complexity of the subject and in order to better fit into the decision-making process, the results of our studies are generally presented in a form that favors diagrams and illustrations while minimizing texts. The general idea is that the information transmitted can be easily assimilated both by the design teams and by the building owner. 


\section{Main issues / open questions}

Since it influences solar gains in winter and cooling needs in mid-season and summer, the use of shading devices is a major issue. While it is relatively easy to simulate the effect of blinds automation systems, it is much harder to reproduce the users' behavior. This one is strongly motivated by personal reactions related to light conditions (glare, feeling of confinement, color perception, ... etc.) that are very difficult to model.

We at Estia believe that for large glazed facades the performance gap (difference between predicted and effective energy consumption) is highly influenced by the control of blinds position (manual or automated). Research on this subject is therefore welcome and we must think about how to take this issue into account in dynamic simulations. 


\subsection{LiTG Scope of Services - Lighting Design}

by Ulf Greiner Mai, Member of the Management Board of the LiTG and leading author of the Scope of Services, Germany, and

David Geisler-Moroder, Bartenbach, Austria

In January 2019, the German LiTG (Lichttechnische Gesellschaft e.V.) released the publication 38 "Leistungsbilder Lichtplanung". It has been worked out by a taskforce of appointed professionals of the LiTG. In the meantime, it was tested by more than 60 lighting design offices in Germany, Austria and Switzerland.

Modern lighting design is a conscious design of objects of indoor and outdoor spaces with the help of light - and the result stands out: illuminated buildings determine the cityscape, light makes architecture interesting, well-lit buildings and rooms are more valuable and can be trademarks. Light guides, directs, gives orientation and creates atmosphere.

Professional lighting design for interiors consists of two subareas: "Daylight design" and "Artificial lighting design". Daylight design is the planning of the natural lighting with daylight. Artificial lighting design is the planning of artificial lighting of objects using electrical light sources. In both areas, user-oriented, creative, (perceptual) psychological, physiological and biological, functional, mathematical-physical, technical, economic and ecological aspects must be considered. This quality claim can only be implemented through a holistic and professional lighting design.

The "Scope of Services - Lighting Design" (German: Leistungsbilder Lichtplanung, "LB LP") indicate which workflow and modern approaches are required for a high-quality lighting design and tabulate both the "basic services" as well as the "special services" in the frame of lighting design. The publication is the first scope of services for planners that covers possible effects of the new planning contract law in the BGB. Though the European Court of Justice expectedly overturned the fee regulation for architects and engineers (HOAI) in its judgment of 4 July 2019, the LB LP closely follow the well-established and precious structure and defined phases in this regulation. With this, the LB LP is particularly suitable for use in contracts, settlements and performance evaluations.

The publication is aimed at lighting designers and professionals who design lighting. That can be architects, building planners as well as engineers, electrical planners and specialized third parties. Lighting designers only take care of the lighting design while others perform the lighting design in addition to other planning services. For both groups, the "Scope of Services: Lighting Design" provides a toolbox of potential planning and surveillance services.

Table 4: Proposed phases of the LiTG "Scope of Services: Lighting Design" following the well-established phases in the HOAl

\begin{tabular}{l|l}
\hline Phase & Description \\
\hline LPH 0 & Design criteria as special services \\
\hline LPH 1 & Basic evaluation \\
\hline LPH 2 & Preliminary design \\
\hline LPH 3 & Basic design \\
\hline LPH 4 & Approval planning \\
\hline LPH 5 & Detailed design (planning for execution) \\
\hline LPH 6 & Preparation of contracting \\
\hline LPH 7 & Assistance in contracting \\
\hline LPH 8 & Site (construction) supervision and documentation \\
\hline LPH 9 & Project support \\
\hline
\end{tabular}


Detailed information about the "Scope of Services: Lighting Design" and the contents of the single phases can be found in the corresponding LiTG publication [1].

\section{Main issues / open questions}

The new LiTG "Scope of Services: Lighting Design" contribute significantly to enhancing light planning and transdisciplinary planning goals. After the European Court of Justice overturned the $\mathrm{HOAl}$, they are putting the lighting design into in a pioneering role in terms of providing recommendations for well-defined scopes of services. The LB LP provide a comprehensive toolbox of possible lighting design services. However, it leaves the decision on which services to offer in a project to the designer as it does not provide guidelines or examples for different project types.

The services for daylighting design and artificial lighting design are defined and presented separately. This reflects the current practice in the design process. In view of the growing importance of an integrative design, it misses some recommendations on how to define the phases for an integrated daylighting and artificial lighting design service.

The LB LP cover daylighting and electric lighting design. For 2020 the LiTG is planning to release further recommendations to cover also exterior and street lighting.

\section{References}

[1] LiTG, Deutsche Lichttechnische Gesellschaft e.V., Leistungsbilder Lichtplanung: Teil 1 „Tages- und Kunstlicht“, LiTG Publikation 38, 2019. 


\section{Analysis of Simulation Software Tools}

The example design projects in chapter 0 are used as basis for the qualitative description of different software tools used in the design workflows for integrated electric lighting and daylighting solutions. This analysis should show the potential and features of the different tools and disclose the shortcomings where additional functionality or features are desirable.

It is not intended here to perform comparative simulations to evaluate the accuracy and deviations between the different tools. For this, the interested reader is referred to the IEA SHC Task 50 report "Methods and tools for lighting retrofits: State of the art review"20.

${ }^{20} \mathrm{~J}$. Kaempf, B. Paule, et al., Methods and tools for lighting Retrofits: State of the art review, A Technical Report of IEA SHC Task 50, online:

http://task50.iea-shc.org/Data/Sites/1/publications/Technical Report T50 C2 final.pdf 


\subsection{Comparison of Software Tools}

\begin{tabular}{|c|c|c|c|c|c|c|c|c|c|c|c|c|c|}
\hline & \multicolumn{12}{|c|}{$\begin{array}{c}\text { Applies to Software } \\
+=\text { yes, } 0=\text { partly, }--=\text { no }\end{array}$} & \multirow[b]{2}{*}{$\begin{array}{c}\text { Remarks / } \\
\text { explanations }\end{array}$} \\
\hline & స్ & $\begin{array}{l}\frac{\infty}{O} \\
\frac{0}{\varepsilon} \\
\frac{E}{\bar{L}}\end{array}$ & 崫 & $\frac{\stackrel{x}{3}}{\Delta}$ & $\frac{+}{\frac{1}{0}}$ & 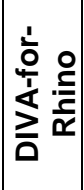 & 品 & 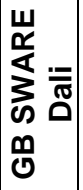 & 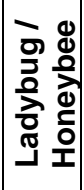 & $\begin{array}{l}\sum_{n} \\
\frac{y}{n}\end{array}$ & 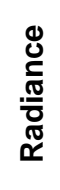 & $\stackrel{\stackrel{x}{ב}}{\underset{\sim}{\widetilde{x}}}$ & \\
\hline \multicolumn{14}{|l|}{$\begin{array}{l}\text { GENERAL } \\
\text { INFORMATION }\end{array}$} \\
\hline $\begin{array}{l}\text { Graphical user } \\
\text { interface }\end{array}$ & + & + & + & + & + & + & + & + & + & + & -- & + & \\
\hline $\begin{array}{l}\text { Command line } \\
\text { interface }\end{array}$ & -- & -- & -- & -- & -- & -- & + & -- & -- & -- & + & -- & \\
\hline CAD Import & + & + & -- & + & -- & + & -- & + & + & + & + & + & \\
\hline 3D Modeling & + & + & -- & + & + & + & -- & + & + & + & $0^{11}$ & + & $\begin{array}{l}\text { 11: some tools to } \\
\text { create and collect } \\
\text { geometry }\end{array}$ \\
\hline 3D Rendering & + & + & -- & + & -- & + & -- & + & + & + & + & + & \\
\hline Scripting & -- & -- & -- & -- & -- & + & + & + & + & -- & + & -- & \\
\hline \multicolumn{14}{|l|}{ USERS } \\
\hline $\begin{array}{l}\text { Suited for lighting } \\
\text { designers }\end{array}$ & + & + & + & + & + & + & + & + & $--^{9}$ & --10 & + & + & $\begin{array}{l}9,10 \text { : further } \\
\text { development of tools } \\
\text { and methods used } \\
\text { for lighting design } \\
\text { are planned for the } \\
\text { future }\end{array}$ \\
\hline $\begin{array}{l}\text { Suited for } \\
\text { architects }\end{array}$ & + & + & + & + & + & + & + & + & + & + & + & + & \\
\hline $\begin{array}{l}\text { Suited for electric } \\
\text { engineers }\end{array}$ & + & + & + & + & + & -- & -- & + & -- & -- & -- & $++^{12}$ & $\begin{array}{l}\text { 12: with the add-on } \\
\text { "ReluxCAD for Revit" } \\
\text { in Revit for BIM } \\
\text { projects }\end{array}$ \\
\hline $\begin{array}{l}\text { Suited for HVAC } \\
\text { engineers }\end{array}$ & -- & -- & + & -- & -- & -- & -- & + & + & + & -- & $+^{12}$ & $\begin{array}{l}\text { 12: with the add-on } \\
\text { "ReluxCAD for Revit" } \\
\text { in Revit for BIM } \\
\text { projects }\end{array}$ \\
\hline $\begin{array}{l}\text { Suited for building } \\
\text { engineers/planners }\end{array}$ & + & + & + & + & + & + & + & + & + & + & -- & + & \\
\hline $\begin{array}{l}\text { Suited for } \\
\text { researchers }\end{array}$ & + & + & + & + & + & + & + & + & + & + & + & + & \\
\hline \multicolumn{14}{|l|}{ DESIGN PHASE } \\
\hline $\begin{array}{l}\text { Suited for early } \\
\text { design }\end{array}$ & + & + & + & + & + & + & + & + & + & + & + & + & \\
\hline $\begin{array}{l}\text { Suited for detailed } \\
\text { design }\end{array}$ & + & + & -- & + & + & + & -- & + & + & + & + & + & \\
\hline
\end{tabular}




\begin{tabular}{|c|c|c|c|c|c|c|c|c|c|c|c|c|c|}
\hline & \multicolumn{12}{|c|}{$\begin{array}{c}\text { Applies to Software } \\
+=\text { yes, } 0=\text { partly, }--=\text { no }\end{array}$} & \multirow[b]{2}{*}{$\begin{array}{l}\text { Remarks / } \\
\text { explanations }\end{array}$} \\
\hline & స్ల్ & 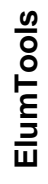 & 崫 & 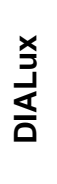 & $\frac{+}{\frac{1}{\Delta}}$ & 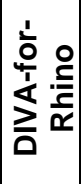 & 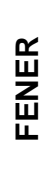 & 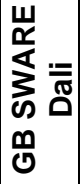 & 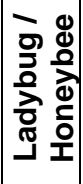 & $\begin{array}{l}\sum_{n} \\
\frac{x}{a}\end{array}$ & 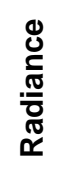 & 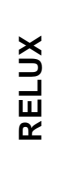 & \\
\hline \multicolumn{14}{|l|}{$\begin{array}{l}\text { ALGORITHMS / } \\
\text { ENGINES }\end{array}$} \\
\hline Ray tracing & $0^{1}$ & $0^{2}$ & + & + & + & + & + & + & + & + & + & + & $\begin{array}{l}1,2 \text { : post radiosity } \\
\text { process for } \\
\text { visualization only }\end{array}$ \\
\hline Photon mapping & -- & -- & -- & + & -- & $0^{6}$ & -- & -- & -- & -- & + & -- & $\begin{array}{l}\text { 6: limited photon } \\
\text { mapping capabilities for } \\
\text { renderings }\end{array}$ \\
\hline Radiosity & + & + & -- & -- & -- & -- & -- & -- & -- & -- & -- & + & \\
\hline Radiance kernel & -- & -- & + & - & + & + & + & + & + & + & + & + & \\
\hline 3 Phase Method & -- & -- & + & -- & + & -- & + & -- & + & -- & + & -- & \\
\hline 5 Phase Method & -- & -- & -- & -- & -- & -- & -- & -- & $0^{9}$ & -- & + & -- & $\begin{array}{l}\text { 9: limited capabilities } \\
\text { through Honeybee Plus }\end{array}$ \\
\hline $\begin{array}{l}\text { Daylight } \\
\text { Coefficient } \\
\text { Method }\end{array}$ & -- & -- & + & -- & -- & + & -- & + & + & + & + & -- & \\
\hline $\begin{array}{l}\text { Spectral } \\
\text { calculations }\end{array}$ & -- & -- & -- & $0^{4}$ & -- & -- & -- & -- & -- & -- & $0^{11}$ & $0^{12}$ & $\begin{array}{l}4,12 \text { : light source } \\
\text { spectrum is taken into } \\
\text { account but reduced to } \\
\text { RGB during calculation } \\
11 \text { : RGB calculations; } \\
\text { more channels possible } \\
\text { with post processing }\end{array}$ \\
\hline \multicolumn{14}{|l|}{$\begin{array}{l}\text { ELECTRIC } \\
\text { LIGHTING }\end{array}$} \\
\hline $\begin{array}{l}\text { Illuminance } \\
\text { values }\end{array}$ & + & + & + & + & + & + & -- & + & + & -- & + & + & \\
\hline Luminance values & + & + & + & + & + & + & -- & + & + & -- & + & + & \\
\hline $\begin{array}{l}\text { Glare calculations } \\
(\mathrm{UGR}, \mathrm{VCP}, \ldots)\end{array}$ & + & + & -- & + & -- & + & -- & -- & -- & -- & + & + & \\
\hline $\begin{array}{l}\text { Calculation of } \\
\text { connected } \\
\text { wattage } \\
\end{array}$ & + & + & + & + & + & + & -- & -- & + & -- & -- & + & \\
\hline $\begin{array}{l}\text { Calculation of } \\
\text { annual electricity } \\
\text { consumption }\end{array}$ & -- & -- & + & + & + & + & + & -- & + & -- & -- & + & \\
\hline $\begin{array}{l}\text { Import of } \\
\text { luminaires (IES, } \\
\text { Eulumdat, etc.). }\end{array}$ & + & + & $0^{3}$ & + & + & $0^{6}$ & -- & + & + & -- & $0^{11}$ & + & $\begin{array}{l}\text { 3: Eulumdat or ZPF } \\
\text { only } \\
6 / 11 \text { : IES import only }\end{array}$ \\
\hline $\begin{array}{l}\text { Data base of } \\
\text { luminaires }\end{array}$ & + & + & $0^{3}$ & + & + & -- & -- & + & -- & -- & -- & + & $\begin{array}{l}\text { 3: generic luminous } \\
\text { intensity distributions } \\
\text { available }\end{array}$ \\
\hline
\end{tabular}




\begin{tabular}{|c|c|c|c|c|c|c|c|c|c|c|c|c|c|}
\hline & \multicolumn{12}{|c|}{$\begin{array}{c}\text { Applies to Software } \\
+=\text { yes, } 0=\text { partly, }--=\text { no }\end{array}$} & \multirow[b]{2}{*}{$\begin{array}{l}\text { Remarks / } \\
\text { explanations }\end{array}$} \\
\hline & స్ & $\frac{\frac{o}{O}}{\stackrel{0}{\varepsilon}}$ & 岂 & 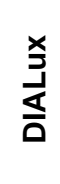 & $\stackrel{+}{\frac{1}{\Delta}}$ & 竞 & 妥 & 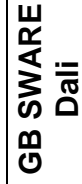 & 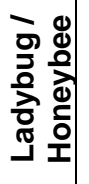 & $\begin{array}{l}\sum \\
\frac{1}{a} \\
\frac{1}{a}\end{array}$ & 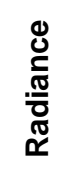 & 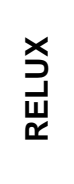 & \\
\hline \multicolumn{14}{|l|}{ DAYLIGHTING } \\
\hline $\begin{array}{l}\text { Point-in-time } \\
\text { simulation }\end{array}$ & + & + & -- & + & + & + & + & + & + & + & + & + & \\
\hline $\begin{array}{l}\text { Climate-based } \\
\text { annual simulation }\end{array}$ & -- & -- & + & -- & + & + & + & -- & + & + & + & -- & \\
\hline Illuminance values & + & + & + & + & + & + & + & + & + & + & + & + & \\
\hline Luminance values & + & + & + & + & + & + & -- & + & + & + & + & + & \\
\hline $\begin{array}{l}\text { Daylight factor } \\
\text { values }\end{array}$ & + & + & -- & + & + & + & + & + & + & + & + & + & \\
\hline $\begin{array}{l}\text { Daylight autonomy } \\
\text { (DA, cDA, sDA) }\end{array}$ & -- & -- & + & -- & + & + & + & + & + & + & $0^{11}$ & $\mathrm{o}^{12}$ & $\begin{array}{l}11: \text { calculation from } \\
\text { annual illuminance } \\
\text { values (post processing) } \\
\text { 12: calculation of } \\
\text { daylight autonomy } \\
\text { depending on daylight } \\
\text { factor for the sensor } \\
\end{array}$ \\
\hline $\begin{array}{l}\text { Glare calculations } \\
\text { (DGP, DGI, ...) }\end{array}$ & -- & -- & -- & -- & -- & + & + & + & + & + & + & -- & \\
\hline CIE sky models & + & + & $0^{3}$ & + & + & + & -- & + & + & + & + & + & $\begin{array}{l}\text { 3: diffuse part modeled } \\
\text { as CIE uniform sky }\end{array}$ \\
\hline Perez sky model & + & + & -- & -- & + & + & + & + & + & + & + & -- & \\
\hline $\begin{array}{l}\text { Sensible to } \\
\text { orientation }\end{array}$ & + & + & + & + & + & + & + & + & + & + & + & + & \\
\hline $\begin{array}{l}\text { Consideration of } \\
\text { daylight systems } \\
\text { as geometry }\end{array}$ & + & + & -- & + & + & + & + & + & $0^{9}$ & $0^{10}$ & + & + & $\begin{array}{l}\text { 9,10: partly considered; } \\
\text { model complexity and } \\
\text { calculation accuracy } \\
\text { depend on the settings } \\
\text { of the engine } \\
\text { (Radiance) }\end{array}$ \\
\hline \begin{tabular}{|l|} 
Import of \\
daylighting \\
systems as BSDF \\
data
\end{tabular} & -- & -- & $t^{3}$ & $+^{4}$ & -- & -- & + & + & + & -- & + & $+^{12}$ & $\begin{array}{l}\text { 3: XML import in Klems } \\
\text { format in next release } \\
\text { 4: import of DDLS and } \\
\text { ODLS format; includes } \\
\text { measured BSDF data } \\
\text { 12: import available in } \\
\text { Radiance format } \\
\end{array}$ \\
\hline $\begin{array}{l}\text { Data base of } \\
\text { daylight systems }\end{array}$ & -- & -- & + & + & -- & -- & + & + & -- & + & -- & + & \\
\hline $\begin{array}{l}\text { Consideration of } \\
\text { outdoor } \\
\text { obstructions }\end{array}$ & + & + & $0^{3}$ & $0^{4}$ & + & + & + & + & + & + & + & + & $\begin{array}{l}\text { 3: horizontal obstruction } \\
\text { or overhang possible as } \\
\text { exterior shading } \\
\text { 4: reflection of outdoor } \\
\text { surfaces not considered }\end{array}$ \\
\hline
\end{tabular}




\begin{tabular}{|c|c|c|c|c|c|c|c|c|c|c|c|c|c|}
\hline & \multicolumn{12}{|c|}{$\begin{array}{c}\text { Applies to Software } \\
+=\text { yes, } 0=\text { partly, }-=\text { no }\end{array}$} & \multirow[b]{2}{*}{$\begin{array}{l}\text { Remarks / } \\
\text { explanations }\end{array}$} \\
\hline & ণ্লি & $\frac{\frac{c}{8}}{\frac{0}{\varepsilon}}$ & 㟧 & 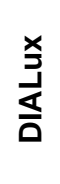 & $\stackrel{+}{\frac{1}{5}}$ & 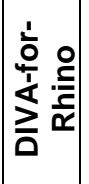 & 妥 & 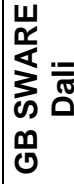 & 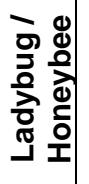 & $\begin{array}{l}\sum_{0} \\
\frac{x}{\alpha}\end{array}$ & 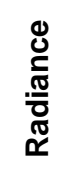 & 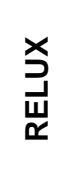 & \\
\hline \multicolumn{14}{|l|}{$\begin{array}{l}\text { CONTROL } \\
\text { SYSTEM }\end{array}$} \\
\hline $\begin{array}{l}\text { Preset control } \\
\text { strategies for } \\
\text { electric lighting }\end{array}$ & -- & -- & + & -- & + & + & + & -- & + & -- & - & - & \\
\hline $\begin{array}{l}\text { Preset control } \\
\text { strategies for } \\
\text { daylight system }\end{array}$ & -- & -- & + & -- & + & + & + & -- & + & -- & -- & -- & \\
\hline $\begin{array}{l}\text { Preset integrated } \\
\text { control strategies } \\
\text { for electric and } \\
\text { daylight systems }\end{array}$ & -- & -- & + & -- & -- & + & + & -- & $0^{9}$ & -- & -- & -- & $\begin{array}{l}\text { 9: detailed methods not } \\
\text { supported yet }\end{array}$ \\
\hline \begin{tabular}{|l|} 
User-defined \\
control strategies \\
for electric lighting
\end{tabular} & + & + & $0^{3}$ & -- & -- & + & + & -- & + & -- & $0^{11}$ & -- & $\begin{array}{l}\text { 3: thresholds definable } \\
\text { by user } \\
11 \text { : possible by scripting }\end{array}$ \\
\hline \begin{tabular}{|l|} 
User-defined \\
control strategies \\
for daylight system
\end{tabular} & -- & -- & $0^{3}$ & -- & + & + & + & -- & + & -- & $0^{11}$ & -- & $\begin{array}{l}\text { 3: thresholds definable } \\
\text { by user } \\
11 \text { : possible by scripting }\end{array}$ \\
\hline $\begin{array}{l}\text { User-defined } \\
\text { integrated control } \\
\text { strategies for } \\
\text { electric and } \\
\text { daylight systems } \\
\end{array}$ & -- & -- & $0^{3}$ & -- & -- & + & + & -- & $0^{9}$ & -- & $0^{11}$ & -- & $\begin{array}{l}\text { 3: thresholds definable } \\
\text { by user } \\
\text { 9: detailed methods not } \\
\text { supported yet } \\
\text { 11: possible by scripting }\end{array}$ \\
\hline $\begin{array}{l}\text { Calculation of } \\
\text { annual electricity } \\
\text { consumption }\end{array}$ & -- & -- & + & -- & + & + & + & -- & $0^{9}$ & -- & -- & -- & $\begin{array}{l}\text { 9: detailed methods not } \\
\text { supported yet }\end{array}$ \\
\hline \multicolumn{14}{|l|}{$\begin{array}{l}\text { EXTENDED } \\
\text { SCOPE }\end{array}$} \\
\hline $\begin{array}{l}\text { Evaluation of non- } \\
\text { visual lighting } \\
\text { effects }\end{array}$ & -- & -- & $0^{3}$ & -- & -- & - & -- & -- & -- & -- & $0^{11}$ & -- & $\begin{array}{l}\text { 3: evaluation of vertical } \\
\text { illuminances } \\
\text { 11: possible in post } \\
\text { processing }\end{array}$ \\
\hline $\begin{array}{l}\text { Integration of } \\
\text { lighting and } \\
\text { thermal } \\
\text { simulations }\end{array}$ & -- & -- & + & -- & + & + & + & -- & + & -- & - & -- & \\
\hline BIM interface & -- & $t^{2}$ & -- & + & -- & -- & -- & -- & $+^{9}$ & + & -- & $+^{12}$ & $\begin{array}{l}\text { 2: ElumTools is a plug- } \\
\text { in for Revit, runs using } \\
\text { all Revit model data } \\
\text { 9: through Dynamo } \\
\text { version of plugins } \\
\text { 12: sophisticated } \\
\text { bidirectional interface } \\
\text { with add-on "ReluxCAD } \\
\text { for Revit" }\end{array}$ \\
\hline
\end{tabular}




\title{
Comparison of glare assessments in simulation interfaces for façade components
}

\author{
by Bruno Bueno, Fraunhofer ISE, Germany
}

Within the framework of the ICON project between LBNL and Fraunhofer ISE, the most important simulation interfaces that deal with façade components have been reviewed. The study shows that these widely used simulation interfaces offer limited methods for glare risk assessment. A summary can be found in the following table. The programs COMFEN and IES are able to render images from view positions using Radiance and to derive luminance-based glare indexes for a few timesteps in a year. On the other hand, LightSolve and DIVA4Rhino implement detailed methods for calculating glare dynamically but do not support BSDF representations of fenestration systems. All the other reviewed simulation interfaces did not offer state-of-the-art glare evaluation methods.

One of the barriers for the implementation of glare assessment methods in simulation tools is that they require detailed characterization of fenestration systems, costly computation capacity and expertise. New BSDF representations, such as high-resolution BSDF and peak extraction, may contribute to the standardization, simplification and reliability of these methods.

\begin{tabular}{l|l|l}
\hline Simulation interface & $\begin{array}{l}\text { Simulation engine } \\
\text { (Model) }\end{array}$ & Metric \\
\hline IDA-ICE (EQUA) & None & None \\
\hline COMFEN (LBNL) & Radiance (raytracing) & DGI \\
\hline Open Studio (NREL) & None & None \\
\hline LightSolve (EPFL) & Own raytracer (graphic acceleration) & DGP \\
\hline DIALux-EVO (DIAL) & None & None \\
\hline DIVA for RHINO & $\begin{array}{l}\text { Daysim,Radiance } \\
\text { (Daylight coefficnts, raytracing) }\end{array}$ & Enhanced simplified DGP \\
\hline IES & $\begin{array}{l}\text { Radiance } \\
\text { (raytracing) }\end{array}$ & CIE Glare Index \\
\hline Design Builder & EnergyPlus & EnergyPlus glare index \\
\hline
\end{tabular}




\subsection{AGi32}

by Chris Jackson, Lighting Analysts Ltd, UK and

Dave Speer, Lighting Analysts Inc, USA

\section{Calculations}

AGi32 is a computational program that performs numerical point-by-point calculations of incident direct or reflected light on any real surface or imaginary plane. Within this scope, it is used to predict or quantify the distribution of artificial or natural light in any environment.

AGi32 is the tool of choice when quantifying the amount of light present in any architectural application. Whether the problem be a 500-luminaire professional sports facility, large shopping mall parking area, commercial interior or single emergency luminaire in a hallway, AGi32 can produce the required numerical results quickly and accurately. AGi32 is used daily to present point-by-point illuminance, roadway pavement luminance, ceiling exitance and other specific lighting quantities for all types of lighting applications. If your position on the design team requires you to submit numeric evidence of lighting quantity and quality, AGi32 is able to produce the data you require.

\section{Two Calculation Methods}

AGi32 has two calculation methods to assist with the computation required in the most efficient manner. For strictly numeric results in an exterior parking, floodlighting, or roadway application, AGi32 has an extremely fast direct-component calculation engine. The Direct Only calculation method will consider the shadowing effect of objects in the scene and produce point-by-point illuminance on any surface or plane in space.

For interior or exterior projects where reflected light is important, AGi32's Full Radiosity calculation method will compute the interaction between light and surface using its state-ofthe-art calculation engine. In this mode all surfaces can be assigned a color and reflectance and accurate luminance levels are computed for the entire environment. An interactive lightaccurate rendering is produced automatically.

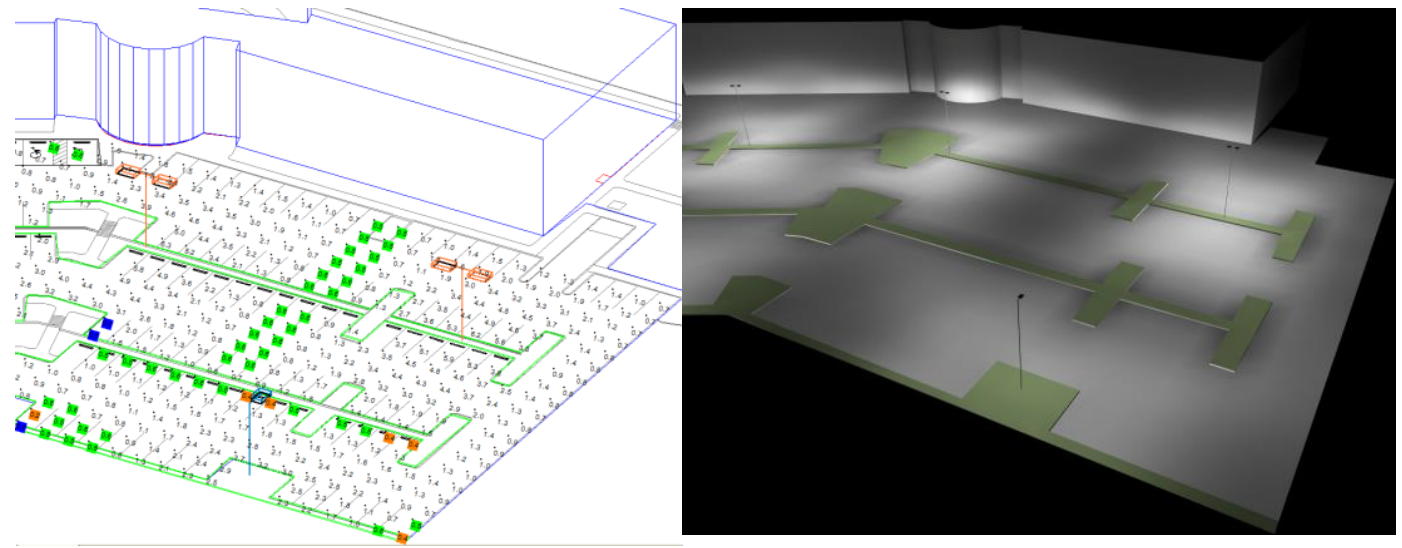

Figure 65: Direct calculation method exterior with user-defined point highlighting (left), Exterior rendering generated automatically with the Full Radiosity calculation method (right). 
AGi32 can utilize luminaire photometric data in IES (*.IES), EULUMDAT (*.LDT) and CIBSE $\left({ }^{*}\right.$.CIB) formats. These files can be located anywhere on your network or can be dragged from many manufacturer websites directly into AGi32.

Many of the lighting industry's most prominent manufacturers provide photometric libraries to Lighting Analysts unique cloud-based database we call the Instabase. This is a powerful forum for data access with the ability to specify unique search parameters to query across multiple manufacturers of your choice for products matching your specific needs.

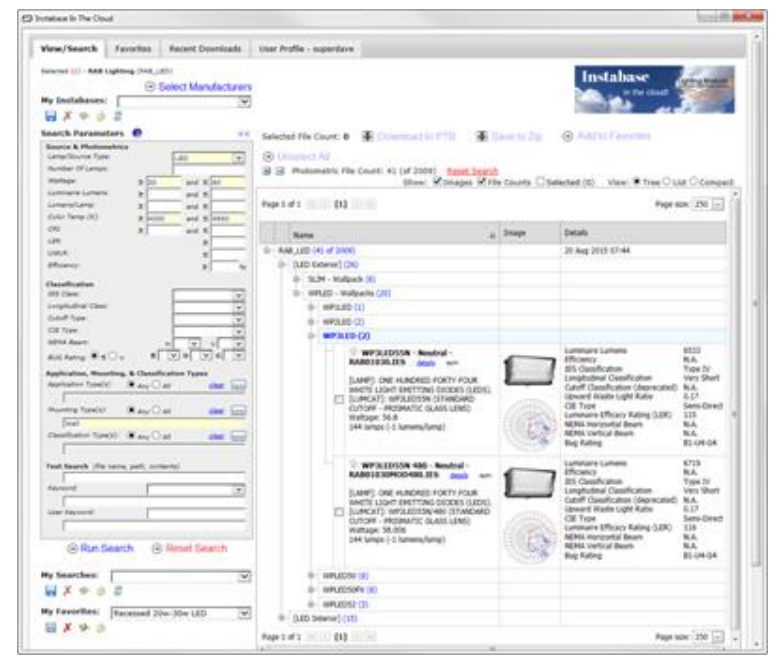

Manufacturers have $24 / 7 / 365$ access to their data for immediate update capabilities. The current list of participating manufacturers can be examined on our website.

\section{Specific calculations}

AGi32 can perform a variety of illumination engineering calculations for your specification requirements. Which quantities you elect to compute will depend on the lighting application and/or your specific interests.

\begin{tabular}{|c|c|}
\hline Application & Computation possibilities \\
\hline Interior & $\begin{array}{l}\text { Illuminance (fc or lux) } \\
\quad \text { Horizontal, Vertical, Variable meter aiming } \\
\text { Luminous Exitance (Im/sq ft or Im/sq m) } \\
\text { Lighting Power Density (watts/ sq ft) } \\
\text { Unified Glare Rating } \\
\text { Luminance }\left(\mathrm{cd} / \mathrm{m}^{2}\right) \text { in rendered pseudocolor }\end{array}$ \\
\hline $\begin{array}{l}\text { Exterior } \\
\text { (general) }\end{array}$ & $\begin{array}{l}\text { Illuminance (fc or lux) } \\
\text { Horizontal, Vertical, Variable meter aiming } \\
\text { Luminous Exitance (Im/sq ft or Im/sq m) from surfaces } \\
\text { Lighting Power Density (watts/ sq ft) } \\
\left.\text { Luminance (cd } / \mathrm{m}^{2}\right) \text { in rendered pseudocolor } \\
\text { Glare and obtrusive light quantities: } \\
\text { Maximum intensity at a point } \\
\text { Threshold Increment } \\
\text { Obtrusive light compliance reporting: } \\
\text { Model Lighting Ordinance } \\
\text { LEED v4 SSc6 } \\
\text { CIE 150-2017 } \\
\text { AS4282-2020 }\end{array}$ \\
\hline Sports & $\begin{array}{l}\text { Illuminance (fc or lux) } \\
\quad \text { Horizontal, Vertical, Variable meter aiming (TV illuminance) } \\
\text { CIE Glare Rating } \\
\text { Uniformity Gradient, Coefficient of Variance } \\
\text { Aiming diagrams }\end{array}$ \\
\hline Roadway & $\begin{array}{l}\text { Illuminance (fc or lux) } \\
\text { Horizontal, Vertical, Variable meter aiming } \\
\text { Lighting Power Density (watts/ sq ft) }\end{array}$ \\
\hline
\end{tabular}




\begin{tabular}{|c|c|}
\hline & $\begin{array}{l}\text { Pavement Luminance }\left(\mathrm{cd} / \mathrm{m}^{2}\right) \text { and associated quantities for IES, CIE and AS/NZ } \\
\text { methods } \\
\text { Veiling Luminance } \\
\text { Threshold Increment } \\
\text { Small Target Visibility (STV) }\end{array}$ \\
\hline Daylighting & $\begin{array}{l}\text { Illuminance (fc or lux) } \\
\quad \text { Horizontal, Vertical, Variable meter aiming } \\
\text { IES, CIE and Perez all-weather sky models } \\
\text { Daylight Factor (DF) } \\
\text { LEED criteria (Version 4, Option } 2 \text { ) } \\
\text { Luminance }\left(\mathrm{cd} / \mathrm{m}^{2}\right) \text { in rendered pseudocolor (Fisheye capture in HDR format available) } \\
\text { Luminous Exitance ( }(\mathrm{m} / \mathrm{sq} \mathrm{ft} \text { or } \mathrm{Im} / \mathrm{sq} \mathrm{m}) \text { from surfaces }\end{array}$ \\
\hline
\end{tabular}

\section{Calculation Point Options}

AGi32 provides a number of different options for locating calculation points. The most effective option will depend on the application and the desired calculations. All options have flexibility in meter aiming (horizontal, vertical, variable, camera).

- Automatic Placement on any surface or workplane

- 2-point or 3-point grid specification, flat or sloped

- Polygon

- Line
- $\quad$ Scattered

- Obtrusive light (Horizontal and Vertical planes)

- $\quad$ Glare Rating (sports specific)

- Unified Glare Rating (interior)

- Roadway criteria
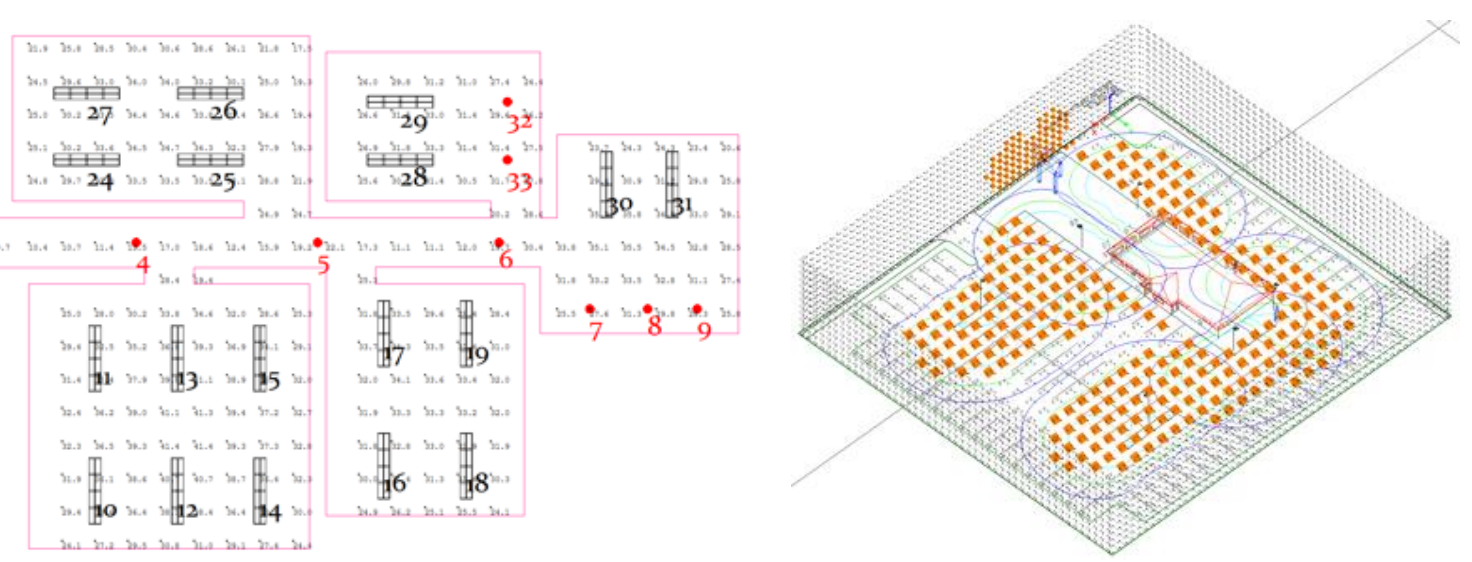

Figure 66: Automatic Placement calculation points on the room floor or workplane (left), obtrusive light calculation points at the property line (vertical planes; right).

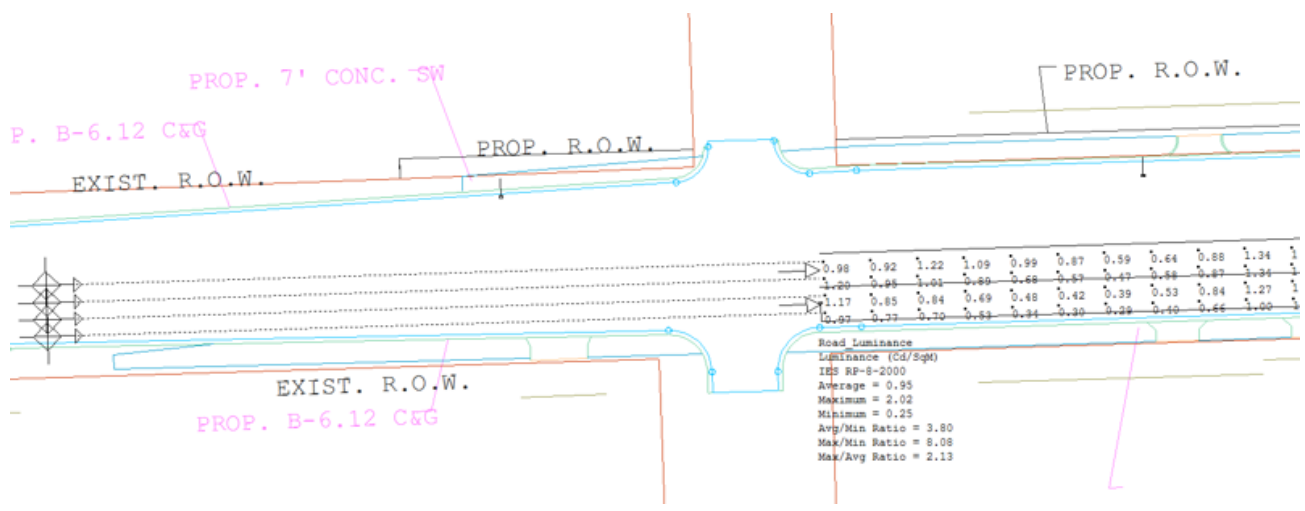

Figure 67: Roadway specific calculations (luminance, illuminance, veiling luminance, STV and more can be switched for visibility) 


\section{Evaluation of results}

AGi32 offers a dynamic and intuitive working environment to evaluate your calculated results, make changes and fine tune your projects to meet specifications. Value highlighting is one very effective method to see a project's weak points at a glance. Monitor the overall statistics for all calculations, even those that are not currently visible from the Statistics window.

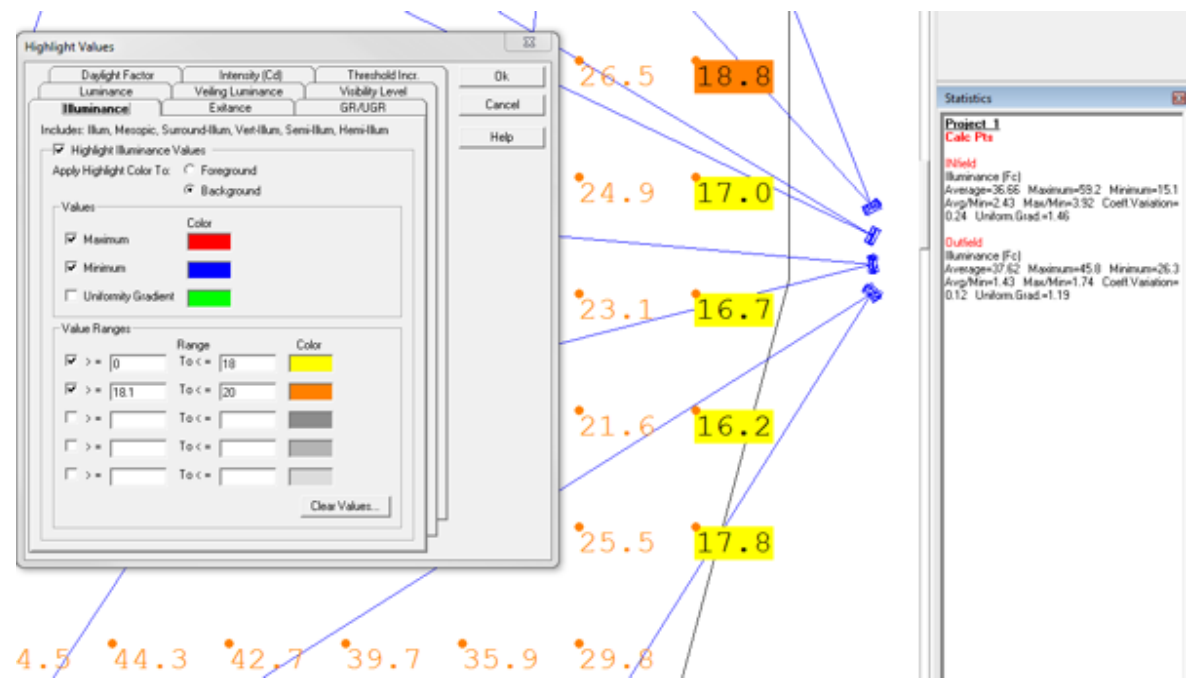

\section{Modeling}

AGi32 is a simple yet extraordinary model builder capable of constructing almost any architectural environment. Vaults, domes, curves, slopes and extrusions are easily created, allowing you to accurately model the architectural elements you encounter every day. For those with existing 3D models, AGi32 can import 3D geometry via DWG, DXF and through our LAI Data Exchange (LaiDex) as exported from our free SketchUp plugin.
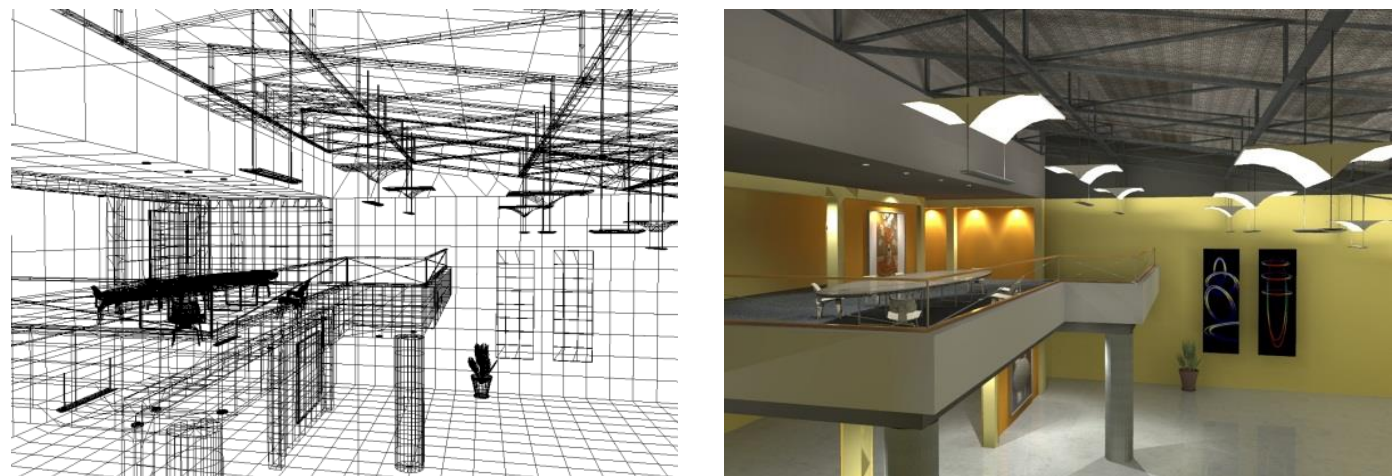

Figure 68: Model created in AGi32 - wireframe (left), Rendered: radiosity plus raytrace (right).

AGi32 provides the tools needed to model many common architectural spaces. Using shapes like barrel vaults, cones, spheres, pyramids and vertical extrusions, you can build complex geometries directly in AGi32.

However, if you already have a three-dimensional CAD model composed of surface information, it can be imported and utilized as if created internally. Surface properties such as color, reflectance, texture and surface type (glass for example) can be easily assigned during the import process. AGi32 imports and exports DWG and DXF formats using the Autodesk RealDWG® toolkit. Our free plug-in for Trimble ${ }^{\circledR}$ SketchUp $\AA$ exports to an intermediate format (LaiDex) readable by AGi32. For simple point by point calculations with no surfaces (exterior 
site lighting for example), AGi32 can easily import two-dimensional CAD drawings to be used as a background reference.

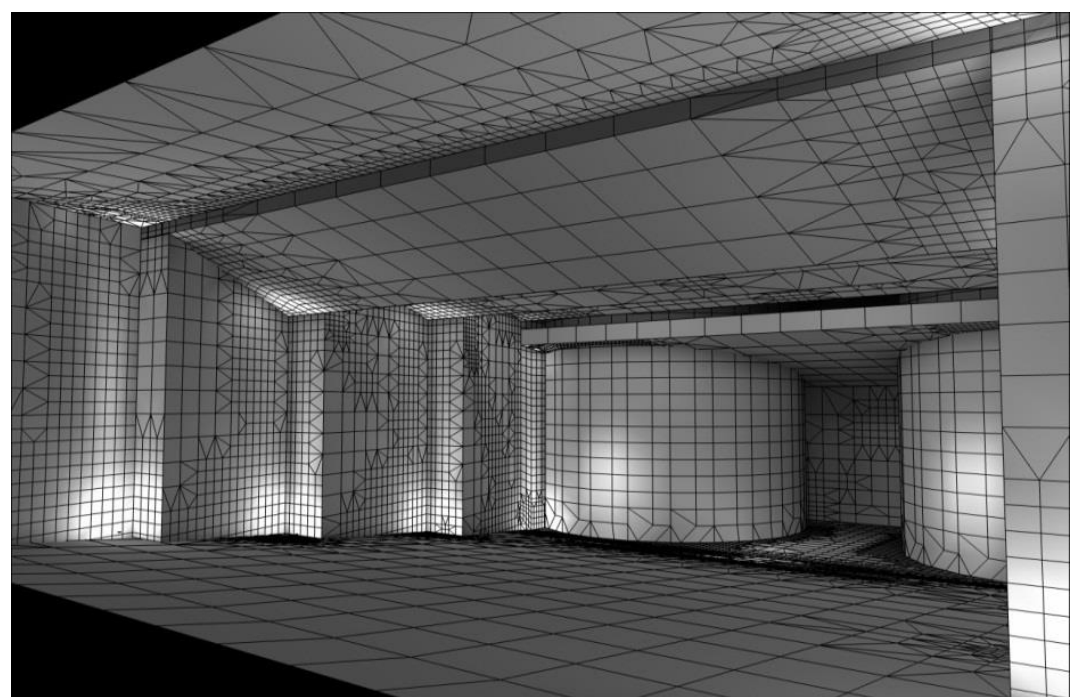

Figure 69: AGi32 created architectural geometry

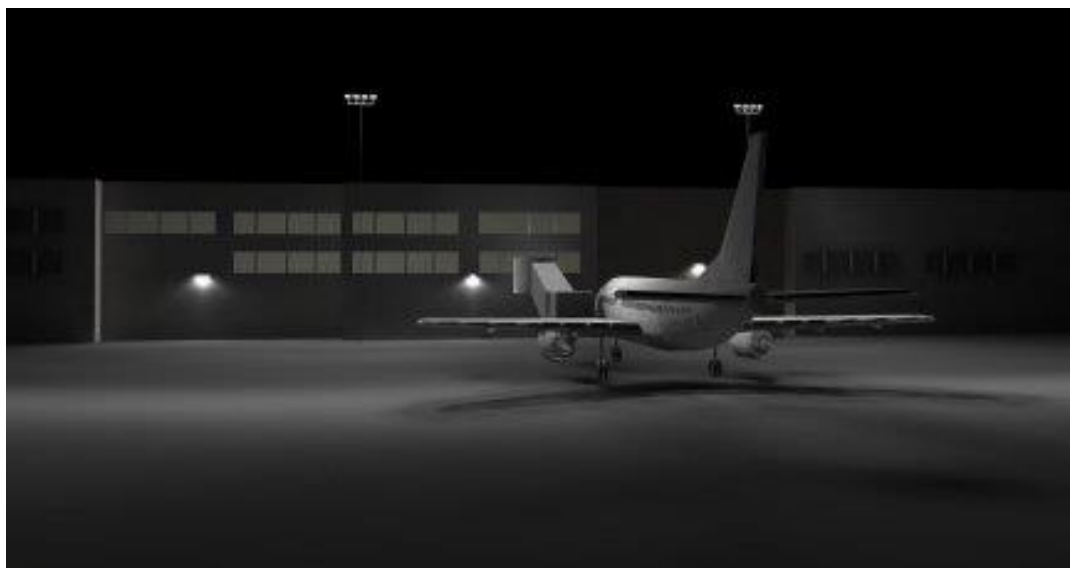

Figure 70: 3D CAD model of Boeing 737 imported

\section{Object Libraries}

AGi32 is delivered with a number of factory-provided library objects that may be used at any time to add detail, scale and realism to any lighting project.

Objects you create or import from CAD or SketchUp ${ }^{\circledR}$ can also be added to custom libraries and organized to suit your needs.
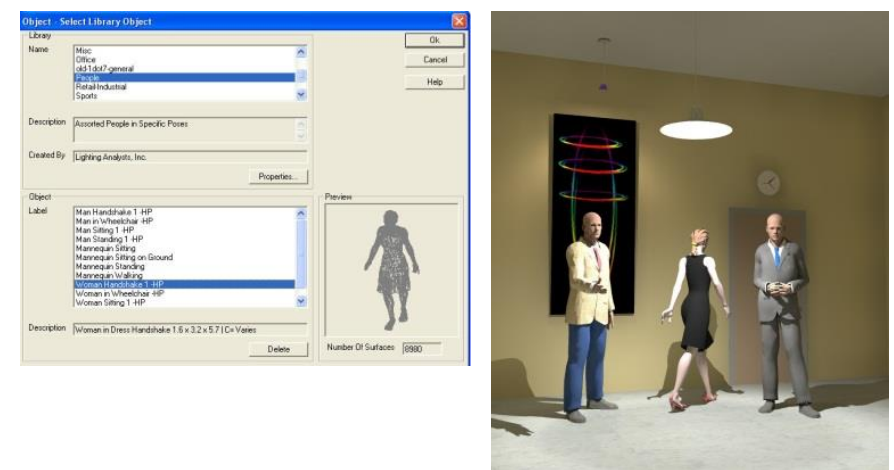


\section{Rendering}

AGi32 is a wonderfully fun and interactive rendering program. Employed on this level, AGi32 can be used to generate extremely fast and photometrically accurate color images of the behavior of light within the environment. As the rendering engine is fast enough to be used on an iterative basis, designers now have the ability to quickly visualize and share different lighting scenarios before they are specified, purchased and installed.

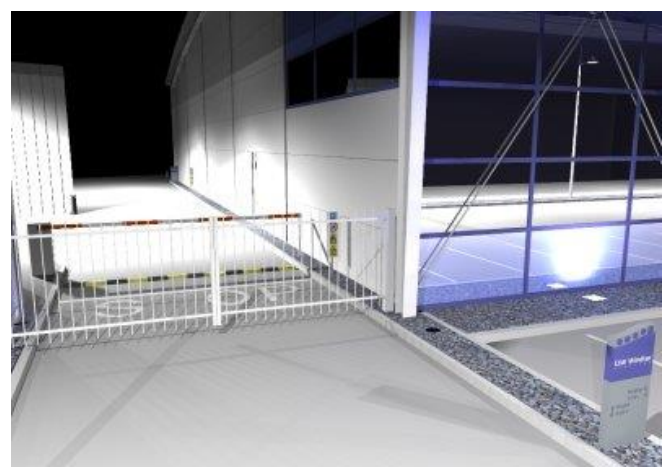

Figure 71: David Boud, DW Windsor Lighting, United Kingdom

\section{Radiosity}

AGi32's rendering engine uses the latest developments in radiosity techniques to compute the direct and interreflected components of light in your environment. Radiosity calculations can accurately model color bleed, enhancing the realism of your visualizations. All calculations performed in Full Radiosity calculation method produce a radiosity based rendering automatically. This rendering can be viewed interactively without recalculation. Available interactive tools include Walk, Orbit, Pan, Dolly, Zoom and Clip.

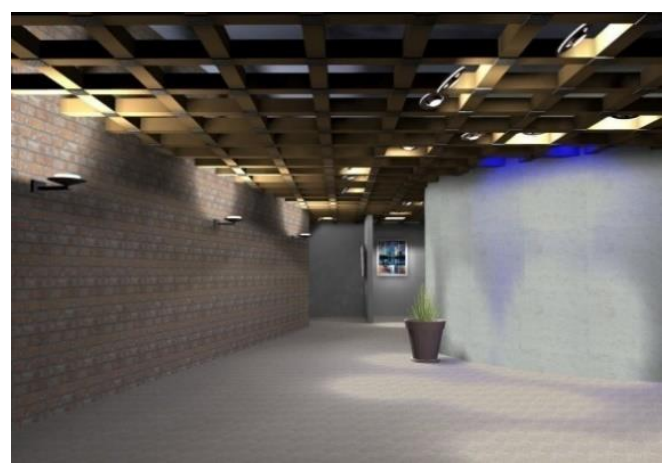

\section{Texture Mapping}

Textures are bitmap images that may be applied to any surface in AGi32. The image can be stretched across the surface, or a repeating pattern may be applied to the surface by tiling the texture with a fixed texture size. AGi32 is provided with a textures database from which you can select a number of common architectural materials such as brick, tile, fabric, and wood. Making your own textures is easy by cropping your digital images and importing to the library.

New to AGi32 version 19 is the ability to modulate the reflectance value of your textures. This makes the library more flexible and enhances the role of textures to conform to your project specifications. Also new to version 19 is the ability to easily make textures out of your Google Earth or PDF images. This can impart a new sense of realism to a rendered site and ground your presentations in reality.
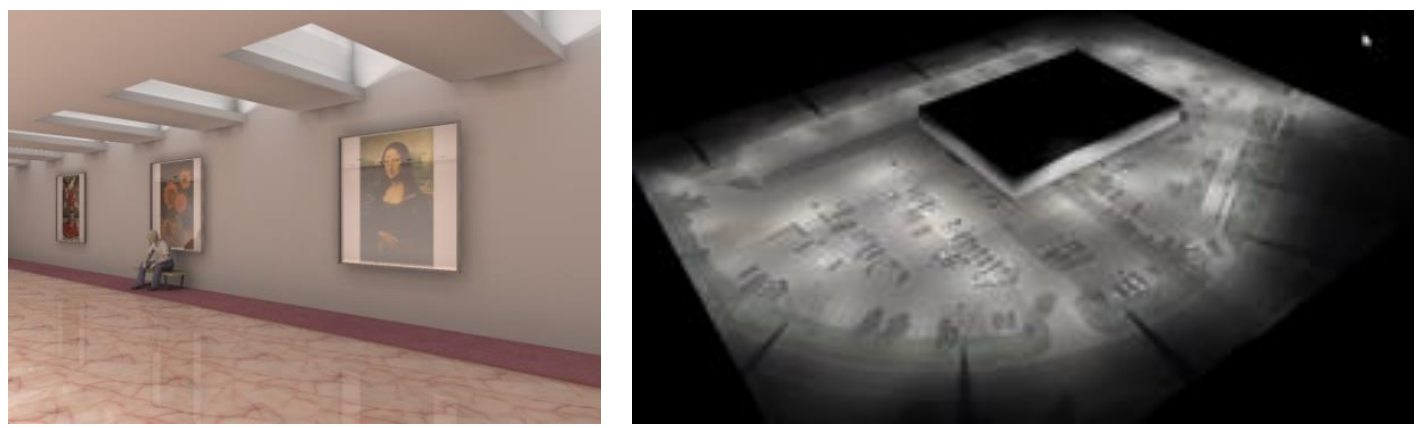

Figure 72: Textures can make your visualizations look more realistic (left), assign a real image of the site as a texture (right). 


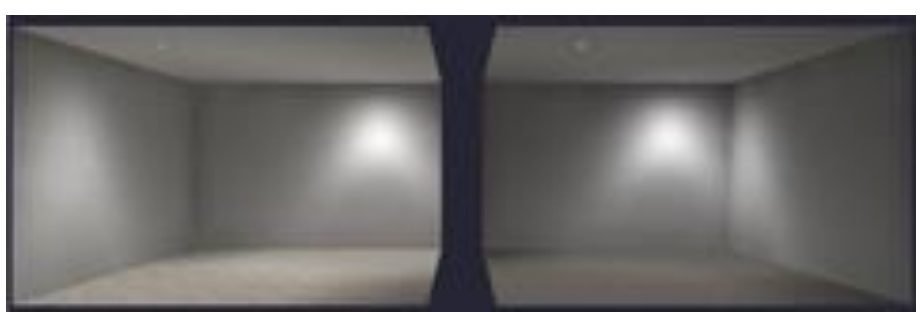

Figure 73: Carpet on left of $50 \%$, carpet on right is $20 \%$ using same texture.

\section{Pseudocolor with Scaling}

Pseudocolor provides a numerically accurate color representation of the calculated environment. Each luminance or illuminance value is assigned a unique color value ranging from blue (minimum value) to red (maximum value). This allows an alternative way to view the luminance or illuminance distribution in the environment without displaying numeric values.

A scale can be assigned to the image to discern precise illuminance or luminance information. Renderings from different lighting scenarios can be compared by setting an equivalent maximum point.

\section{Model Overlay}

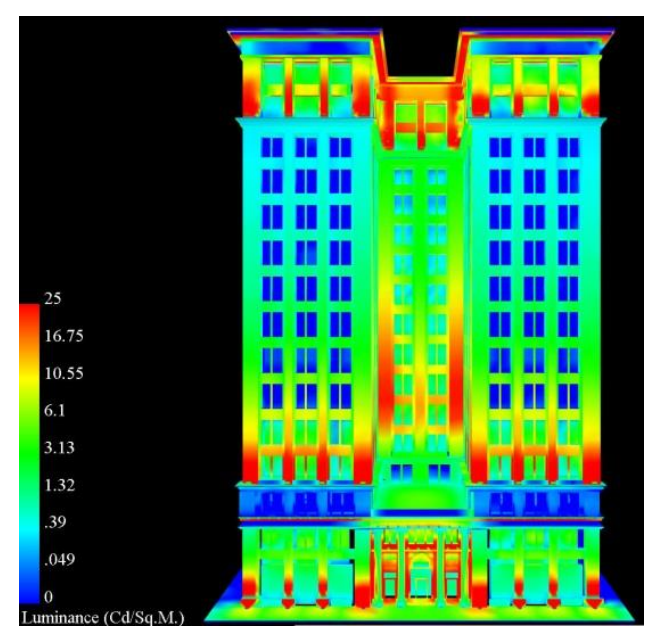

Figure 74: Mike Noon, Palindrome Lighting Design

Visualization is an indispensable tool in any designer's workflow, not only for presentation, but often more importantly, for constant evaluation of results as you work. AGi32 provides the ability to overlay the rendered model with imported CAD backgrounds, text, isolines and calculated values, creating a more effective frame of reference and clarity of results.

\section{Ray Tracing}

AGi32 provides a post-radiosity process ray tracing engine to enhance any single view to approach photorealism. Specular reflections can be rendered by assigning a specular component to appropriate surfaces. This allows materials such as glass, tile and mirror to appear realistic in a rendered view. Advanced techniques such as glossiness and soft shadows can also be applied. Raytracing can be applied to any single viewpoint or batched with multiple
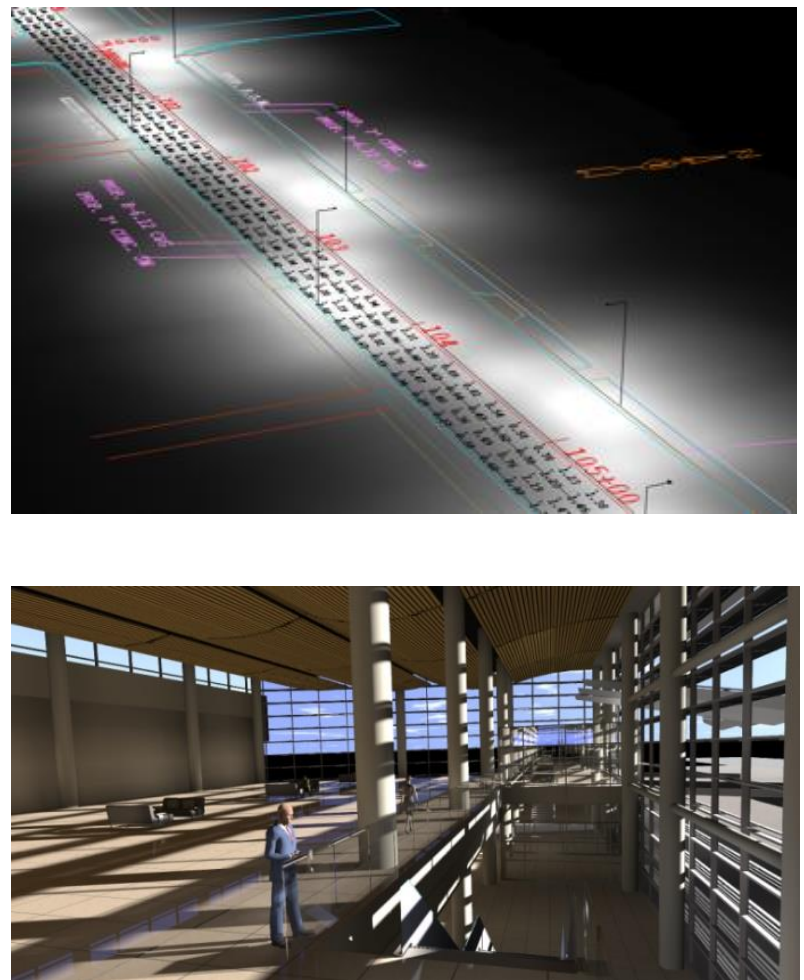

Figure 75: Paul Boken Mulvey \& Banani International viewpoints and be automatically saved as a JPG or BMP image. 


\section{Animation}

Any AGi32 rendering can be animated by recording a series of viewpoints while using AGi32's interactive viewing commands. The animation path is then computed with adjustable walk speed and pause capability. Animations can be created with multiple scenes, frame sizes and opening and closing frames. An interactive preview function makes it easy to create successful animations. It is also possible to ray trace all frames to make a truly professional production. The result is an $\mathrm{AVI}$ animation that can be viewed on any computer, independent of AGi32.

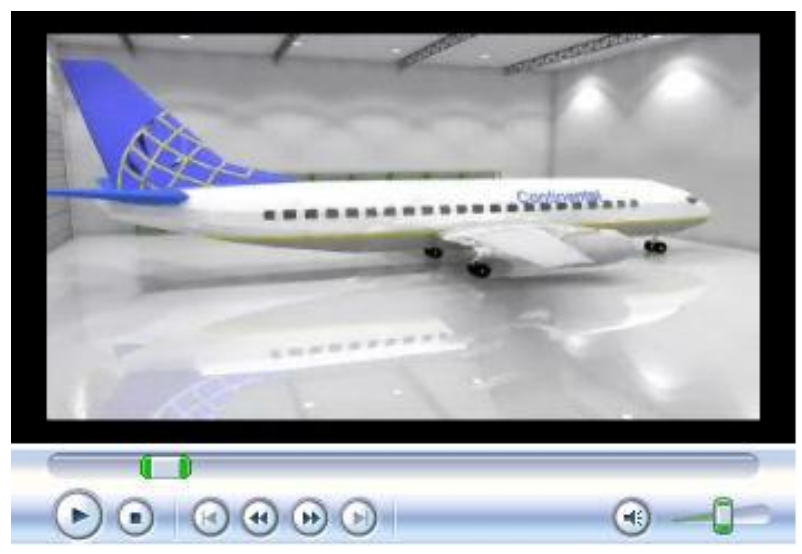

Figure 76: Peer Eric Moldvar, Eclairage Techno

\section{And More...}

\section{Presentation Output}

AGi32 can produce output in many ways. For example: anything you see in AGi32's Model construction mode can be printed in WYSIWYG fashion, and all calculations can be exported to DWG or DXF for integration with your CAD software. Renderings can be exported to single bitmap images (JPG, BMP) and can be sized independently of your display. Renderings can also be animated and saved as AVI movie files for playback independently on any computer. However, all of these methods aside, it is the AGi32 Page Builder function that provides the ability to produce printed or electronic output containing your choice of calculation and visualization views for a truly complete presentation.
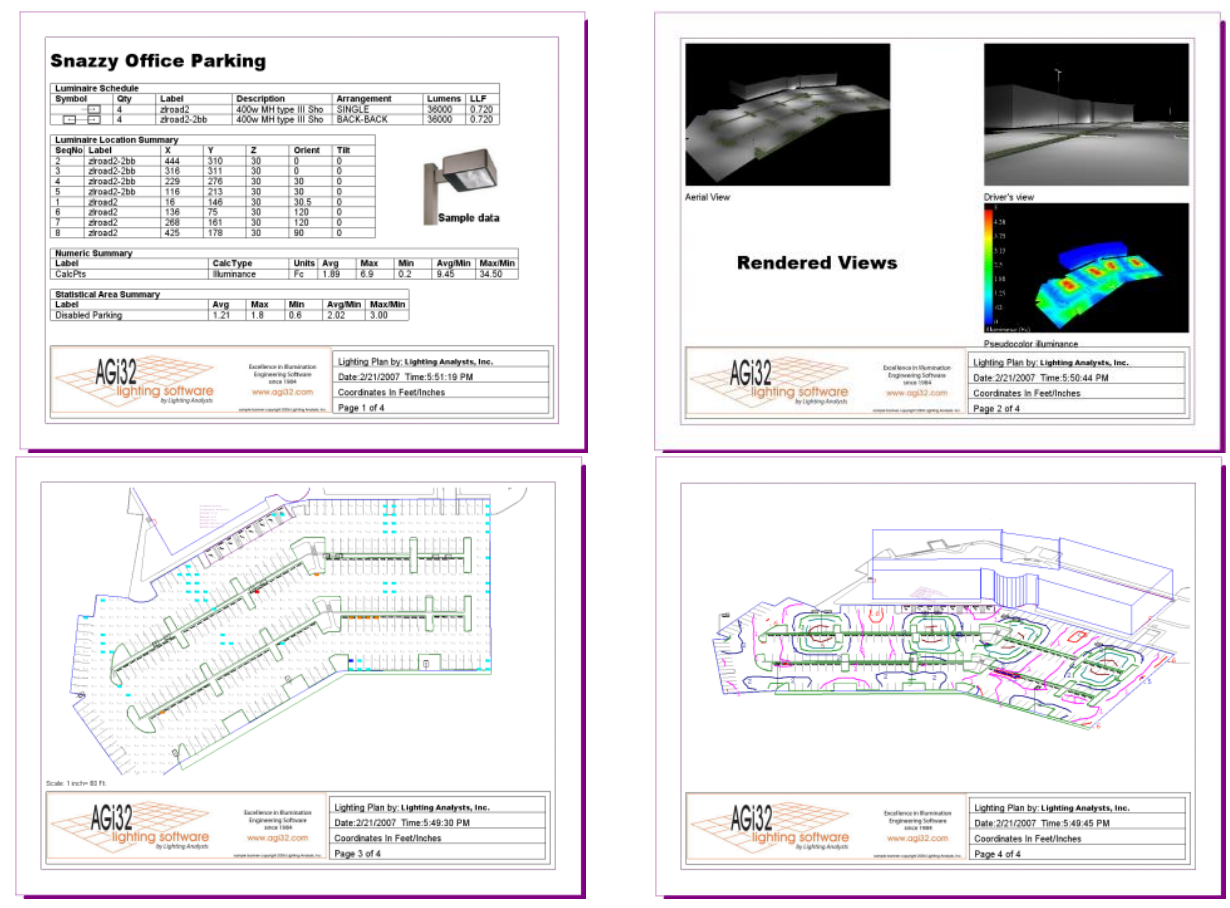

With Page Builder you can utilize a completely automated approach to output, or, select any media size and number of pages to hold your project presentation. Take a few minutes to create a series of master templates containing your logos and title blocks (bitmaps too) to be 
used anytime. Then call up a template and place your various point-by-point views, schedules, and visualizations on the various pages. You can also incorporate external files (TXT) for disclaimers, if required. When complete, either print/plot or export to PDF* or MDI. *PDF writer required.

\section{Daylight Study}

AGi32 can run complete daylight studies over multiple days and multiple hours per day in a single execution. Once a daylight study has been completed, the rendered images are written to the project folder to be viewed in sequence using Windows Preview or the tools of your choice.

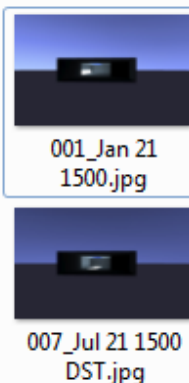

DST.jpg

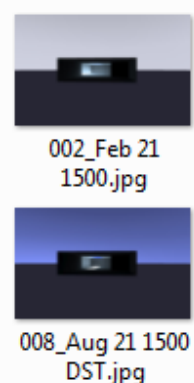

DST.jpg

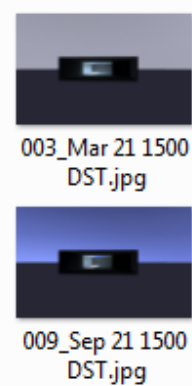

DST.jpg

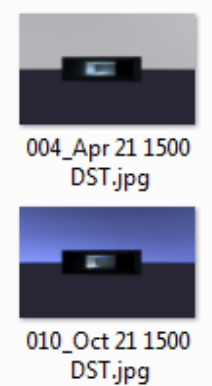

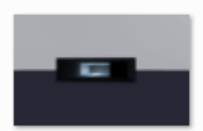

005 May 211500 DST.jpg

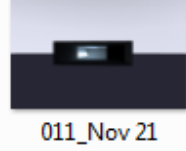

1500.jpg

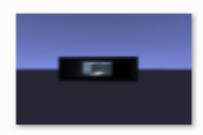

006_Jun 211500 DST.jpg

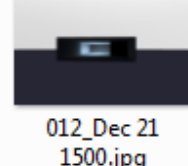

1500.jpg

Figure 77: Daylight Study Images

\section{Background Images}

AGi32 can import a series of JPG or PDF images to be used as a background for your lighting work. The images can be scaled, seamed together and faded to show underneath your lighting layout and calculations. This is immensely powerful for retrofit work as images can be captured in seconds from Google Earth, all you need is an address. Images can also be automatically added to the textures library to be used in renderings.
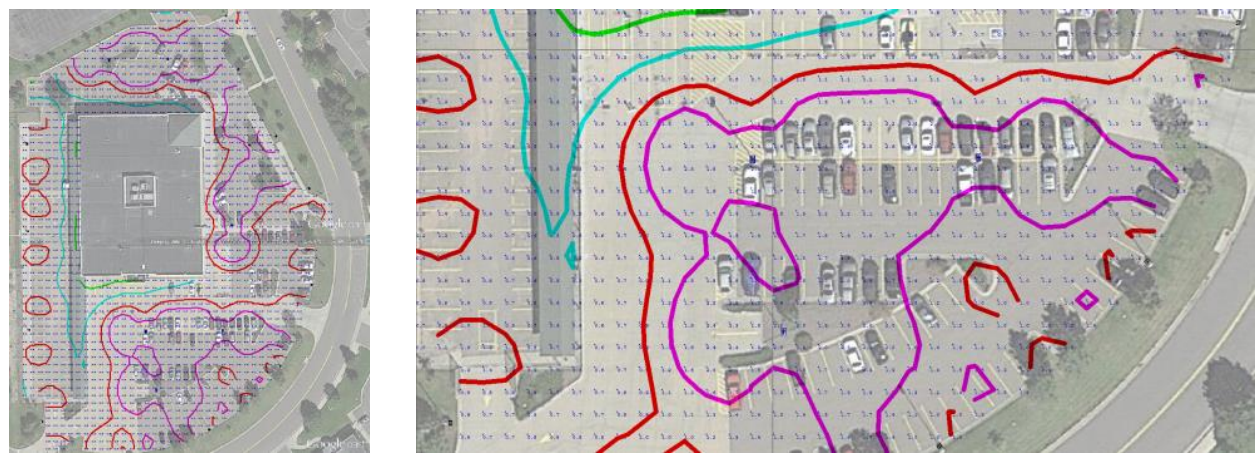

\section{Supplier and contact}

AGi32 is developed by Lighting Analysts (www.lightinganalysts.com).

An overview video is available on YouTube, courses can be found on the AGi32 Education Microsite. Online resources are provided at www.support.agi32.com or the main website.

Contact information: info@agi32.com or (303) 972-8852. 


\subsection{ElumTools}

by Chris Jackson, Lighting Analysts Ltd, UK and

Dave Speer, Lighting Analysts Inc, USA

The growth of BIM (Building Information Modeling) software is exploding, and in many architectural design and engineering firms, it is almost completely replacing CAD software for the purposes of architectural and building system design. To date, the industry standard illumination design software programs lack the ability to easily exchange information with models in the BIM environment. The reason for this is two-fold; current illumination software utilizes a complete environment approach to the calculation of illuminance which is burdened by the large size of the BIM model, and the complexity of exported geometry from BIM is beyond the needs of practical calculation of workplane or surface illuminance. With today's illumination design software not getting the job done, there exists a distinct need to quickly and accurately compute lighting results from electric and daylight sources within individual environments in a BIM model, and assimilate the results in a way consistent with the behavior of the BIM software.

ElumTools is a calculation Add-in used to predict the performance of electric lighting systems and daylight for any environment within an Autodesk $\AA$ Revit ${ }^{\circledR}$ project. With ElumTools, the need to utilize external software to compute illuminance from light sources placed in Revit is completely obsolete.

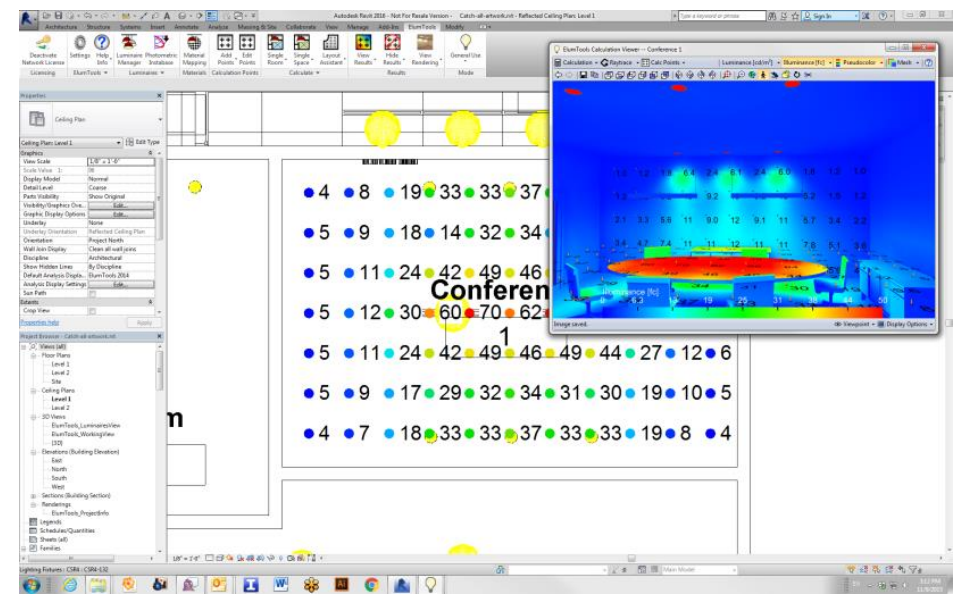

When ElumTools is installed in Revit, it appears with its own tab on the top menu bar. Selecting the ElumTools tab reveals the icons for the various ElumTools commands.

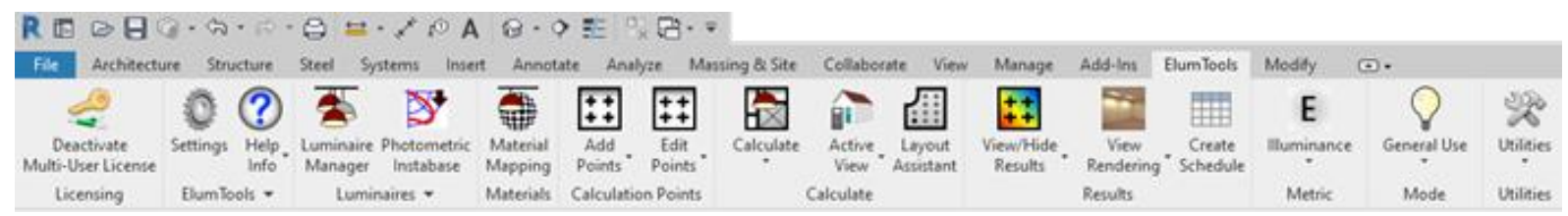




\section{ElumTools concept}

The entire concept of ElumTools as a Revit Addin is based around the ability to leverage content that is already present in the Revit model. Utilizing existing content from Revit allows the lighting software functionality to be simplified to only those tasks necessary for the accurate modeling of light.

The accurate calculation of illuminance on a workplane or surface requires the following components: surface geometry, surface reflectance/color, luminaire locations and luminaire photometry. ElumTools is able to extract

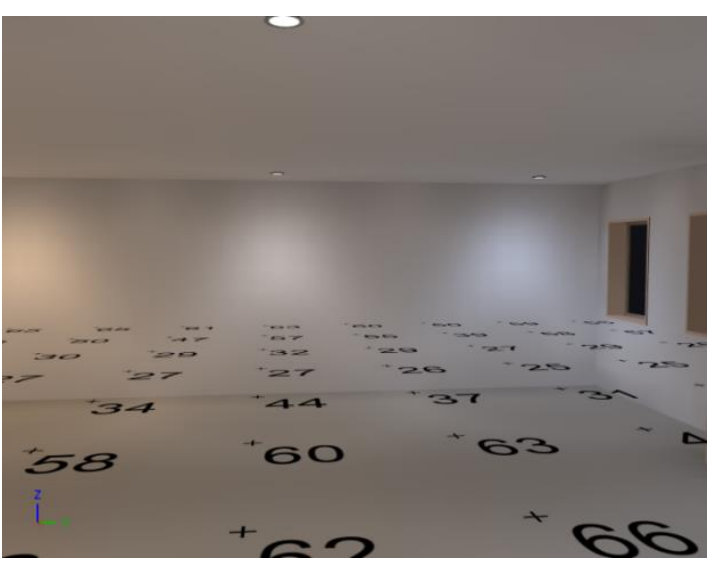
surface geometry from Revit using "Rooms", "Spaces", "Areas", "Filled Regions" and even "by View".

Surface reflectance and color can be interpreted from the Revit "Graphics Shading" property of the surface and "mapped" to a more suitable reflectance and/or color as necessary on a material basis, or by entire "Category" such as Ceilings, Walls and Floors. Luminaire families already present in Revit are recognized by ElumTools, and photometric file associations are easily created if not already present. The final step prior to computation is the assignment of calculation points to any surface or workplane to verify illuminance present from the Revit layout of luminaires. This is easily accomplished using ElumTools Calculation Points commands.

With these elements known, ElumTools has the information required to utilize the radiosity process to compute the selected geometry, present an interactive visualization depicting the luminance of all surfaces, and show the illuminance on the selected calculation point locations. Revit defined boundary representations (Rooms, Spaces, Regions, Areas, Views) can be computed alone or as a group if they contribute light to one another. The computed results are presented in an interactive visualization window. The pointby-point illuminance results can be seen in the visualization as well as directly in the Revit model Views or Sheets of choice. All statistics are available to Revit's scheduling tools for summary and inclusion in the BIM model.
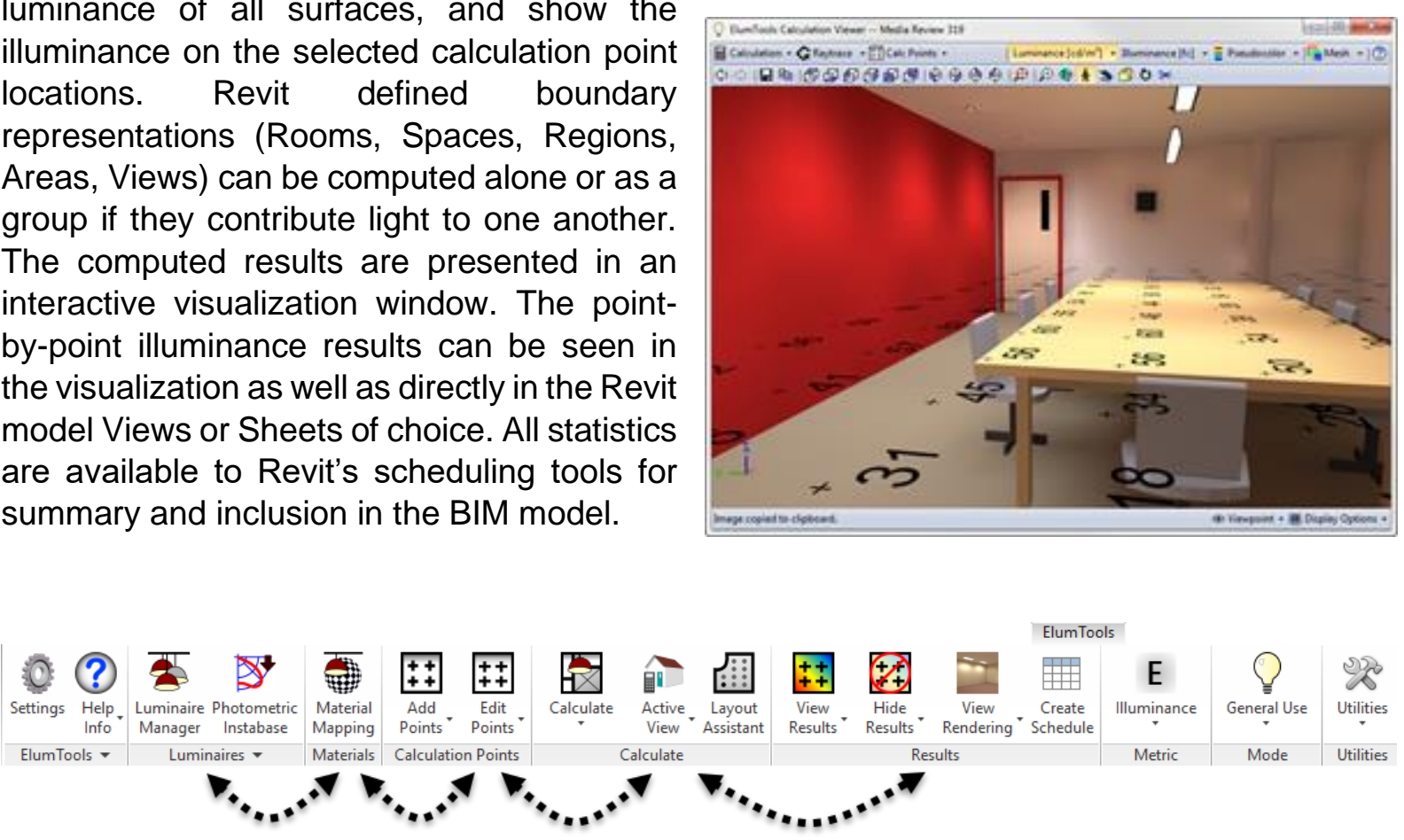

Figure 78: Typical workflow in ElumTools 
For the calculation of electric lighting scenarios, the ElumTools Luminaire Manager provides simple access to most necessary inputs for your luminaire families. Using the Layout Assistant, ElumTools can compute luminaire quantity to meet a specific light level (on the floor, workplane or calculation point surface) for any room, space, area or region.

Besides this classical mode for electric lighting scenarios, ElumTools additionally offers specific calculation modes for

- Emergency lighting,

- Horticulture lighting, and

- Daylighting.

Additionally, ElumTools can also render the correlated color temperature (CCT) of light sources, accurately simulate colored sources due to filters or otherwise, and ray trace your favorite viewpoints for higher quality visualizations.

The concept of computing the lighting results directly within the Revit environment using a boundary specific methodology fosters a fast and efficient workflow removing the long calculation times associated with the whole-environment approach of external software. Designers can utilize the software as a design tool on an iterative basis as needed. Point-bypoint results provide validation of required lighting criteria, and interactive draft visualizations yield an understanding of the lighting system only possible with radiosity rendering.

Unlike many of today's all-encompassing lighting simulation programs, the ElumTools software is exceptionally intuitive, streamlined and approachable. By design, the software can be productive for any Revit user with basic lighting knowledge, and very little if any training is required.

\section{Supplier information}

ElumTools is developed by Lighting Analysts, learning videos are available at www.lightinganalysts.com. 


\subsection{DALEC}

by David Geisler-Moroder, Bartenbach, Austria

DALEC (Day- and Artificial Light with Energy Calculation) [1, 2] is an online concept evaluation tool for architects, building engineers, lighting designers and building owners. Although easy to use and its short calculation times, the software accounts for the complex thermal and light processes in buildings and allows a simple evaluation of heating, cooling and electric lighting loads. Location and orientation of the facade, climate data, thermal and photometric properties of the room, different shading and electric lighting systems are taken into account in the calculation.

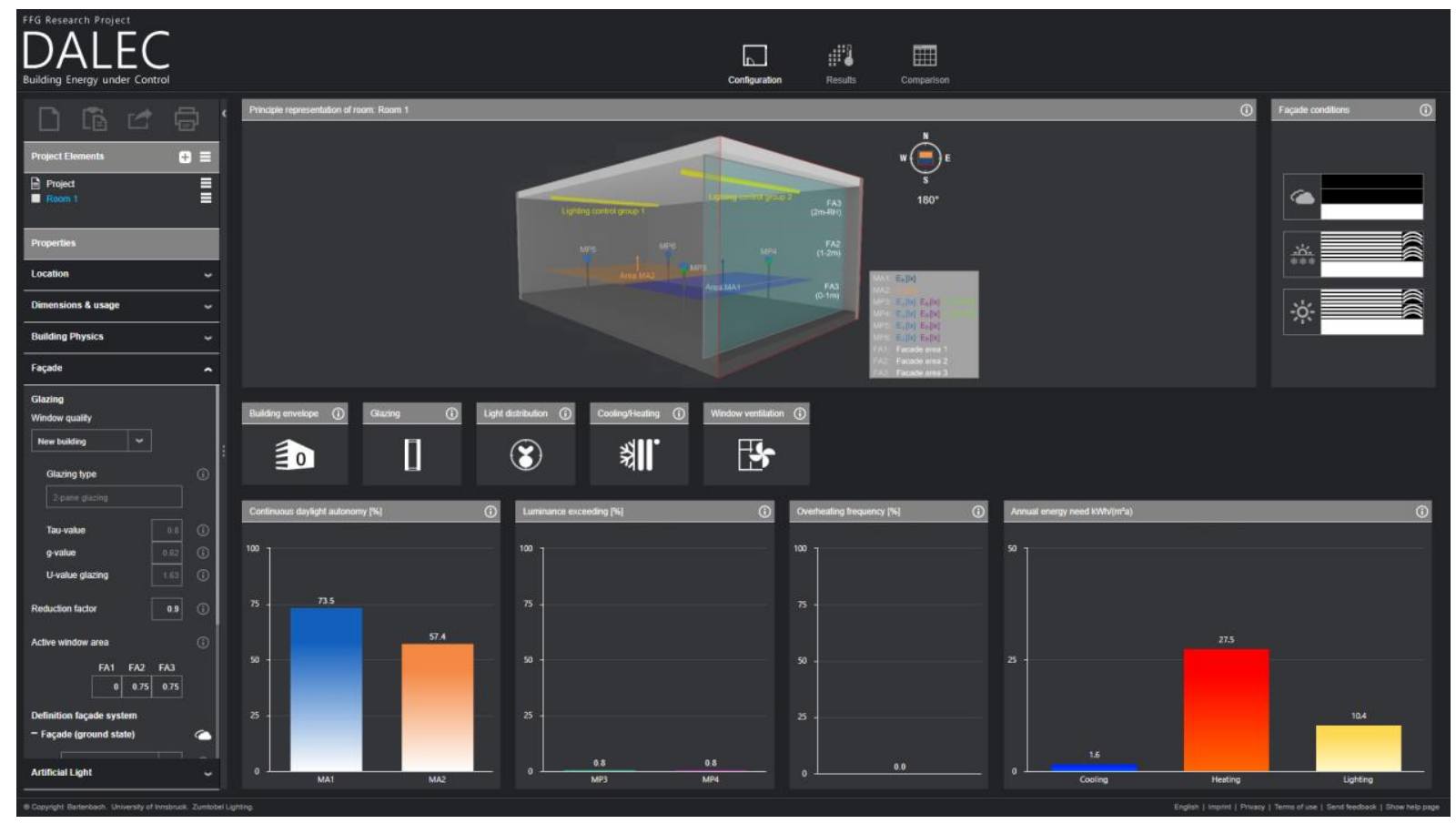

Figure 79: User interface of the DALEC web-tool (www.dalec.net).

Not only energy, but also user behavior is considered (e.g. in terms of overheating and glare protection) and visual and thermal comfort is evaluated. This innovative, holistic approach facilitates and accelerates the design of sustainable and energy-efficient buildings for new structures as well as for refurbishments. The energetic optimization of façade and electric lighting solutions is highly simplified, enabling building design with reduced energy demands.

The motivation behind the development of DALEC is to simplify the handling of the complexity coming along with the interaction of the thermal and lighting energy performance aspects. Furthermore, the simulation time must be less than a few seconds to allow optimizations of different façade situations. To realize that, the sophisticated lighting simulation components are pre-calculated for the most common room setups.

With this approach no simulation expertise is necessary for the tool user and calculation times are very fast. This allows optimizations of the façade settings, the artificial lighting installation and the thermal parameters of a building in an early design phase. It is not intended that DALEC replaces the existing, sophisticated energy and lighting simulation tools, but it will allow an accurate estimation of the influence of different façade setups on the electric lighting installation and different control strategies. 


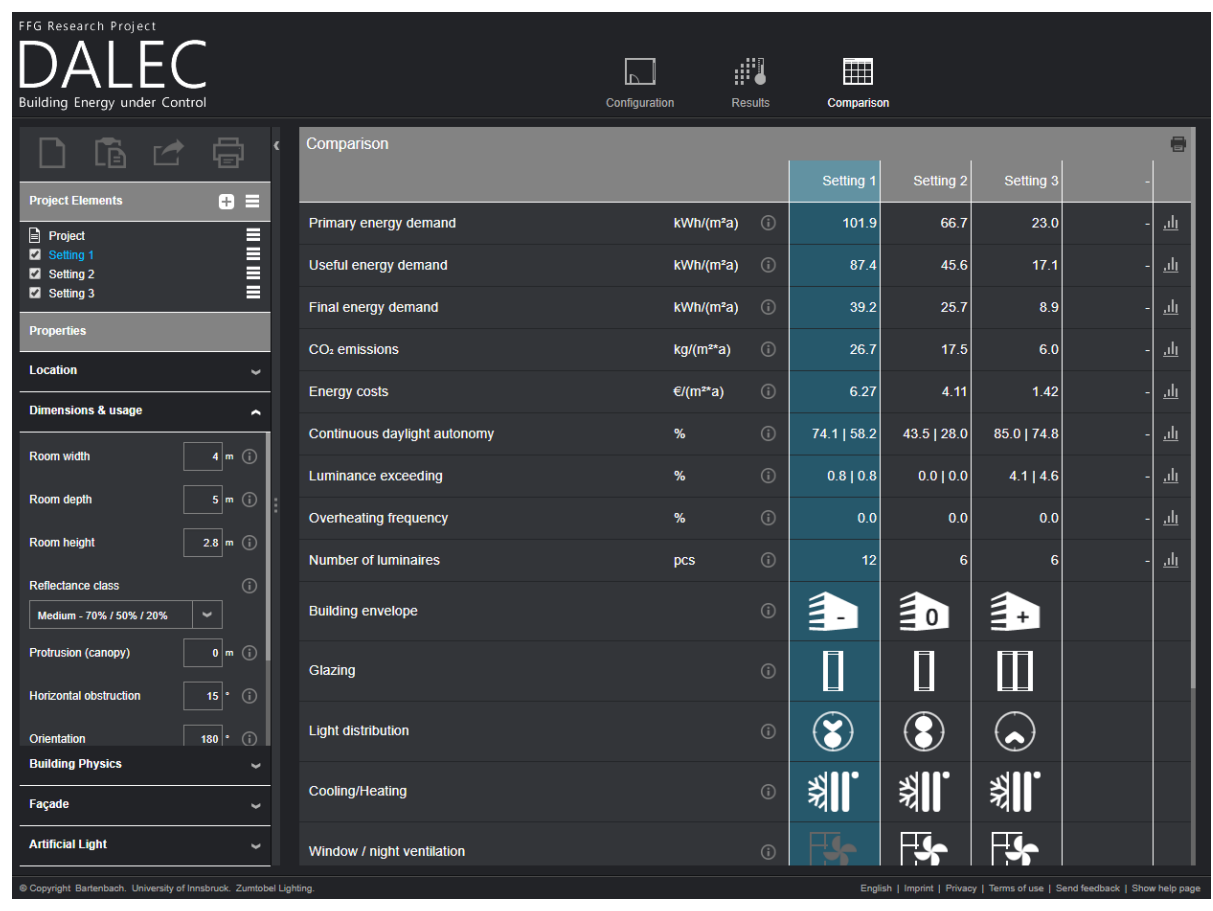

Figure 80: Direct comparison of various design options.

The software DALEC has been developed in a cooperation between the companies Bartenbach $\mathrm{GmbH}$ and Zumtobel Lighting $\mathrm{GmbH}$ together with the University of Innsbruck.

\section{DALEC calculation workflow}

Due to the consideration of the interaction of daylight, artificial light and thermal aspects, the tool is divided into five separate modules (climate, daylight, artificial light, thermal, and occupant and control). This distribution allows a simplified but realistic, physically correct approach to the interaction of the different phenomena.

The principle of the data-flow and data-processing, as well as the input and output values of each module are shown in the flow chart below. This process is executed for each time step, that is, every hour of the year.

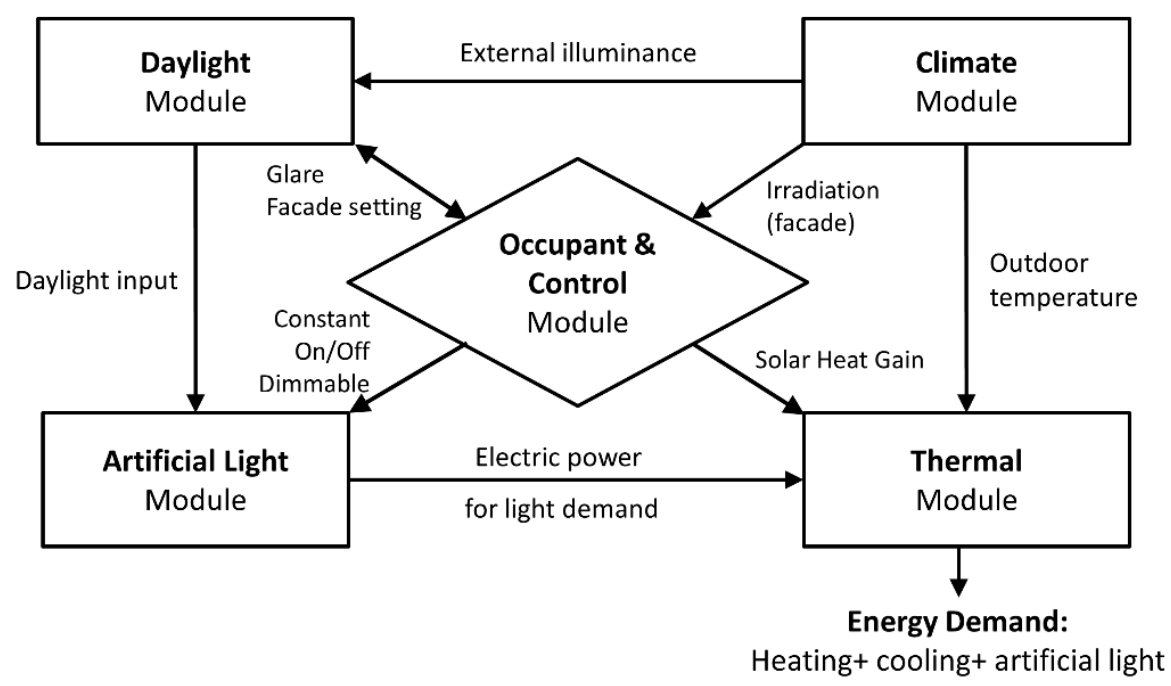

Figure 81: Schematic workflow of DALEC 


\section{Climate Module}

The climate module stores more than 3000 IWEC2 (International Weather for Energy Calculation), TMY3 (Typical Meteorological Year) and CWEC (Canadian Weather Year for Energy Calculation) weather data sets distributed worldwide [3] .Three climatic parameters from the weather files are required for the calculation: (i) diffuse and direct horizontal illuminance, (ii) diffuse and beam irradiance, and (iii) outdoor temperature. The climate module imports these data from the weather file prepares these for the other modules. The only input necessary for the daylight module is the direct and diffuse horizontal illuminance. The vertical irradiance at the façade plane is used in the occupant and control module as a trigger for setting of the sun shading system and for calculation of solar heat gains, which is the required input for the thermal module. Therefore, the equations from the DIN 5034 [4] are used for calculating the sun position and thus the direct vertical irradiance on the façade. Furthermore, the thermal module uses the outdoor temperature, which is delivered from the climate module for each time step as well.

\section{Daylight Module}

The daylight module is responsible for the calculation of the annual daylighting levels of the analyzed room. An adapted and simplified daylight coefficient approach is used, which has been derived from the daylight coefficient model for dynamic daylighting simulations [5]. Factors for both parts of daylight - the direct sunlight and the diffuse skylight - are precalculated for all configurations of room and façade system settings. Based on a parametric study [6], the decisive parameters influencing the daylighting in a room were elaborated and the sampling points for the pre-calculations defined.

To allow the usage of complex fenestration systems and to enable an efficient pre-calculation of the factors, the three-phase method [7] based on the validated simulation software RADIANCE $[8,9]$ is used. The transfer of light through the façade system is described by the BSDF of the system. This function characterizes the geometrical-optical properties for transmission and reflectance of a system, and thus enables the consideration of CFS in RADIANCE. We use the BSDF discretization proposed by Klems, that is, a subdivision of the hemisphere into 145 patches corresponding to approximately equal projected solid angles [10].

Currently, the user can select from a number of pre-defined daylight systems and corresponding control strategies. An interface for user-inputs to load individual BSDFs is under development.

\section{Artificial Light Module}

The artificial lighting module is responsible for calculating the hourly electric power of the selected artificial lighting solution, taking into account the hourly daylight entry and the selected control strategy for the luminaires. The calculation of the required number of luminaires and maintained illuminance is based on the lumen efficiency methodology [11]. For the luminaire configuration, there are five basic light distribution curves (LDC) available, which are distinguished by direct and indirect components. The direct and indirect LDCs can be combined with each other and can be adjusted in their weighting. Thus, there are 60 different possible combinations of luminaire light distributions to choose from. Alternatively, the user can import own luminaire data in the Eulumdat $\left({ }^{*}\right.$.Idt) or the Zumtobel $\left({ }^{*} . \mathrm{zp}\right)$ format.

The user can select from three different control strategies for the electric lighting: (i) daylight dependent dimming, (ii) daylight dependent On/Off, or (iii) always on. For the former, the hourly dimming values of the luminaire groups are calculated based on the current daylight entry. For every time step, the necessary artificial light supplement is adjusted to achieve the average target illuminance. The spillover portions of the luminaire groups are considered on the respective measurement areas. In the case of switchable luminaires (On/Off control), the tool evaluates whether the target illuminance can be achieved by daylighting alone. If this is not the case, the respective lighting group is switched $100 \%$ on. 
From the calculated hourly dimming levels or the switched-on running hours, the determined number of luminaires, the specified connected load and the selected lamp dimming characteristics, DALEC determines the hourly electric power requirement of the artificial lighting solution. This is used as input by the thermal module.

\section{Occupant and control module}

The occupant and control module combines the control strategies for the façade, the artificial lighting and the heating and cooling, as well as the behavior of the occupants.

Using DALEC, it is possible to define three different façade setups in order to consider several conditions. The setting of the first façade describes the situation when neither glare nor sun protection is needed, that is, just glazing. The description of the second façade defines a situation in winter where glare protection is necessary, for example, glazing + internal screen. By defining the situation of a third façade, glare and sun protection can be set for the summer, for example, external venetian blind + glazing. Depending on which period (cooling or heating) the current time step takes place and on whether or not glare or sun protection is necessary, the respective façade situation is chosen. The case of glare can be detected by the exceeding of a luminance threshold at the inner side of the façade. The user can define this input value, and thus different room usages can be investigated, for example, reading and meeting.

To avoid overheating of the building, a control strategy for façades is implemented. A shading system is often used where the summertime radiation limit on the façade is exceeded. Using DALEC, it is possible to set a threshold in order to activate the sunshade (third façade definition) in the same manner. This module also sets the inputs for the artificial light where the three abovementioned control settings are possible. The electric light strategies imitate a simplified occupant behavior.

\section{Thermal module}

With a dynamic building model, a realistic hourly building behavior is achieved [12]. Therefore, the thermal module consists of a simplified model and allows a quick and realistic evaluation of performance according to building physics. It is based on the simple hourly method of the standard EN 13790 [13], which can be described in a resistance-capacity-model.

For the calculation an hourly time step is used, and the input data vary each hour according to the climate data. The mass temperature from the previous time step is used as the initial value for the next time step. The output values are therefore the internal air temperature and the heating and cooling demand, under consideration of an internal minimum and maximum temperature range. If no active cooling system is installed, the overheating frequency can also be calculated.
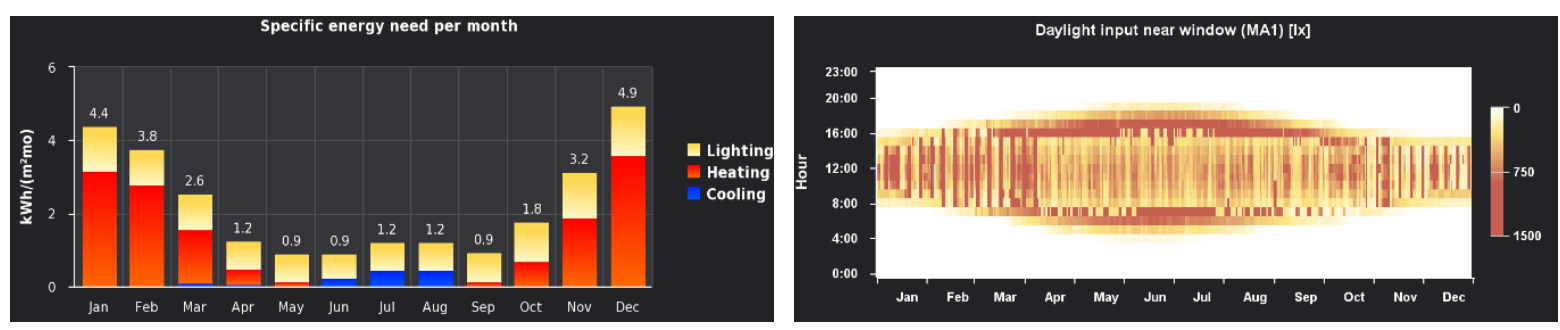

Figure 82: Exemplary output showing monthly energy needs and hourly daylight availability over the year 


\section{References}

[1] DALEC - www.dalec.net, Online concept evaluation tool, retrieved: October 31, 2018

[2] M. Werner, D. Geisler-Moroder, B. Junghans, O. Ebert, W. Feist, DALEC - A Novel WebTool for Integrated Day- and Artificial Light \& Energy Calculation, Journal of Building Performance Simulation, Volume 10, Issue 3, 2017.

[3] D. Crawley, J. Hand, L. Lawrie, Improving the Weather Information Available To Simulation Programs, Sixth International IBPSA Conference, Vol. 2, 529-536, 1999.

[4] Deutsches Institut für Normung e.V. 1985. DIN 5034-2 Tageslicht in Innenräumen.

[5] D. Bourgeois, C.F. Reinhart, G. Ward, Standard Daylight Coefficient Model for Dynamic Daylight Simulations, Building Research and Information 36 (1): 68-82, 2008.

[6] M.Werner, R. Pfluger, W. Feist, D. Geisler-Moroder, Tageslicht-Parameterstudie mit Hilfe einer Matlab-Radiance-Koppelung, IBPSA - BauSim 2012, Berlin, 2012.

[7] G. Ward, R. Mistrick, E.S. Lee, A. McNeil, J. Jonsson, Simulating the Daylight

Performance of Complex Fenestration Systems using Bidirectional Scattering Distribution

Functions within Radiance, Leukos, Journal of Illuminating Engineering, 7(4), 2011.

[8] G. Ward, R. Shakespeare, Rendering with RADIANCE - The Art and Science of Lighting Visualization, 1998.

[9] D. Geisler-Moroder, A. Dür, Validation of Radiance against CIE171:2006 and Improved Adaptive Subdivision of Circular Light Sources, $7^{\text {th }}$ International RADIANCE Workshop, Fribourg, 2008.

[10] J.H. Klems, J.L. Warner, G.O. Kelley, A New Method for Predicting the Solar Heat Gain of Complex Fenestration Systems, Technical Report, Lawrence Berkeley Laboratory, 1995.

[11] LiTG-Publ. Nr.3.5, Projektierung von Beleuchtungsanlagen nach dem Wirkungsgradverfahren, Berlin, 1988.

[12] W. Feist, Thermische Gebäudesimulation - Kritische Prüfung unterschiedlicher Modellansätze, 1994

[13] Austrian Standards Institute, ÖNORM EN ISO 13790 - Energieeffizienz von Gebäuden, Berechnung des Energiebedarfes für Heizung und Kühlung, 2008. 


\subsection{DIALux}

by Daniel Witzel, DIAL, Germany

DIAL develops the world's leading software for planning, calculation and visualization of light for indoor and outdoor spaces, DIALux. With a community of over 700000 users, the lighting design tool is available in 25 languages and is free for the user. Renowned luminaire manufacturers offer digital product data for planning in DIALux. The software makes professional lighting design easier and accessible to everyone. As a platform and tool, it connects planners and manufacturers all over the world. DIALux is available both as a desktop version and as a mobile app for tablet computers and cell phones.

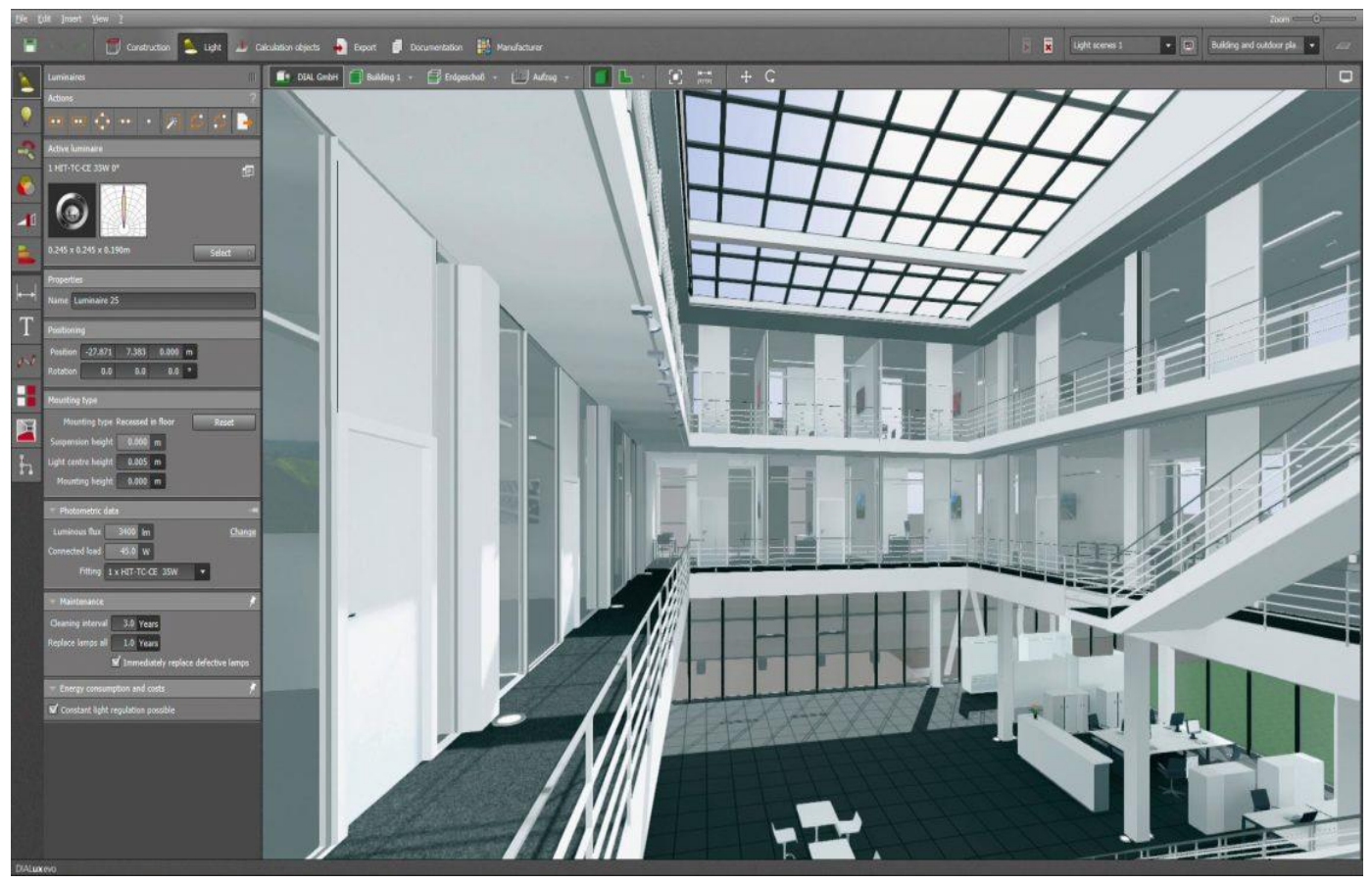

Figure 83: DIALux evo user interface

The current version DIALux evo 8 offers the possibility to simulate lighting solutions of entire buildings. Interior and exterior effects are calculated simultaneously, so there is an exchange between building interior and exterior. But also individual rooms and smaller areas can be calculated quickly and easily. By allocating room and application profiles the planner receives lighting proposals according to current standards such as EN 12464 parts 1 and 2. All required photometric values and data sheets are available in the documentation. The road lighting calculation is according to EN 13201.

The calculation of daylight uses the real building geometry and also takes light directing facade systems into account. Illuminance, daylight factor and the effect of direct sunlight are calculated. The calculation is based on CIE sky models.

DIALux offers interfaces for several $C A D$ programs as a basis for the lighting design. It supports IFC, STF, JPG, PNG, BMP, DWG and DXF format. If the building model is not available as a BIM model, the design is done by simply tracing the geometry from the $2 \mathrm{D}$ plans with numerous tools. 
Luminaires can be imported via the freely available catalogues from the manufacturers or via the file formats ULD, LDT, IES, CIB and LTLI. DIALux imports façade elements via the open interface ODLS.

With an extensive texture catalogue and an integrated raytracer, sophisticated and representative visualizations can be generated and integrated into the documentation. 


\subsection{DIAL+ lighting}

by Bernard Paule, Estia SA, Switzerland

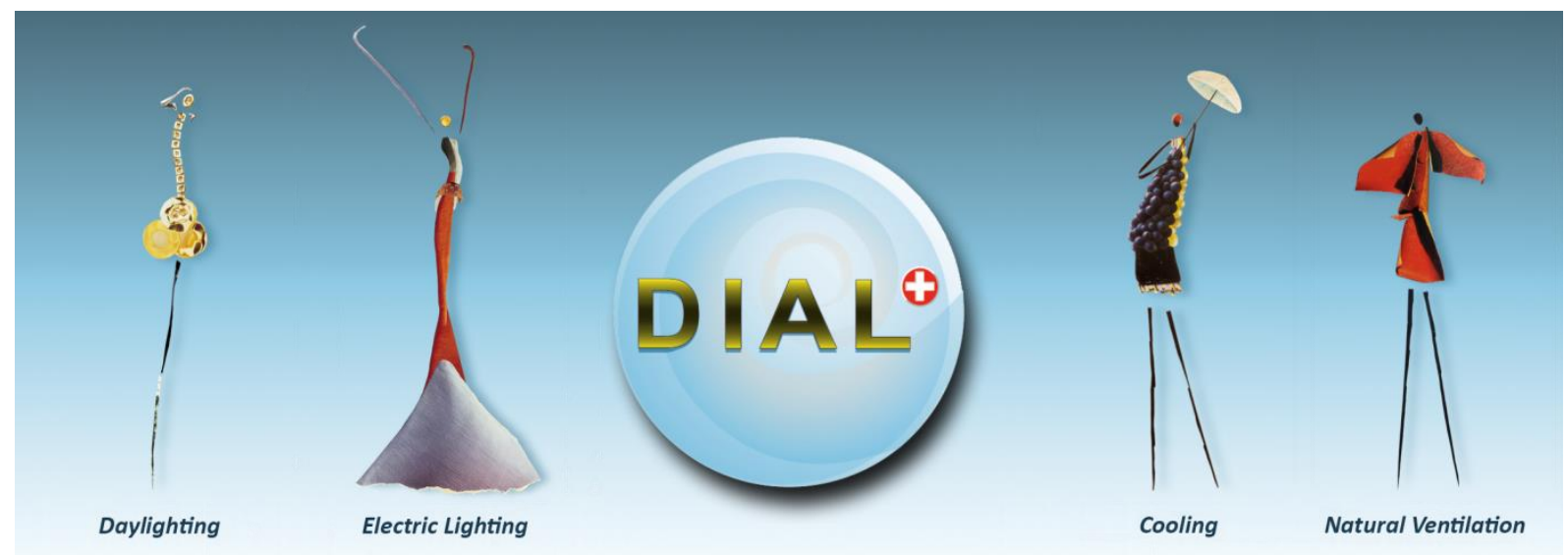

Figure 84: Illustration of the 4 simulation modules of DIAL+, CEstia

The DIAL+ suite (www.dialplus.ch) has been jointly developed by Estia SA and the Swiss Federal Institute for Technology, Lausanne (LAURE-EPFL). DIAL+ is distributed by Estia SA, Lausanne (dial@estia.ch). The last released version is 2.6. This software suite is composed of two simulation modules dealing respectively with:

- Daylighting \& Electric Lighting: DIAL+Lighting

- Dynamic thermal simulation \& Natural ventilation: DIAL+Cooling

DIAL+ is available for Windows and Mac OS X. There are five language options: English, French, German, Italian and Spanish. The user guide is available in English and French.

\section{Functions}

DIAL+ allows to either launch lighting simulations (Radiance $\left.{ }^{\circledR}\right)$ or to calculate the thermal and cooling loads on the room scale.

The lighting module allows producing reports that include the following results:

- Daylight factor values (DF)

- Diffuse Daylighting Autonomy values (DDA)

- Spatial Daylight Autonomy (sDA)

- Useful Daylight Illuminance (UDI)

- Autonomy for Minergie-ECOß (Swiss)

- Illuminance values due to electric lighting

- Annual lighting electricity consumption (SIA 380/4, Minergie®)

- Sunpath diagram including outdoor obstructions

- Shading studies (sunshine factor, viewed sky fraction)

- EN-17037: daylight provision, sunlight exposure, horizontal sight angle

The cooling module gives access to the following results:

- Heating \& Cooling loads (EN 15251, EN 15255, EN 15265, ISO 13791, SIA 382/1, SIA $382 / 2)$

- Air flows due to natural ventilation (Cockroft model).

The lighting module of DIAL+ has been validated against the following standards:

- CIE 171:2006 "Test Cases to Assess the Accuracy of Lighting Computer Programs". 
The cooling module of DIAL+ has been validated against the following standards:

- ISO-13792: 2004, "Thermal performance of buildings - Calculation of internal temperatures of a room in summer without mechanical cooling - General criteria and validation procedures".

- EN-15255: 2007, "Energy performance of buildings - Sensible room cooling load calculation - General criteria and validation procedures".

- EN-15265: 2008, "Energy performance of buildings - Calculation of energy needs for space heating and cooling using dynamic methods - General criteria and validation procedures"

\section{Design Stage, users}

DIAL+ is very adapted to the optimization stage of the design process. Its speed and simplicity allow realizing very quickly parametric studies and comparing the different variants of a given facade.

The interface was designed so that a non-expert user can easily describe all the room parameters and it can thus be used either by engineers or architects. It is also very well suited for educational purposes. However, the use of all the features (lighting and thermal) assumes that the user has a minimum educational background regarding building behavior.

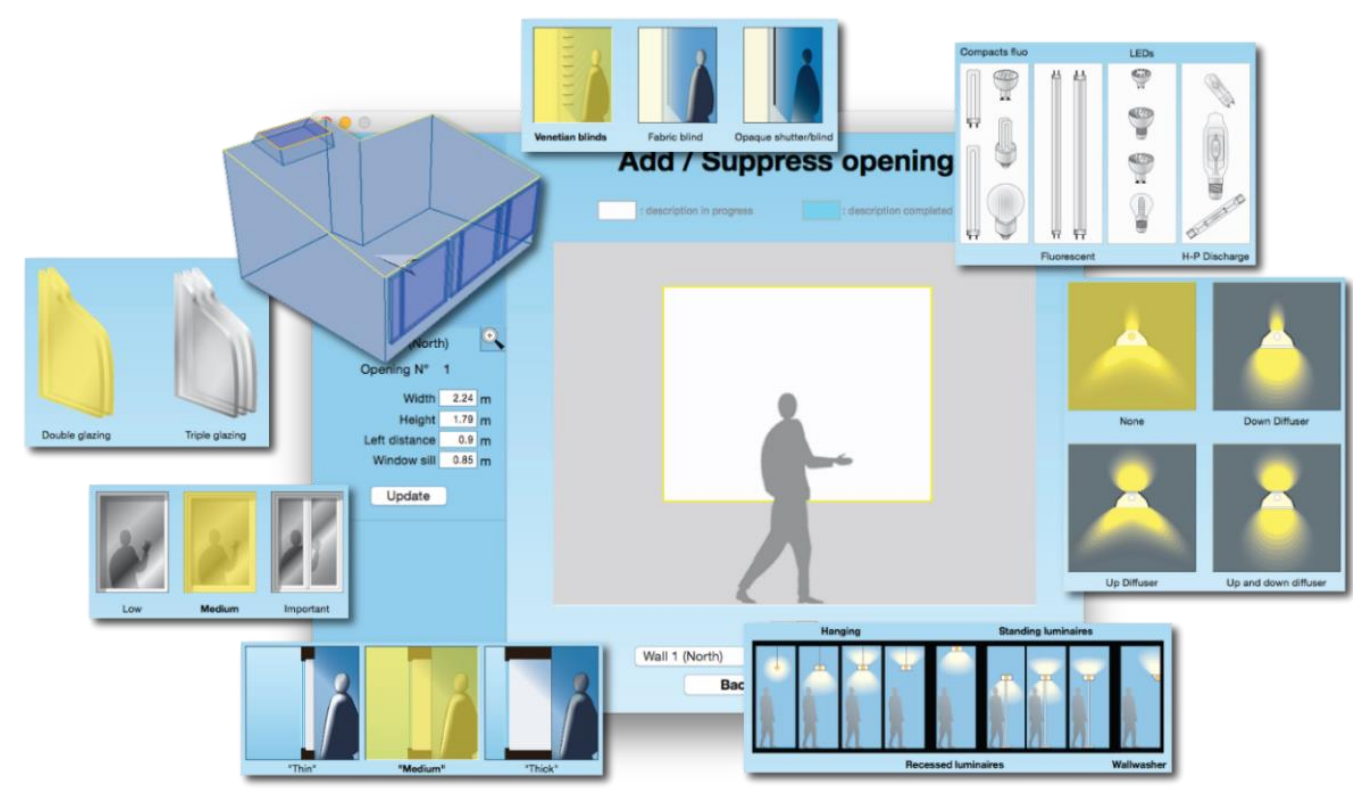

Figure 85: Illustration of the input parameters aiming to facilitate the room description

\section{Description Procedure}

DIAL+ includes a simplified 3D modeler dealing with the description of rectangular, L-shape or trapeze rooms fitted with horizontal, mono-pitch or ridge roofs. The complexity of the internal geometry may be supplemented by the addition of opaque or transparent objects. The average time requested to describe all the parameters of a typical room requires less than 10 minutes. 


\section{Results}

The lighting simulations are performed with Radiance (Three Phase method for dynamic simulations). The results are displayed with 2D maps and graphs (DF, Autonomy, Illuminance, etc.) on the work plane or on the walls.
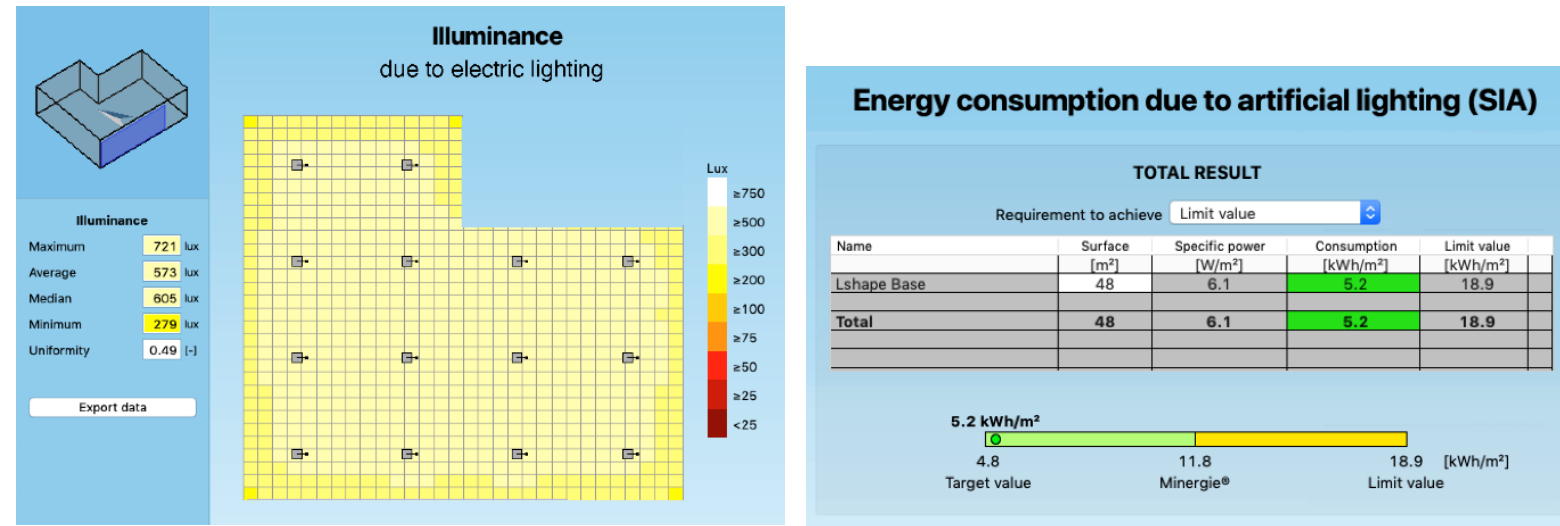

Figure 86: Screenshots of typical results obtained for electric lighting simulation

(Left: illuminance values on the work plane;

Right: Energy consumption due to electric lighting (SIA 387/4).
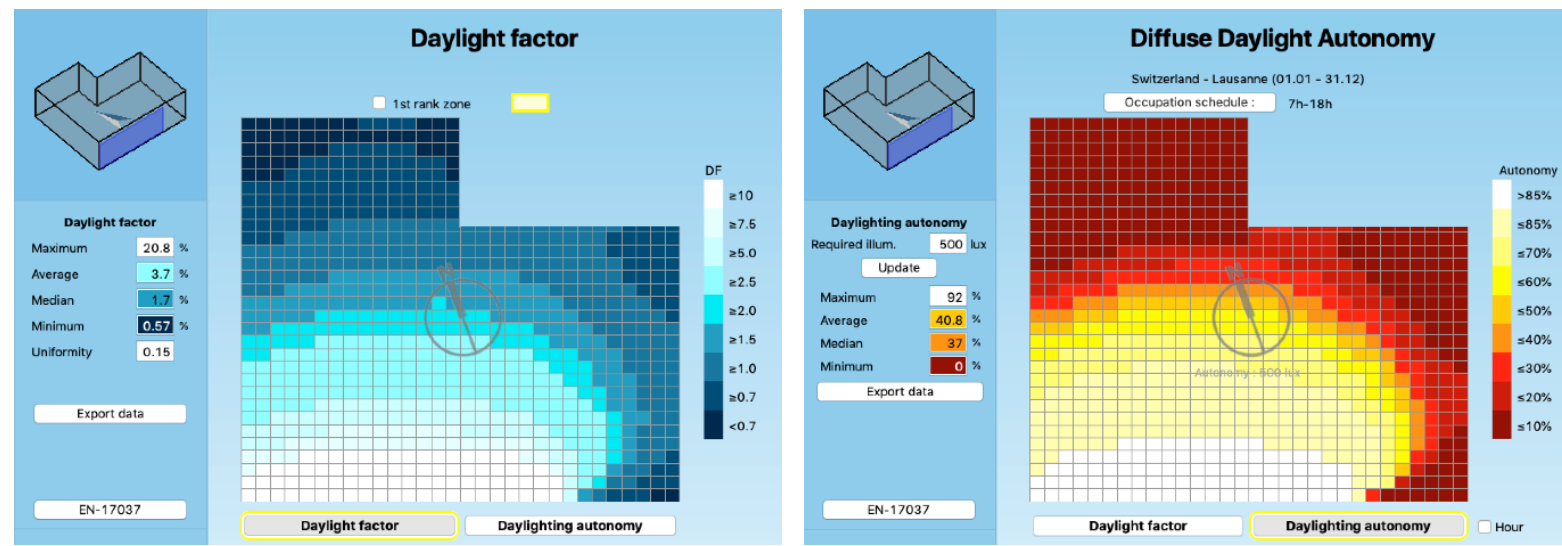

Figure 87: Screenshots of two typical lighting simulation results from static simulations with DIAL+ Lighting (Left: Daylight factor values on the work plane; Right: Diffuse Daylight Autonomy).
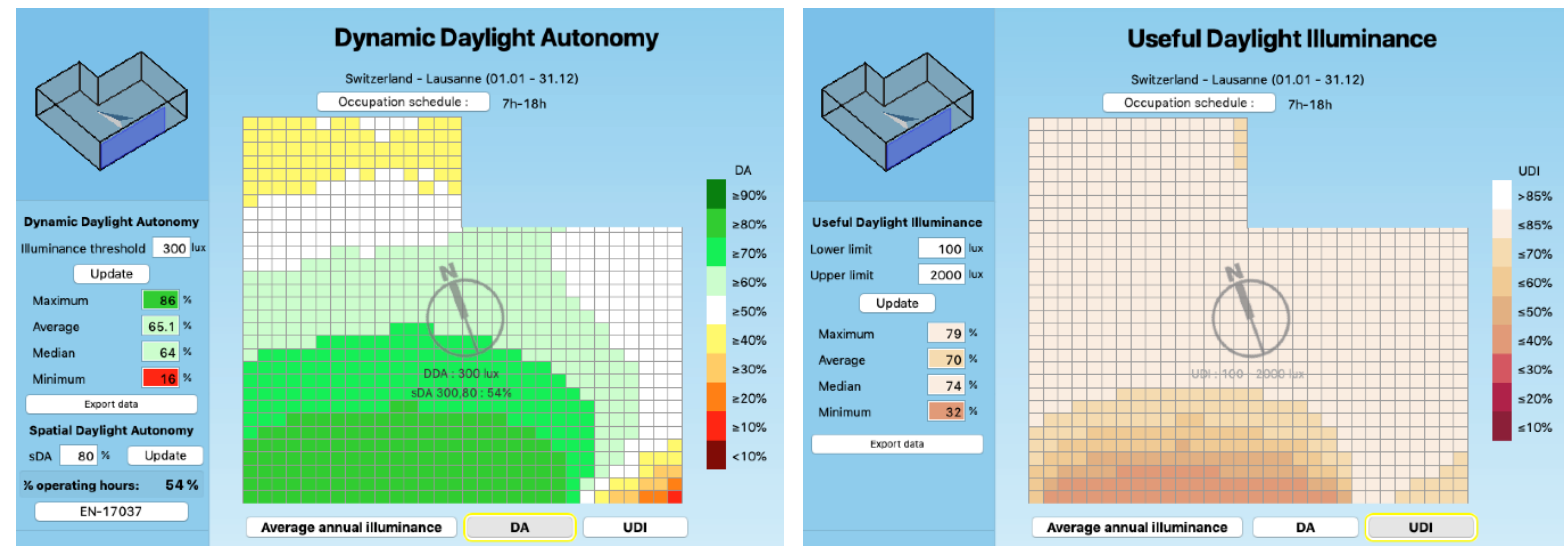

Figure 88: Screenshots of two typical lighting simulation results from dynamic simulations with DIAL+ Lighting (Left: Spatial Daylight Autonomy, Right: Useful Daylight Illuminance). 
The last version of DIAL+ also embeds EN-17037 calculations. Among the results dedicated to this Daylighting European Standard, one can mention:

- Daylight Provision (median and minimum values for both simplified and detailed calculation methods),

- Sunlight Exposure,

- Horizontal Sight Angle.
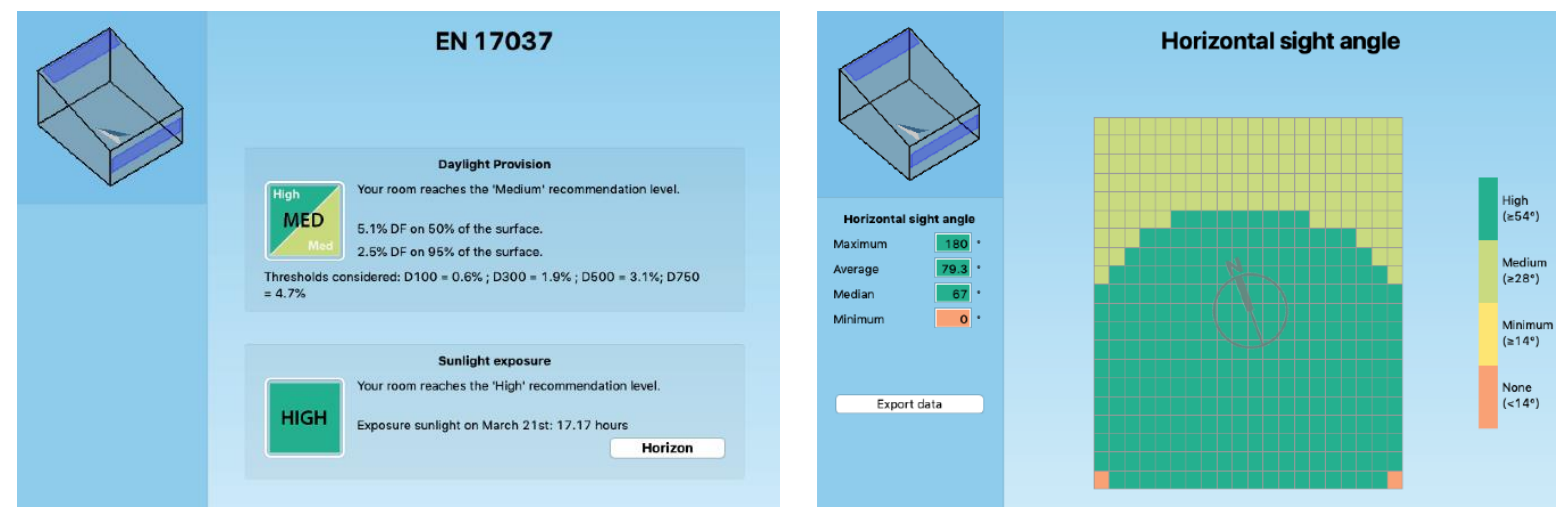

Figure 89: Screenshots of the EN-17037 evaluation (Left: ranking of the Daylight provision and sunlight exposure; Right: horizontal sight angle from each point of the room).

\section{Import/export}

There are no possibilities to import models from existing CAD systems. However, the interface of DIAL+ allows the user to very easily and quickly describe a project without being a specialist.

For electric lighting, it is possible to import existing luminaires files (.Idt).

Weather data as well as utilization \& occupation profiles or specific walls composition can be imported as text files.

After simulation, DIAL+ displays the result output optionally as graph, tables and temporal maps. The final reports containing all information about the room model and users' function can be printed or edited as .pdf files.

\section{DIAL+ Heavy users}

As mentioned before, the DIAL+ suite also allows to handle the thermal aspects.

DIAL+ heavy users thus have the opportunity to examine the lighting behavior of a given room, but also to quantify the solar gains, the heating and cooling needs, and the potential for natural ventilation.

This is our daily practice in Estia, analyzing the projects in which we participate with all the features of DIAL +, in order to give the best possible contribution to the designers from the early stages of design. 


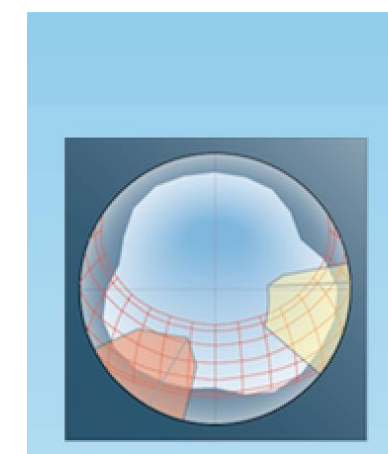

Horizon

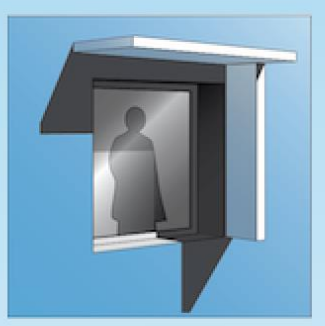

Shading study

\section{Evaluation}

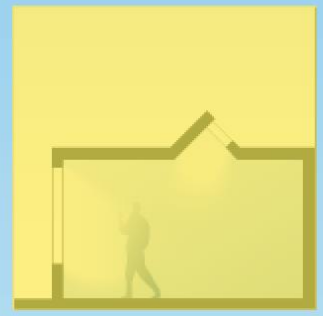

Daylighting

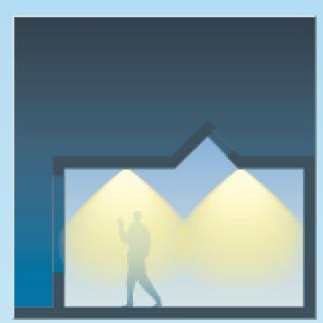

Artificial lighting

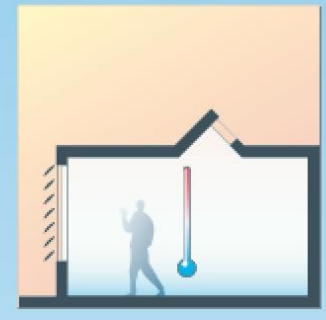

Thermal

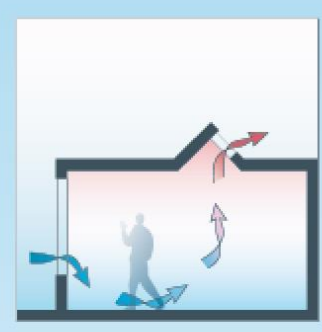

Natural ventilation

Figure 90: Screenshot illustrating all the simulation possibilities offered by DIAL+

\section{References}

[1] B. Paule, J. Boutillier, S. Pantet, Y Sutter: "A lighting simulation tool for the new European daylighting standard" Proceedings of the LUX EUROPA Conference, September 2017, Ljubliana, Slovenia.

[2] Estia: "DIAL+Lighting Validation case test CIE-171-2006", February 2013, Lausanne, Switzerland.

[3] B. Paule, F. Flourentzou, S. Pantet, J. Boutillier: "DIAL+Suite, a complete but simple suite of tools to optimize the global performance of building openings. Daylight / Natural Ventilation / Overheating Risks". Proceedings of the CISBAT'11 Conference, Lausanne, 2011.

[4] B. Paule, Eloise Sok, S. Pantet, J. Boutillier, "Electrochromic glazings: simulation of both daylight and thermal performance", Proceedings of the CISBAT'17 Conference, Lausanne, 2017.

[5] B. Paule, J. Boutillier, S. Pantet, Y. Sutter: « A lighting simulation tool for the new European daylighting standard", Proceedings of the IBPSA Conference, Cambridge, 2018.

[6] http://www.diaplus.ch

[7] http://www.buildingenergysoftwaretools.com/

[8] https://www.minergie.ch/fr/certifier/eco/ 


\subsection{DIVA-for-Rhino}

by J. Alstan Jakubiec, University of Toronto, Canada and Solemma, LLC, USA

DIVA-for-Rhino is a highly optimized daylighting and energy modeling plug-in for Rhinoceros 3D, a NURBS-based modeling software. The plug-in was initially developed at the Graduate School of Design at Harvard University and is distributed by Solemma LLC. DIVA-for-Rhino allows users to carry out a series of environmental performance evaluations of individual buildings and urban landscapes including Radiation Maps, Photorealistic Renderings, ClimateBased Daylighting Metrics, Annual and Individual Time Step Glare Analysis, LEED and CHPS Daylighting Compliance, and Thermal Energy and Load Calculations, which can be coupled with the daylight analysis. The DIVA interface is available as a part of the Rhinoceros 3D basic viewport and as part of the popular Grasshopper plugin for generative design modelling, which means that nearly anything can be modelled at simulated in DIVA.

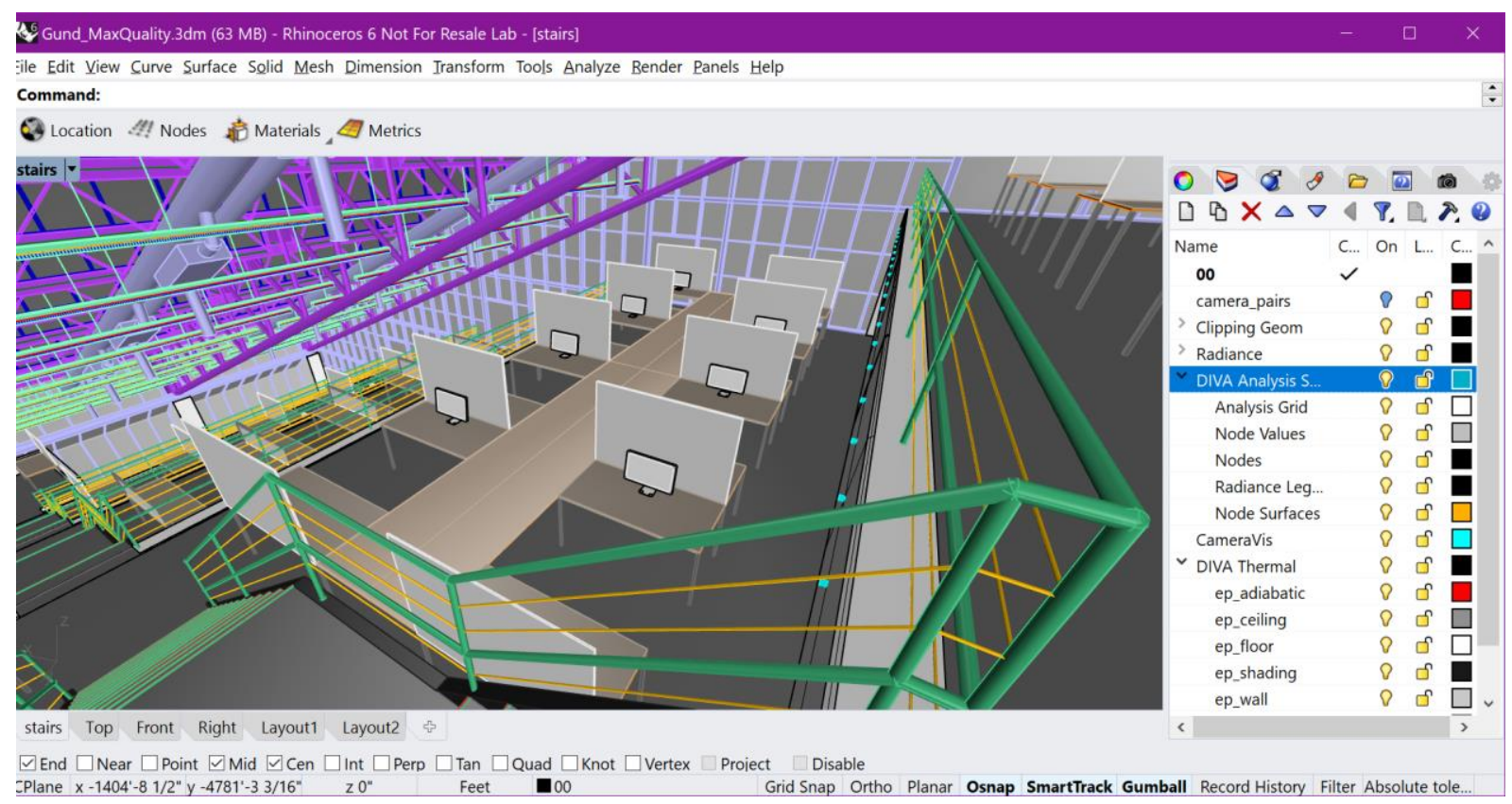

Figure 91: DIVA toolbar visible in a daylighting model

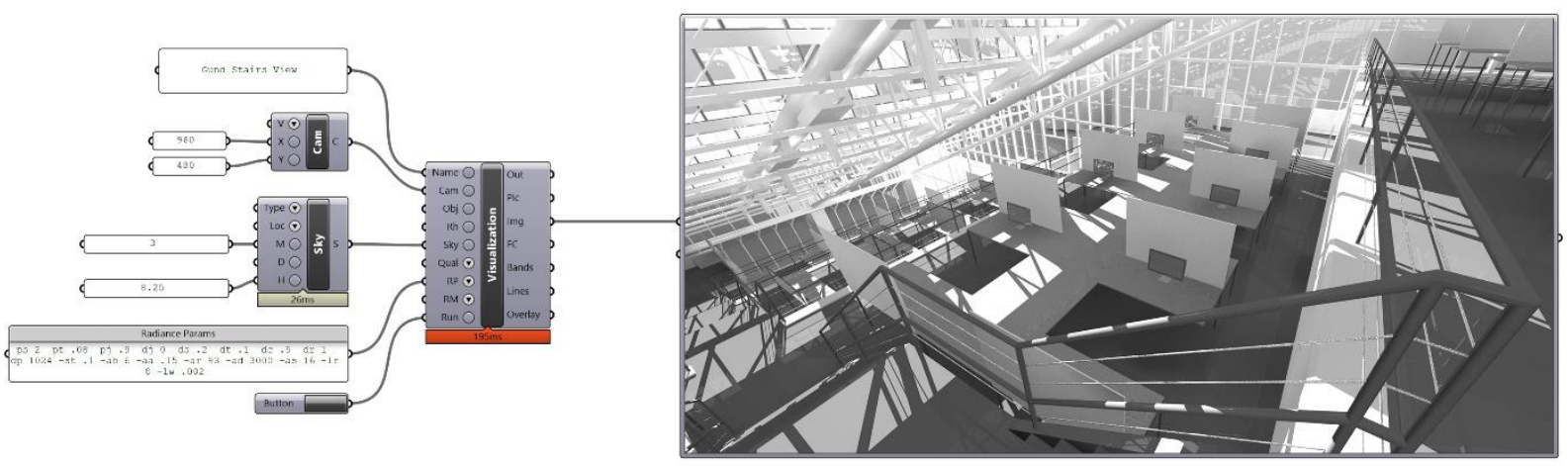

Figure 92: DIVA interface in the Grasshopper modelling environment

DIVA provides a relatively full access to the Radiance suite of raytracing calculations. Pointin-time illuminance and luminance calculations can be made with the CIE sky models, the Utah 
colored sky model, and the Perez all-weather sky model. Glare analysis is automated through the evalglare program. Annual climate-based daylighting calculations are available through the Daysim daylight coefficient based method, and annual glare calculations are available through the gen_dgp_profile program. DIVA has detailed calculation modes for automated and usercontrolled dynamic shading and electric lighting systems. Custom dynamic shades can be modelled geometrically, but a robust BSDF implementation will not be available until version 5 of the software. Electric lighting can be controlled manually or using an idealized dimming system. The scheduled annual lighting and shading outputs can be coupled with single or multi-zone thermal simulations available in the software.

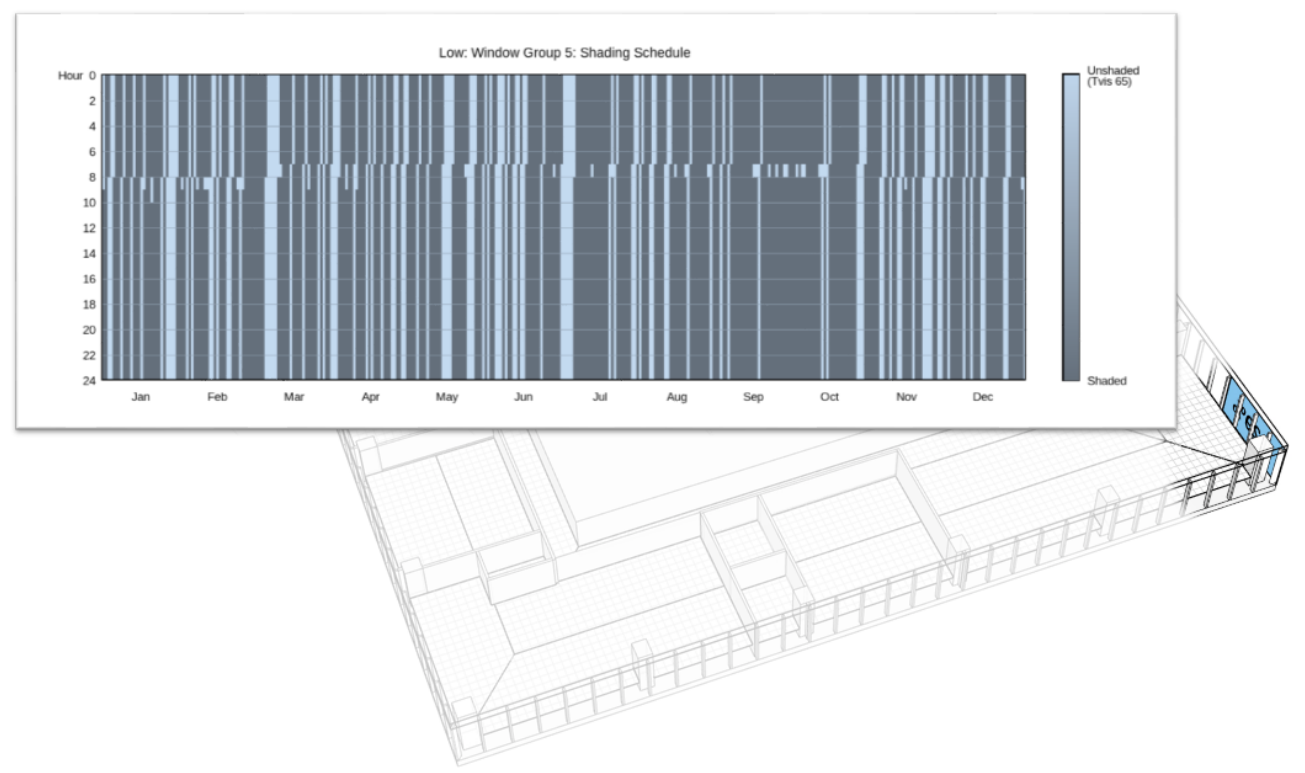

Figure 93: DIVA annual shading schedule displayed for a selected window group 


\subsection{The Fener simulation engine}

by Bruno Bueno, Fraunhofer ISE, Germany

Fener is a building simulation engine based on the three-phase method [1] and a detailed energy balance of one room. It calculates simultaneously the heating and cooling energy demand of the room, thermal comfort metrics, daylighting metrics and daylight glare indexes. The simulation engine has been specifically designed for the evaluation and design of complex fenestration systems and their control. It cannot be used for the design of electric lighting. The tool provides significant flexibility and accuracy in the definition of fenestration systems and is very powerful testing innovative control strategies for them.

Apart from weather data and information about the building use, Fener takes the U-value, Bidirectional Scattering Distribution Functions (BSDF) and Directional Solar Heat Gain Coefficients (DSHGC) as input parameters for the fenestration system. The DSHGC or angledependent $g$-value is a measure of the total fraction of incident solar irradiance that is transmitted into the building through a fenestration system for different incoming directions. By using alternative optical and heat transfer models for the fenestration system [2], the Fener tool avoids the conventional layer-by-layer model approach. This approach (e.g. ISO15099) relies on a number of assumptions that are not justified in the case of three-dimensional structures, air-permeable layers and deviations from ideal geometries, which are common features in commercial daylighting and solar-control systems.

More information about Fener can be found in [3].

\section{References}

[1] G. Ward. Simulating the Daylight Performance of Complex Fenestration Systems Using Bidirectional Scattering Distribution Functions within Radiance. Leukos 7.4 (2011) 241-261.

[2] B. Bueno, J.-M. Cejudo-Lopez, T. E. Kuhn, A general method for the evaluation of the thermal impact of complex fenestration systems in building zones, Energy and Buildings 155 (2017) 43-53.

[3] J. Kaempf, B. Paule, et al. Methods and tools for lighting retrofits - State of the art review. A Technical Report of IEA SHC Task 50, online (retrieved 29.11.2018): http://task50.ieashc.org/Data/Sites/1/publications/Technical Report T50 C2 final.pdf. 


\subsection{GB SWARE Dali}

by Zhen Tian, School of Architecture, Soochow University, Suzhou, China

The GBSWARE software package is developed by Beijing Green Building Software Company [1], a private software firm providing software for green building performance simulation, including building energy, lighting and daylighting, acoustics, CFD, etc. The software is most convenient for its "one model for all sorts of modeling". Dali is the program for building lighting and daylighting simulation with the Radiance program as its major calculation engine.

Dali has an easy to user graphical interface, the interface is based on the AutoCAD platform with added model parametric information. The program can import AutoCAD, Revit, SketchUp model files for parametric setup and simulation. The Dali program input tabs are listed on the left side of the interface. Users are expected to click the tabs on the left and then input the necessary values and setup parameters and get the simulation accomplished.

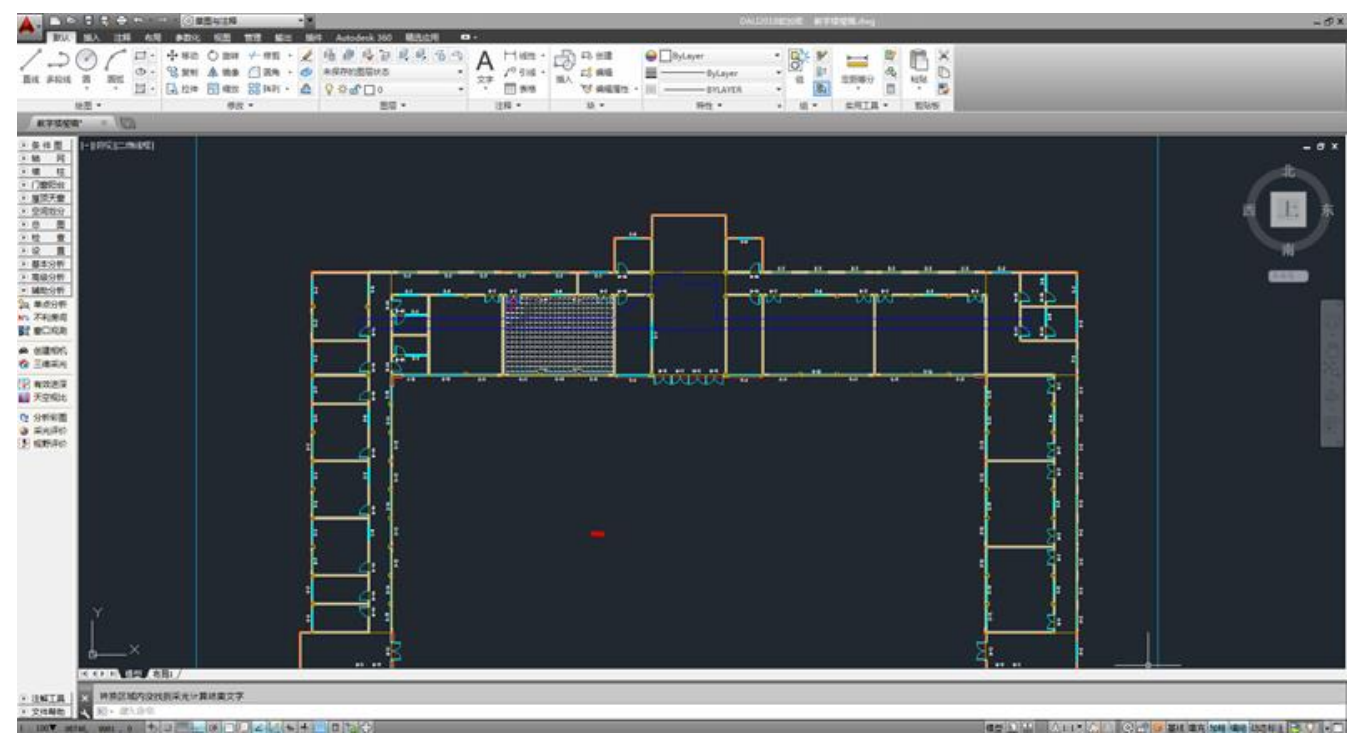

Figure 94: GBSWARE Dali user interface

The program can provide building daylighting and electric lighting modeling. Dali lighting and daylighting analysis includes Fundamental Analysis, Advanced Analysis, and Assisted Analysis. The Fundamental Analysis is for daylighting simulation and analysis with conventional glazing, the analysis includes daylight coefficient analysis, exterior view analysis and glare analysis. The newest version (V2020) can model dynamic daylighting as well as daylighting performance with Complex Fenestration Systems (CFS).

\section{Advanced daylighting simulation}

Besides fundamental daylighting coefficient simulation to meet China Standard for Daylighting Design of Buildings (GB 50033) [2], Dali presents Advanced Analysis capability for dynamic daylighting analysis. Various evaluation indices can be incorporated for results comparison and analysis, such as Daylight Autonomy, Useful Daylight Illuminance, LEED daylighting simulation requirements, and etc.

Dali is also developing its capability to model daylighting with CFS such as prismatic sunredirecting systems, tubular daylighting systems, etc. Users first model conventional glazing and define CFS types and then assign the CFS type to the intended glazing for simulation. 


\section{Electric lighting simulation}

Dali electric lighting includes interior electric lighting and exterior elevation lighting for calculating interior lighting distribution and exterior light pollution. An important feature of Dali electric lighting module is its combination of electric lighting and daylighting. In the Area Illuminance calculation, the program can simulate the combination effect of electric lighting and daylighting on the calculated area plane. This provides the possibility for the integrated solution for daylighting and electric lighting.

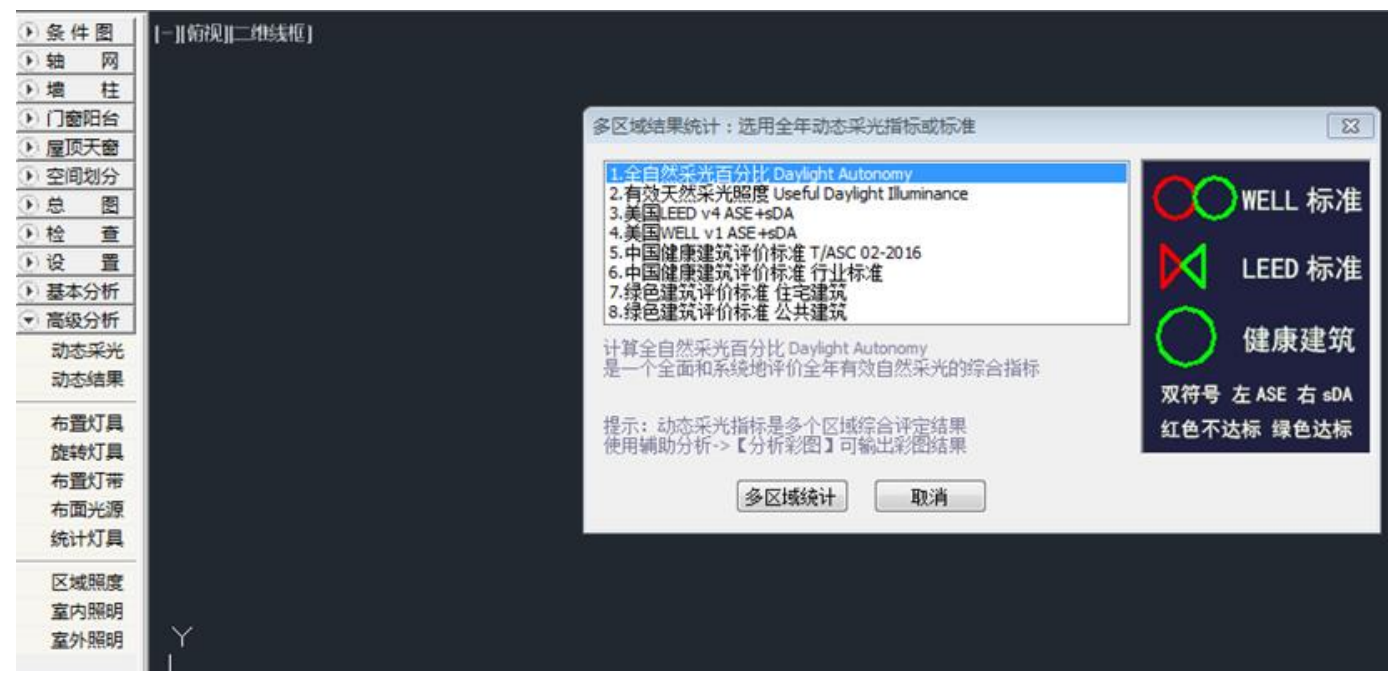

Figure 95 Dali Advanced daylighting and electric lighting

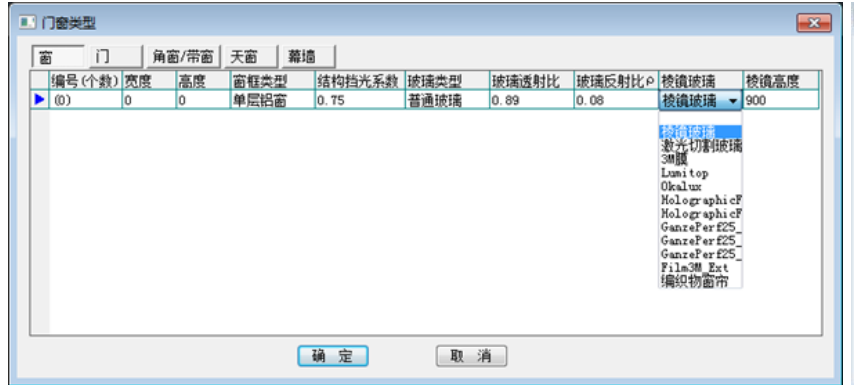

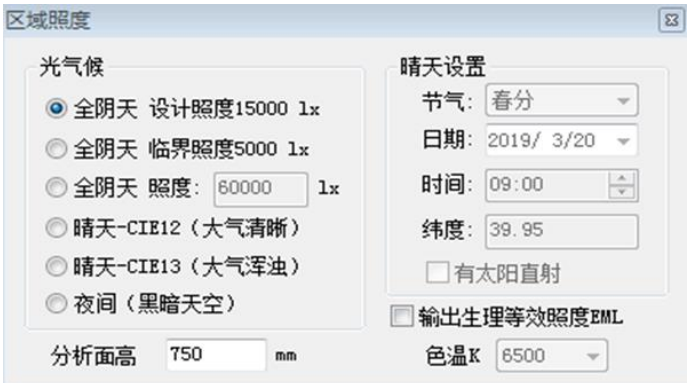

Figure 96: Dali Advanced daylighting with Complex Fenestration Systems (left) and Dali Area illuminance calculation with daylighting and electric lighting (right).

\section{References}

[1] GBSWARE (2019) Beijing Green Building Software. Web address: http://www.glbsware.com.cn/

[2] Standard for daylighting design of buildings (2013). GB 50033 Ministry of Housing, Urban and Rural Development, China. 


\subsection{Ladybug and Honeybee}

by Marios Liaros and Harris Poirazis, Inform Design, Sweden

Ladybug and Honeybee are part of the Ladybug Tools plug-ins, an environmental design toolset developed for Dynamo [1] and Grasshopper [2]. Ladybug focuses on advanced climate analysis (e.g. solar radiation and sunlight hours analyses, psychrometric charts, etc.), while Honeybee is mostly related to thermodynamic and daylight modeling (e.g. heating/cooling energy usage, envelope heat flow modeling, annual daylight studies, glare analyses, etc.). Most often, both tools are used jointly, as the output from Ladybug is needed as input for the components of Honeybee.

\section{The case of Grasshopper}

Ladybug and Honeybee connect Radiance, Daysim, EnergyPlus, OpenStudio and Therm to a 3D geometry in Rhino (3D modeling software) through Grasshopper (Rhino's environment for visual programming). In Grasshopper, Ladybug and Honeybee offer a user-friendly interface for the aforementioned software/engines, providing a direct and real-time connection to the 3D geometry.

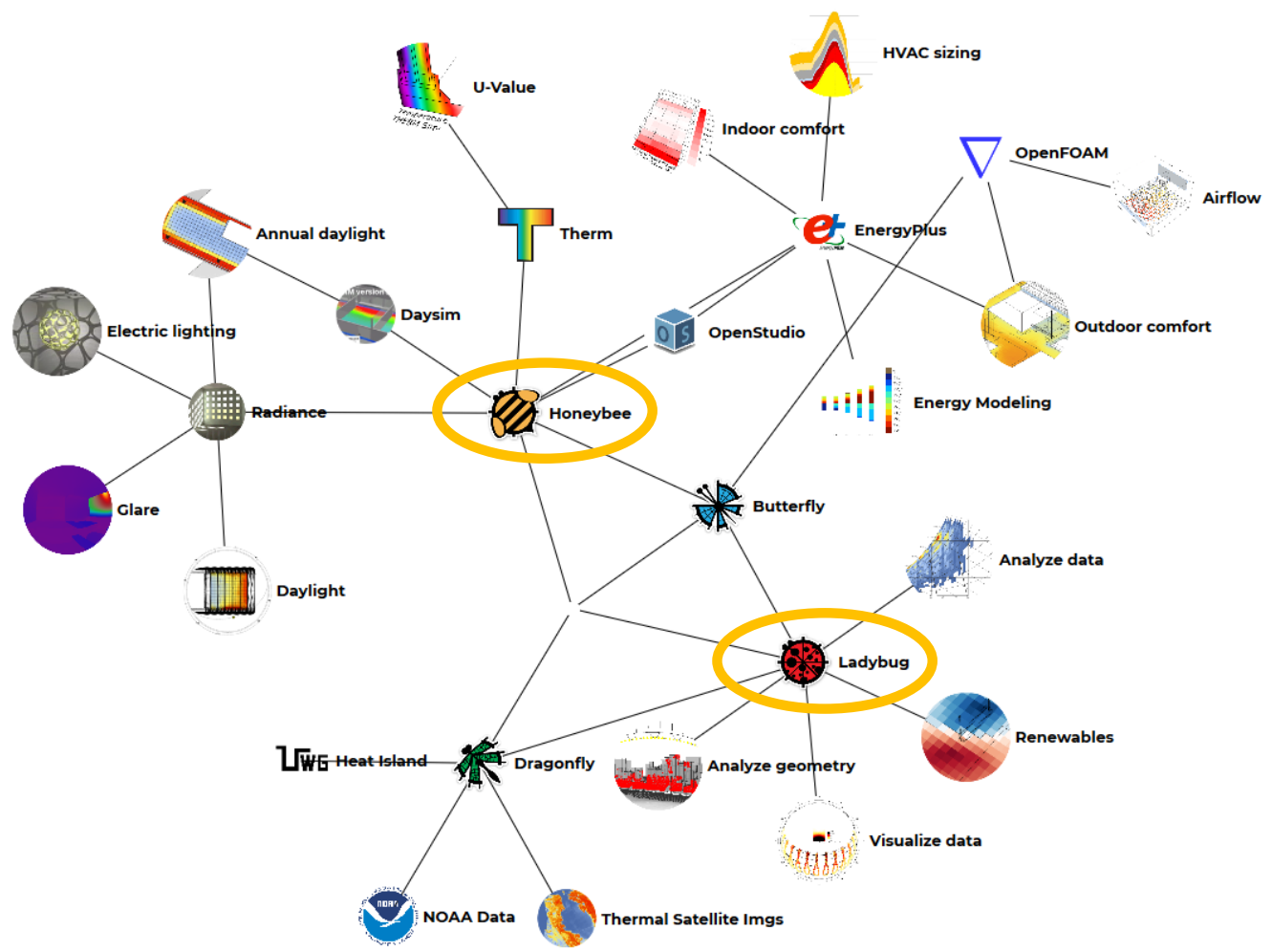

\section{Daylight analysis}

Radiance and Daysim are two software tools/engines used for daylight analyses in Honeybee. Honeybee is capable of running point-in-time analysis, both grid and image based, daylight factor calculations, as well as annual daylight simulations.

Regarding the grid and image-based analyses, Honeybee offers different types of simulations, namely, illuminance (lux), radiation ( $\mathrm{kWh}$ ) and luminance $\left(\mathrm{cd} / \mathrm{m}^{2}\right)$. In the first case (grid-based analysis) the user is able to set a grid of points (derived from a selected surface) or provide 
individual measurement points. For the second case (image-based analysis) the selection of the view(port) and the camera type are needed. The supported types of cameras are perspective, fisheye and parallel.

The Daylight Factor calculations are quite straightforward offering the option to change between CIE overcast and uniform sky (the latter to be used for sky factor calculations). The measurement points are set in this case similarly to the grid-based analysis.

The simulation related to most of the metrics used by several certifications is the annual daylight simulation. The weather file used for the annual daylight simulation in Honeybee is a climate-based sky, created from statistically processed climatic data in the standard EnergyPlus format (epw). The rest of the input is similar to those needed for the Daylight Factor calculations. The indices which are directly calculated and outputted from this type of analysis are: Daylight Autonomy (DA), continuous Daylight Autonomy (cDA), Useful Daylight Illuminance metrics (UDI) and spatial Daylight Autonomy (sDA). The hourly values/results for each measurement point can also be extracted and processed in a basic/adequate level (i.e. to assign working/lunch hours, time step, minimum/maximum thresholds).

In the case of the annual daylight analysis, Honeybee can optionally incorporate the Dynamic Shading Module of Daysim extending further the simulation to an annual glare analysis considering up to two dynamic shading groups if desired. This particular setting (Dynamic Shading Module in Daysim) is linked to the Electric Lighting Module of Daysim [3] which is used when daylight and electric lighting are combined in Honeybee. More information about this is provided in the following paragraphs.

It is important to notice that for setting all the daylight analyses, Honeybee utilizes all the Radiance parameters which can be set by the user according to the needs of the analysis. Apart from individually setting the parameters, an option for quick settings is also provided based on the desired quality of the simulation (following suggestions from Radiance documentation).

\section{Electric light analysis}

The integration of electric lighting design in Honeybee is also based on both Radiance and Daysim. The photometric data of the desired luminaire is imported as an "ies" photometric file and translated into Radiance geometry and material in order to be integrated into the simulated scene. The user can create and use a custom lamp for the luminaires, choosing from a predefined list with chromaticity coordinates or set a color temperature. The options provided for the placement, orientation, tilt and other geometrical aspects of the luminaires are many, allowing for quick and effective handling of the luminaires.

Concerning the electrical lighting controls, Honeybee utilizes Daysim [4]. The user is able to select a predefined scenario for the controls and accordingly, if needed, set the points where the sensors are located in the scene. Additional information needed for the controls includes lighting power and setpoint, ballast loss factor, standby power and delay time (in the case of automated switch-off).

The use of lighting control systems is available only for annual daylight simulations, providing information for the energy used/saved during the occupied period. As discussed above, the Dynamic Shading Module is considered for these calculations, thus, its impact is included in the final lighting schedule produced. 


\section{Integration of daylight and electric light analyses}

The process of integrating daylight and electric light analyses is most often referred to dimming the lighting system according to the daylight provided, in order to achieve the desired illuminance for the task carried out, while making sure that no excess energy is wasted. As a result, this process mainly refers to the potentials and limitations of the controls themselves (Daysim) rather than the available options provided by the interface (Honeybee).

In more detail, the official description of the lighting controls related to the photosensorcontrolled dimmed systems states:

"This lighting system corresponds to an ideally commissioned, photosensor-controlled, dimmed lighting system. The photocell dims the activated lighting until the total work plane illuminance (daylight \& electric light) reaches the minimum illuminance threshold. At a minimum lighting output of $1 \%$ the system consumes $15 \%$ of its full electric power." [4]

The lighting system currently available in Daysim is ideal, meaning that:

"... the electric lighting system itself is actually not being modeled but instead the daylight in the space is modeled. For this simpler option the only parameter required to describe the lighting system for each zone is the installed lighting power and the target illuminance. It is assumed that the lighting system will deliver this target illuminance when fully switched on." [5]

These assumptions allow for only rough estimations of the savings, based on annual daylight availability and neglecting the actual performance of the luminaires used. In order to be able to drive the design of such installations, the integration of electric light modelling is necessary both in terms of actual illuminance level achieved on each measurement point and energy used according to the technical information of the luminaires utilized.

\section{Further improvements}

Future steps for proper integration of electric light modelling are planned by the developers including the development of a more detailed electrical lighting system. The Actual Lighting System, as it is called, will integrate the modelling of the luminaires in Radiance/Daysim, allowing for accurately monitoring the interaction between the electric lighting and daylight.

\section{References}

[1] Dynamo software (2018). Autodesk Inc. Web address:

https://www.autodesk.com/products/dynamo-studio/overview

[2] Grasshopper software (2018). Robert McNeel \& Associates. Web address: https://www.rhino3d.com/

[3] DAYSIM user guide (2018). Christoph Reinhart. Web address: http://daysim.ning.com/page/keyword-shading

[4] DAYSIM user guide (2018). Christoph Reinhart. Web address: http://daysim.ning.com/page/keyword-lighting-control

[5] DAYSIM user guide (2018). Christoph Reinhart. Web address: https://daysim.ning.com/page/header-file-keyword-electric-lighting-system 


\subsection{PKPM-Daylight - Daylight Simulation and Analysis Software for Green Building}

by Luo Tao, CABR, China

\section{Overview of software}

PKPM-Daylight, daylight simulation and analysis software for green building, is developed by China Academy of Building Research and Beijing Glory PKPM Technology Co. Ltd. The software is installed on AutoCAD and BIM platforms and supports two calculation methods: theoretical formulas and simulations based on a Radiance kernel.

PKPM-Daylight supports relevant requirements of China national standards "Assessment standard for green building" GB/T 50378(2019 Edition, 2014 Edition, 2006 Edition), "Standard for daylighting design of buildings" GB50033, "Standard for Green Performance Calculation of Civil Buildings" JGJ/T 449-2018. Professional parameters can be set automatically, and traceable reports on daylight and glare simulation/analysis can be automatically generated. The software can help users for the design, evaluation and optimization of indoor daylight environment.

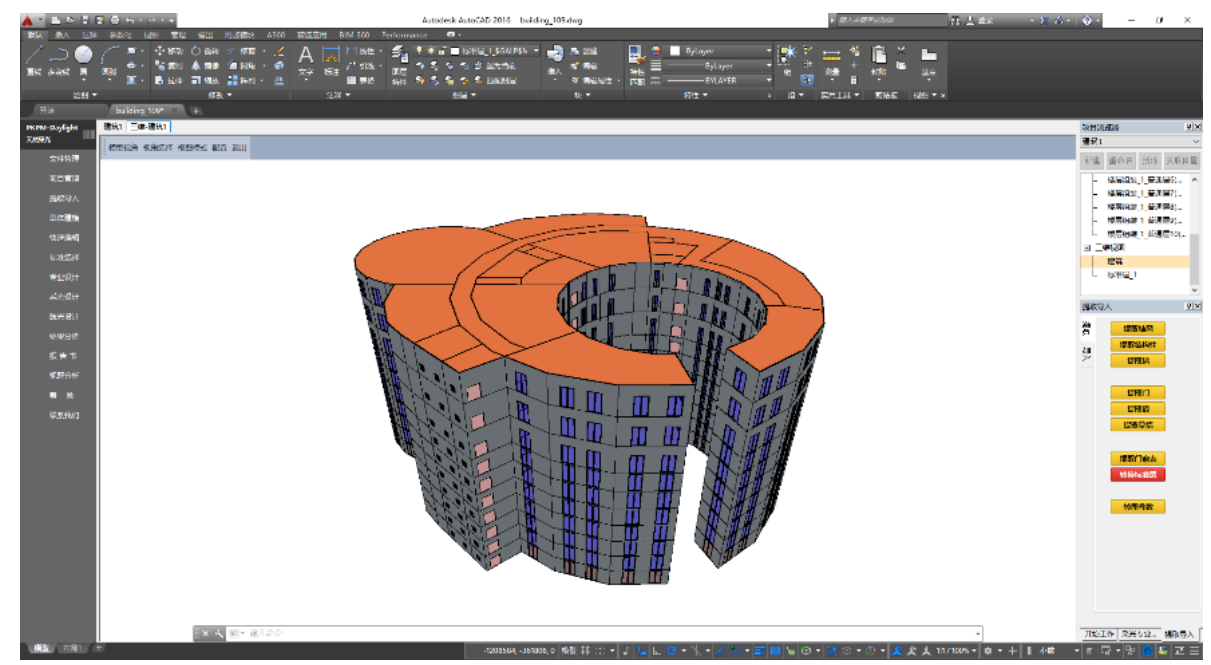

Figure 97: Integral interface of PKPM-Daylight.

\section{Major highlights of the software}

\section{1) BIM idea}

As one of the main modules of the PKPM green building software series, PKPM-Daylight can share model and data with other modules such as overall evaluation on green building design (PKPM-GBD), energy-saving design of enclosure structure (PKPM-PBECA), simulation analysis on wind environment (PKPM-CFD), simulation analysis on sound environment (PKPM-Sound), simulation analysis on energy consumption (PKPM-Energy), simulation analysis on thermal environment (PKPM-TED), analysis on air quality and pollutant concentration (PKPM-AQ), etc.

\section{2) Support for multiple common model formats}

The software supports both planar DWG 2-D extraction and 3-D import. Two-dimensional import can be based on DWG plane drawings. Building components such as axle net, column, 
wall, door, window and curtain wall are extracted separately. Three-dimensional import supports multiple formats, includes Revit model, Tangent model, THSware model, PKPM-BIM, SKP understanding, STL entity and so on.

\section{3) Special design of daylight environment}

I. Multiple built-in style libraries for windows and doors with support for custom design

PKPM-Daylight provides window and door table functions. The windows and doors in the model can be extracted directly, and their size and shape can be set quickly. Besides, PKPMDaylight supports custom drawing of doors and windows.

\section{Material design of transparent components}

PKPM-Daylight supports uniform or precise material design of transparent components such as doors and windows, transparent curtain walls, etc. Materials and parameters commonly used in construction industry are built in. Transparent component materials can be set uniformly according to component type, layer number and orientation; they can also be designed separately for selected components.
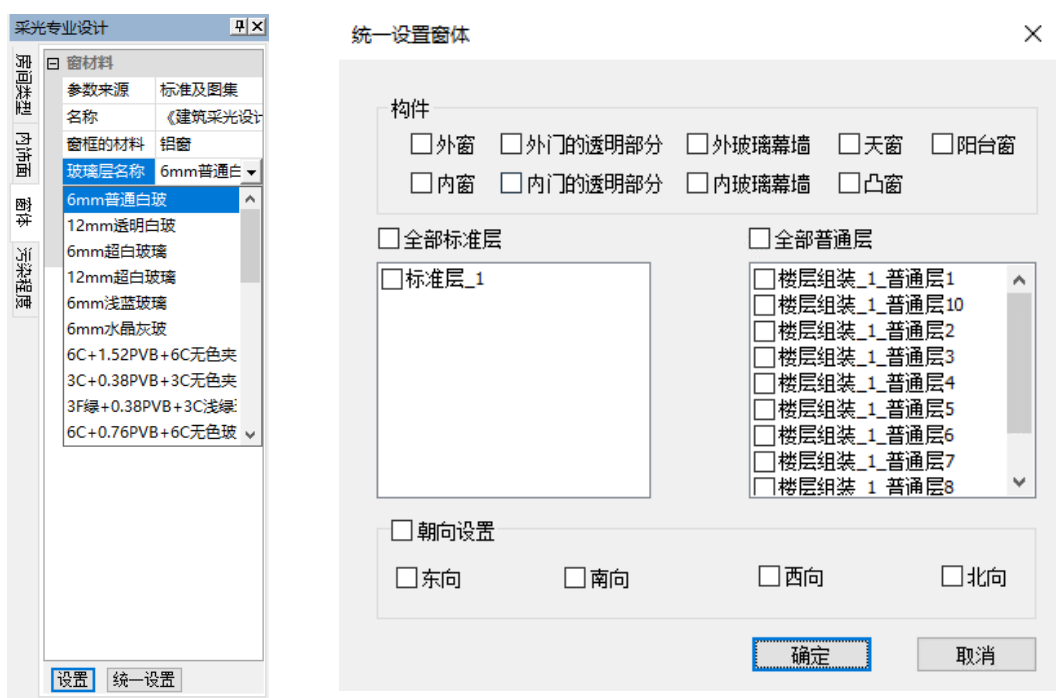

Figure 98: Transparent Component Material Editing (left) and Unified Material Setting for Transparent Components (right).

\section{Pollution Degree Design of Transparent Components}

PKPM-Daylight supports uniform or precise design of transparent components. The pollution degree can be set uniformly according to component type, or separately for selected components.

\section{Interior decoration design}

PKPM-Daylight supports uniform or separate editing of interior decoration faces. Interior decoration materials can be set on both sides of a wall. The software includes various built-in interior decoration materials and supports custom material editing. 


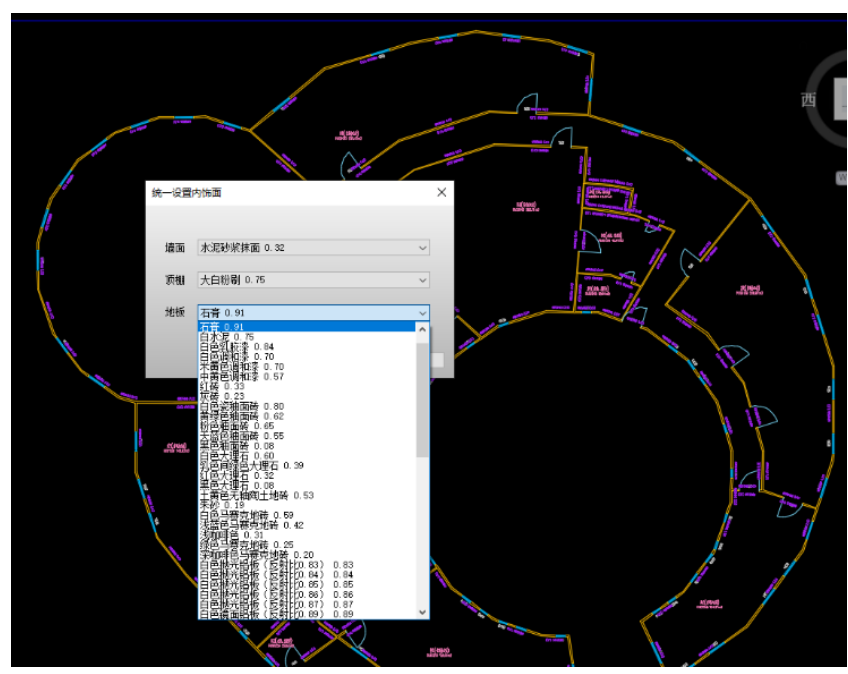

Figure 99: Editing interior materials.

\section{4) Configuration interfaces for daylight and glare}

I. Support for multiple daylight calculation methods and fine-tuning of simulation/analysis parameters

PKPM-Daylight supports three methods of daylight simulation: annual climate-based simulation, formula-based calculation, and steady-state simulation with a cloudy sky. It is also customizable in mesh spacing and number of grid points per room to achieve optimization in both calculation efficiency and accuracy.

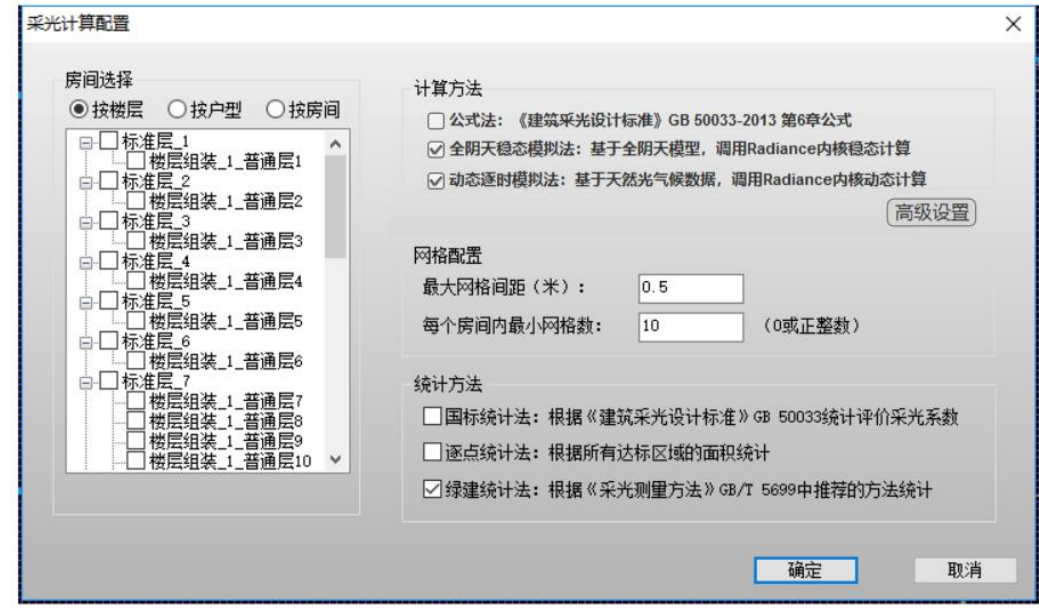

Figure 100: Optical environment computing configuration.

\section{Support for glare calculation}

PKPM-Daylight supports multiple camera settings (mimicking human eyes), including manual settings and unified settings. Camera positions can be adjusted when necessary and a variety of glare control measures are provided for optimum design. 

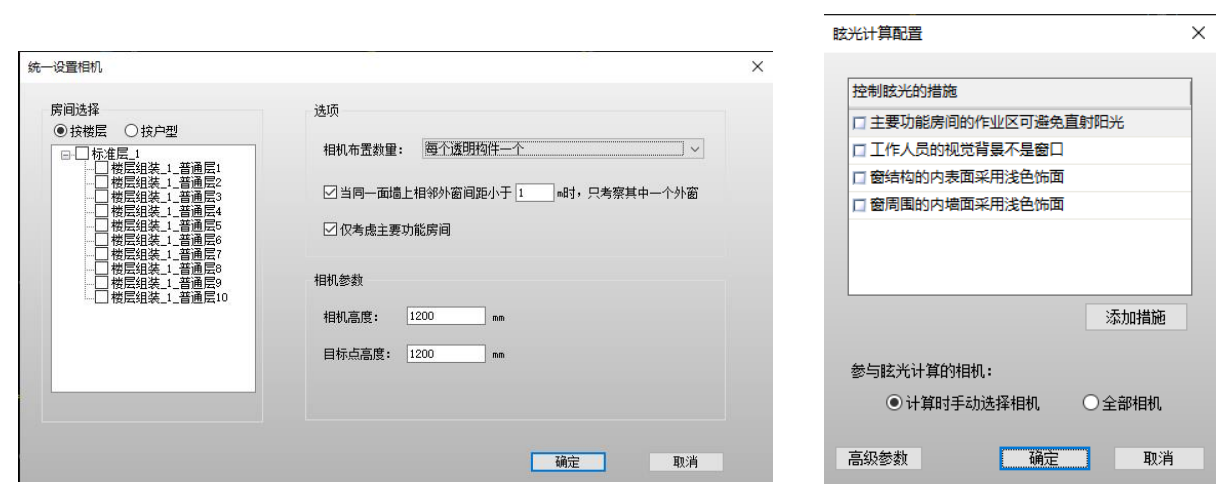

Figure 101: Camera settings (left) and adding glare control measures (right).

\section{Support for multi-core computing}

PKPM-Daylight supports multi-threaded computing, which improves the computing speed substantially, and can display the computing progress in real time.

\section{5) Result analysis and optimization suggestions}

\section{Annual dynamic daylight analysis}

PKPM-Daylight computes the standard hours of the annual dynamic illumination (default $3001 \mathrm{x}$ as the threshold) according to the model, professional design parameters, calculation period, etc., and outputs the annual daily illumination chart.

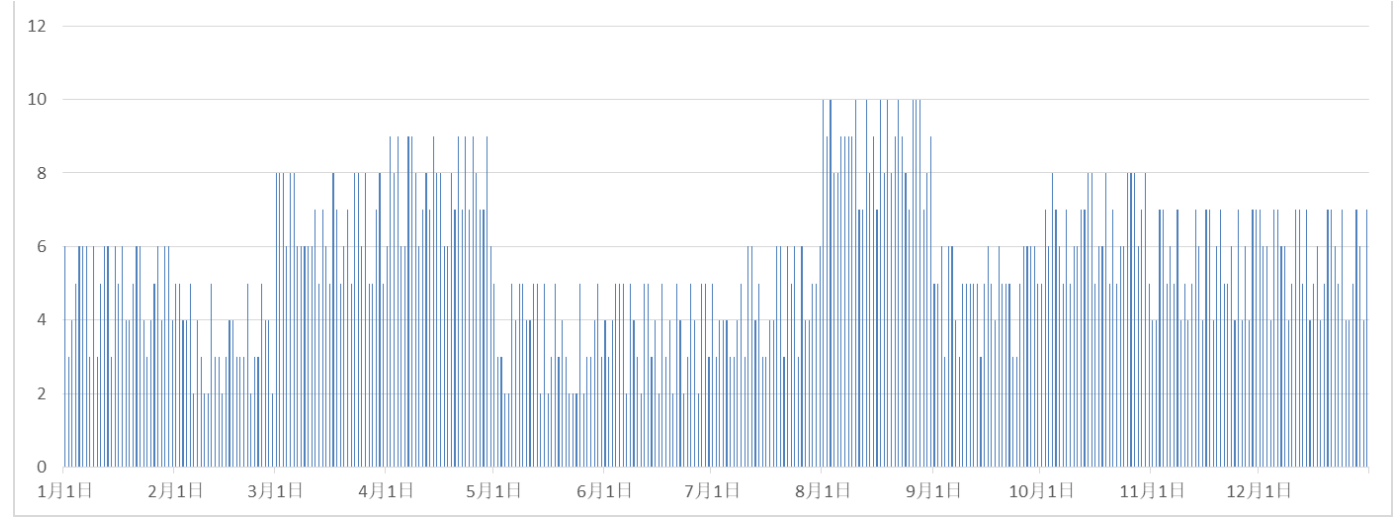

Figure 102: Daily illumination hours diagram for the year.

\section{Visualization and Optimizing Suggestions of Daylight Factor Distribution}

PKPM-Daylight calculates the daylight factors point by point according to the model, material, calculation period, etc., and outputs the annual dynamic average or steady-state daylight factor distribution plot.

PKPM-Daylight compares the daylight factors of each grid point to the standard values and outputs color maps of rooms where green means the grid point meets the standards and red means the grid point falls below the standards.

PKPM-Daylight uses the interior area (usually within 5 meters from the building's periphery) and outputs the daylight factor map of the interior area automatically. 

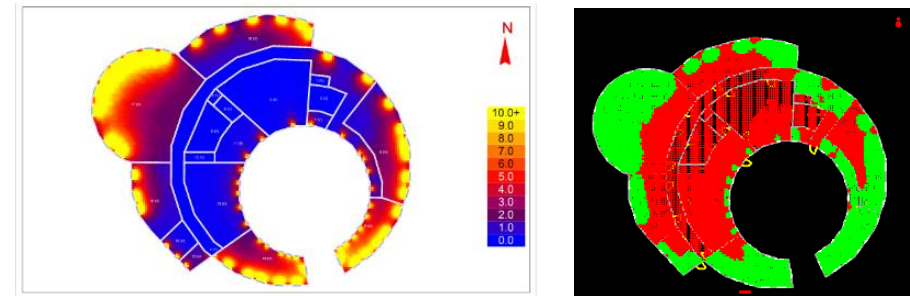

Figure 103: Distribution map of daylighting coefficient (left), diagram of lighting coefficient reaching standard (center), internal lighting coefficient map (right).

III. Statistics and judgment of uncomfortable glare index

The discomfort glare index (DGI) is obtained by calling radiance kernel according to the set camera, and whether the standards are met is automatically determined.

\begin{tabular}{|c|c|c|c|c|c|c|c|c|}
\hline 楼层 & 区域 & 房间编号 & 房间名称 & 采光等级 & 窗编号 & 不舒话眩光指数(DGI) & DGI限值 & 是否满只 \\
\hline 10层 & -- & 3 & 普通办公室 & III & EWIN0100044 & 22.9 & 25 & 满足 \\
\hline 10层 & -- & 11 & 晋通办公室 & III & EWIN0 100003 & 23.4 & 25 & 满足 \\
\hline 10层 & - & 11 & 普通办公室 & III & EWIN0 100043 & 21.9 & 25 & 满足 \\
\hline 10层 & -- & 13 & 普通办公室 & III & EWIN0 100004 & 20.8 & 25 & 满足 \\
\hline 10层 & - & 13 & 普通办公室 & III & EWIN0 100039 & 23.4 & 25 & 满足 \\
\hline 10层 & -- & 13 & 普通办公室 & III & EWIN0 100040 & 24.2 & 25 & 满足 \\
\hline 10层 & -- & 13 & 普通办公室 & III & EWIN0 100041 & 23.9 & 25 & 满足 \\
\hline 10层 & -- & 13 & 普通办公室 & III & EWIN0 100042 & 23.1 & 25 & 满足 \\
\hline 10层 & -- & 14 & 普通办公室 & III & EWIN0 100008 & 21.1 & 25 & 满足 \\
\hline 10层 & -- & 14 & 普通办公室 & III & EWIN0100018 & 16.7 & 25 & 满足 \\
\hline 10层 & -- & 14 & 普通办公室 & III & EWIN0 100019 & 18.6 & 25 & 满足 \\
\hline 10层 & -- & 14 & 普通办公室 & III & EWIN0100020 & 19.1 & 25 & 满足 \\
\hline 10层 & -- & 14 & 普通办公室 & III & EWIN0100021 & 20.5 & 25 & 满足 \\
\hline 10层 & -- & 14 & 普通办公室 & III & EWIN0100034 & 无䏠光 & 25 & 满足 \\
\hline 10层 & -- & 14 & 普通办公室 & III & EWIN0 100035 & 无胘光 & 25 & 满足 \\
\hline 10层 & -- & 14 & 普通办公室 & III & EWIN0 100036 & 无胘光 & 25 & 满足 \\
\hline 10层 & -- & 14 & 普通办公室 & III & EWIN0100037 & 无胘光 & 25 & 满足 \\
\hline 10层 & -- & 14 & 普通办公室 & III & EWIN0 100038 & 6.9 & 25 & \\
\hline 10层 & -- & 14 & 普通办公室 & III & EWIN0 100064 & 无胘光 & 25 & 满足 \\
\hline 10层 & -- & 4 & 走道、楼梯间 & v & EWINO 100001 & 10.9 & 28 & \\
\hline ine & & & 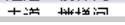 & & 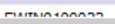 & $n+n$ & $\mathrm{nn}$ & \\
\hline
\end{tabular}

Figure 104: Computation of uncomfortable glare index

\section{Automated report output}

PKPM-Daylight automatically outputs traceable reports for indoor natural daylighting and glare simulation/analysis, in line with the requirements of reviews and inspections. The reports contain information about project location, building function, model information, index requirements, simulation principle, boundary conditions, input parameters, grid partition, calculation and analysis of color maps, statistical results, analysis results, etc. 


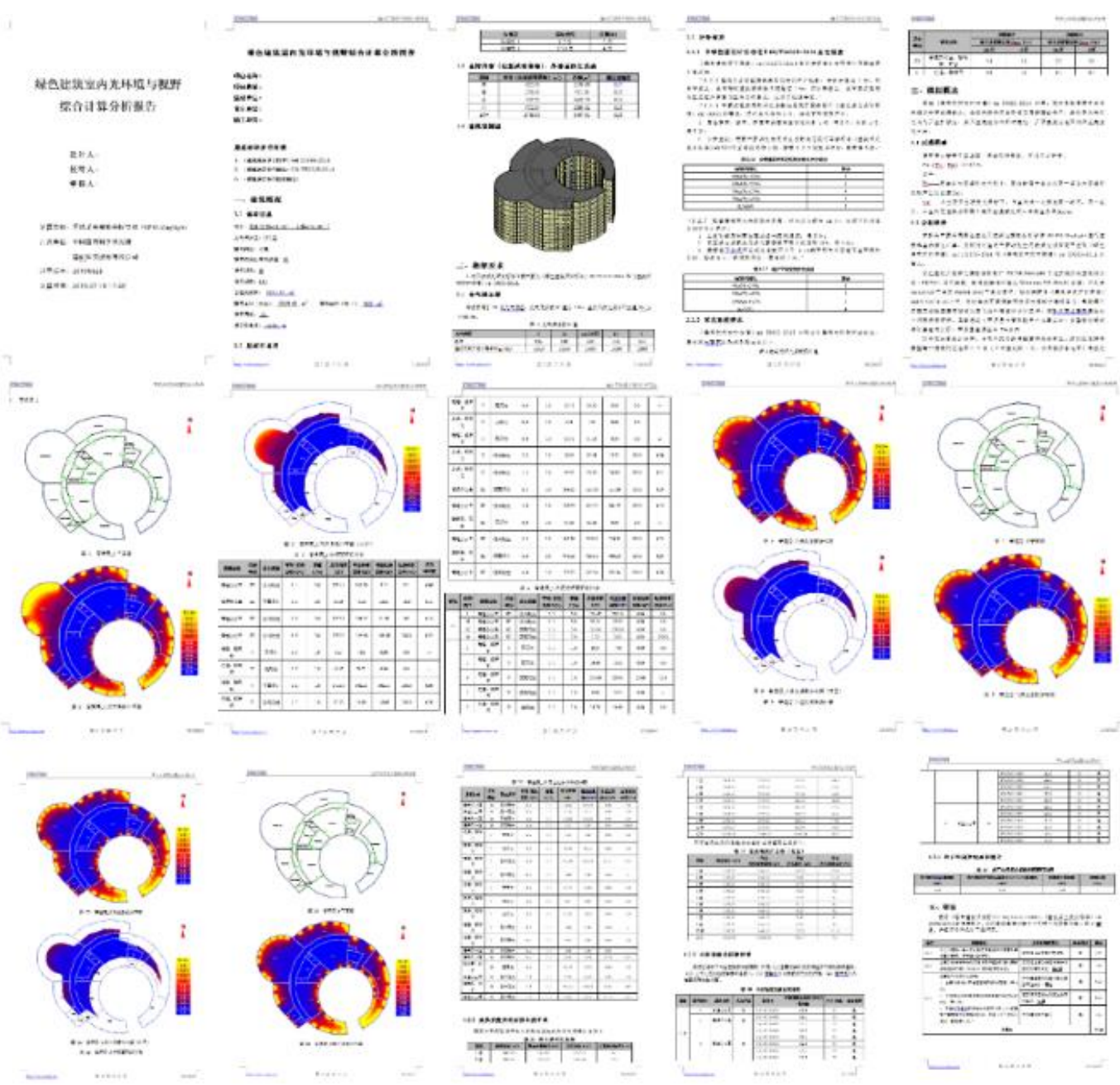

Figure 105: One-click generate report 


\subsection{RADIANCE}

by David Geisler-Moroder, Bartenbach, and

Taoning Wang, Lawrence Berkeley National Laboratory, California, USA
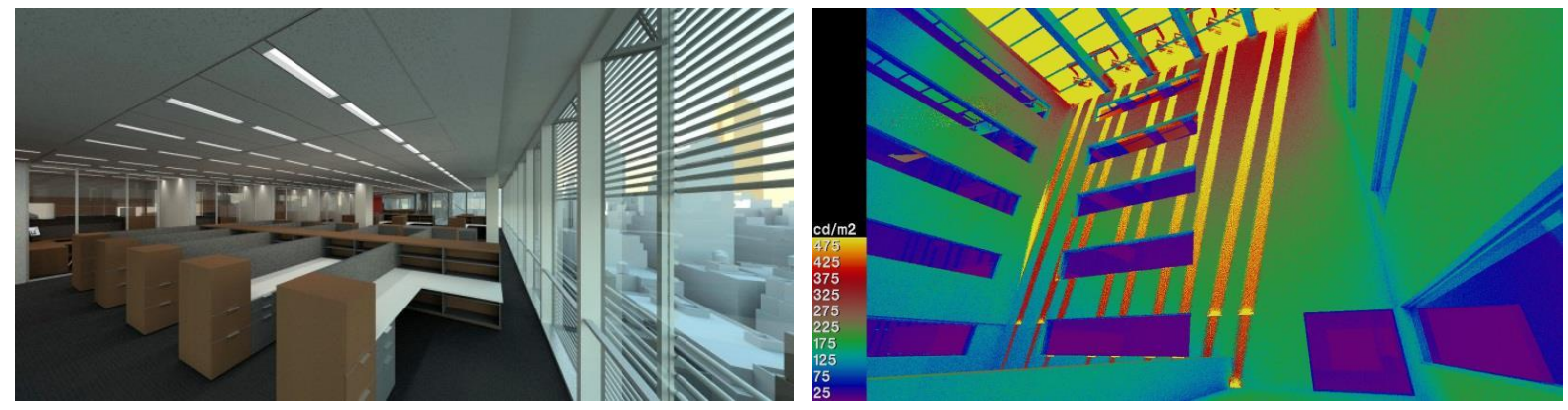

Figure 106: Screenshots of the results obtained with Radiance (Left: @ www.radiance-online.org, Right: ( ) Bartenbach GmbH)

Radiance [1] is a physically-based cross-platform backward ray-tracing tool that is mainly used for lighting and daylighting simulation. Radiance development started in 1984 by its principal author, Greg Ward, at Lawrence Berkeley National Laboratory (LBNL). Current source code of the official release, 5.2, can be downloaded at https://www.radiance-online.org, where the unofficial, could be unstable, HEAD release can also be downloaded. The National Renewable Energy Laboratory (NREL) provides up-to-date compiled packages for each of the major operating systems: Windows, Mac, and Linux [2].

The rendering method is based on hybrid deterministic and stochastic (Monte Carlo) backward ray tracing. Direct illumination levels and specular reflections are calculated deterministically, while indirect diffuse contributions are evaluated through MC sampling. Radiance simulation methods have been thoroughly validated through field measurements within the international research community. Architects and engineers rely on Radiance to predict accurately the light levels and appearance of space with various artificial lighting and daylighting concepts prior to construction. Researchers also use it to evaluate new lighting products. The software can be used in each stage of lighting design for daylighting and artificial lighting simulations. It allows the simulation of a wide variety of space geometries and lighting conditions.

Radiance was originally developed for electric lighting simulation. To this date, Radiance has many features to support the physically-accurate modeling of electric lighting using a ies file that describes the luminous output distribution of a lighting fixture. Radiance also has the capability to model the flux transfer through luminaire to support luminaire designers. Radiance deploys efficient algorithms for multi-source and large-source sub-sampling, which enables designers to render large complex electrical lighting scenes while maintaining physical accuracy.

Daylight modeling development started in the late 80es and is still under constant upgrades. Simulations can be performed using different CIE skies (clear, uniform, overcast) or the Perez all weather sky model. With an additional plugin even the 15 new CIE skies are available. The Perez model is also the basis for annual daylight simulations based on measured climate data. The 3- and 5-phase methods allow users to efficiently perform annual daylight calculations even including complex daylighting systems that are characterized by their BSDFs. Evaluation tools that e.g. allow the calculation of glare indices such as the Guth VCP, UGR, DGI, or DGP complement the Radiance software toolkit. Radiance has been validated against the CIE $171: 2006$ "Test Cases to Assess the Accuracy of Lighting Computer Programs" [3,4]. 
Radiance follows the non-graphical Unix-toolbox model, currently consists of more than 100 individual programs, including programs for modelling and translating scene geometry, luminaire data and material properties. It takes 3D geometric models as input and allows calculating physically correct results and high-quality renderings (luminance / illuminance values and images). False-color and isoline presentations simplify the understanding of the results. There are hardly any limitations on geometry and materials, which can be defined based on built-in models or via data input based on measurements of color and bidirectional scattering distribution functions (BSDF).

As a command line tool, Radiance does not include a 3D modelling engine. The geometry and material definitions have to be textual input. While defining the geometry directly in Radiance is not easy to handle, there are many methods to import CAD geometry via converted files. 3D geometry can for example be imported with the obj2rad tool from .obj files, exported from Sketchup with the su2rad plug-in or directly exported from Ecotect in .rad and .mat file formats.

Radiance provides various file format converters for input and output. To import models into Radiance, obj2rad converts Wavefront .obj files, mgf2rad does the same for the Materials and Geometry Format .mgf. Luminaire data in .ies format can be imported using the tool ies2rad.

Radiance exports RGBE HDR images in the original HDR file format that can be converted to various image formats such as .bmp, .gif, .pict, .ppm, .ps or .tiff for external usage. The point grid calculation results of luminance and illuminance are exported in text format that can be further used in a spreadsheet for evaluations.

\section{Advanced functions for Complex Fenestration Systems}

To better account for specular reflections, Radiance does not only work with matrix based BSDF data but is also able to generate and use variable-resolution BSDFs. The 3- and 5phase-methods allow users to efficiently perform annual daylight calculations even including complex daylighting systems that are characterized by their BSDFs.
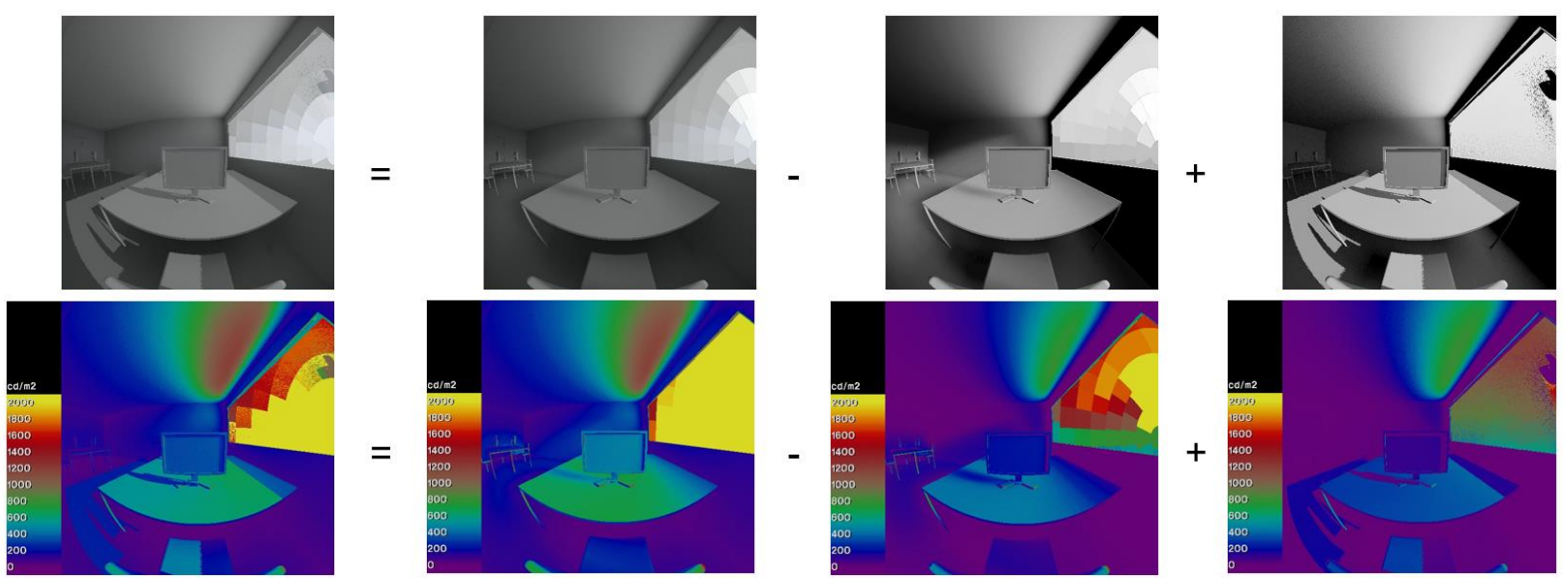

Figure 107: Example simulation showing the single steps of the 5-phase-method: 5-phase-method result, 3-phase-method result, direct solar contribution from 3-phase-method, high accurate direct solar contribution (from left to right).

Moreover, Radiance allows a combined usage of a system's BSDF and its geometry to provide an improved calculation of the direct sun contribution as well as a more realistic visualization. 

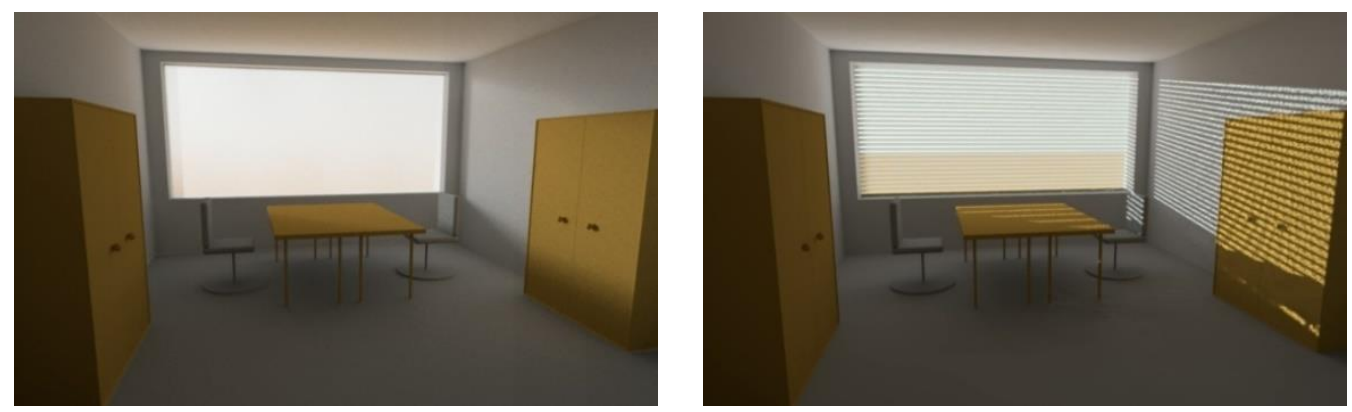

Figure 108: Simulation of a daylighting system represented by its BSDF (left) and by a combination of BSDF and geometry (right)

BSDFs files that are described in the Window XML format can be imported for the ray-tracing simulations. Standard formats include Klems' full, half or quarter representation $(145 \times 145$, $73 \times 73$ or $41 \times 41$ patches) and tensor tree variable resolution BSDFs, but all other discretization basis can be used if properly defined in the XML header.

\section{References}

[1] Radiance online, https://www.radiance-online.org/, 2019.

[2] OpenStudio, https://www.openstudio.net, 2019.

[3] D. Geisler-Moroder, A. Dür, Validation of Radiance against CIE171:2006 and Improved Adaptive Subdivision of Circular Light Sources, 7th International Radiance Workshop, Fribourg, 2007, online: http://www.radianceonline.org/community/workshops/2008fribourg/Content/Geisler-Moroder/RW2008 DGM AD.pdf

[4] D. Geisler-Moroder, Accuracy Improvements for Computational Methods and Color Rendering Index Calculations in Global Illumination Model, Dissertation, University of Innsbruck, 2010.

[5] G. Ward, R. A. Shakespeare, "Rendering with RADIANCE - The Art and Science of Lighting Visualization", 1998.

[6] G. Ward, R. Mistrick, E.S. Lee, A. McNeil, J. Jonsson, "Simulating the Daylight Performance of Complex Fenestration Systems Using Bidirectional Scattering Distribution Functions within Radiance", 2011. 


\subsection{RELUX}

by Jérôme Kämpf, Idiap Research Institute and kaemco, Switzerland and Markus Hegi, Relux Informatik AG, Switzerland

ReluxDesktop [1] is a high-performance, intuitively operated application for simulating artificial light and daylight. The software has been developed by Relux Informatik AG for over 20 years. The last officially released version is 2019.2. ReluxDesktop provides calculations of luminance and illuminance levels, national and international standards, and is compatible with CAD and BIM systems. The application is available free of charge on the homepage of Relux. The manufacturers of luminaires have to pay an annual feel to be in the ReluxDesktop database locally or online. The software has more than 380000 users worldwide and is available in twenty-six languages.

ReluxDesktop has a user-friendly interface that provides an easy-to-use yet powerful 2D and 3D import feature for the architectural plans and a 3D modeler. It has an important luminaire database that allows defining the position of luminaires in the building and thanks to its fast rendering engine (based on radiosity calculations), it delivers visualization results in a short time. Moreover, the dynamic planning tool allows an interactive visualization of the direct component of the light from the luminaires. For each of the building zones, the calculated illuminance levels can be obtained together with the uniformities $g_{1}$ and $g_{2}$. It also features a ray-tracing engine to predict the daylight penetration in buildings. It is therefore possible to obtain daylight factors in the rooms of the building and optimize the use of daylight.

\section{The design procedure}

ReluxDesktop includes 3D modeling functionality which is manageable and very easy. The classical way to deal with 3D Models in ReluxDesktop is to import the 2D architectural plans and build the third dimension on top of it, but it can also import building 3D models in the format gbXML. The definition of the building is first determined with its internal partitions in different rooms. In a further step, these rooms can be fitted with furnishings and luminaires taken from a vast database. Window openings can be defined in the walls and likewise other elements like doors.

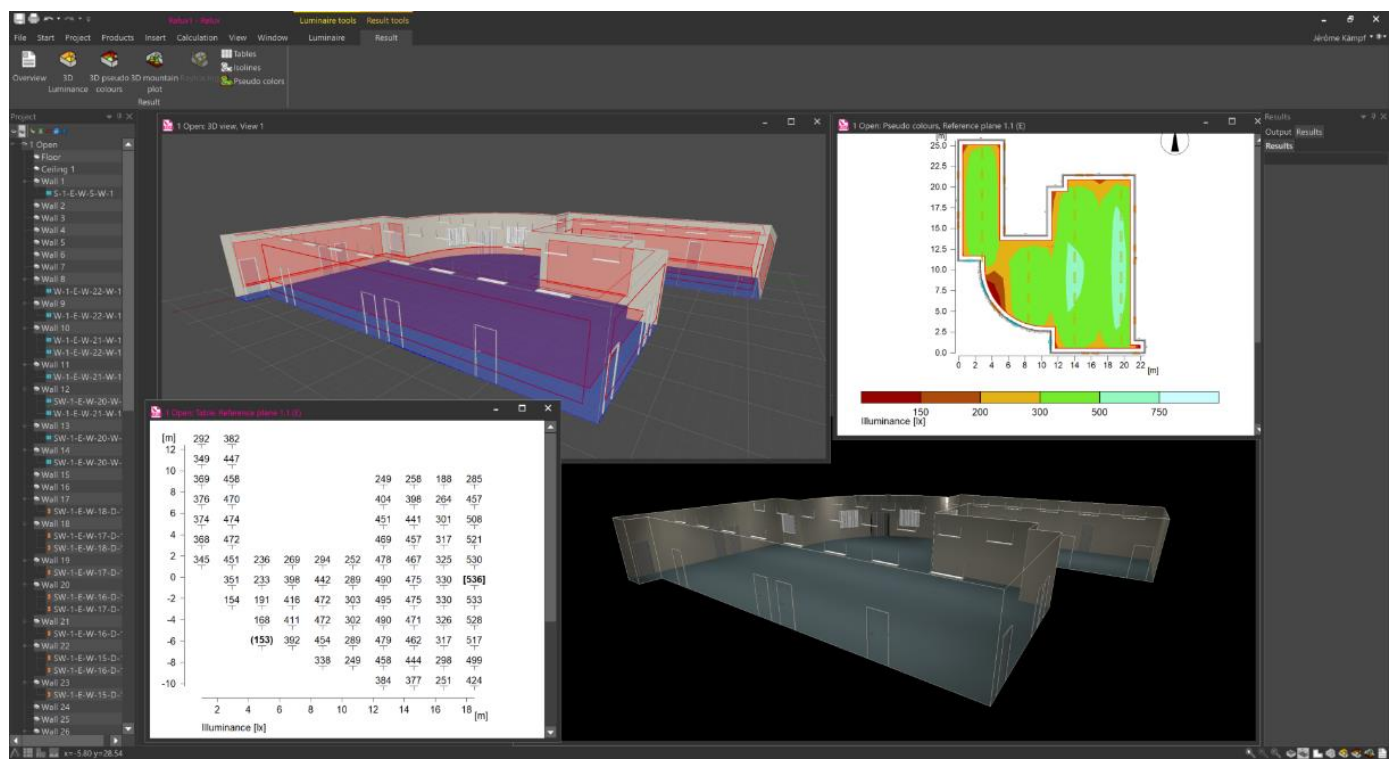

Figure 109: A sample gbXML office building imported and fitted with luminaires 
To control the consistence of the 3D building model, it is useful to use the existing visualization functionality. The results of the rendering can be exported as .jpg, .bmp, and HDR image files for external usage.

The 2D drawing file import function of ReluxDesktop contains the import of vector files like .dxf or .dwg as well as images like .bmp, .jpg, .wmf. After simulation, ReluxDesktop displays the result output optionally as graph, grid or tables, which later can be exported to clip board or file as .csv or .bmp. Several or single scenes can be exported into .dxf or .dwg formatted files including installed luminaires and calculation result. At the moment, it is possible to export a .csv report file containing all information about the building model (volume, areas, area of built envelope, and zone data like elements, constructions and users' activity definitions). The simulation output data can be exported separately.

ReluxCAD for Revit [2] is an add-on for Revit that allows artificial light calculations according to the Zonal Cavity Method and sensor simulations directly in Revit. Thanks to a bidirectional interface between the add-on and ReluxDesktop, all further planning - including daylight can be carried out directly in ReluxDesktop without having to reproduce the geometries of buildings or floors again.

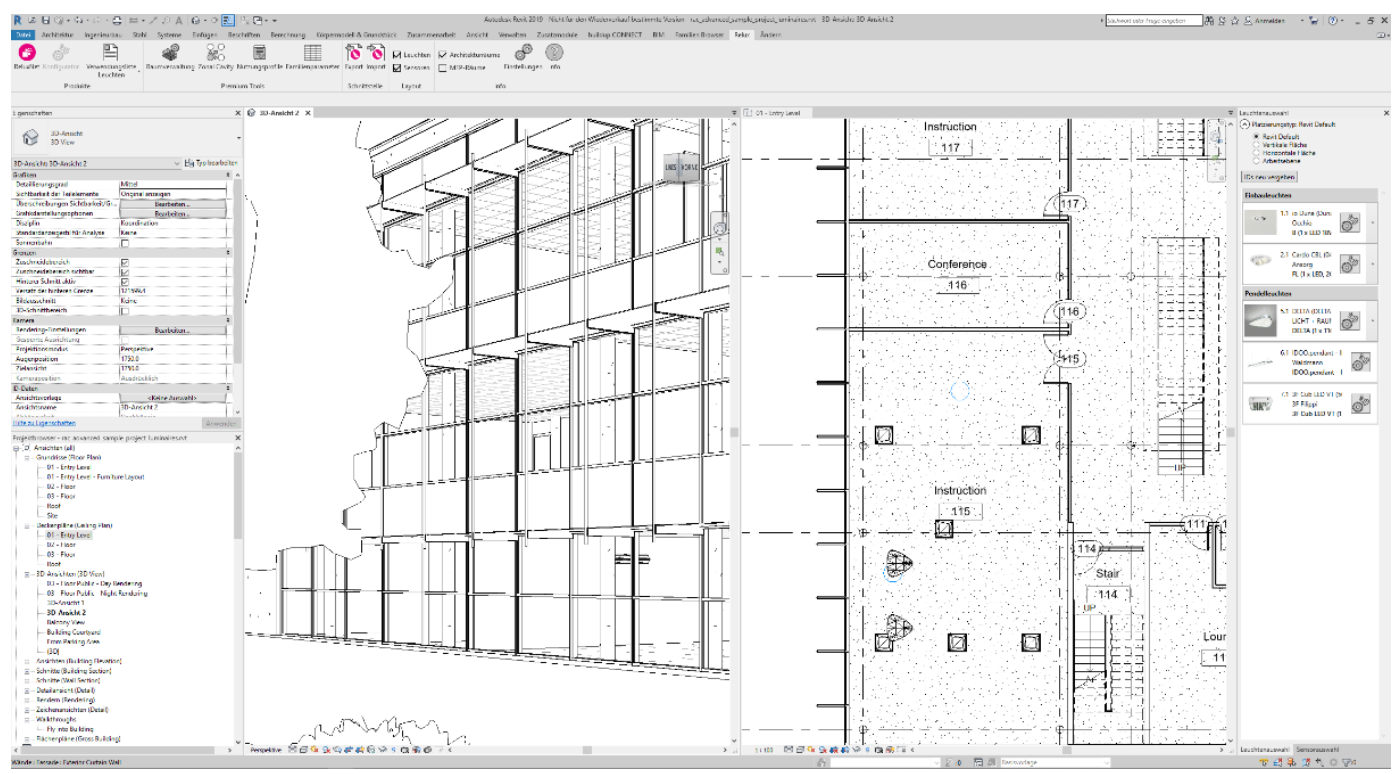

Figure 110: ReluxCAD makes lighting planning with BIM possible. However, this add-on is not free of charge unlike ReluxDesktop.

\section{References}

[1] ReluxDesktop (2019). Relux Informatik AG. Web address: https://reluxnet.relux.com/en/relux-desktop.html

[2] ReluxCAD for Revit (2019) Relux Infirmatik AG. Web address: https://relux.com/en/reluxcad-revit.html 


\section{Conclusion}

The evaluation of planning workflows for the design of integrated solutions for daylighting, electric lighting and lighting controls shows a broad spectrum of approaches. This also reflects the variety and differences in real world lighting design projects. The described workflows can thus be seen as design processes representing well-working examples. All in all, they provide a toolbox of options and workflow steps to choose from and to assemble a specific workflow for the targeted project and its requirements.

Together, the investigated lighting design software tools provide the possibility for every checked feature. However, no single software can cover all relevant aspects. Similar to the workflows, also the tools are designed for specific applications with special focuses. Some are for example mainly developed for daylighting analyses, while others strongly focus on electric lighting design or BIM functionality. As a general result one can see that basic functionality such as illuminance calculation is covered by all tools. On the other side, databases for either luminaires or daylighting systems, glare evaluations and the functionality to use BSDF data for daylighting systems are only available in selected tools. Even more, the relatively new field of non-visual effects of lighting is hardly covered in the software systems. For these evaluations, special tools such as ALFA ${ }^{21}$ or LARK ${ }^{22}$ are available. However, as they are limited in their functionality to evaluate integrated solutions for daylighting, electric lighting and control, which is the main topic here, they have not been considered in the current work.

${ }^{21}$ ALFA - Adaptive Lighting for Alertness, https://www.solemma.com/Alfa.html

${ }^{22}$ LARK Spectral Lighting, https://faculty.washington.edu/inanici/Lark/Lark home page.html 